\title{
Global Carbon Budget 2021
}

Pierre Friedlingstein ${ }^{1,2}$, Matthew W. Jones ${ }^{3}$, Michael O'Sullivan ${ }^{1}$, Robbie M. Andrew ${ }^{4}$, Dorothee, C. E. Bakker ${ }^{5}$, Judith Hauck ${ }^{6}$, Corinne Le Quéré ${ }^{3}$, Glen P. Peters ${ }^{4}$, Wouter Peters $^{7,8}$, Julia Pongratz ${ }^{9,10}$, Stephen Sitch ${ }^{11}$, Josep G. Canadell ${ }^{12}$, Philippe Ciais ${ }^{13}$, Rob B. Jackson $^{14}$, Simone R. Alin ${ }^{15}$, Peter Anthoni ${ }^{16}$, Nicholas R. Bates ${ }^{17}$, Meike Becker ${ }^{18,19}$, Nicolas Bellouin $^{20}$, Laurent Bopp ${ }^{2}$, Thi Tuyet Trang Chau ${ }^{13}$, Frédéric Chevallier ${ }^{13}$, Louise P. Chini ${ }^{21}$, Margot Cronin ${ }^{22}$, Kim I. Currie ${ }^{23}$, Bertrand Decharme ${ }^{24}$, Laique M. Djeutchouang ${ }^{25,26}$, Xinyu Dou $^{27}$, Wiley Evans ${ }^{28}$, Richard A. Feely ${ }^{15}$, Liang Feng ${ }^{29}$, Thomas Gasser ${ }^{30}$, Dennis Gilfillan ${ }^{31}$, Thanos Gkritzalis ${ }^{32}$, Giacomo Grassi ${ }^{33}$, Luke Gregor ${ }^{34}$, Nicolas Gruber ${ }^{34}$, Özgür Gürses ${ }^{6}$, Ian Harris $^{35}$, Richard A. Houghton ${ }^{36}$, George C. Hurtt ${ }^{21}$, Yosuke lida ${ }^{37}$, Tatiana llyina ${ }^{10}$, Ingrid T. Luijkx $^{7}$, Atul Jain ${ }^{38}$, Steve D. Jones ${ }^{18,19}$, Etsushi Kato ${ }^{39}$, Daniel Kennedy ${ }^{40}$, Kees Klein Goldewijk $^{41}$, Jürgen Knauer ${ }^{12,42}$, Jan Ivar Korsbakken ${ }^{4}$, Arne Körtzinger ${ }^{43}$, Peter Landschützer $^{10}$, Siv K. Lauvset ${ }^{19,44}$, Nathalie Lefèvre ${ }^{45}$, Sebastian Lienert ${ }^{46}$, Junjie Liu ${ }^{47}$, Gregg Marland $^{48,49}$, Patrick C. McGuire ${ }^{50}$, Joe R. Melton ${ }^{51}$, David R. Munro ${ }^{52,53}$, Julia E.M.S. Nabel $^{10,54}$, Shin-Ichiro Nakaoka ${ }^{55}$, Yosuke Niwa ${ }^{55,56}$, Tsuneo Ono ${ }^{57}$, Denis Pierrot ${ }^{58}$, Benjamin Poulter $^{59}$, Gregor Rehder ${ }^{60}$, Laure Resplandy ${ }^{61}$, Eddy Robertson ${ }^{62}$, Christian Rödenbeck ${ }^{54}$, Thais M. Rosan ${ }^{11}$, Jörg Schwinger ${ }^{19,44}$, Clemens Schwingshackl ${ }^{9}$, Roland Séférian ${ }^{24}$, Adrienne J. Sutton ${ }^{15}$, Colm Sweeney ${ }^{53}$, Toste Tanhua ${ }^{43}$, Pieter P. Tans ${ }^{63}$, Hanqin Tian ${ }^{64}$, Bronte Tilbrook ${ }^{65,66}$, Francesco Tubiello ${ }^{67}$, Guido van der Werf ${ }^{68}$, Nicolas Vuichard ${ }^{13}$, Chisato Wada $^{55}$, Rik Wanninkhof ${ }^{58}$, Andrew J. Watson ${ }^{11}$, David Willis ${ }^{3}$, Andrew J. Wiltshire ${ }^{62}$, Wenping Yuan ${ }^{69}$, Chao Yue ${ }^{13}, \mathrm{Xu} \mathrm{Yue}^{70}$, Sönke Zaehle ${ }^{54}$, Jiye Zeng ${ }^{55}$

${ }^{1}$ College of Engineering, Mathematics and Physical Sciences, University of Exeter, Exeter EX4 4QF, UK

${ }^{2}$ Laboratoire de Météorologie Dynamique / Institut Pierre-Simon Laplace, CNRS, Ecole Normale Supérieure / Université PSL, Sorbonne Université, Ecole Polytechnique, Paris, France

${ }^{3}$ Tyndall Centre for Climate Change Research, School of Environmental Sciences, University of East Anglia, Norwich Research Park, Norwich NR4 7TJ, UK

${ }^{4}$ CICERO Center for International Climate Research, Oslo 0349, Norway

${ }^{5}$ School of Environmental Sciences, University of East Anglia, Norwich Research Park, Norwich NR4 7TJ, UK

${ }^{6}$ Alfred-Wegener-Institut, Helmholtz-Zentrum für Polar- und Meeresforschung, Am Handelshafen 12, 27570 Bremerhaven

${ }^{7}$ Wageningen University, Environmental Sciences Group, P.O. Box 47, 6700AA, Wageningen, The Netherlands

${ }^{8}$ University of Groningen, Centre for Isotope Research, Groningen, The Netherlands

${ }^{9}$ Ludwig-Maximilians-Universität München, Luisenstr. 37, 80333 München, Germany

10 Max Planck Institute for Meteorology, Bundesstr. 53, 20146 Hamburg, Germany

${ }^{11}$ College of Life and Environmental Sciences, University of Exeter, Exeter EX4 4RJ, UK

12 CSIRO Oceans and Atmosphere, Canberra, ACT 2101, Australia

${ }^{13}$ Laboratoire des Sciences du Climat et de l'Environnement, LSCE/IPSL, CEA-CNRS-UVSQ, Université Paris-Saclay, F-91198 Gif-sur-Yvette, France

${ }^{14}$ Department of Earth System Science, Woods Institute for the Environment, and Precourt Institute for Energy, Stanford University, Stanford, CA 94305-2210, United States of America

${ }^{15}$ National Oceanic \& Atmospheric Administration, Pacific Marine Environmental Laboratory (NOAA/PMEL), 7600 Sand Point Way NE, Seattle, WA 98115, USA 
$1{ }^{16}$ Karlsruhe Institute of Technology, Institute of Meteorology and Climate Research/Atmospheric

2 Environmental Research, 82467 Garmisch-Partenkirchen, Germany

$3{ }^{17}$ Bermuda Institute of Ocean Sciences (BIOS), 17 Biological Lane, Ferry Reach, St. Georges, GEO1,

4 Bermuda

$5{ }^{18}$ Geophysical Institute, University of Bergen, Bergen, Norway

$6 \quad{ }^{19}$ Bjerknes Centre for Climate Research, Bergen, Norway

$7{ }^{20}$ Department of Meteorology, University of Reading, Reading, UK

$8{ }^{21}$ Department of Geographical Sciences, University of Maryland, College Park, Maryland 20742, USA

$9 \quad{ }^{22}$ Marine Institute Ireland, Galway, Rinville, Ireland

$10{ }^{23}$ NIWA, Union Place West, Dunedin, New Zealand

$11{ }^{24}$ CNRM, Université de Toulouse, Météo-France, CNRS, Toulouse, France

$12{ }^{25}$ Department of Oceanography, University of Cape Town, Cape Town, 7701, South Africa

$13{ }^{26}$ SOCCO, Council for Scientific and Industrial Research, Cape Town, 7700, South Africa

$14 \quad{ }^{27}$ Department of Earth System Science, Tsinghua University, Beijing, China

$15{ }^{28}$ Hakai Institute, Heriot Bay, BC, Canada

$16{ }^{29}$ National Centre for Earth Observation, University of Edinburgh, UK

$17{ }^{30}$ International Institute for Applied Systems Analysis (IIASA), Schlossplatz 1

18 A-2361 Laxenburg, Austria

$19{ }^{31}$ North Carolina School for Science and Mathematics, Durham, North Carolina, USA

$20{ }^{32}$ Flanders Marine Institute (VLIZ), InnovOceanSite, Wandelaarkaai 7, 8400 Ostend, Belgium

$21{ }^{33}$ European Commission, Joint Research Centre, 21027 Ispra (VA), Italy

${ }^{34}$ Environmental Physics Group, ETH Zürich, Institute of Biogeochemistry and Pollutant Dynamics and Center for Climate Systems Modeling (C2SM), 8092 Zurich, Switzerland

${ }^{35}$ NCAS-Climate, Climatic Research Unit, School of Environmental Sciences, University of East Anglia, Norwich Research Park, Norwich, NR4 7TJ, UK

${ }^{36}$ Woodwell Climate Research Center, Falmouth, MA 02540, USA

${ }^{37}$ Atmosphere and Ocean Department, Japan Meteorological Agency, Minato-Ku, Tokyo 105-8431, Japan

38 Department of Atmospheric Sciences, University of Illinois, Urbana, IL 61821, USA

39 Institute of Applied Energy (IAE), Minato-ku, Tokyo 105-0003, Japan

40 National Center for Atmospheric Research, Climate and Global Dynamics, Terrestrial Sciences

Section, Boulder, CO 80305, USA

41 Utrecht University, Faculty of Geosciences, Department IMEW, Copernicus Institute of Sustainable Development, Heidelberglaan 2, P.O. Box 80115, 3508 TC, Utrecht, the Netherlands

42 Hawkesbury Institute for the Environment, Western Sydney University, Penrith, New South Wales, Australia

43 GEOMAR Helmholtz Centre for Ocean Research Kiel, Düsternbrooker Weg 20, 24105 Kiel, Germany

${ }^{44}$ NORCE Norwegian Research Centre, Jahnebakken 5, 5007 Bergen, Norway

45 LOCEAN/IPSL laboratory, Sorbonne Université, CNRS/IRD/MNHN, Paris, France

${ }^{46}$ Climate and Environmental Physics, Physics Institute and Oeschger Centre for Climate Change Research, University of Bern, Bern, Switzerland

47 Jet Propulsion Laboratory, California Institute of Technology, Pasadena, CA, USA.

${ }^{48}$ Research Institute for Environment, Energy, and Economics, Appalachian State University, Boone, North Carolina, USA

49 Department of Geological and Environmental Sciences, Appalachian State University, Boone,

47 North Carolina, USA 


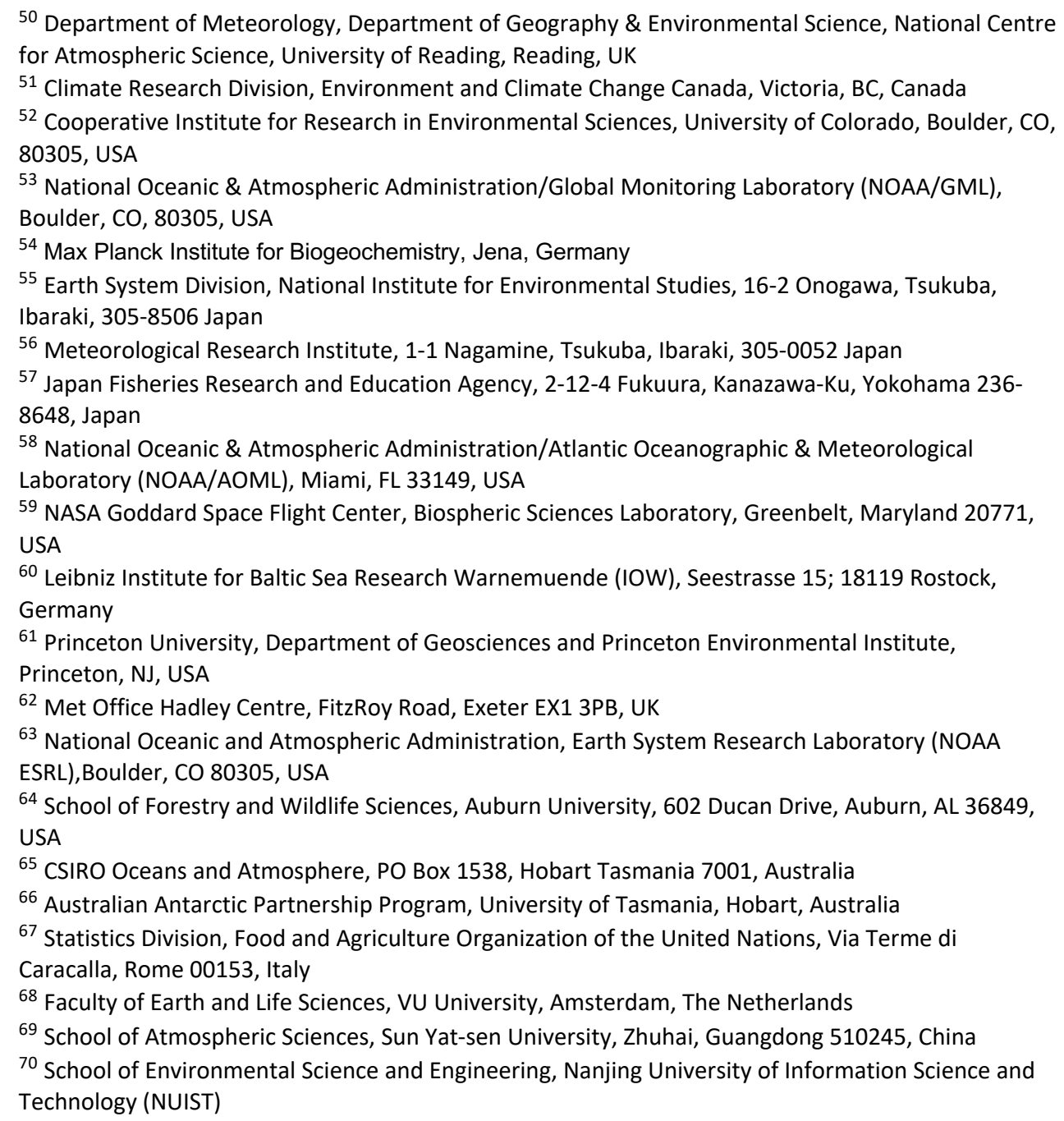

\section{Abstract}

Accurate assessment of anthropogenic carbon dioxide $\left(\mathrm{CO}_{2}\right)$ emissions and their redistribution among the atmosphere, ocean, and terrestrial biosphere in a changing

43 climate is critical to better understand the global carbon cycle, support the development of

44 climate policies, and project future climate change. Here we describe and synthesize data

45 sets and methodology to quantify the five major components of the global carbon budget

46 and their uncertainties. Fossil $\mathrm{CO}_{2}$ emissions ( $\left.\mathrm{E}_{\mathrm{FOS}}\right)$ are based on energy statistics and 
cement production data, while emissions from land-use change (Etuc), mainly deforestation,

2 are based on land-use and land-use change data and bookkeeping models. Atmospheric $\mathrm{CO}_{2}$

3 concentration is measured directly, and its growth rate $\left(G_{\text {AтM }}\right)$ is computed from the annual

4 changes in concentration. The ocean $\mathrm{CO}_{2} \operatorname{sink}$ (SOCEAN) is estimated with global ocean

5 biogeochemistry models and observation-based data-products. The terrestrial $\mathrm{CO}_{2} \operatorname{sink}$

6 (S LAND $)$ is estimated with dynamic global vegetation models. The resulting carbon budget

7 imbalance $\left(B_{I M}\right)$, the difference between the estimated total emissions and the estimated

8 changes in the atmosphere, ocean, and terrestrial biosphere, is a measure of imperfect data

9 and understanding of the contemporary carbon cycle. All uncertainties are reported as $\pm 1 \sigma$.

10 For the first time, an approach is shown to reconcile the difference in our Eluc estimate with

11 the one from national greenhouse gases inventories, supporting the assessment of

12 collective countries' climate progress.

13 For the year 2020, EFos declined by 5.4\% relative to 2019, with fossil emissions at $9.5 \pm 0.5$

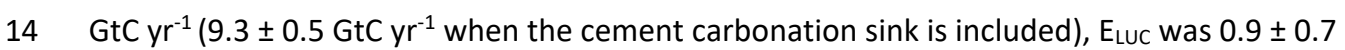

$15 \mathrm{GtC} \mathrm{yr}^{-1}$, for a total anthropogenic $\mathrm{CO}_{2}$ emission of $10.2 \pm 0.8 \mathrm{GtC}^{-1}\left(37.4 \pm 2.9 \mathrm{GtCO}_{2}\right)$.

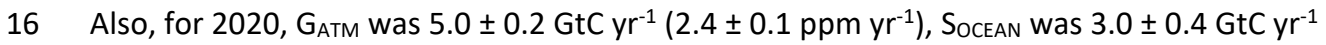

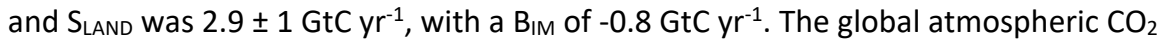
concentration averaged over 2020 reached $412.45 \pm 0.1 \mathrm{ppm}$. Preliminary data for 2021, suggest a rebound in $\mathrm{E}_{\mathrm{FOS}}$ relative to 2020 of $+4.9 \%$ (4.1\% to $5.7 \%$ ) globally.

20 Overall, the mean and trend in the components of the global carbon budget are consistently

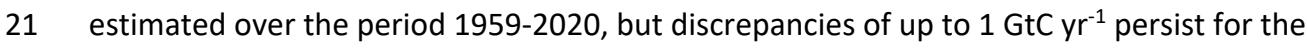
22 representation of annual to semi-decadal variability in $\mathrm{CO}_{2}$ fluxes. Comparison of estimates

23 from multiple approaches and observations shows: (1) a persistent large uncertainty in the

24 estimate of land-use changes emissions, (2) a low agreement between the different methods on the magnitude of the land $\mathrm{CO}_{2}$ flux in the northern extra-tropics, and ( 3 ) a discrepancy between the different methods on the strength of the ocean sink over the last decade. This living data update documents changes in the methods and data sets used in this new global carbon budget and the progress in understanding of the global carbon cycle compared with previous publications of this data set (Friedlingstein et al., 2020;

30 Friedlingstein et al., 2019; Le Quéré et al., 2018b, 2018a, 2016, 2015b, 2015a, 2014, 2013).

31 The data presented in this work are available at https://doi.org/10.18160/gcp-2021

32 (Friedlingstein et al., 2021). 
2 Global fossil $\mathrm{CO}_{2}$ emissions (excluding cement carbonation) in 2021 are returning towards

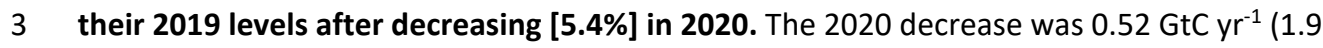

$\left.4 \mathrm{GtCO}_{2} \mathrm{yr}^{-1}\right)$, bringing 2020 emissions to $9.5 \pm 0.5 \mathrm{GtC} \mathrm{yr}^{-1}\left(34.8 \pm 1.8 \mathrm{GtCO}_{2} \mathrm{yr}^{-1}\right)$, comparable

5 to the emissions level of 2012. Preliminary estimates based on data available in October

62021 and a projection for the rest of the year suggest fossil $\mathrm{CO}_{2}$ emissions will rebound $4.9 \%$

7 in 2021 (4.1\% to 5.7\%), bringing emissions at $9.9 \mathrm{GtC} \mathrm{yr}^{-1}\left(36.4 \mathrm{GtCO}_{2} \mathrm{yr}^{-1}\right)$, back to about the

8 same level as in $2019\left(10.0 \pm 0.5 \mathrm{GtC}_{\mathrm{yr}}{ }^{-1}, 36.7 \pm 1.8 \mathrm{GtCO}_{2} \mathrm{yr}^{-1}\right)$. Emissions from coal and gas

9 in 2021 are expected to rebound above 2019 levels, while emissions from oil are still below

10 their 2019 level. Emissions in China are expected to be 5.5\% higher in 2021 than in 2019,

11 reaching $3.0 \mathrm{GtC}\left(11.1 \mathrm{GtCO}_{2}\right)$ and also higher in India with a $4.4 \%$ increase in 2021 relative

12 to 2019 , reaching $0.75 \mathrm{GtC}\left(2.7 \mathrm{GtCO}_{2}\right)$. In contrast, projected 2021 emissions in the United

13 States (1.4 GtC, $\left.5.1 \mathrm{GtCO}_{2}\right)$, European Union (0.8 GtC, $\left.2.8 \mathrm{GtCO}_{2}\right)$, and the rest of the world

14 (4.0 GtC, $14.8 \mathrm{GtCO}_{2}$, in aggregate) remain respectively $3.7 \%, 4.2 \%$, and $4.2 \%$ below their

152019 levels. These patterns reflect the stringency of the COVID-19 confinement levels and

16 the background trends in emissions in these countries.

17 Fossil $\mathrm{CO}_{2}$ emissions significantly decreased in 23 countries during the decade 2010-2019.

18 Altogether, these 23 countries contribute to about $2.5 \mathrm{GtC} \mathrm{yr}^{-1}$ fossil fuel $\mathrm{CO}_{2}$ emissions over

19 the last decade, only about one quarter of world $\mathrm{CO}_{2}$ fossil emissions.

\section{Global $\mathrm{CO}_{2}$ emissions from land-use, land-use change, and forestry (LUC) converge based} on revised data of land-use change and show a small decrease over the past two decades. Near constant gross emissions estimated at 3.8 $\pm 0.6 \mathrm{GtC} \mathrm{yr}^{-1}$ in the 2011-2020 decade are

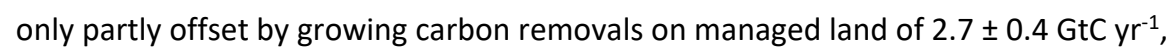

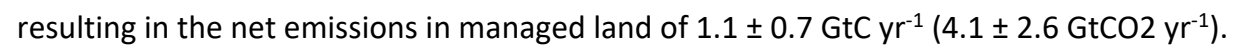
These net emissions decreased by $0.2 \mathrm{GtC}$ in 2020 compared to 2019 levels, with large uncertainty. Preliminary estimates for emissions in 2021 suggest a $0.1 \mathrm{GtC}$ decrease for 2021, giving net emissions of $0.8 \mathrm{GtC} \mathrm{yr}^{-1}\left(2.9 \mathrm{GtCO} \mathrm{yr}^{-1}\right)$. The convergence of different emission estimates does not reflect the high uncertainty in land-use change datasets, which likely underestimate interannual variability and the (rising) importance of degradation, highlighting the need for accurate land-use data. For the first time, we link the global carbon 
1 budget models' estimates to the official country reporting of national greenhouse gases

2 inventories. While the global carbon budget distinguishes anthropogenic from natural

3 drivers of land carbon fluxes, country reporting is area based and attributes part of the

4 natural terrestrial sink on managed land to the land-use sector. Accounting for this

5 redistribution, the two approaches are shown to be consistent with each other.

6 The remaining carbon budget for a $50 \%$ likelihood to limit global warming to $1.5^{\circ} \mathrm{C}, 1.7^{\circ} \mathrm{C}$

7 and $2^{\circ} \mathrm{C}$ has shrunk to $120 \mathrm{GtC}\left(420 \mathrm{GtCO}_{2}\right), 210 \mathrm{GtC}\left(770 \mathrm{GtCO}_{2}\right)$ and $350 \mathrm{GtC}\left(1270 \mathrm{GtCO}_{2}\right)$

8 respectively, equivalent to 11, 20 and 32 years from the beginning of 2022, assuming 2021

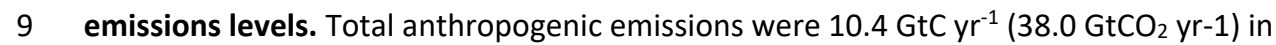

102020 , with a preliminary estimate of $10.7 \mathrm{GtC} \mathrm{yr}^{-1}\left(39.4 \mathrm{GtCO} \mathrm{yr}^{-1}\right)$ for 2021. The remaining

11 carbon budget to keep global temperatures below the climate targets of the Paris

12 Agreement has shrunk by $21 \mathrm{GtC}\left(77 \mathrm{GtCO}_{2}\right)$ relative to the remaining carbon budget

13 estimate assessed in the IPCC AR6 Working Group 1 assessment. Reaching net zero $\mathrm{CO}_{2}$

14 emissions by 2050 entails cutting total anthropogenic $\mathrm{CO}_{2}$ emissions by about $0.4 \mathrm{GtC}$ (1.4

$15 \mathrm{GtCO}_{2}$ ) each year on average, comparable to the decrease during 2020, highlighting the

16 scale of the action needed.

17 The concentration of $\mathrm{CO}_{2}$ in the atmosphere is set to reach $414.7 \mathrm{ppm}$ in $2021,49 \%$ above

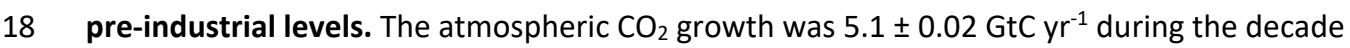

$192011-2020$ (47\% of total $\mathrm{CO}_{2}$ emissions) with a preliminary 2021 growth rate estimate of

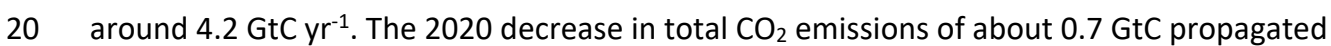

21 to a reduction of the atmospheric $\mathrm{CO}_{2}$ growth rate of $0.38 \mathrm{GtC}(0.18 \mathrm{ppm})$.

22 The ocean $\mathrm{CO}_{2}$ sink resumed a more rapid growth in the past decade after low or no

23 growth during the 1991-2002 period. However, the growth of the ocean $\mathrm{CO}_{2}$ sink in the

24 past decade has an uncertainty of a factor of three, with estimates based on data products

25 and estimates based on models showing an ocean sink increase of $0.9 \mathrm{GtC}_{\mathrm{yr}}^{-1}$ and $0.3 \mathrm{GtC}$

$26 \mathrm{yr}^{-1}$ since 2010, respectively. The discrepancy in the trend originates from all latitudes but is

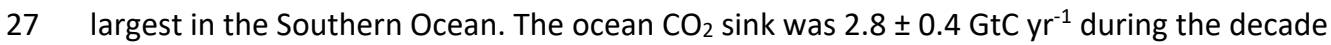

$282011-2020$ (26\% of total $\mathrm{CO}_{2}$ emissions), with a preliminary 2021 estimate of around $2.9 \mathrm{GtC}$

$29 \mathrm{yr}^{-1}$. 
1 The land $\mathrm{CO}_{2}$ sink continued to increase during the 2011-2020 period primarily in response

2 to increased atmospheric $\mathrm{CO}_{2}$, albeit with large interannual variability. The land $\mathrm{CO}_{2} \operatorname{sink}$

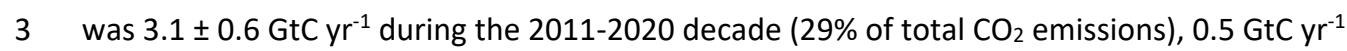

4 larger than during the previous decade (2000-2009), with a preliminary 2021 estimate of

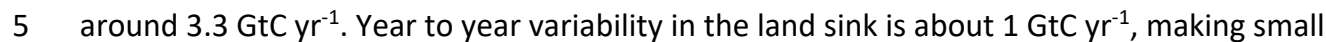

6 annual changes in anthropogenic emissions hard to detect in global atmospheric $\mathrm{CO}_{2}$

7 concentration. 


\section{$1 \quad 1$ Introduction}

2 The concentration of carbon dioxide $\left(\mathrm{CO}_{2}\right)$ in the atmosphere has increased from

3 approximately 277 parts per million (ppm) in 1750 (Joos and Spahni, 2008), the beginning of

4 the Industrial Era, to $412.4 \pm 0.1$ ppm in 2020 (Dlugokencky and Tans, 2021); Fig. 1). The

5 atmospheric $\mathrm{CO}_{2}$ increase above pre-industrial levels was, initially, primarily caused by the

6 release of carbon to the atmosphere from deforestation and other land-use change

7 activities (Canadell et al., 2021). While emissions from fossil fuels started before the

8 Industrial Era, they became the dominant source of anthropogenic emissions to the

9 atmosphere from around 1950 and their relative share has continued to increase until

10 present. Anthropogenic emissions occur on top of an active natural carbon cycle that

11 circulates carbon between the reservoirs of the atmosphere, ocean, and terrestrial

12 biosphere on time scales from sub-daily to millennia, while exchanges with geologic

13 reservoirs occur at longer timescales (Archer et al., 2009).

14 The global carbon budget (GCB) presented here refers to the mean, variations, and trends in

15 the perturbation of $\mathrm{CO}_{2}$ in the environment, referenced to the beginning of the Industrial

16 Era (defined here as 1750). This paper describes the components of the global carbon cycle

17 over the historical period with a stronger focus on the recent period (since 1958, onset of

18 atmospheric $\mathrm{CO}_{2}$ measurements), the last decade (2011-2020), the last year (2020) and the

19 current year (2021). We quantify the input of $\mathrm{CO}_{2}$ to the atmosphere by emissions from

20 human activities, the growth rate of atmospheric $\mathrm{CO}_{2}$ concentration, and the resulting

21 changes in the storage of carbon in the land and ocean reservoirs in response to increasing

22 atmospheric $\mathrm{CO}_{2}$ levels, climate change and variability, and other anthropogenic and natural

23 changes (Fig. 2). An understanding of this perturbation budget over time and the underlying

24 variability and trends of the natural carbon cycle is necessary to understand the response of

25 natural sinks to changes in climate, $\mathrm{CO}_{2}$ and land-use change drivers, and to quantify the

26 permissible emissions for a given climate stabilization target.

27 The components of the $\mathrm{CO}_{2}$ budget that are reported annually in this paper include separate

28 and independent estimates for the $\mathrm{CO}_{2}$ emissions from (1) fossil fuel combustion and

29 oxidation from all energy and industrial processes; also including cement production and

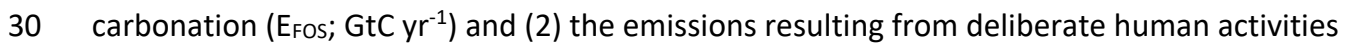

31 on land, including those leading to land-use change ( $\left.E_{L u c} ; G t C ~ y r-1\right)$; and their partitioning 
1 among (3) the growth rate of atmospheric $\mathrm{CO}_{2}$ concentration $\left(\mathrm{G}_{\mathrm{ATM}} ; \mathrm{GtC} \mathrm{yr}^{-1}\right)$, and the

2 uptake of $\mathrm{CO}_{2}$ (the ' $\mathrm{CO}_{2}$ sinks') in (4) the ocean (Socean; GtC yr ${ }^{-1}$ ) and (5) on land (SLAND; GtC

$3 \mathrm{yr}^{-1}$ ). The $\mathrm{CO}_{2}$ sinks as defined here conceptually include the response of the land (including

4 inland waters and estuaries) and ocean (including coasts and territorial seas) to elevated

$5 \mathrm{CO}_{2}$ and changes in climate and other environmental conditions, although in practice not all

6 processes are fully accounted for (see Section 2.7). Global emissions and their partitioning

7 among the atmosphere, ocean and land are in reality in balance. Due to the combination of

8 imperfect spatial and/or temporal data coverage, errors in each estimate, and smaller terms

9 not included in our budget estimate (discussed in Section 2.7), the independent estimates

10 (1) to (5) above do not necessarily add up to zero. We therefore (a) additionally assess a set

11 of global atmospheric inverse model results that by design close the global carbon balance

12 (see Section 2.6), and (b) estimate a budget imbalance ( $\left.\mathrm{B}_{\mathrm{IM}}\right)$, which is a measure of the

13 mismatch between the estimated emissions and the estimated changes in the atmosphere,

14 land and ocean, as follows:

$15 B_{I M}=E_{F O S}+E_{L U C}-\left(G_{A T M}+S_{O C E A N}+S_{L A N D}\right)$

$16 \mathrm{G}_{\text {ATM }}$ is usually reported in $\mathrm{ppm} \mathrm{yr}^{-1}$, which we convert to units of carbon mass per year, GtC

$17 \mathrm{yr}^{-1}$, using $1 \mathrm{ppm}=2.124 \mathrm{GtC}$ (Ballantyne et al., 2012; Table 1). All quantities are presented

18 in units of gigatonnes of carbon $\left(\mathrm{GtC}, 10^{15} \mathrm{gC}\right.$ ), which is the same as petagrams of carbon

19 (PgC; Table 1). Units of gigatonnes of $\mathrm{CO}_{2}$ (or billion tonnes of $\mathrm{CO}_{2}$ ) used in policy are equal

20 to 3.664 multiplied by the value in units of GtC.

21 We also include a quantification of EFos by country, computed with both territorial and

22 consumption-based accounting (see Section 2), and discuss missing terms from sources

23 other than the combustion of fossil fuels (see Section 2.7).

24 The global $\mathrm{CO}_{2}$ budget has been assessed by the Intergovernmental Panel on Climate

25 Change (IPCC) in all assessment reports (Prentice et al., 2001; Schimel et al., 1995; Watson

26 et al., 1990; Denman et al., 2007; Ciais et al., 2013; Canadell et al., 2021), and by others (e.g.

27 Ballantyne et al., 2012). The Global Carbon Project (GCP, www.globalcarbonproject.org, last

28 access: 15 October 2021) has coordinated this cooperative community effort for the annual

29 publication of global carbon budgets for the year 2005 (Raupach et al., 2007; including fossil

30 emissions only), year 2006 (Canadell et al., 2007), year 2007 (GCP, 2008), year 2008 (Le

31 Quéré et al., 2009), year 2009 (Friedlingstein et al., 2010), year 2010 (Peters et al., 2012b), 
1 year 2012 (Le Quéré et al., 2013; Peters et al., 2013), year 2013 (Le Quéré et al., 2014), year

22014 (Le Quéré et al., 2015a; Friedlingstein et al., 2014), year 2015 (Jackson et al., 2016; Le

3 Quéré et al., 2015b), year 2016 (Le Quéré et al., 2016), year 2017 (Le Quéré et al., 2018a;

4 Peters et al., 2017), year 2018 (Le Quéré et al., 2018b; Jackson et al., 2018) year 2019

5 (Friedlingstein et al., 2019; Jackson et al., 2019; Peters et al., 2020) and more recently the

6 year 2020 (Friedlingstein et al., 2020; Le Quéré et al., 2021) . Each of these papers updated

7 previous estimates with the latest available information for the entire time series.

8 We adopt a range of \pm 1 standard deviation $(\sigma)$ to report the uncertainties in our estimates,

9 representing a likelihood of $68 \%$ that the true value will be within the provided range if the

10 errors have a Gaussian distribution, and no bias is assumed. This choice reflects the difficulty

11 of characterising the uncertainty in the $\mathrm{CO}_{2}$ fluxes between the atmosphere and the ocean

12 and land reservoirs individually, particularly on an annual basis, as well as the difficulty of

13 updating the $\mathrm{CO}_{2}$ emissions from land-use change. A likelihood of $68 \%$ provides an

14 indication of our current capability to quantify each term and its uncertainty given the

15 available information. The uncertainties reported here combine statistical analysis of the

16 underlying data, assessments of uncertainties in the generation of the data sets, and expert

17 judgement of the likelihood of results lying outside this range. The limitations of current

18 information are discussed in the paper and have been examined in detail elsewhere

19 (Ballantyne et al., 2015; Zscheischler et al., 2017). We also use a qualitative assessment of

20 confidence level to characterise the annual estimates from each term based on the type,

21 amount, quality, and consistency of the evidence as defined by the IPCC (Stocker et al.,

22 2013).

23 This paper provides a detailed description of the data sets and methodology used to

24 compute the global carbon budget estimates for the industrial period, from 1750 to 2020,

25 and in more detail for the period since 1959. It also provides decadal averages starting in

261960 including the most recent decade (2011-2020), results for the year 2020, and a

27 projection for the year 2021. Finally, it provides cumulative emissions from fossil fuels and

28 land-use change since the year 1750, the pre-industrial period; and since the year 1850, the

29 reference year for historical simulations in IPCC AR6 (Eyring et al., 2016). This paper is

30 updated every year using the format of 'living data' to keep a record of budget versions and

31 the changes in new data, revision of data, and changes in methodology that lead to changes 
1 in estimates of the carbon budget. Additional materials associated with the release of each

2 new version will be posted at the Global Carbon Project (GCP) website

3 (http://www.globalcarbonproject.org/carbonbudget, last access: 15 October 2021), with

4 fossil fuel emissions also available through the Global Carbon Atlas

5 (http://www.globalcarbonatlas.org, last access: 15 October 2021). With this approach, we

6 aim to provide the highest transparency and traceability in the reporting of $\mathrm{CO}_{2}$, the key

7 driver of climate change.

\section{Methods}

9 Multiple organizations and research groups around the world generated the original 10 measurements and data used to complete the global carbon budget. The effort presented

11 here is thus mainly one of synthesis, where results from individual groups are collated,

12 analysed, and evaluated for consistency. We facilitate access to original data with the

13 understanding that primary data sets will be referenced in future work (see Table 2 for how

14 to cite the data sets). Descriptions of the measurements, models, and methodologies follow

15 below, and detailed descriptions of each component are provided elsewhere.

16 This is the 16th version of the global carbon budget and the tenth revised version in the

17 format of a living data update in Earth System Science Data. It builds on the latest published 18 global carbon budget of Friedlingstein et al. (2020). The main changes are: the inclusion of

19 (1) data to year 2020 and a projection for the global carbon budget for year 2021; (2) a Kaya

20 analysis to identify the driving factors behind the recent trends in fossil fuel emissions

21 (changes in population, GDP per person, energy use per GDP, and $\mathrm{CO}_{2}$ emissions per unit

22 energy), (3) an estimate of the ocean sink from models and data-products combined, (4) an

23 assessment of the relative contributions of increased atmospheric $\mathrm{CO}_{2}$ and climate change

24 in driving the land and ocean sinks, and (5) an assessment of the current trends in

25 anthropogenic emissions and implications for the remaining carbon budget for specific

26 climate targets. The main methodological differences between recent annual carbon

27 budgets (2016-2020) are summarised in Table 3 and previous changes since 2006 are

28 provided in Table A7. 
12.1 Fossil $\mathrm{CO}_{2}$ emissions (EFos)

2 2.1.1 Historical period $1850-2020$

3 The estimates of global and national fossil $\mathrm{CO}_{2}$ emissions ( $\mathrm{E}_{\mathrm{FOS}}$ ) include the oxidation of fossil

4 fuels through both combustion (e.g., transport, heating) and chemical oxidation (e.g. carbon

5 anode decomposition in aluminium refining) activities, and the decomposition of carbonates

6 in industrial processes (e.g. the production of cement). We also include $\mathrm{CO}_{2}$ uptake from the

7 cement carbonation process. Several emissions sources are not estimated or not fully

8 covered: coverage of emissions from lime production are not global, and decomposition of

9 carbonates in glass and ceramic production are included only for UNFCCC Annex 1 countries

10 for lack of activity data. These omissions are considered to be minor. Short-cycle carbon

11 emissions - for example from combustion of biomass - are not included.

12 Our estimates of fossil $\mathrm{CO}_{2}$ emissions are derived using the standard approach of activity

13 data and emission factors, relying on data collection by many other parties. Our goal is to

14 produce the best estimate of this flux, and we therefore use a prioritisation framework to

15 combine data from different sources that have used different methods, while being careful

16 to avoid double counting and undercounting of emissions sources. The CDIAC-FF emissions

17 dataset, derived largely from UN energy data, forms the foundation, and we extend

18 emissions to year Y-1 using energy growth rates reported by BP. We then proceed to replace

19 estimates using data from what we consider to be superior sources, for example Annex 1

20 countries' official submissions to the UNFCCC. All data points are potentially subject to

21 revision, not just the latest year. For full details see Andrew and Peters (2021).

22 Other estimates of global fossil $\mathrm{CO}_{2}$ emissions exist, and these are compared by Andrew

23 (2020a). The most common reason for differences in estimates of global fossil $\mathrm{CO}_{2}$ emissions

24 is a difference in which emissions sources are included in the datasets. Datasets such as

25 those published by BP, the US Energy Information Administration, and the International

26 Energy Agency's ' $\mathrm{CO}_{2}$ emissions from fuel combustion' are all generally limited to emissions

27 from combustion of fossil fuels. In contrast, datasets such as PRIMAP-hist, CEDS, EDGAR,

28 and GCP's dataset aim to include all sources of fossil $\mathrm{CO}_{2}$ emissions. See Andrew (2020a) for

29 detailed comparisons and discussion.

30 Cement absorbs $\mathrm{CO}_{2}$ from the atmosphere over its lifetime, a process known as 'cement

31 carbonation'. We estimate this $\mathrm{CO}_{2}$ sink as the average of two studies in the literature (Cao 
1 et al., 2020; Guo et al., 2021). Both studies use the same model, developed by Xi et al.

2 (2016), with different parameterisations and input data. Since carbonation is a function of

3 both current and previous cement production, we extend these estimates by one year to

42020 by using the growth rate derived from the smoothed cement emissions (10-year

5 smoothing) fitted to the carbonation data.

6 We use the Kaya Identity for a simple decomposition of $\mathrm{CO}_{2}$ emissions into the key drivers

7 (Raupach et al., 2007). While there are variations (Peters et al 2017), we focus here on a

8 decomposition of $\mathrm{CO}_{2}$ emissions into population, GDP per person, energy use per GDP, and

$9 \mathrm{CO}_{2}$ emissions per energy. Multiplying these individual components together returns the

$10 \mathrm{CO}_{2}$ emissions. Using the decomposition, it is possible to attribute the change in $\mathrm{CO}_{2}$

11 emissions to the change in each of the drivers. This method gives a first order understanding

12 of what causes $\mathrm{CO}_{2}$ emissions to change each year.

\section{$13 \quad 2.1 .2 \quad 2021$ projection}

14 We provide a projection of global $\mathrm{CO}_{2}$ emissions in 2021 by combining separate projections

15 for China, USA, EU, India, and all other countries combined. The methods are different for each of these. For China we combine monthly fossil fuel production data from the National Bureau of Statistics, import/export data from the Customs Administration, and monthly coal consumption estimates from SX Coal (2021), giving us partial data for the growth rates to date of natural gas, petroleum, and cement, and of the consumption itself for raw coal. We then use a regression model to project full-year emissions based on historical observations.

21 For the USA our projection is taken directly from the Energy Information Administration's

22 (EIA) Short-Term Energy Outlook (EIA, 2021), combined with the year-to-date growth rate of cement production. For the EU we use monthly energy data from Eurostat to derive estimates of monthly $\mathrm{CO}_{2}$ emissions through July, with coal emissions extended first through September using a statistical relationship with reported electricity generation from coal and other factors, then through December assuming normal seasonal patterns. EU emissions from natural gas - a strongly seasonal cycle - are extended through December using biasadjusted Holt-Winters exponential smoothing (Chatfield, 1978). EU emissions from oil are derived using the EIA's projection of oil consumption for Europe. EU cement emissions are based on available year-to-date data from two of the largest producers, Germany and 
1 for coal) using the methods of Andrew (2020b) and extrapolated assuming normal seasonal

2 patterns. Emissions for the rest of the world are derived using projected growth in economic

3 production from the IMF (2021) combined with extrapolated changes in emissions intensity

4 of economic production. More details on the EFos methodology and its 2021 projection can

5 be found in Appendix C.1.

$6 \quad 2.2 \mathrm{CO}_{2}$ emissions from land-use, land-use change and forestry (ELuc)

7 The net $\mathrm{CO}_{2}$ flux from land-use, land-use change and forestry ( $E_{\mathrm{LUc}}$, called land-use change

8 emissions in the rest of the text) includes $\mathrm{CO}_{2}$ fluxes from deforestation, afforestation,

9 logging and forest degradation (including harvest activity), shifting cultivation (cycle of

10 cutting forest for agriculture, then abandoning), and regrowth of forests following wood

11 harvest or abandonment of agriculture. Emissions from peat burning and drainage are

12 added from external datasets.

13 Three bookkeeping approaches (updated estimates each of BLUE (Hansis et al., 2015),

14 OSCAR (Gasser et al., 2020), and H\&N2017 (Houghton and Nassikas, 2017)) were used to

15 quantify gross sources and sinks and the resulting net $E_{L u c}$. Uncertainty estimates were

16 derived from the DGVMs ensemble for the time period prior to 1960, using for the recent

17 decades an uncertainty range of $\pm 0.7 \mathrm{GtC}$ yr-1, which is a semi-quantitative measure for

18 annual and decadal emissions and reflects our best value judgment that there is at least $68 \%$

19 chance $( \pm 1 \sigma)$ that the true land-use change emission lies within the given range, for the

20 range of processes considered here. This uncertainty range had been increased from $0.5 \mathrm{GtC}$

$21 \mathrm{yr}-1$ after new bookkeeping models were included that indicated a larger spread than

22 assumed before (Le Quéré et al., 2018). Projections for 2021 are based on fire activity from

23 tropical deforestation and degradation as well as emissions from peat fires and drainage.

Our ELuc estimates follow the definition of global carbon cycle models of $\mathrm{CO}_{2}$ fluxes related to land-use and land management and differ from IPCC definitions adopted in national GHG

27 inventories (NGHGI) for reporting under the UNFCCC, which additionally generally include,

28 through adoption of the IPCC so-called managed land proxy approach, the terrestrial fluxes

29 occurring on land defined by countries as managed. This partly includes fluxes due to

30 environmental change (e.g. atmospheric $\mathrm{CO}_{2}$ increase), which are part of $\mathrm{S}_{\text {LAND }}$ in our

31 definition. This causes the global emission estimates to be smaller for NGHGI than for the 
1 global carbon budget definition (Grassi et al., 2018). The same is the case for FAO estimates

2 of carbon fluxes on forest land, which include, compared to SLAND, both anthropogenic and

3 natural sources on managed land (Tubiello et al., 2021). Using the approach outlined in

4 Grassi et al. (2021), here we map as additional information the two definitions to each

5 other, to provide a comparison of the anthropogenic carbon budget to the official country

6 reporting to the climate convention. More details on the ELUC methodology can be found in

7 Appendix C.2.

\section{$8 \quad 2.3$ Growth rate in atmospheric $\mathrm{CO}_{2}$ concentration $\left(\mathrm{G}_{\mathrm{ATM}}\right)$}

\section{$9 \quad$ 2.3.1 Historical period}

10 The rate of growth of the atmospheric $\mathrm{CO}_{2}$ concentration is provided for years 1959-2020 by

11 the US National Oceanic and Atmospheric Administration Earth System Research Laboratory

12 (NOAA/ESRL; Dlugokencky and Tans, 2021), which is updated from Ballantyne et al. (2012)

13 and includes recent revisions to the calibration scale of atmospheric $\mathrm{CO}_{2}$ measurements

14 (Hall et al., 2021). For the 1959-1979 period, the global growth rate is based on

15 measurements of atmospheric $\mathrm{CO}_{2}$ concentration averaged from the Mauna Loa and South

16 Pole stations, as observed by the $\mathrm{CO}_{2}$ Program at Scripps Institution of Oceanography

17 (Keeling et al., 1976). For the 1980-2020 time period, the global growth rate is based on the

18 average of multiple stations selected from the marine boundary layer sites with well-mixed

19 background air (Ballantyne et al., 2012), after fitting each station with a smoothed curve as

20 a function of time, and averaging by latitude band (Masarie and Tans, 1995). The annual

21 growth rate is estimated by Dlugokencky and Tans (2021) from atmospheric $\mathrm{CO}_{2}$

22 concentration by taking the average of the most recent December-January months

23 corrected for the average seasonal cycle and subtracting this same average one year earlier.

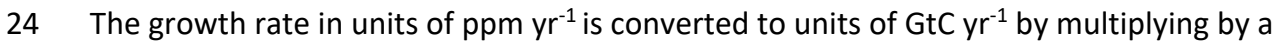

25 factor of $2.124 \mathrm{GtC}$ per ppm, assuming instantaneous mixing of $\mathrm{CO}_{2}$ throughout the

26 atmosphere (Ballantyne et al., 2012).

27 Starting in 2020, NOAA/ESRL now provides estimates of atmospheric $\mathrm{CO}_{2}$ concentrations

28 with respect to a new calibration scale, referred to as WMO-CO2-X2019, in line with the

29 recommendation of the World Meteorological Organization (WMO) Global Atmosphere

30 Watch (GAW) community (Hall et al., 2021). The WMO-CO2-X2019 scale improves upon the 
1 earlier WMO-CO2-X2007 scale by including a broader set of standards, which contain $\mathrm{CO}_{2}$ in

2 a wider range of concentrations that span the range 250-800 ppm (versus 250-520 ppm for

3 WMO-CO2-X2007). In addition, NOAA/ESRL made two minor corrections to the analytical

4 procedure used to quantify $\mathrm{CO}_{2}$ concentrations, fixing an error in the second virial

5 coefficient of $\mathrm{CO}_{2}$ and accounting for loss of a small amount of $\mathrm{CO}_{2}$ to materials in the

6 manometer during the measurement process. The difference in concentrations measured

7 using WMO-CO2-X2019 versus WMO-CO2-X2007 is +0.18 ppm at $400 \mathrm{ppm}$ and the

8 observational record of atmospheric $\mathrm{CO}_{2}$ concentrations have been revised accordingly. The

9 revisions have been applied retrospectively in all cases where the calibrations were

10 performed by NOAA/ESRL, thus affecting measurements made by members of the WMO-

11 GAW programme and other regionally coordinated programmes (e.g., Integrated Carbon

12 Observing System, ICOS). Changes to the $\mathrm{CO}_{2}$ concentrations measured across these

13 networks propagate to the global mean $\mathrm{CO}_{2}$ concentrations. Comparing the estimates of

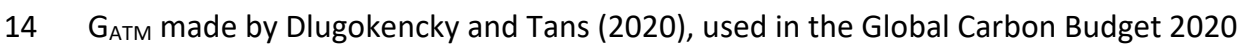

15 (Friedlingstein et al., 2020), with updated estimates from Dlugokencky and Tans (2021),

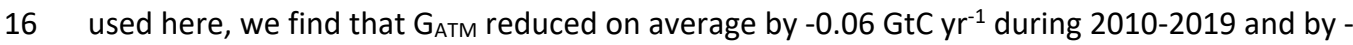

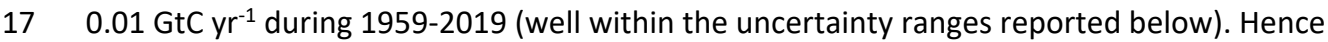

18 the change in analytical procedures made by NOAA/ESRL has a negligible impact on the

19 atmospheric growth rate $\mathrm{G}_{\text {ATM }}$.

20 The uncertainty around the atmospheric growth rate is due to four main factors. First, the

21 long-term reproducibility of reference gas standards (around $0.03 \mathrm{ppm}$ for $1 \sigma$ from the

22 1980s; Dlugokencky and Tans, 2021). Second, small unexplained systematic analytical errors

23 that may have a duration of several months to two years come and go. They have been

24 simulated by randomizing both the duration and the magnitude (determined from the

25 existing evidence) in a Monte Carlo procedure. Third, the network composition of the

26 marine boundary layer with some sites coming or going, gaps in the time series at each site,

27 etc (Dlugokencky and Tans, 2021). The latter uncertainty was estimated by NOAA/ESRL with

28 a Monte Carlo method by constructing 100 "alternative" networks (Masarie and Tans, 1995;

29 NOAA/ESRL, 2019). The second and third uncertainties, summed in quadrature, add up to

300.085 ppm on average (Dlugokencky and Tans, 2021). Fourth, the uncertainty associated

31 with using the average $\mathrm{CO}_{2}$ concentration from a surface network to approximate the true 
1 atmospheric average $\mathrm{CO}_{2}$ concentration (mass-weighted, in 3 dimensions) as needed to

2 assess the total atmospheric $\mathrm{CO}_{2}$ burden. In reality, $\mathrm{CO}_{2}$ variations measured at the stations

3 will not exactly track changes in total atmospheric burden, with offsets in magnitude and

4 phasing due to vertical and horizontal mixing. This effect must be very small on decadal and

5 longer time scales, when the atmosphere can be considered well mixed. Preliminary

6 estimates suggest this effect would increase the annual uncertainty, but a full analysis is not

7 yet available. We therefore maintain an uncertainty around the annual growth rate based

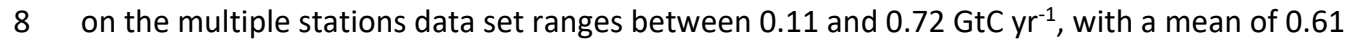

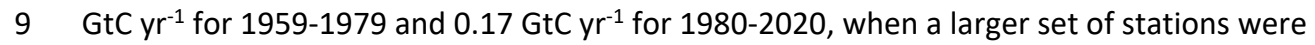

10 available as provided by Dlugokencky and Tans (2021) but recognise further exploration of

11 this uncertainty is required. At this time, we estimate the uncertainty of the decadal

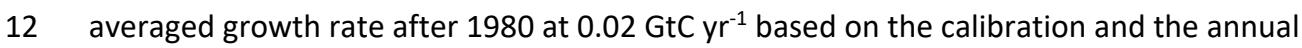

13 growth rate uncertainty but stretched over a 10-year interval. For years prior to 1980, we

14 estimate the decadal averaged uncertainty to be $0.07 \mathrm{GtC} \mathrm{rr}^{-1}$ based on a factor

15 proportional to the annual uncertainty prior and after $1980\left(0.02 *[0.61 / 0.17] \mathrm{GtC} \mathrm{yr}^{-1}\right)$.

16 We assign a high confidence to the annual estimates of $\mathrm{G}_{\mathrm{ATM}}$ because they are based on

17 direct measurements from multiple and consistent instruments and stations distributed

18 around the world (Ballantyne et al., 2012; Hall et al., 2021).

19 To estimate the total carbon accumulated in the atmosphere since 1750 or 1850 , we use an

20 atmospheric $\mathrm{CO}_{2}$ concentration of $277 \pm 3 \mathrm{ppm}$ or $286 \pm 3 \mathrm{ppm}$, respectively, based on a

21 cubic spline fit to ice core data (Joos and Spahni, 2008). For the construction of the

22 cumulative budget shown in Figure 3, we use the fitted estimates of $\mathrm{CO}_{2}$ concentration from

23 Joos and Spahni (2008) to estimate the annual atmospheric growth rate using the

24 conversion factors shown in Table 1. The uncertainty of $\pm 3 \mathrm{ppm}$ (converted to $\pm 1 \sigma$ ) is taken

25 directly from the IPCC's AR5 assessment (Ciais et al., 2013). Typical uncertainties in the

26 growth rate in atmospheric $\mathrm{CO}_{2}$ concentration from ice core data are equivalent to \pm 0.1 -

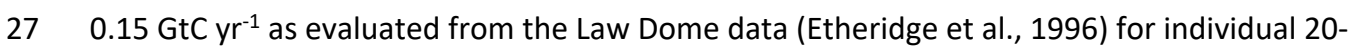

28 year intervals over the period from 1850 to 1960 (Bruno and Joos, 1997). 


\section{$1 \quad 2.3 .22021$ projection}

2 We provide an assessment of $\mathrm{G}_{\text {ATM }}$ for 2021 based on the monthly calculated global

3 atmospheric $\mathrm{CO}_{2}$ concentration (GLO) through August (Dlugokencky and Tans, 2021), and

4 bias-adjusted Holt-Winters exponential smoothing with additive seasonality (Chatfield,

5 1978) to project to January 2022. Additional analysis suggests that the first half of the year

6 (the boreal winter-spring-summer transition) shows more interannual variability than the

7 second half of the year (the boreal summer-autumn-winter transition), so that the exact

8 projection method applied to the second half of the year has a relatively smaller impact on

9 the projection of the full year. Uncertainty is estimated from past variability using the

10 standard deviation of the last 5 years' monthly growth rates.

\subsection{Ocean $\mathrm{CO}_{2}$ sink}

12 The reported estimate of the global ocean anthropogenic $\mathrm{CO}_{2}$ sink SocEAN is derived as the

13 average of two estimates. The first estimate is derived as the mean over an ensemble of

14 eight global ocean biogeochemistry models (GOBMs, Table 4 and Table A2). The second

15 estimate is obtained as the mean over an ensemble of seven observation-based data-

16 products (Table 4 and Table A3). The GOBMs simulate both the natural and anthropogenic

$17 \mathrm{CO}_{2}$ cycles in the ocean. They constrain the anthropogenic air-sea $\mathrm{CO}_{2}$ flux (the dominant

18 component of SOCEAN) by the transport of carbon into the ocean interior, which is also the

19 controlling factor of present-day ocean carbon uptake in the real world. They cover the full

20 globe and all seasons and were recently evaluated against surface ocean carbon

21 observations, suggesting they are suitable to estimate the annual ocean carbon sink (Hauck

22 et al., 2020). The data-products are tightly linked to observations of $\mathrm{fCO}_{2}$ (fugacity of $\mathrm{CO}_{2}$,

23 which equals $\mathrm{pCO}_{2}$ corrected for the non-ideal behaviour of the gas; Pfeil et al., 2013), which

24 carry imprints of temporal and spatial variability, but are also sensitive to uncertainties in

25 gas-exchange parameterizations and data-sparsity. Their asset is the assessment of

26 interannual and spatial variability (Hauck et al., 2020). We further use two diagnostic ocean

27 models to estimate Socean over the industrial era (1781-1958).

28 The global $\mathrm{fCO}_{2}$-based flux estimates were adjusted to remove the pre-industrial ocean

29 source of $\mathrm{CO}_{2}$ to the atmosphere of $0.61 \mathrm{GtC} \mathrm{yr}^{-1}$ from river input to the ocean (the average

30 of $0.45 \pm 0.18 \mathrm{GtC}^{-1}$ by Jacobson et al. (2007) and $0.78 \pm 0.41 \mathrm{GtC}^{-1} \mathrm{r}^{-1}$ by Resplandy et al., 
1 2018), to satisfy our definition of SocEAN (Hauck et al., 2020). The river flux adjustment was

2 distributed over the latitudinal bands using the regional distribution of Aumont et al. (2001;

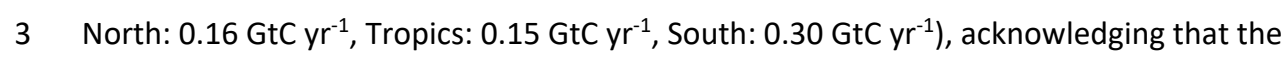

4 boundaries of Aumont et al $\left(2001\right.$; namely $20^{\circ} \mathrm{S}$ and $\left.20^{\circ} \mathrm{N}\right)$ are not consistent with the

5 boundaries otherwise used in the GCB $\left(30^{\circ} \mathrm{S}\right.$ and $\left.30^{\circ} \mathrm{N}\right)$. A recent modelling study (Lacroix et

6 al., 2020) suggests that more of the riverine outgassing is located in the tropics than in the

7 Southern Ocean; and hence this regional distribution is associated with a major uncertainty.

8 Anthropogenic perturbations of river carbon and nutrient transport to the ocean are not

9 considered (see section 2.7).

10 We derive SOCEAN from GOBMs by using a simulation $(\operatorname{sim} A)$ with historical forcing of climate

11 and atmospheric $\mathrm{CO}_{2}$, accounting for model biases and drift from a control simulation (sim

12 B) with constant atmospheric $\mathrm{CO}_{2}$ and normal year climate forcing. A third simulation (sim

13 C) with historical atmospheric $\mathrm{CO}_{2}$ increase and normal year climate forcing is used to

14 attribute the ocean sink to $\mathrm{CO}_{2}(\operatorname{sim} \mathrm{C}$ minus $\operatorname{sim} \mathrm{B}$ ) and climate (sim A minus $\operatorname{sim} \mathrm{C}$ ) effects.

15 Data-products are adjusted to represent the full ocean area by a simple scaling approach

16 when coverage is below $98 \%$. GOBMs and data-products fall within the observational

17 constraints over the $1990 \mathrm{~s}$ ( $2.2 \pm 0.7 \mathrm{GtC} \mathrm{yr}^{-1}$, Ciais et al., 2013) after applying adjustments .

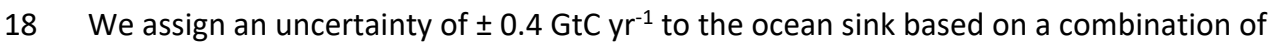

19 random (ensemble standard deviation) and systematic uncertainties (GOBMs bias in

20 anthropogenic carbon accumulation, previously reported uncertainties in $\mathrm{fCO}_{2}$-based data-

21 products; see section C.3.3). We assess a medium confidence level to the annual ocean $\mathrm{CO}_{2}$

22 sink and its uncertainty because it is based on multiple lines of evidence, it is consistent with

23 ocean interior carbon estimates (Gruber et al., 2019, see section 3.5.5) and the results are

24 consistent in that the interannual variability in the GOBMs and data-based estimates are all

25 generally small compared to the variability in the growth rate of atmospheric $\mathrm{CO}_{2}$

26 concentration. We refrain from assigning a high confidence because of the systematic

27 deviation between the GOBM and data-product trends since around 2002. More details on

28 the Socean methodology can be found in Appendix C.3.

29 The ocean $\mathrm{CO}_{2}$ sink forecast for the year 2021 is based on the annual historical and

30 estimated 2021 atmospheric $\mathrm{CO}_{2}$ concentration (Dlugokencky and Tans 2021), historical and

31 estimated 2021 annual global fossil fuel emissions from this year's carbon budget, and the

32 spring (March, April, May) Oceanic Niño Index (ONI) index (NCEP, 2021). Using a non-linear 
1 regression approach, i.e., a feed-forward neural network, atmospheric $\mathrm{CO}_{2}$, the $\mathrm{ONI}$ index

2 and the fossil fuel emissions are used as training data to best match the annual ocean $\mathrm{CO}_{2}$

3 sink (i.e. combined SOCEAN estimate from GOBMs and data products) from 1959 through

42020 from this year's carbon budget. Using this relationship, the 2021 Socean can then be

5 estimated from the projected 2021 input data using the non-linear relationship established

6 during the network training. To avoid overfitting, the neural network was trained with a

7 variable number of hidden neurons (varying between 2-5) and $20 \%$ of the randomly

8 selected training data were withheld for independent internal testing. Based on the best

9 output performance (tested using the $20 \%$ withheld input data), the best performing

10 number of neurons was selected. In a second step, we trained the network 10 times using

11 the best number of neurons identified in step 1 and different sets of randomly selected

12 training data. The mean of the 10 trainings is considered our best forecast, whereas the

13 standard deviation of the 10 ensembles provides a first order estimate of the forecast

14 uncertainty. This uncertainty is then combined with the SocEAN uncertainty $\left(0.4 \mathrm{GtC}_{\mathrm{yr}}{ }^{-1}\right)$ to

15 estimate the overall uncertainty of the 2021 prediction.

\section{$16 \quad 2.5$ Terrestrial $\mathrm{CO}_{2}$ sink}

17 The terrestrial land sink (S

18 by rising atmospheric $\mathrm{CO}_{2}$ and $\mathrm{N}$ inputs on plant growth, as well as the effects of climate

19 change such as the lengthening of the growing season in northern temperate and boreal

20 areas. S SAND does not include land sinks directly resulting from land-use and land-use change

21 (e.g., regrowth of vegetation) as these are part of the land-use flux (ELuc), although system

22 boundaries make it difficult to attribute exactly $\mathrm{CO}_{2}$ fluxes on land between SLAND and ELUC

23 (Erb et al., 2013).

$24 S_{\text {LAND }}$ is estimated from the multi-model mean of 17 DGVMs (Table A1). As described in

25 Appendix C.4, DGVMs simulations include all climate variability and $\mathrm{CO}_{2}$ effects over land,

26 with 12 DGVMs also including the effect of $\mathrm{N}$ inputs. The DGVMs estimate of SLAND does not

27 include the export of carbon to aquatic systems or its historical perturbation, which is

28 discussed in Appendix D3. See Appendix C.4 for DGVMs evaluation and uncertainty

29 assessment for SLAND, using the International Land Model Benchmarking system (ILAMB;

30 Collier et al., 2018). More details on the SLAND methodology can be found in Appendix C.4. 
1 Like the ocean forecast, the land $\mathrm{CO}_{2} \operatorname{sink}$ (SLAND) forecast is based on the annual historical

2 and estimated 2021 atmospheric $\mathrm{CO}_{2}$ concentration (Dlugokencky and Tans 2021), historical

3 and estimated 2021 annual global fossil fuel emissions from this year's carbon budget, and

4 the summer (June, July, August) ONI index (NCEP, 2021). All training data are again used to

5 best match S LAND from 1959 through 2020 from this year's carbon budget using a feed-

6 forward neural network. To avoid overfitting, the neural network was trained with a variable

7 number of hidden neurons (varying between 2-15), larger than for SocEan prediction due to

8 the stronger land carbon interannual variability. As done for SOCEAN, a pre-training selects the

9 optimal number of hidden neurons based on $20 \%$ withheld input data, and in a second step,

10 an ensemble of 10 forecasts is produced to provide the mean forecast plus uncertainty. This

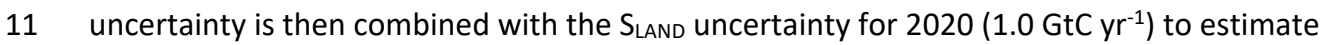

12 the overall uncertainty of the 2021 prediction.

\section{$13 \quad 2.6$ The atmospheric perspective}

14 The world-wide network of in-situ atmospheric measurements and satellite derived

15 atmospheric $\mathrm{CO}_{2}$ column $\left(x \mathrm{CO}_{2}\right)$ observations put a strong constraint on changes in the

16 atmospheric abundance of $\mathrm{CO}_{2}$. This is true globally (hence our large confidence in $\mathrm{G}_{\text {AтM }}$ ),

17 but also regionally in regions with sufficient observational density found mostly in the extra-

18 tropics. This allows atmospheric inversion methods to constrain the magnitude and location

19 of the combined total surface $\mathrm{CO}_{2}$ fluxes from all sources, including fossil and land-use

20 change emissions and land and ocean $\mathrm{CO}_{2}$ fluxes. The inversions assume $\mathrm{E}_{\mathrm{Fos}}$ to be well

21 known, and they solve for the spatial and temporal distribution of land and ocean fluxes

22 from the residual gradients of $\mathrm{CO}_{2}$ between stations that are not explained by fossil fuel

23 emissions. By design, such systems thus close the carbon balance $\left(B_{I M}=0\right)$ and thus provide

24 an additional perspective on the independent estimates of the ocean and land fluxes.

25 This year's release includes six inversion systems that are described in Table A4. Each system

26 is rooted in Bayesian inversion principles but uses slightly different methodologies. These

27 differences concern the selection of atmospheric $\mathrm{CO}_{2}$ data and the choice of a-priori fluxes

28 to refine with these datas. They also differ in spatial and temporal resolution, assumed

29 correlation structures, and mathematical approach of the models (see references in Table

30 A4 for details). Importantly, the systems use a variety of transport models, which was

31 demonstrated to be a driving factor behind differences in atmospheric inversion-based flux 
1 estimates, and specifically their distribution across latitudinal bands (Gaubert et al., 2019;

2 Schuh et al., 2019). Multiple inversion systems (UoE, CTE, and CAMS) were previously tested

3 with satellite $\mathrm{xCO}_{2}$ retrievals from GOSAT or OCO-2 measurements, but their results at the

4 larger scales (as discussed in this work) did not deviate substantially from their in-situ

5 counterparts and are therefore not separately included. One inversion this year (CMS-Flux)

6 used ACOS-GOSAT v9 retrievals between July 2009 and Dec 2014 and OCO-2 b10 retrievals

7 between Jan 2015 to Dec 2015, in addition to the in-situ observational $\mathrm{CO}_{2}$ mole fraction

8 records.

9 The original products delivered by the inverse modelers were modified to facilitate the

10 comparison to the other elements of the budget, specifically on 3 accounts: (1) global total

11 fossil fuel emissions, (2) riverine $\mathrm{CO}_{2}$ transport, and (3) cement carbonation $\mathrm{CO}_{2}$ uptake.

12 Details are given below. We note that with these adjustments the inverse results no longer

13 represent the net atmosphere-surface exchange over land/ocean areas as sensed by

14 atmospheric observations. Instead for land they become the net loss/uptake of $\mathrm{CO}_{2}$ by

15 vegetation and soils that is not exported by fluvial systems, similar to the DGVMs estimates.

16 For oceans, they become the net uptake of anthropogenic $\mathrm{CO}_{2}$, similar to the GOBMs

17 estimates.

18 The inversion systems prescribe global fossil fuel emissions based on the GCP's Gridded

19 Fossil Emissions Dataset version 2021.2 (GCP-GridFEDv2021.2; Jones et al., 2021b), which is

20 an update to 2019 of the first version of GCP-GridFED presented by Jones et al. (2021a).

21 GCP-GridFEDv2021.2 scales gridded estimates of $\mathrm{CO}_{2}$ emissions from EDGARv4.3.2

22 (Janssens-Maenhout et al., 2019) within national territories to match national emissions

23 estimates provided by the GCB for the years 1959-2020, which were compiled following the

24 methodology described in Section 2.1 with all datasets available on August 14th 2021 (R.

25 Andrew, pers. comm.). Small differences between the systems due to for instance regridding

26 to the transport model resolution are corrected for in the latitudinal partitioning we

27 present, to ensure agreement with the estimate of $\mathrm{E}_{\mathrm{Fos}}$ in this budget. We also note that the

28 ocean fluxes used as prior by 5 out of 6 inversions are part of the suite of the ocean process

29 model or $\mathrm{fCO} 2$ data products suite listed in Section 2.4. Although these fluxes are further

30 adjusted by the atmospheric inversions, it makes the inversion estimates of the ocean fluxes

31 not completely independent of SocEAN assessed here. 
1 To facilitate comparisons to the independent SOCEAN and SLAND, we used the same corrections

2 for transport and outgassing of carbon transported from land to ocean, as done for the

3 observation-based estimates of SOCEAN (see Appendix C.3). Furthermore, the inversions did

4 not include a cement carbonation sink (see section 2.1) and therefore this GCB component

5 is implicitly part of their total land sink estimate. In the numbers presented in this budget,

6 each year's global carbonation sink from cement was subtracted from each year's estimated

7 land sink in each inversion, distributed proportional to fossil fuel emissions per region

8 (North-Tropics-South).

9 The atmospheric inversions are evaluated using vertical profiles of atmospheric $\mathrm{CO}_{2}$

10 concentrations (Fig. B4). More than 30 aircraft programs over the globe, either regular

11 programs or repeated surveys over at least 9 months, have been used to assess model

12 performance (with space-time observational coverage sparse in the SH and tropics, and

13 denser in NH mid-latitudes; Table A6). The six models are compared to the independent

14 aircraft $\mathrm{CO}_{2}$ measurements between 2 and $7 \mathrm{~km}$ above sea level between 2001 and 2020.

15 Results are shown in Fig. B4 and discussed in Section 3.7.

16 With a relatively small ensemble $(\mathrm{N}=6)$ of systems that moreover share some a-priori fluxes used with one another, or with the process-based models, it is difficult to justify using their mean and standard deviation as a metric for uncertainty across the ensemble. We therefore

19 report their full range (min-max) without their mean. More details on the atmospheric

20 inversions methodology can be found in Appendix C.5.

\section{$21 \quad 2.7$ Processes not included in the global carbon budget}

22 The contribution of anthropogenic $\mathrm{CO}$ and $\mathrm{CH} 4$ to the global carbon budget is not fully

23 accounted for in Eq. (1) and is described in Appendix D1. The contributions of other

24 carbonates to $\mathrm{CO}_{2}$ emissions is described in Appendix D2. The contribution of anthropogenic

25 changes in river fluxes is conceptually included in Eq. (1) in SOCEAN and in SLAND, but it is not

26 represented in the process models used to quantify these fluxes. This effect is discussed in

27 Appendix D3. Similarly, the loss of additional sink capacity from reduced forest cover is

28 missing in the combination of approaches used here to estimate both land fluxes (E $E_{L U C}$ and

29 S SAND) and its potential effect is discussed and quantified in Appendix D4. 


\section{Results}

2 For each component of the global carbon budget, we present results for three different time

3 periods: the full historical period, from 1850 to 2020, the six decades in which we have

4 atmospheric concentration records from Mauna Loa (1960-2020), a specific focus on last

5 year (2020), and the projection for the current year (2021). Subsequently, we assess the

6 combined constraints from the budget components (often referred to as a bottom-up

7 budget) against the top-down constraints from inverse modeling of atmospheric

8 observations. We do this for the global balance of the last decade, as well as for a regional

9 breakdown of land and ocean sinks by broad latitude bands.

\section{$10 \quad 3.1$ Fossil $\mathrm{CO}_{2}$ Emissions}

\section{$11 \quad 3.1 .1$ Historical period $\mathbf{1 8 5 0 - 2 0 2 0}$}

12 Cumulative fossil $\mathrm{CO}_{2}$ emissions for $1850-2020$ were $455 \pm 25 \mathrm{GtC}$, including the cement 13 carbonation sink (Fig. 3, Table 8).

14 In this period, $46 \%$ of fossil $\mathrm{CO}_{2}$ emissions came from coal, $35 \%$ from oil, $14 \%$ from natural

15 gas, $3 \%$ from decomposition of carbonates, and $1 \%$ from flaring.

16 In 1850 , the UK stood for $62 \%$ of global fossil $\mathrm{CO}_{2}$ emissions. In 1891 the combined

17 cumulative emissions of the current members of the European Union reached and

18 subsequently surpassed the level of the UK. Since 1917 US cumulative emissions have been

19 the largest. Over the entire period 1850-2020, US cumulative emissions amount to 110GtC

20 (25\% of world total), the EU's to $80 \mathrm{GtC}(18 \%)$, and China's to $60 \mathrm{GtC}(14 \%)$.

21 There are three additional global datasets that include all sources of fossil $\mathrm{CO}_{2}$ emissions:

22 CDIAC-FF (Gilfillan and Marland, 2021), CEDS version v_2021_04_21 (Hoesly et al., 2018);

23 O'Rourke et al., 2021) and PRIMAP-hist version 2.3.1 (Gütschow et al., 2016, 2021), although

24 these datasets are not independent. CDIAC-FF has the lowest cumulative emissions over

25 1750-2018 at 437 GtC, GCP has 443 GtC, CEDS 445 GtC, PRIMAP-hist TP 453 GtC, and

26 PRIMAP-hist CR 455 GtC. CDIAC-FF excludes emissions from lime production, while both

27 CDIAC-FF and GCP exclude emissions from international bunker fuels prior to 1950. CEDS

28 has higher emissions from international shipping in recent years, while PRIMAP-hist has

29 higher fugitive emissions than the other datasets. However, in general these four datasets

30 are in relative agreement as to total historical global emissions of fossil $\mathrm{CO}_{2}$. 


\section{$1 \quad 3.1 .2$ Recent period $\mathbf{1 9 6 0 - 2 0 2 0}$}

2 Global fossil $\mathrm{CO}_{2}$ emissions, EFos (including the cement carbonation sink), have increased

3 every decade from an average of $3.0 \pm 0.2 \mathrm{GtC}^{-1} \mathrm{r}^{-1}$ for the decade of the $1960 \mathrm{~s}$ to an average

4 of $9.5 \pm 0.5 \mathrm{GtC}^{-1} \mathrm{r}^{-1}$ during 2011-2020 (Table 6, Fig. 2 and Fig. 5). The growth rate in these

5 emissions decreased between the 1960s and the 1990s, from $4.3 \% \mathrm{yr}^{-1}$ in the $1960 \mathrm{~s}$ (1960-

6 1969), 3.2\% $\mathrm{yr}^{-1}$ in the $1970 \mathrm{~s}$ (1970-1979), $1.6 \% \mathrm{yr}^{-1}$ in the $1980 \mathrm{~s}$ (1980-1989), to $0.9 \% \mathrm{yr}^{-1}$ in

7 the 1990s (1990-1999). After this period, the growth rate began increasing again in the

$82000 \mathrm{~s}$ at an average growth rate of $3.0 \% \mathrm{yr}^{-1}$, decreasing to $0.6 \% \mathrm{yr}^{-1}$ for the last decade

9 (2011-2020). China's emissions increased by $+1.0 \% \mathrm{yr}^{-1}$ on average over the last 10 years

10 dominating the global trend, followed by India's emissions increase by $+3.9 \% \mathrm{yr}^{-1}$, while

11 emissions decreased in EU27 by $-1.9 \% \mathrm{yr}^{-1}$, and in the USA by $-1.1 \% \mathrm{yr}^{-1}$. Fig.6 illustrates the

12 spatial distribution of fossil fuel emissions for the 2011-2020 period.

$13 \mathrm{E}_{\mathrm{Fos}}$ includes the uptake of $\mathrm{CO}_{2}$ by cement via carbonation which has increased with

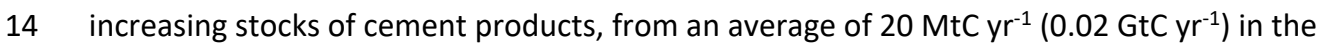

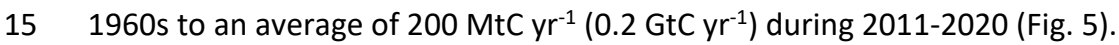

\section{$16 \quad 3.1 .3$ Final year 2020}

17 The estimate of global fossil $\mathrm{CO}_{2}$ emissions for 2020 is $5.4 \%$ lower than in 2019, declining 0.5

$18 \mathrm{GtC}$ to reach $9.5 \pm 0.5 \mathrm{GtC}(9.3 \pm 0.5 \mathrm{GtC}$ when including the cement carbonation sink $)$ in

192020 (Fig. 5), distributed among coal (40\%), oil (32\%), natural gas (21\%), cement (5\%) and

20 others (2\%). Compared to the previous year, 2020 emissions from coal, oil and gas declined

21 by $4.4 \%, 9.7 \%$ and $2.3 \%$ respectively, while emissions from cement increased by $0.8 \%$. All

22 growth rates presented are adjusted for the leap year, unless stated otherwise.

23 In 2020, the largest absolute contributions to global fossil $\mathrm{CO}_{2}$ emissions were from China

24 (31\%), the USA (14\%), the EU27 (7\%), and India (7\%). These four regions account for $59 \%$ of

25 global $\mathrm{CO}_{2}$ emissions, while the rest of the world contributed $41 \%$, including international

26 aviation and marine bunker fuels (2.9\% of the total). Growth rates for these countries from

272019 to 2020 were $+1.4 \%$ (China), $-10.6 \%$ (USA), $-10.9 \%$ (EU27), and $-7.3 \%$ (India), with -

$287.0 \%$ for the rest of the world. The per-capita fossil $\mathrm{CO}_{2}$ emissions in 2020 were $1.2 \mathrm{tC}$

29 person $^{-1} \mathrm{yr}^{-1}$ for the globe, and were 3.9 (USA), 2.0 (China), 1.6 (EU27) and 0.5 (India) tC

30 person ${ }^{-1} \mathrm{yr}^{-1}$ for the four highest emitting countries (Fig. 5). 
1 The decline in emissions of $-5.4 \%$ in 2020 is close to the projected decline of $-6.7 \%$, which

2 was the median of four approaches, published in Friedlingstein et al. (2020). Of the four

3 approaches, the 'GCP' method was closest at $-5.8 \%$. That method was based on national

4 emissions projections for China, the USA, the EU27, and India using reported monthly

5 activity data when available and projections of gross domestic product corrected for trends

6 in fossil fuel intensity (IFos) for the rest of the world. Of the regions, the projection for the

7 EU27 was least accurate, and the reasons for this are discussed by Andrew (2021).

\section{$8 \quad 3.1 .4$ Year 2021 Projection}

9 Globally, we estimate that global fossil $\mathrm{CO}_{2}$ emissions will rebound $4.9 \%$ in 2021 (4.1\% to

$105.7 \%$ ) to $9.9 \mathrm{GtC}\left(36.4 \mathrm{GtCO}_{2}\right)$, returning near their 2019 emission levels of $10.0 \mathrm{GtC}$ (36.7

$11 \mathrm{GtCO}_{2}$ ). Global increase in 2021 emissions per fuel types are $+5.7 \%$ (range $4.5 \%$ to $6.8 \%$ ) for

12 coal, $+4.4 \%$ (range $3.0 \%$ to $5.8 \%$ ) for oil, $+4.3 \%$ (range $3.2 \%$ to $5.4 \%$ ) for natural gas, and

$13+6.5 \%$ (range $4.8 \%$ to $8.3 \%$ ) for cement.

14 For China, projected fossil emissions in 2021 are expected to increase by $4.0 \%$ (range $2.1 \%$

15 to 5.8\%) compared with 2020 emissions, bringing 2021 emissions for China around $3.0 \mathrm{GtC}$

$16 \mathrm{yr}^{-1}\left(11.1 \mathrm{GtCO}_{2} \mathrm{yr}^{-1}\right)$. Chinese emissions appear to have risen in both 2020 and 2021 despite

17 the economic disruptions of COVID-19. Increases in fuel specific projections for China are

$18+2.5 \%$ for coal, $+6.0 \%$ for oil, $+15.3 \%$ natural gas, and $+6.4 \%$ for cement.

19 For the USA, the Energy Information Administration (EIA) emissions projection for 2021

20 combined with cement clinker data from USGS gives an increase of $7.6 \%$ (range $5.3 \%$ to

21 10.0\%) compared to 2020, bringing USA 2021 emissions around $1.4 \mathrm{GtC}^{-1}\left(5.1 \mathrm{GtCO}_{2} \mathrm{yr}^{-1}\right)$.

22 This is based on separate projections for coal $+20.4 \%$, oil $+9.1 \%$, natural gas $-0.4 \%$, and

23 cement $+0.7 \%$.

24 For the European Union, our projection for 2021 is for an increase of 7.6\% (range 5.6\% to

$259.5 \%)$ over 2020, with 2021 emissions around $0.8 \mathrm{GtC} \mathrm{yr}^{-1}\left(2.8 \mathrm{GtCO}_{2} \mathrm{yr}^{-1}\right)$. This is based on

26 separate projections for coal of $+15.4 \%$, oil $+4.3 \%$, natural gas $+7.6 \%$, and cement $-0.2 \%$.

27 For India, our projection for 2021 is an increase of $12.6 \%$ (range of $10.7 \%$ to $13.6 \%$ ) over

282020 , with 2021 emissions around $0.7 \mathrm{GtC} \mathrm{yr}^{-1}\left(2.7 \mathrm{GtCO}_{2} \mathrm{yr}^{-1}\right)$. This is based on separate

29 projections for coal of $+14.8 \%$, oil $+6.7 \%$, natural gas $+4.7 \%$, and cement $+21.4 \%$. 
1 For the rest of the world, the expected growth rate for 2021 is $2.9 \%$ (range $1.8 \%$ to $4.1 \%$ ).

2 This is computed using the GDP projection for the world (excluding China, the USA, the EU,

3 and India) of $4.4 \%$ made by the IMF (2021) and a decrease in $I_{\text {FOS }}$ of $-1.7 \% \mathrm{yr}^{-1}$, which is the

4 average over 2011-2020. The uncertainty range is based on the standard deviation of the

5 interannual variability in $I_{\text {Fos }}$ during $2011-2020$ of $0.6 \% \mathrm{yr}^{-1}$ and our estimates of uncertainty

6 in the IMF's GDP forecast of $0.6 \%$. The methodology allows independent projections for

7 coal, oil, natural gas, cement, and other components, which add to the total emissions in

8 the rest of the world. The fuel specific projected 2021 growth rates for the rest of the world

9 are: $+3.0 \%$ (range $0.5 \%$ to $5.6 \%)$ for coal, $+2.1 \%(-0.5 \%$ to $+4.7 \%)$ for oil, $+3.9 \%(2.4 \%$ to

$105.5 \%)$ for natural gas, $+4.6 \%(+2.5 \%$ to $+6.7 \%)$ for cement.

11 Independently, the IEA has published two forecasts of global fossil energy $\mathrm{CO}_{2}$ emissions

12 (i.e., a subset of fossil $\mathrm{CO}_{2}$ emissions), first in April (4.8\%; IEA, 2021a) and so revised in

13 October at 4\% (IEA, 2021b). Carbon Monitor produces estimates of global emissions with

14 low temporal lag, and their estimates suggest that emissions in the first eight months of

152021 were $7.0 \%$ higher than in the same period in 2020 (Carbon Monitor, 2021).

\section{$16 \quad 3.2$ Emissions from Land Use Changes}

\section{$17 \quad 3.2 .1$ Historical period $\mathbf{1 8 5 0 - 2 0 2 0}$}

18 Cumulative $\mathrm{CO}_{2}$ emissions from land-use changes ( $E_{L U C}$ ) for $1850-2020$ were $200 \pm 65 \mathrm{GtC}$

19 (Table 8; Fig. 3; Fig. 13). The cumulative emissions from $E_{\text {Luc }}$ are particularly uncertain, with

20 large spread among individual estimates of $140 \mathrm{GtC}$ (updated H\&N2017), $270 \mathrm{GtC}$ (BLUE),

21 and $195 \mathrm{GtC}$ (OSCAR) for the three bookkeeping models and a similar wide estimate of $190 \pm$ $60 \mathrm{GtC}$ for the DGVMs (all cumulative numbers are rounded to the nearest $5 \mathrm{GtC}$ ). These estimates are broadly consistent with indirect constraints from vegetation biomass observations, giving a cumulative source of $155 \pm 50 \mathrm{GtC}$ over the 1901-2012 period (Li et al., 2017). However, given the large spread a best estimate is difficult to ascertain.

\subsubsection{Recent period 1960-2020}

27 In contrast to growing fossil emissions, $\mathrm{CO}_{2}$ emissions from land-use, land-use change and

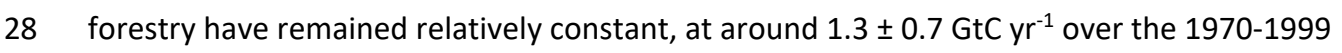

29 period, and even show a slight decrease over the last 20 years (Table 6) but with large

30 spread across estimates (Table 5, Fig. 7). Emissions are relatively constant in the DGVMs 
1 ensemble of models since the 1970s, with similar mean values until the 1990s as the

2 bookkeeping mean and large model spread (Table 5, Fig. 7). The DGVMs average grows

3 larger than the bookkeeping average in the recent decades and shows no sign of decreasing

4 emissions, which is, however, expected as DGVM-based estimates include the loss of

5 additional sink capacity, which grows with time, while the bookkeeping estimates do not

6 (Appendix D4).

7 Eluc is a net term of various gross fluxes, which comprise emissions and removals. Gross

8 emissions are on average 2-4 times larger than the net ELUC emissions, and remained largely

9 constant over the last 60 years, with a moderate increase from an average of $3.4 \pm 0.9 \mathrm{GtC}$

$10 \mathrm{yr}^{-1}$ for the decade of the 1960s to an average of $3.8 \pm 0.6 \mathrm{GtC}^{-1}$ during 2011-2020 (Fig.7,

11 Table 5), showing the relevance of land management such as harvesting or rotational

12 agriculture. Increases in gross removals, from $1.9 \pm 0.4 \mathrm{GtC}^{-1} \mathrm{r}^{-1}$ for the 1960 s to $2.7 \pm 0.4 \mathrm{GtC}$

$13 \mathrm{yr}^{-1}$ for 2011-2020, were larger than the increase in gross emissions. Since the processes

14 behind gross removals, foremost forest regrowth and soil recovery, are all slow, while gross

15 emissions include a large instantaneous component, short-term changes in land-use

16 dynamics, such as a temporary decrease in deforestation, influences gross emissions

17 dynamics more than gross removals dynamics. It is these relative changes to each other that

18 explain the decrease in net $E_{L U C}$ emissions over the last two decades and the last few years.

19 Gross fluxes differ more across the three bookkeeping estimates than net fluxes, which is

20 expected due to different process representation; in particular, treatment of shifting

21 cultivation, which increases both gross emissions and removals, differs across models.

22 There is a decrease in net $\mathrm{CO}_{2}$ emissions from land-use change over the last decade (Fig. 7,

23 Table 6), in contrast to earlier estimates of no clear trend across Eluc estimates

24 (Friedlingstein et al., 2020, Hong et al., 2021). The trend in the last decade is now about $-4 \%$

25 per year, compared to the $+1.8 \%$ per year reported by Friedlingstein et al. (2020). This

26 decrease is principally attributable to changes in Etuc estimates from BLUE and OSCAR,

27 which relate to changes in the underlying land-use forcing, LUH2 (Chini et al. 2021, Hurtt et

28 al. 2020) based on HYDE3.3 (Klein Goldewijk et al., 2017a, b). HYDE3.3 now incorporates

29 updated estimates of agricultural areas by the FAO (see Appendix C.2.2) and uses multi-

30 annual land cover maps from satellite remote sensing (ESA CCI Land Cover) to constrain

31 contemporary land cover patterns. These changes lead to lower global ELuc estimates in the 
1 last two decades compared to earlier versions of the global carbon budget due most notably

2 to lower emissions from cropland expansion, particularly in the tropical regions. Rosan et al.

3 (2021) showed that for Brazil, the new HYDE3.3 version is closer to independent, regional

4 estimates of land-use and land cover change (MapBiomas, 2021) with respect to spatial

5 patterns, but it shows less land-use and land cover changes than these independent

6 estimates, while HYDE3.2-based estimates had shown higher changes. The update in land-

7 use forcing leads to a decrease in estimated emissions in Brazil across several models after

8 the documented deforestation peak of 2003-2004 that preceded policies and monitoring

9 systems decreasing deforestation rates. However, estimated emissions based on the new

10 land-use forcing do not reflect the rise in Brazilian deforestation in the recent few years

11 (Silva Junior, 2021), and associated increasing emissions from deforestation would have

12 been missed here. The update in FAO agricultural areas in Brazil also implied that substantial

13 interannual variability reported to earlier FAO assessment and captured by the HYDE3.2

14 version since 2000 was removed. Due to the asymmetry of (fast) decay (like clearing by fire)

15 and (slower) regrowth, such reduced variability is expected to decrease annual emissions.

16 Also, the approach by Houghton and Nassikas (2017) smooths land use area changes before calculating carbon fluxes by a 5-year running mean, hence the three emission estimates are

18 in better agreement than in previous GCB estimates. However, differences still exist, which

19 highlight the need for accurate knowledge of land-use transitions and their spatial and

20 temporal variability. A further caveat is that global land-use change data for model input

21 does not capture forest degradation, which often occurs on small scale or without forest

22 cover changes easily detectable from remote sensing and poses a growing threat to forest

23 area and carbon stocks that may surpass deforestation effects (e.g., Matricardi et al., 2020,

24 Qin et al., 2021).

25 Highest land-use emissions occur in the tropical regions of all three continents, including the

26 Arc of Deforestation in the Amazon basin (Fig. 6b). This is related to massive expansion of

27 cropland, particularly in the last few decades in Latin America, Southeast Asia, and sub-

28 Saharan Africa Emissions (Hong et al., 2021), to a substantial part for export (Pendrill et al.,

29 2019). Emission intensity is high in many tropical countries, particularly of Southeast Asia,

30 due to high rates of land conversion in regions of carbon-dense and often still pristine,

31 undegraded natural forests (Hong et al., 2021). Emissions are further increased by peat fires 
1 in equatorial Asia (GFED4s, van der Werf et al., 2017). Uptake due to land-use change

2 occurs, particularly in Europe, partly related to expanding forest area as a consequence of

3 the forest transition in the $19^{\text {th }}$ and $20^{\text {th }}$ century and subsequent regrowth of forest (Fig. 6b)

4 (Mather 2001; McGrath et al., 2015).

5 National GHG inventory data (NGHGI) under the LULUCF sector or data submitted by

6 countries to FAOSTAT differ from the global models' definition of ELUC we adopt here in that

7 in the NGHGI reporting, the natural fluxes ( $S_{L A N D}$ ) are counted towards $E_{L U C}$ when they occur

8 on managed land (Grassi et al., 2018). In order to compare our results to the NGHGI

9 approach, we perform a re-mapping of our ELUC estimate by including the SLAND over

10 managed forest from the DGVMs simulations (following Grassi et al., 2021) to the

11 bookkeeping ELuc estimate (see Appendix C.2.3). For the 2010-2019 period, we estimate

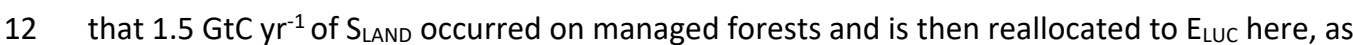

13 done in the NGHGI method. Doing so, our mean estimate of Eluc is reduced from a source of

$141.2 \mathrm{GtC}$ to a sink of $-0.4 \mathrm{GtC}$, very similar to the NGHGI estimate of $-0.3 \mathrm{GtC}$ (Table A.8).

15 Though estimates between GHGI, FAOSTAT, individual process-based models and the

16 mapped budget estimates still differ in value and need further analysis, the approach taken

17 here provides a possibility to relate the global models' and NGHGI approach to each other

18 routinely and thus link the anthropogenic carbon budget estimates of land $\mathrm{CO}_{2}$ fluxes

19 directly to the Global Stocktake, as part of UNFCCC Paris Agreement.

\section{$20 \quad 3.2 .3$ Final year 2020}

21 The global $\mathrm{CO}_{2}$ emissions from land-use change are estimated as $0.9 \pm 0.7 \mathrm{GtC}$ in $2020,0.2$

22 GtC lower than 2019, which had featured particularly large peat and tropical

23 deforestation/degradation fires. The surge in deforestation fires in the Amazon, causing

24 about 30\% higher emissions from deforestation and degradation fires in 2019 over the

25 previous decade, continued into 2020 (GFED4.1s, van der Werf et al., 2017). However, the

26 unusually dry conditions for a non-El Niño year that occurred in Indonesia in 2019 and led to

27 fire emissions from peat burning, deforestation and degradation in equatorial Asia to be

28 about twice as large as the average over the previous decade (GFED4.1s, van der Werf et al.,

29 2017) ceased in 2020. However, confidence in the annual change remains low. 
1 Land-use change and related emissions may have been affected by the COVID-19 pandemic

2 (e.g. Poulter et al., 2021). Although emissions from tropical deforestation and degradation

3 fires have been decreasing from 2019 to 2020 on the global scale, they increased in Latin

4 America (GFED4s; van der Werf et al., 2017). During the period of the pandemic,

5 environmental protection policies and their implementation may have been weakened in

6 Brazil (Vale et al., 2021). In other countries, too, monitoring capacities and legal

7 enforcement of measures to reduce tropical deforestation have been reduced due to

8 budget restrictions of environmental agencies or impairments to ground-based monitoring

9 that prevents land grabs and tenure conflicts (Brancalion et al., 2020, Amador-Jiménez et

10 al., 2020). Effects of the pandemic on trends in fire activity or forest cover changes are hard

11 to separate from those of general political developments and environmental changes and

12 the long-term consequences of disruptions in agricultural and forestry economic activities

13 (e.g., Gruère and Brooks, 2020; Golar et al., 2020; Beckman and Countryman, 2021) remain

14 to be seen.

$15 \quad 3.2 .4$ Year 2021 Projection

16 With wet conditions in Indonesia and a below-average fire season in South America our

17 preliminary estimate of ELuc for 2021 is substantially lower than the 2011-2020 average. By

18 the end of September 2021 emissions from tropical deforestation and degradation fires

19 were estimated to be $192 \mathrm{TgC}$, down from $347 \mathrm{TgC}$ in 2019 and 288 in 2020 (315 TgC 1997-

202020 average). Peat fire emissions in Equatorial Asia were estimated to be $1 \mathrm{TgC}$, down from

21117 TgC in 2019 and 2 TgC in 2020 (74 TgC 1997-2020 average) (GFED4.1s, van der Werf et

22 al., 2017). Based on the fire emissions until the end of September, we expect ELuc emissions

23 of around $0.8 \mathrm{GtC}$ in 2021 . Note that although our extrapolation is based on tropical

24 deforestation and degradation fires, degradation attributable to selective logging, edge-

25 effects or fragmentation will not be captured.

\section{$26 \quad 3.3$ Total anthropogenic emissions}

27 Cumulative anthropogenic $\mathrm{CO}_{2}$ emissions for $1850-2020$ totalled $660 \pm 65 \mathrm{GtC}(2420 \pm 240$

$\left.28 \mathrm{GtCO}_{2}\right)$, of which almost 70\% (455 GtC) occurred since 1960 and more than 30\% (205 GtC)

29 since 2000 (Table 6 and 8). Total anthropogenic emissions more than doubled over the last 


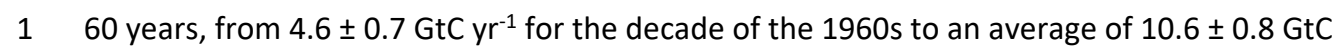

$2 \mathrm{yr}^{-1}$ during 2011-2020.

3 The total anthropogenic $\mathrm{CO}_{2}$ emissions from fossil plus land-use change amounted to $10.2 \pm$

$40.8 \mathrm{GtC}\left(37.2 \pm 2.9 \mathrm{GtCO}_{2}\right)$ in 2020 , while for 2021 , we project global total anthropogenic

$5 \mathrm{CO}_{2}$ emissions from fossil and land use changes to be around $10.5 \mathrm{GtC}\left(38.5 \mathrm{GtCO}_{2}\right)$.

6 During the historical period 1850-2020, 30\% of historical emissions were from land use

7 change and $70 \%$ from fossil emissions. However, fossil emissions have grown significantly

8 since 1960 while land use changes have not, and consequently the contributions of land use

9 change to total anthropogenic emissions were smaller during recent periods (17\% during

10 the period $1960-2020$ and $10 \%$ during $2011-2020$ ).

\section{$11 \quad 3.4 \quad$ Atmospheric $\mathrm{CO}_{2}$}

\section{$12 \quad 3.4 .1$ Historical period $\mathbf{1 8 5 0 - 2 0 2 0}$}

13 Atmospheric $\mathrm{CO}_{2}$ concentration was approximately 277 parts per million (ppm) in 1750

14 (Joos and Spahni, 2008), reaching 300ppm in the 1910s, 350ppm in the late 1980s, and

15 reaching $412.44 \pm 0.1 \mathrm{ppm}$ in 2020 (Dlugokencky and Tans, 2021); Fig. 1). The mass of

16 carbon in the atmosphere increased by $48 \%$ from $590 \mathrm{GtC}$ in 1750 to $876 \mathrm{GtC}$ in 2020.

17 Current $\mathrm{CO}_{2}$ concentrations in the atmosphere are unprecedented in the last 2 million years

18 and the current rate of atmospheric $\mathrm{CO}_{2}$ increase is at least 10 times faster than at any other

19 time during the last 800,000 years (Canadell et al., 2021).

\section{$20 \quad 3.4 .2$ Recent period $1960-2020$}

21 The growth rate in atmospheric $\mathrm{CO}_{2}$ level increased from $1.7 \pm 0.07 \mathrm{GtC}^{-1}$ in the 1960 s to

$225.1 \pm 0.02 \mathrm{GtC}^{-1}{ }^{-1}$ during 2011-2020 with important decadal variations (Table 6, Fig. 3 and

23 Fig 4).

24 During the last decade (2011-2020), the growth rate in atmospheric $\mathrm{CO}_{2}$ concentration

25 continued to increase, albeit with large interannual variability (Fig. 4).

26 The airborne fraction (AF), defined as the ratio of atmospheric $\mathrm{CO}_{2}$ growth rate to total

27 anthropogenic emissions:

$28 A F=G_{A T M} /\left(E_{F O S}+E_{L U C}\right)$ 
1 provides a diagnostic of the relative strength of the land and ocean carbon sinks in removing

2 part of the anthropogenic $\mathrm{CO}_{2}$ perturbation. The evolution of $\mathrm{AF}$ over the last 60 years

3 shows no significant trend, remaining nearly at around $45 \%$, albeit showing a large

4 interannual variability driven by the year-to-year variability in $\mathrm{G}_{\text {ATM }}$ (Fig. 8). The observed

5 stability of the airborne fraction over the 1960-2020 period indicates that the ocean and

6 land $\mathrm{CO}_{2}$ sinks have been removing on average about $55 \%$ of the anthropogenic emissions

7 (see sections 3.5 and 3.6).

\section{$8 \quad 3.4 .3 \quad$ Final year 2020}

9 The growth rate in atmospheric $\mathrm{CO}_{2}$ concentration was $5.0 \pm 0.2 \mathrm{GtC}(2.37 \pm 0.08 \mathrm{ppm})$ in

102020 (Fig. 4; Dlugokencky and Tans, 2021), very close to the 2011-2020 average. The 2020

11 decrease in $\mathrm{E}_{\mathrm{FOS}}$ and $\mathrm{E}_{\mathrm{LUC}}$ of about $0.7 \mathrm{GtC}$ propagated to an atmospheric $\mathrm{CO}_{2}$ growth rate

12 reduction of $0.38 \mathrm{GtC}(0.18 \mathrm{ppm})$, given the significant interannual variability of the land

13 carbon sink.

\section{$14 \quad 3.4 .4$ Year 2021 Projection}

15 The 2021 growth in atmospheric $\mathrm{CO}_{2}$ concentration $\left(\mathrm{G}_{\mathrm{ATM}}\right)$ is projected to be about $4.2 \mathrm{GtC}$

16 (1.98 ppm) based on GLO observations until the end of July 2021, bringing the atmospheric

$17 \mathrm{CO}_{2}$ concentration to an expected level of $414.7 \mathrm{ppm}$ averaged over the year, $49 \%$ over the

18 pre-industrial level.

\section{$19 \quad 3.5 \quad$ Ocean Sink}

$20 \quad 3.5 .1$ Historical period $\mathbf{1 8 5 0 - 2 0 2 0}$

21 Cumulated since 1850, the ocean sink adds up to $170 \pm 35 \mathrm{GtC}$, with two thirds of this

22 amount being taken up by the global ocean since 1960. Over the historical period, the ocean

23 sink increased in pace with the anthropogenic emissions exponential increase (Fig. 3b).

24 Since 1850 , the ocean has removed $26 \%$ of total anthropogenic emissions.

\section{$25 \quad 3.5 .2$ Recent period $1960-2020$}

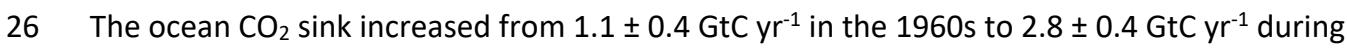

27 2011-2020 (Table 6), with interannual variations of the order of a few tenths of GtC $\mathrm{yr}^{-1}$ (Fig.

28 9). The ocean-borne fraction ( $\mathrm{S}_{\text {OCEAN }} /\left(\mathrm{E}_{\mathrm{FOS}}+\mathrm{E}_{\mathrm{LUC}}\right.$ ) has been remarkably constant around $25 \%$ 
1 on average (Fig. 8). Variations around this mean illustrate decadal variability of the ocean

2 carbon sink. So far, there is no indication of a decrease in the ocean-borne fraction from

31960 to 2020 . The increase of the ocean sink is primarily driven by the increased

4 atmospheric $\mathrm{CO}_{2}$ concentration, with the strongest $\mathrm{CO}_{2}$ induced signal in the North Atlantic

5 and the Southern Ocean (Fig. 10a). The effect of climate change is much weaker, reducing

6 the ocean sink globally by $0.12 \pm 0.07 \mathrm{GtC} \mathrm{rr}^{-1}$ or $5 \%$ (2011-2020, range -0.8 to $\left.-7.4 \%\right)$, and

7 does not show clear spatial patterns across the GOBMs ensemble (Fig. 10b). This is the

8 combined effect of change and variability in all atmospheric forcing fields, previously

9 attributed to wind and temperature changes in one model (LeQuéré et al., 2010).

10 The global net air-sea $\mathrm{CO}_{2}$ flux is a residual of large natural and anthropogenic $\mathrm{CO}_{2}$ fluxes

11 into and out of the ocean with distinct regional and seasonal variations (Fig. 6 and B1).

12 Natural fluxes dominate on regional scales, but largely cancel out when integrated globally

13 (Gruber et al., 2009). Mid-latitudes in all basins and the high-latitude North Atlantic

14 dominate the ocean $\mathrm{CO}_{2}$ uptake where low temperatures and high wind speeds facilitate

$15 \mathrm{CO}_{2}$ uptake at the surface (Takahashi et al., 2009). In these regions, formation of mode,

16 intermediate and deep-water masses transport anthropogenic carbon into the ocean

17 interior, thus allowing for continued $\mathrm{CO}_{2}$ uptake at the surface. Outgassing of natural $\mathrm{CO}_{2}$

18 occurs mostly in the tropics, especially in the equatorial upwelling region, and to a lesser

19 extent in the North Pacific and polar Southern Ocean, mirroring a well-established

20 understanding of regional patterns of air-sea $\mathrm{CO}_{2}$ exchange (e.g., Takahashi et al., 2009,

21 Gruber et al., 2009). These patterns are also noticeable in the Surface Ocean $\mathrm{CO}_{2}$ Atlas

22 (SOCAT) dataset, where an ocean $\mathrm{fCO}_{2}$ value above the atmospheric level indicates

23 outgassing (Fig. B1). This map further illustrates the data-sparsity in the Indian Ocean and the southern hemisphere in general.

25 Interannual variability of the ocean carbon sink is driven by climate variability with a first-

26 order effect from a stronger ocean sink during large El Niño events (e.g., 1997-1998) (Fig. 9;

27 Rödenbeck et al., 2014, Hauck et al., 2020). The GOBMs show the same patterns of decadal

28 variability as the mean of the $\mathrm{fCO}_{2}$-based data products, with a stagnation of the ocean sink

29 in the 1990s and a strengthening since the early 2000s (Fig. 9, Le Quéré et al., 2007;

30 Landschützer et al., 2015, 2016; DeVries et al., 2017; Hauck et al., 2020; McKinley et al.,

31 2020). Different explanations have been proposed for this decadal variability, ranging from 
1 the ocean's response to changes in atmospheric wind and pressure systems (e.g., Le Quéré

2 et al., 2007, Keppler and Landschützer, 2019), including variations in upper ocean

3 overturning circulation (DeVries et al., 2017) to the eruption of Mount Pinatubo and its

4 effects on sea surface temperature and slowed atmospheric $\mathrm{CO}_{2}$ growth rate in the 1990s

5 (McKinley et al., 2020). The main origin of the decadal variability is a matter of debate with a

6 number of studies initially pointing to the Southern Ocean (see review in Canadell et al.,

7 2021), but also contributions from the North Atlantic and North Pacific (Landschützer et al.,

8 2016, DeVries et al., 2019), or a global signal (McKinley et al., 2020) were proposed.

9 Although all individual GOBMs and data-products fall within the observational constraint,

10 the ensemble means of GOBMs, and data-products adjusted for the riverine flux diverge

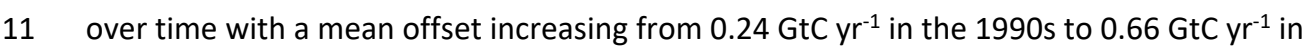

12 the decade 2011-2020 and reaching $1.1 \mathrm{GtC} \mathrm{yr}^{-1}$ in 2020. The Socean trend diverges with a

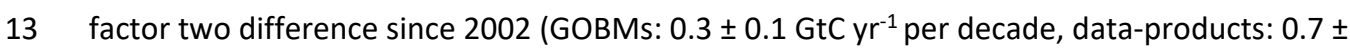

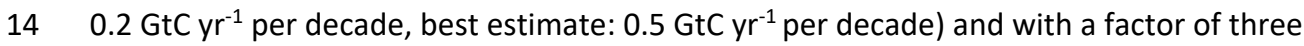

15 since 2010 (GOBMs: $0.3 \pm 0.1 \mathrm{GtC} \mathrm{yr}^{-1}$ per decade, data-products: $0.9 \pm 0.3 \mathrm{GtC} \mathrm{yr}^{-1}$ per

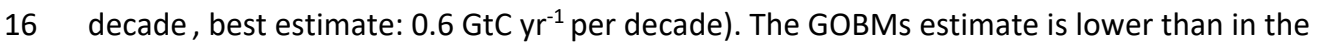

17 previous global carbon budget (Friedlingstein et al., 2020), because one high-sink model was

18 not available. The effect of two models (CNRM, MOM6-COBALT) revising their estimates

19 downwards was largely balanced by two models revising their estimate upwards (FESOM-

20 REcoM, PlankTOM).

21 The discrepancy between the two types of estimates stems mostly from a larger Southern

22 Ocean sink in the data-products prior to 2001 , and from a larger SOCEAN trend in the northern

23 and southern extra-tropics since then (Fig. 12). Possible explanations for the discrepancy in

24 the Southern Ocean could be missing winter observations and data sparsity in general

25 (Bushinsky et al., 2019, Gloege et al., 2021), model biases (as indicated by the large model

26 spread in the South, Figure 12, and the larger model-data mismatch, Figure B2), or

27 uncertainties in the regional river flux adjustment (Hauck et al., 2020, Lacroix et al., 2020).

28 During 2010-2016, the ocean $\mathrm{CO}_{2}$ sink appears to have intensified in line with the expected

29 increase from atmospheric $\mathrm{CO}_{2}$ (McKinley et al., 2020). This effect is stronger in the $\mathrm{fCO}_{2}$ -

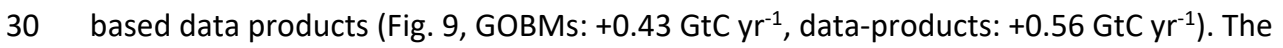

31 reduction of $-0.09 \mathrm{GtC} \mathrm{yr}^{-1}$ (range: -0.30 to $+0.12 \mathrm{GtC} \mathrm{yr}^{-1}$ ) in the ocean $\mathrm{CO}_{2} \operatorname{sink}$ in 2017 is 
1 consistent with the return to normal conditions after the El Niño in 2015/16, which caused

2 an enhanced sink in previous years. After 2017, the GOBMs ensemble mean suggests the

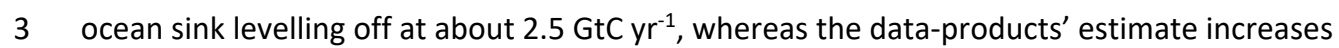

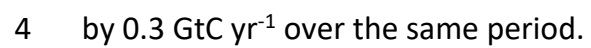

$5 \quad 3.5 .3 \quad$ Final year 2020

6 The estimated ocean $\mathrm{CO}_{2}$ sink was $3.0 \pm 0.4 \mathrm{GtC}$ in 2020. This is the average of GOBMs and

7 data-products, and is a small increase of $0.02 \mathrm{GtC}$ compared to 2019 , in line with the

8 competing effects from an expected sink strengthening from atmospheric $\mathrm{CO}_{2}$ growth and

9 expected sink weakening from La Nina conditions. There is, however, a substantial

10 difference between $\mathrm{GOBMs}$ and $\mathrm{fCO}_{2}$-based data-products in their mean 2020 SOCEAN

11 estimate (GOBMs: $2.5 \mathrm{GtC}$, data-products: $3.5 \mathrm{GtC}$ ). While the GOBMs simulate a stagnation

12 of the sink from 2019 to 2020 (-0.02 \pm 0.11 GtCGtC), the data-products suggest an increase

13 by $0.06 \mathrm{GtC}$, although not significant at the $1 \sigma$ level $( \pm 0.13 \mathrm{GtC})$. Four models and four data

14 products show an increase of SOCEAN (GOBMs up to $+0.18 \mathrm{GtC}$, data-product up to +0.21

$15 \mathrm{GtC})$, while four models and three data products show no change or a decrease of SOCEAN

16 (GOBMs down to $-0.12 \mathrm{GtC}$, data-products down to $-0.13 \mathrm{GtC}$; Fig. 9). The data-products

17 have a larger uncertainty at the tails of the reconstructed time series (e.g., Watson et al.,

18 2020). Specifically, the data-products' estimate of the last year is regularly adjusted in the

19 following release owing to the tail effect and an incrementally increasing data availability

20 with 1-5 years lag (Figure 9 bottom).

\section{$21 \quad 3.5 .4 \quad$ Year 2021 Projection}

22 Using a feed-forward neural network method (see section 2.4) we project an ocean sink of

$232.9 \mathrm{GtC}$ for 2021 . This is a reduction of the sink by $0.1 \mathrm{GtC}$ relative to the 2020 value which

24 we attribute to La Niña conditions in January to May 2021 and projections of a re-

25 emergence of La Niña later in the year.

\section{$26 \quad 3.5 .5 \quad$ Model Evaluation}

27 The evaluation of the ocean estimates (Fig. B2) shows an RMSE from annually detrended

28 data of 1.3 to $2.8 \mu$ atm for the seven $\mathrm{fCO}_{2}$-based data products over the globe, relative to

29 the $\mathrm{fCO}_{2}$ observations from the SOCAT v2021 dataset for the period 1990-2020. The GOBMs 


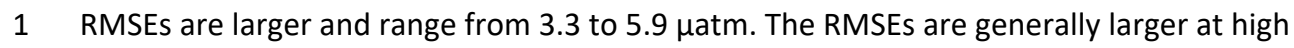

2 latitudes compared to the tropics, for both the data products and the GOBMs. The data

3 products have RMSEs of 1.3 to $3.6 \mu$ atm in the tropics, 1.3 to $2.7 \mu$ atm in the north, and 2.2

4 to $6.1 \mu$ atm in the south. Note that the data products are based on the SOCAT v2021

5 database, hence the latter are not independent dataset for the evaluation of the data

6 products. The GOBMs RMSEs are more spread across regions, ranging from 2.7 to $4.3 \mu$ atm

7 in the tropics, 2.9 to $6.9 \mu$ atm in the North, and 6.4 to $9.8 \mu \mathrm{atm}$ in the South. The higher

8 RMSEs occur in regions with stronger climate variability, such as the northern and southern

9 high latitudes (poleward of the subtropical gyres). The upper-range of the model RMSEs

10 have decreased somewhat relative to Friedlingstein et al. (2020), owing to one model with

11 upper-end RMSE not being represented this year, and the reduction of RMSE in one model

12 (MPIOM-HAMOCC6), presumably related to the inclusion of riverine carbon fluxes.

13 The additional simulation $\mathrm{C}$ allows to separate the steady-state anthropogenic carbon

14 component ( $\operatorname{sim} \mathrm{C}-\operatorname{sim} \mathrm{B}$ ) and to compare the model flux and DIC inventory change directly

15 to the interior ocean estimate of Gruber et al (2019) without further assumptions. The

16 GOBMs ensemble average of steady-state anthropogenic carbon inventory change 1994-

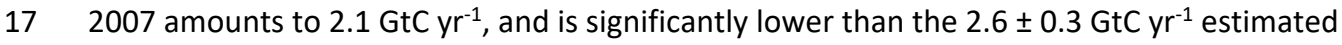

18 by Gruber et al (2019). Only the three models with the highest sink estimate fall within the

19 range reported by Gruber et al. (2019). This suggests that most of the models

20 underestimates anthropogenic carbon uptake by the ocean likely due to biases in ocean

21 carbon transport and mixing from the surface mixed layer to the ocean interior.

22 The reported SOCEAN estimate from GOBMs and data-products is $2.1 \pm 0.4 \mathrm{GtC}_{\mathrm{yr}}{ }^{-1}$ over the

23 period 1994 to 2007, which is in agreement with the ocean interior estimate of $2.2 \pm 0.4 \mathrm{GtC}$

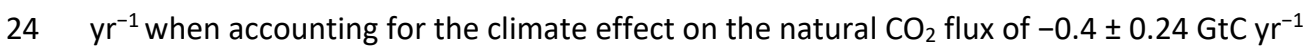

25 (Gruber et al., 2019) to match the definition of SOCEAN used here (Hauck et al., 2020). This

26 comparison depends critically on the estimate of the climate effect on the natural $\mathrm{CO}_{2}$ flux,

27 which is smaller from the GOBMs (section 3.5.2) than in Gruber et al. (2019). 
$1 \quad 3.6$ Land Sink

$2 \quad 3.6 .1$ Historical period $1850-2020$

3 Cumulated since 1850 , the terrestrial $\mathrm{CO}_{2}$ sink amounts to $195 \pm 45 \mathrm{GtC}, 30 \%$ of total

4 anthropogenic emissions. Over the historical period, the sink increased in pace with the

5 anthropogenic emissions exponential increase (Fig. 3b).

$6 \quad 3.6 .2$ Recent period $\mathbf{1 9 6 0 - 2 0 2 0}$

7 The terrestrial $\mathrm{CO}_{2}$ sink increased from $1.2 \pm 0.5 \mathrm{GtC} \mathrm{yr}^{-1}$ in the 1960 s to $3.1 \pm 0.6 \mathrm{GtC}^{-1}$

8 during 2010-2019, with important interannual variations of up to $2 \mathrm{GtC}^{-1} \mathrm{r}^{-1}$ generally

9 showing a decreased land sink during El Niño events (Fig. 7), responsible for the corresponding enhanced growth rate in atmospheric $\mathrm{CO}_{2}$ concentration. The larger land $\mathrm{CO}_{2}$ sink during 2010-2019 compared to the 1960s is reproduced by all the DGVMs in response

12 to the combined atmospheric $\mathrm{CO}_{2}$ increase and the changes in climate, and consistent with

13 constraints from the other budget terms (Table 5).

14 Over the period 1960 to present the increase in the global terrestrial $\mathrm{CO}_{2}$ sink is largely

15 attributed to the $\mathrm{CO}_{2}$ fertilization effect in the models (Prentice et al., 2001, Piao et al., 16 2009), directly stimulating plant photosynthesis and increased plant water use in water 17 limited systems, with a small negative contribution of climate change (Fig. 10). There is a 18 range of evidence to support a positive terrestrial carbon sink in response to increasing 19 atmospheric $\mathrm{CO}_{2}$, albeit with uncertain magnitude (Walker et al., 2021). As expected from

20 theory the greatest $\mathrm{CO}_{2}$ effect is simulated in the tropical forest regions, associated with

21 warm temperatures and long growing seasons (Hickler et al., 2008) (Fig. 10a). However,

22 evidence from tropical intact forest plots indicate an overall decline in the land sink across

23 Amazonia (1985-2011), attributed to enhanced mortality offsetting productivity gains

24 (Brienen et al., 2005, Hubau et al., 2020). During 2011-2020 the land sink is positive in all regions (Fig. 6) with the exception of central and eastern Brazil, Southwest USA and northern Mexico, Southeast Europe and Central Asia, South Africa, and eastern Australia, where the negative effects of climate variability and change (i.e. reduced rainfall) counterbalance $\mathrm{CO}_{2}$ effects. This is clearly visible on Figure 10 where the effects of $\mathrm{CO}_{2}$ (Fig.

29 10a) and climate (Fig. 10b) as simulated by the DGVMs are isolated. The negative effect of

30 climate is the strongest in most of South America, Central America, Southwest US and 
1 Central Europe (Fig. 10b). Globally, climate change reduces the land sink by $0.45 \pm 0.39 \mathrm{GtC}$

$2 \mathrm{yr}^{-1}(2011-2020)$.

3 In the past years several regions experienced record-setting fire events. While global burned

4 area has declined over the past decades mostly due to declining fire activity in savannas

5 (Andela et al., 2017), forest fire emissions are rising and have the potential to counter the

6 negative fire trend in savannas (Zheng et al., 2021). Noteworthy events include the 2019-

72020 Black Summer event in Australia (emissions of roughly 0.2 GtC; van der Velde et al.,

8 2021) and Siberia in 2021 where emissions approached 0.4 GtC or three times the 1997-

92020 average according to GFED4s. While other regions, including Western US and

10 Mediterranean Europe, also experienced intense fire seasons in 2021 their emissions are

11 substantially lower.

12 Despite these regional negative effects of climate change on $S_{L A N D}$, the efficiency of land to

13 remove anthropogenic $\mathrm{CO}_{2}$ emissions has remained broadly constant over the last six

14 decades, with a land-borne fraction (S

\section{$15 \quad 3.6 .3$ Final year 2020}

16 The terrestrial $\mathrm{CO}_{2}$ sink from the DGVMs ensemble was $2.9 \pm 1.0 \mathrm{GtC}$ in 2020 , slightly below

17 the decadal average of $3.1 \mathrm{GtC} \mathrm{yr}^{-1}$ (Fig. 4, Table 6). We note that the DGVMs estimate for

182020 is significantly larger than the $2.1 \pm 0.9 \mathrm{GtC} \mathrm{yr}^{-1}$ estimate from the residual sink from

19 the global budget (EFos $+E_{L U C}-G_{A T M}-$ SocEAN) (Table 5).

\section{$20 \quad$ 3.6.4 Year 2021 Projection}

21 Using a feed-forward neural network method (see section 2.5) we project a land sink of 3.3

$22 \mathrm{GtC}$ for 2021. This is an increase of the land sink by $0.3 \mathrm{GtC}$ relative to the 2020 value which we attribute to La Niña conditions in 2021.

\section{$24 \quad$ 3.6.5 Model Evaluation}

25 The evaluation of the DGVMs (Fig. B3) shows generally high skill scores across models for 26 runoff, and to a lesser extent for vegetation biomass, GPP, and ecosystem respiration (Fig.

27 B3, left panel). Skill score was lowest for leaf area index and net ecosystem exchange, with a 28 widest disparity among models for soil carbon. Further analysis of the results will be 
1 provided separately, focusing on the strengths and weaknesses in the DGVMs ensemble and

2 its validity for use in the global carbon budget.

\section{$3 \quad 3.7$ Partitioning the carbon sinks}

\section{$4 \quad$ 3.7.1 Global sinks and spread of estimates}

5 In the period 2011-2020, the bottom-up view of total global carbon sinks provided by the

6 GCB (SOCEAN $+S_{L A N D}-E_{L U C}$ ) agrees closely with the top-down budget delivered by the

7 atmospheric inversions. Figure 11 shows both total sink estimates of the last decade split by

8 land and ocean, which match the difference between $\mathrm{G}_{\mathrm{ATM}}$ and $\mathrm{E}_{\mathrm{FOs}}$ to within $0.06-0.17 \mathrm{GtC}$

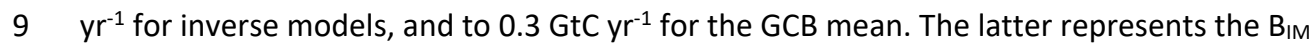

10 discussed in Section 3.8, which by design is minimal for the inverse models.

11 The distributions based on the individual models and data products reveal substantial

12 spread but converge near the decadal means quoted in Tables 5 and 6 . Sink estimates for

13 SOCEAN and from inverse models are mostly non-Gaussian, while the ensemble of DGVMs

14 appears more normally distributed justifying the use of a multi-model mean and standard

15 deviation for their errors in the budget. Noteworthy is that the tails of the distributions

16 provided by the land and ocean bottom-up estimates would not agree with the global

17 constraint provided by the fossil fuel emissions and the observed atmospheric $\mathrm{CO}_{2}$ growth

18 rate $\left(E_{F O S}-G_{A T M}\right)$. This illustrates the power of the atmospheric joint constraint from $G_{A T M}$

19 and the global $\mathrm{CO}_{2}$ observation network it derives from.

\section{$20 \quad$ 3.7.2 Total atmosphere-to-land fluxes}

21 The total atmosphere-to-land fluxes (S $\mathrm{S}_{\text {LAND }}-E_{L U C}$ ), calculated here as the difference between

$22 S_{\text {LAND }}$ from the DGVMs and $E_{L U C}$ from the bookkeeping models, amounts to a $1.9 \pm 0.9 \mathrm{GtC}$ yr

231 sink during 2011-2020 (Table 5). Estimates of total atmosphere-to-land fluxes (S LAND $-E_{\text {LUC }}$ )

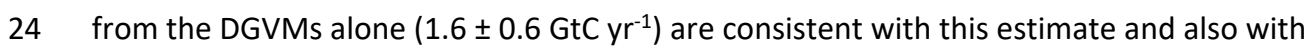

25 the global carbon budget constraint ( $E_{F O S}-G_{A T M}-S_{\text {OCEAN, }} 1.7 \pm 0.8 \mathrm{GtC} \mathrm{yr}^{-1} \mathrm{Table}^{5}$ ).

26 Consistent with the bookkeeping models estimates, the DGVM-based ELuc is substantially

27 lower than in Friedlingstein et al., (2020) due to the improved land cover forcing (see

28 section 3.2.2), increasing their total atmosphere-to-land fluxes and hence the consistency

29 with the budget constraint. For the last decade (2011-2020), the inversions estimate the net 


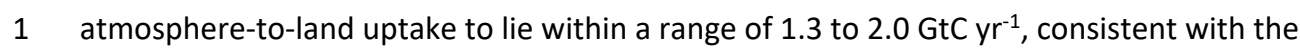

2 GCB and DGVMs estimates of SLAND - ELUC (Figure 11, Figure 12 top row).

\section{$3 \quad 3.7 .3$ Total atmosphere-to-ocean fluxes}

4 For the 2011-2020 period, the GOBMs $\left(2.5 \pm 0.6 \mathrm{GtC}^{-1}\right)$ produce a lower estimate for the

5 ocean sink than the $\mathrm{fCO}_{2}$-based data products $\left(3.1 \pm 0.5 \mathrm{GtC}^{-1}{ }^{-1}\right)$, which shows up in Figure

$6 \quad 11$ as a separate peak in the distribution from the GOBMs (triangle symbols pointing right)

7 and from the $\mathrm{fCO}_{2}$-based products (triangle symbols pointing left). Atmospheric inversions

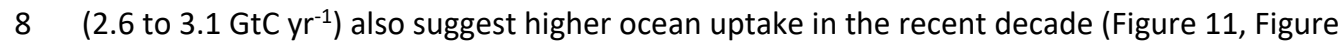

912 top row). In interpreting these differences, we caution that the riverine transport of

10 carbon taken up on land and outgassing from the ocean is a substantial $\left(0.6 \mathrm{GtC}^{-1}\right)$ and

11 uncertain term that separates the various methods. A recent estimate of decadal ocean

12 uptake from observed $\mathrm{O}_{2} / \mathrm{N}_{2}$ ratios (Tohjima et al., 2019) also points towards a larger ocean

13 sink, albeit with large uncertainty (2012-2016: $\left.3.1 \pm 1.5 \mathrm{GtC}^{-1}\right)$.

\section{$14 \quad$ 3.7.4 Regional breakdown and interannual variability}

15 Figure 12 also shows the latitudinal partitioning of the total atmosphere-to-surface fluxes excluding fossil $\mathrm{CO}_{2}$ emissions ( $\mathrm{S}_{\mathrm{OCEAN}}+\mathrm{S}_{\mathrm{LAND}}-\mathrm{E}_{\mathrm{LUC}}$ ) according to the multi-model average estimates from GOBMs and ocean $\mathrm{fCO}_{2}$-based products (SOCEAN) and DGVMs (SLAND $-E_{\text {LUC }}$ ), and from atmospheric inversions (SocEAN and SLAND - EluC).

\subsubsection{North}

Despite being one of the most densely observed and studied regions of our globe, annual mean carbon sink estimates in the northern extra-tropics (north of $30^{\circ} \mathrm{N}$ ) continue to differ

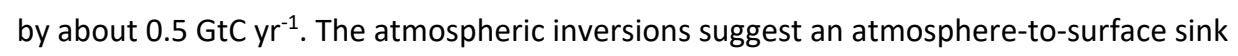

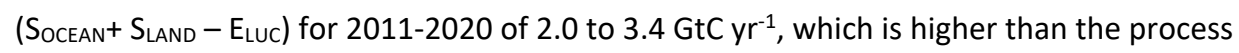

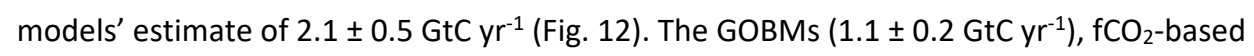
data products $\left(1.3 \pm 0.1 \mathrm{GtC}_{\mathrm{yr}}^{-1}\right)$, and inversion models $\left(0.9\right.$ to $\left.1.5 \mathrm{GtC}^{-1}\right)$ produce consistent estimates of the ocean sink. Thus, the difference mainly arises from the total land

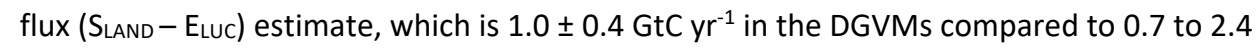
$\mathrm{GtC} \mathrm{yr}^{-1}$ in the atmospheric inversions (Figure 12, second row).

Discrepancies in the northern land fluxes conforms with persistent issues surrounding the quantification of the drivers of the global net land $\mathrm{CO}_{2}$ flux (Arneth et al., 2017; Huntzinger 
1 et al., 2017) and the distribution of atmosphere-to-land fluxes between the tropics and high

2 northern latitudes (Baccini et al., 2017; Schimel et al., 2015; Stephens et al., 2007; Ciais et al.

3 2019; Gaubert et al,. 2019).

4 In the northern extratropics, the process models, inversions, and $\mathrm{fCO}_{2}$-based data products

5 consistently suggest that most of the variability stems from the land (Fig. 12). Inversions

6 generally estimate similar interannual variations (IAV) over land to DGVMs $(0.28-0.47$ vs

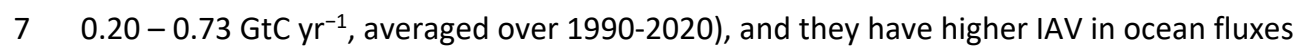

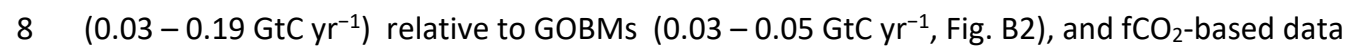

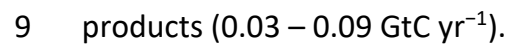

\section{$10 \quad 3.7 .4 .2$ Tropics}

11 In the tropics $\left(30^{\circ} \mathrm{S}-30^{\circ} \mathrm{N}\right)$, both the atmospheric inversions and process models estimate a

12 total carbon balance (SOCEAN $+S_{L A N D}-E_{L U C}$ ) that is close to neutral over the past decade. The

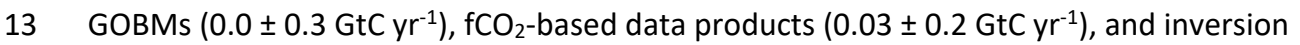

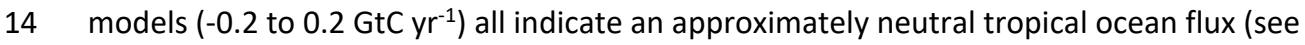

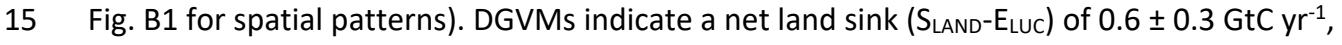

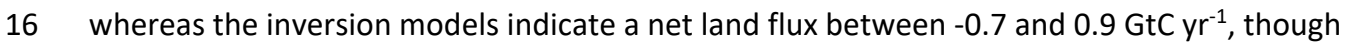

17 with high uncertainty (Figure 12, third row).

18 The tropical lands are the origin of most of the atmospheric $\mathrm{CO}_{2}$ interannual variability

19 (Ahlström et al., 2015), consistently among the process models and inversions (Fig. 12). The

20 interannual variability in the tropics is similar among the ocean data products $(0.07-0.15$

$21 \mathrm{GtC} y r-1)$ and the models $\left(0.07-0.15 \mathrm{GtC}^{-1}{ }^{-1}\right.$, Fig. B2), which is the highest ocean sink

22 variability of all regions. The DGVMs and inversions indicate that atmosphere-to-land $\mathrm{CO}_{2}$

23 fluxes are more variable than atmosphere-to-ocean $\mathrm{CO}_{2}$ fluxes in the tropics, with

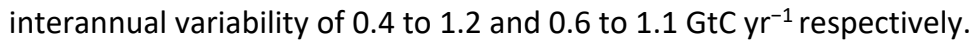

\subsubsection{South}

In the southern extra-tropics (south of $30^{\circ} \mathrm{S}$ ), the atmospheric inversions suggest a total atmosphere-to-surface sink (SOCEAN $+S_{\text {LAND }}-E_{L U C}$ ) for 2011-2020 of 1.6 to $1.9 \mathrm{GtC} \mathrm{yr}^{-1}$, slightly higher than the process models' estimate of $1.4 \pm 0.3 \mathrm{GtC} \mathrm{yr}^{-1}$ (Fig. 12). An approximately neutral total land flux (SLAND-ELUC) for the southern extra-tropics is estimated by both the

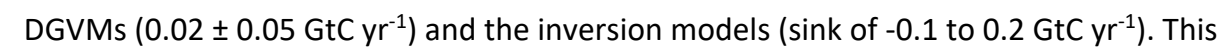


1 means nearly all carbon uptake is due to oceanic sinks south of $30^{\circ} \mathrm{S}$. The southern ocean

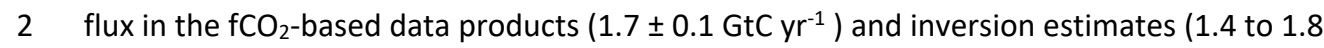

$3 \mathrm{GtCyr}-1)$ is higher than in the GOBMs $\left(1.4 \pm 0.3 \mathrm{GtC} \mathrm{yr}^{-1}\right)$ (Figure 12, bottom row). This might

4 be explained by the data-products potentially underestimating the winter $\mathrm{CO}_{2}$ outgassing

5 south of the Polar Front (Bushinsky et al., 2019), by model biases, or by the uncertainty in

6 the regional distribution of the river flux adjustment (Aumont et al., 2001, Lacroix et al.,

7 2020) applied to $\mathrm{fCO}_{2}$-based data products and inverse models to isolate the anthropogenic

8 SOCEAN flux. $\mathrm{CO}_{2}$ fluxes from this region are more sparsely sampled by all methods, especially

9 in wintertime (Fig. B1).

10 The interannual variability in the southern extra-tropics is low because of the dominance of 11 ocean area with low variability compared to land areas. The split between land ( $S_{L A N D}-E_{L U C}$ )

12 and ocean (SOCEAN) shows a substantial contribution to variability in the south coming from

13 the land, with no consistency between the DGVMs and the inversions or among inversions.

14 This is expected due to the difficulty of separating exactly the land and oceanic fluxes when

15 viewed from atmospheric observations alone. The SOCEAN interannual variability was found to

16 be higher in the $\mathrm{fCO}_{2}$-based data products ( 0.09 to $0.14 \mathrm{GtC}$ yr-1) compared to GOBMs (0.04

17 to $0.06 \mathrm{GtC}$ yr-1) in 1990-2020 (Fig. B2). Model subsampling experiments recently

18 illustrated that observation-based products may overestimate decadal variability in the

19 Southern Ocean carbon sink by $30 \%$ due to data sparsity, based on one data product with

20 the highest decadal variability (Gloege et al., 2021).

\subsubsection{Tropical vs northern land uptake}

22 A continuing conundrum is the partitioning of the global atmosphere-land flux between the northern hemisphere land, and the tropical land (Stephens et al., 2017; Pan et al., 2011; Gaubert et al., 2019). It is of importance because each region has its own history of land-use change, climate drivers, and impact of increasing atmospheric $\mathrm{CO}_{2}$ and nitrogen deposition. Quantifying the magnitude of each sink is a prerequisite to understanding how each individual driver impacts the tropical and mid/high-latitude carbon balance. 
1 preference across models for either a small Northern land sink and a tropical land sink

2 (small N-S difference), a medium Northern land sink and a neutral tropical land flux

3 (medium N-S difference), or a large Northern land sink and a tropical land source (large N-S

4 difference).

5 In the ensemble of DGVMs the N-S difference is $0.5 \pm 0.5 \mathrm{GtC}^{-1} \mathrm{yr}^{-1}$ a much narrower range

6 than the one from inversions. Only three DGVMs have a N-S difference larger than 1.0 GtC

$7 \mathrm{yr}^{-1}$. The larger agreement across DGVMs than across inversions is to be expected as there is

8 no correlation between Northern and Tropical land sinks in the DGVMs as opposed to the

9 inversions where the sum of the two regions being well-constrained leads to an anti-

10 correlation between these two regions. The much smaller spread in the N-S difference

11 between the DGVMs could help to scrutinize the inverse models further. For example, a

12 large northern land sink and a tropical land source in an inversion would suggest a large

13 sensitivity to $\mathrm{CO}_{2}$ fertilization (the dominant factor driving the land sinks) for Northern

14 ecosystems, which would be not mirrored by tropical ecosystems. Such a combination could

15 be hard to reconcile with the process understanding gained from the DGVMs ensembles and

16 independent measurements (e.g., FACE experiments). Such investigations will be further

17 pursued in the upcoming assessment from REgional Carbon Cycle Assessment and Processes

18 (RECCAP2; Ciais et al., 2020).

\section{$19 \quad 3.8$ Closing the Global Carbon Cycle}

\section{$20 \quad$ 3.8.1 Partitioning of Cumulative Emissions and Sink Fluxes}

21 The global carbon budget over the historical period (1850-2020) is shown in Fig. 3.

22 Emissions during the period 1850-2020 amounted to $660 \pm 65 \mathrm{GtC}$ and were partitioned

23 among the atmosphere ( $270 \pm 5 \mathrm{GtC} ; 41 \%)$, ocean ( $170 \pm 35 \mathrm{GtC} ; 26 \%)$, and the land (195 \pm

$24 \quad 45 \mathrm{GtC} ; 30 \%)$. The cumulative land sink is almost equal to the cumulative land-use emissions

25 (200 $\pm 65 \mathrm{GtC})$, making the global land nearly neutral over the whole 1850-2020 period.

26 The use of nearly independent estimates for the individual terms shows a cumulative

27 budget imbalance of $25 \mathrm{GtC}$ (4\%) during 1850-2020 (Fig. 3, Table 8), which, if correct,

28 suggests that emissions are slightly too high by the same proportion (4\%) or that the

29 combined land and ocean sinks are slightly underestimated (by about 7\%). The bulk of the

30 imbalance could originate from the estimation of large $E_{\text {Luc }}$ between the mid 1920s and the 
1 mid 1960s which is unmatched by a growth in atmospheric $\mathrm{CO}_{2}$ concentration as recorded in

2 ice cores (Fig. 3). However, the known loss of additional sink capacity of 30-40 GtC (over the

3 1850-2020 period) due to reduced forest cover has not been accounted for in our method

4 and would further exacerbate the budget imbalance (Section 2.7.4).

5 For the more recent 1960-2020 period where direct atmospheric $\mathrm{CO}_{2}$ measurements are 6 available, $375 \pm 20 \mathrm{GtC}(82 \%)$ of the total emissions ( $\mathrm{E}_{\mathrm{FOS}}+\mathrm{E}_{\mathrm{LuC}}$ ) were caused by fossil $\mathrm{CO}_{2}$ 7 emissions, and $80 \pm 45 \mathrm{GtC}(18 \%)$ by land-use change (Table 8$)$. The total emissions were 8 partitioned among the atmosphere (205 $\pm 5 \mathrm{GtC} ; 47 \%$ ), ocean (115 $\pm 25 \mathrm{GtC} ; 25 \%$ ), and the

9 land (135 $\pm 25 \mathrm{GtC}$; 30\%), with a near zero unattributed budget imbalance. All components

10 except land-use change emissions have significantly grown since 1960, with important

11 interannual variability in the growth rate in atmospheric $\mathrm{CO}_{2}$ concentration and in the land

$12 \mathrm{CO}_{2}$ sink (Fig. 4), and some decadal variability in all terms (Table 6). Differences with

13 previous budget releases are documented in Fig. B5.

14 The global carbon budget averaged over the last decade (2011-2020) is shown in Fig. 2, Fig.

1513 (right panel) and Table 6. For this time period, $90 \%$ of the total emissions (EFos + ELUC)

16 were from fossil $\mathrm{CO}_{2}$ emissions ( $\mathrm{E}_{\mathrm{FOS}}$ ), and $10 \%$ from land-use change ( $\left.\mathrm{E}_{\mathrm{LUC}}\right)$. The total

17 emissions were partitioned among the atmosphere (47\%), ocean (26\%) and land (29\%), with

18 a near-zero unattributed budget imbalance ( $3 \%)$. For single years, the budget imbalance

19 can be larger (Figure 4). For 2020, the combination of our sources and sinks estimates leads

20 to a $B_{\mathrm{IM}}$ of $-0.8 \mathrm{GtC}$, suggesting an underestimation of the anthropogenic sources

21 (potentially $E_{L U C}$ ), and/or an overestimation of the combined land and ocean sinks

\section{$22 \quad 3.8 .2$ Carbon Budget Imbalance}

23 The carbon budget imbalance ( $B_{I M}$; Eq. 1, Fig.4) quantifies the mismatch between the

24 estimated total emissions and the estimated changes in the atmosphere, land, and ocean

25 reservoirs. The mean budget imbalance from 1960 to 2020 is very small (average of $0.03 \mathrm{GtC}$

$26 \mathrm{yr}^{-1)}$ and shows no trend over the full time series. The process models (GOBMs and DGVMs)

27 and data-products have been selected to match observational constraints in the 1990s, but

28 no further constraints have been applied to their representation of trend and variability.

29 Therefore, the near-zero mean and trend in the budget imbalance is seen as evidence of a

30 coherent community understanding of the emissions and their partitioning on those time 
1 scales (Fig. 4). However, the budget imbalance shows substantial variability of the order of

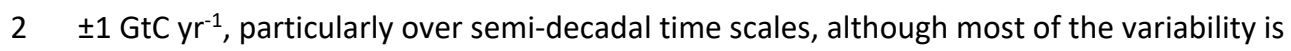

3 within the uncertainty of the estimates. The positive carbon imbalance during the 1960s,

4 and early 1990s, indicates that either the emissions were overestimated, or the sinks were

5 underestimated during these periods. The reverse is true for the 1970s, 1980s, and for the

6 2011-2020 period (Fig. 4, Table 6).

7 We cannot attribute the cause of the variability in the budget imbalance with our analysis,

8 we only note that the budget imbalance is unlikely to be explained by errors or biases in the

9 emissions alone because of its large semi-decadal variability component, a variability that is

10 untypical of emissions and has not changed in the past 60 years despite a near tripling in

11 emissions (Fig. 4). Errors in S SAND and SOCEAN are more likely to be the main cause for the

12 budget imbalance. For example, underestimation of the SLAND by DGVMs has been reported

13 following the eruption of Mount Pinatubo in 1991 possibly due to missing responses to

14 changes in diffuse radiation (Mercado et al., 2009). Although in GCB2021 we have for the

15 first time accounted for aerosol effects on solar radiation quantity and quality (diffuse vs

16 direct), most DGVMs only used the former as input (i.e., total solar radiation). Thus, the

17 ensemble mean may not capture the full effects of volcanic eruptions, i.e. associated with

18 high light scattering sulphate aerosols, on the land carbon sink (O'Sullivan et al., 2021).

19 DGVMs are suspected to overestimate the land sink in response to the wet decade of the

20 1970s (Sitch et al., 2008). Quasi-decadal variability in the ocean sink has also been reported,

21 with all methods agreeing on a smaller than expected ocean $\mathrm{CO}_{2}$ sink in the 1990 s and a

22 larger than expected sink in the 2000s (Fig. 9; Landschützer et al., 2016, DeVries et al., 2019,

23 Hauck et al., 2020, McKinley et al., 2020). Errors in sink estimates could also be driven by

24 errors in the climatic forcing data, particularly precipitation for SLAND and wind for SOCEAN.

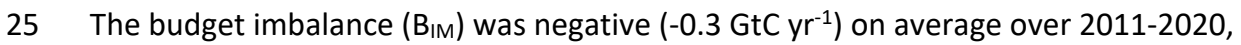

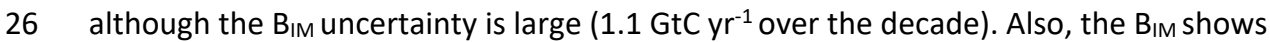

27 substantial departure from zero on yearly time scales (Fig. 4), highlighting unresolved

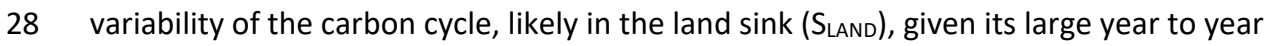

29 variability (Fig. 4e and 7).

30 Both the budget imbalance $\left(B_{I M}\right.$, Table 6$)$ and the residual land sink from the global budget

$31\left(E_{F O S}+E_{L U C}-G_{A T M}-S_{O C E A N}\right.$, Table 5$)$ include an error term due to the inconsistencies that arises 
1 from using ELUC from bookkeeping models, and SLAND from DGVMs, most notably the loss of

2 additional sink capacity (see section 2.7 ). Other differences include a better accounting of

3 land use changes practices and processes in bookkeeping models than in DGVMs, or the

4 bookkeeping models error of having present-day observed carbon densities fixed in the

5 past. That the budget imbalance shows no clear trend towards larger values over time is an

6 indication that these inconsistencies probably play a minor role compared to other errors in

7 SLAND Or SOCEAN.

8 Although the budget imbalance is near zero for the recent decades, it could be due to

9 compensation of errors. We cannot exclude an overestimation of $\mathrm{CO}_{2}$ emissions, particularly

10 from land-use change, given their large uncertainty, as has been suggested elsewhere (Piao

11 et al., 2018), combined with an underestimate of the sinks. A larger S SAND would reconcile

12 model results with inversion estimates for fluxes in the total land during the past decade

13 (Fig. 12; Table 5). Likewise, a larger SocEAn is also possible given the higher estimates from

14 the data-products (see section 3.1.2, Fig. 9 and Fig. 12) and the recently suggested upward

15 correction of the ocean carbon sink (Watson et al., 2020, Fig. 9). If SOcEan were to be based

16 on data-products alone, with all data-products including the Watson et al. (2020)

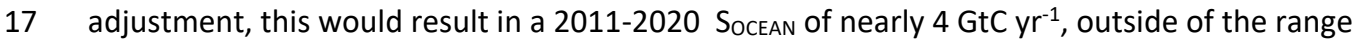

18 supported by the atmospheric inversions, with a negative $B_{I M}$ of more than $1 \mathrm{GtC} \mathrm{rr}^{-1}$

19 indicating that a closure of the budget could only be achieved with either anthropogenic

20 emissions being larger and/or the net land sink being substantially smaller than estimated

21 here. More integrated use of observations in the Global Carbon Budget, either on their own

22 or for further constraining model results, should help resolve some of the budget imbalance

23 (Peters et al., 2017).

\section{$24 \quad 4 \quad$ Tracking progress towards mitigation targets}

25 Fossil $\mathrm{CO}_{2}$ emissions growth peaked at $3 \%$ per year during the 2000 s, driven by the rapid

26 growth in Chinese emissions. In the last decade, however, the growth rate for the preceding

2710 years has slowly declined, reaching a low $0.4 \%$ per year from 2012-2021 (including the

282020 global decline and the expected 2021 emissions rebound). While this slowdown in

29 global fossil $\mathrm{CO}_{2}$ emissions growth is welcome, it is far from what is needed to be consistent

30 with the temperature goals of the Paris Agreement. 
1 Since the 1990s, the average growth rate of fossil $\mathrm{CO}_{2}$ emissions has continuously declined

2 across the group of developed countries of the Organisation for Economic Co-operation and

3 Development (OECD), with emissions peaking in around 2005 and now declining at around

$41 \% \mathrm{yr}^{-1}$ (Le Quéré et al., 2021). In the decade 2010-2019, territorial fossil $\mathrm{CO}_{2}$ emissions

5 decreased significantly (at the 95\% confidence level) in 23 countries whose economies grew

6 significantly (also at the 95\% confidence level): Barbados, Belgium, Croatia, Czech Republic,

7 Denmark, Finland, France, Germany, Israel, Japan, Luxembourg, North Macedonia, Malta,

8 Mexico, Netherlands, Slovakia, Slovenia, Solomon Islands, Sweden, Switzerland, Tuvalu,

9 United Kingdom and the USA (updated from Le Quéré et al., 2019). Altogether, these 23

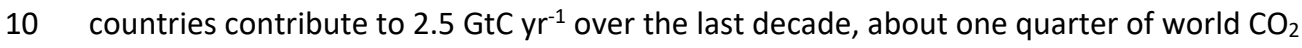

11 fossil emissions. Consumption-based emissions are also falling significantly in 15 of these

12 countries (Belgium, Croatia, Czech Republic, Denmark, Finland, France, Germany, Israel,

13 Japan, Mexico, Netherlands, Slovenia, Sweden, United Kingdom, and the USA). Figure 14

14 shows that the emission declines in the USA and the EU27 are primarily driven by increased

15 decarbonisation ( $\mathrm{CO}_{2}$ emissions per unit energy) in the last decade compared to the

16 previous, with smaller contributions in the EU27 from slightly weaker economic growth and

17 slightly larger declines in energy per GDP. These countries have stable or declining energy

18 use and so decarbonisation policies replace existing fossil fuel infrastructure (Le Quéré et al.

19 2019).

20 In contrast, fossil $\mathrm{CO}_{2}$ emissions continue to grow in non-OECD countries, although the

21 growth rate has slowed from over $5 \% \mathrm{yr}^{-1}$ during the 2000 s to around $2 \% \mathrm{yr}^{-1}$ in the last

22 decade. A large part of this slowdown in non-OECD countries is due to China, which has

23 seen emissions growth declining from nearly $10 \% \mathrm{yr}^{-1}$ in the $2000 \mathrm{~s}$ to $2 \% \mathrm{yr}^{-1}$ in the last

24 decade. Excluding China, non-OECD emissions grew at $3 \% \mathrm{yr}^{-1}$ in the 2000 s compared to $2 \%$

$25 \mathrm{yr}^{-1}$ in the last decade. Figure 14 shows that compared to the previous decade, China has

26 had weaker economic growth in the last decade and a larger decarbonisation rate, with

27 more rapid declines in energy per GDP which are now back to levels during the 1990s. India

28 and the rest of the world have strong economic growth that is not compensated by

29 decarbonisation or declines in energy per GDP, implying fossil $\mathrm{CO}_{2}$ emissions continue to

30 grow. Despite the high deployment of renewables in some countries (e.g., India), fossil

31 energy sources continue to grow to meet growing energy demand (Le Quéré et al. 2019). 
1 Globally, fossil $\mathrm{CO}_{2}$ emissions growth is slowing, and this is primarily due to the emergence

2 of climate policy and emission declines in OECD countries (Eskander and Fankhauser 2020).

3 At the aggregated global level, decarbonisation shows a strong and growing signal in the last

4 decade, with smaller contributions from lower economic growth and declines in energy per

5 GDP. Despite the slowing growth in global fossil $\mathrm{CO}_{2}$ emissions, emissions are still growing,

6 far from the reductions needed to meet the ambitious climate goals of the UNFCCC Paris

7 agreement.

8 We update the remaining carbon budget assessed by the IPCC AR6 (Canadell et al., 2021),

9 accounting for the 2020 and estimated 2021 emissions from fossil fuel combustion (EFos)

10 and land use changes ( $E_{L U C}$ ). From January 2022 , the remaining carbon ( $50 \%$ likelihood) for

11 limiting global warming to $1.5^{\circ} \mathrm{C}, 1.7^{\circ} \mathrm{C}$ and $2^{\circ} \mathrm{C}$ is estimated to amount to 120,210 , and 350

$12 \mathrm{GtC}\left(420,770,1270 \mathrm{GtCO}_{2}\right)$. These numbers include an uncertainty based on model spread

13 (as in IPCC AR6), which is reflected through the percent likelihood of exceeding the given

14 temperature threshold. These remaining abouts correspond to respectively about 11, 20

15 and 32 years from beginning of 2020, at the 2021 level of total $\mathrm{CO}_{2}$ emissions. Reaching net

16 zero $\mathrm{CO}_{2}$ emissions by 2050 entails cutting total anthropogenic $\mathrm{CO}_{2}$ emissions by about 0.4

$17 \mathrm{GtC}\left(1.4 \mathrm{GtCO}_{2}\right)$ each year on average, comparable to the decrease during 2020.

\section{Discussion}

19 Each year when the global carbon budget is published, each flux component is updated for

20 all previous years to consider corrections that are the result of further scrutiny and

21 verification of the underlying data in the primary input data sets. Annual estimates may be

22 updated with improvements in data quality and timeliness (e.g., to eliminate the need for

23 extrapolation of forcing data such as land-use). Of all terms in the global budget, only the

24 fossil $\mathrm{CO}_{2}$ emissions and the growth rate in atmospheric $\mathrm{CO}_{2}$ concentration are based

25 primarily on empirical inputs supporting annual estimates in this carbon budget. The carbon

26 budget imbalance, yet an imperfect measure, provides a strong indication of the limitations

27 in observations in understanding and representing processes in models, and/or in the

28 integration of the carbon budget components.

29 The persistent unexplained variability in the carbon budget imbalance limits our ability to

30 verify reported emissions (Peters et al., 2017) and suggests we do not yet have a complete 
1 understanding of the underlying carbon cycle dynamics on annual to decadal timescales.

2 Resolving most of this unexplained variability should be possible through different and

3 complementary approaches. First, as intended with our annual updates, the imbalance as an

4 error term is reduced by improvements of individual components of the global carbon

5 budget that follow from improving the underlying data and statistics and by improving the

6 models through the resolution of some of the key uncertainties detailed in Table 9. Second,

7 additional clues to the origin and processes responsible for the variability in the budget

8 imbalance could be obtained through a closer scrutiny of carbon variability in light of other

9 Earth system data (e.g., heat balance, water balance), and the use of a wider range of

10 biogeochemical observations to better understand the land-ocean partitioning of the carbon

11 imbalance (e.g. oxygen, carbon isotopes). Finally, additional information could also be

12 obtained through higher resolution and process knowledge at the regional level, and

13 through the introduction of inferred fluxes such as those based on satellite $\mathrm{CO}_{2}$ retrievals.

14 The limit of the resolution of the carbon budget imbalance is yet unclear, but most certainly

15 not yet reached given the possibilities for improvements that lie ahead.

16 Estimates of global fossil $\mathrm{CO}_{2}$ emissions from different datasets are in relatively good

17 agreement when the different system boundaries of these datasets are considered

18 (Andrew, 2020a). But while estimates of $\mathrm{E}_{\mathrm{Fos}}$ are derived from reported activity data

19 requiring much fewer complex transformations than some other components of the budget,

20 uncertainties remain, and one reason for the apparently low variation between datasets is

21 precisely the reliance on the same underlying reported energy data. The budget excludes

22 some sources of fossil $\mathrm{CO}_{2}$ emissions, which available evidence suggests are relatively small

$23(<1 \%)$. We have added emissions from lime production in China and the US, but these are

24 still absent in most other non-Annex I countries, and before 1990 in other Annex I countries.

25 Further changes to EFos this year are documented by Andrew and Peters (2021).

26 Estimates of Eluc suffer from a range of intertwined issues, including the poor quality of

27 historical land-cover and land-use change maps, the rudimentary representation of

28 management processes in most models, and the confusion in methodologies and boundary

29 conditions used across methods (e.g., Arneth et al., 2017; Pongratz et al., 2014, see also

30 Section 2.7.4 on the loss of sink capacity; Bastos et al., 2021). Uncertainties in current and

31 historical carbon stocks in soils and vegetation also add uncertainty in the $E_{L U C}$ estimates. 
1 Unless a major effort to resolve these issues is made, little progress is expected in the

2 resolution of Eluc. This is particularly concerning given the growing importance of Eluc for

3 climate mitigation strategies, and the large issues in the quantification of the cumulative

4 emissions over the historical period that arise from large uncertainties in Eluc.

5 By adding the DGVMs estimates of $\mathrm{CO}_{2}$ fluxes due to environmental change from countries'

6 managed forest areas (part of SLAND in this budget) to the budget $E_{\text {LUC }}$ estimate, we

7 successfully reconciled the large gap between our Eluc estimate and the land use flux from

8 NGHGls using the approach described in Grassi et al. (2021). This latter estimate has been

9 used in the recent UNFCCC's Synthesis Report on Nationally Determined Contribution

10 (UNFCCC, 2021b) to enable the total national emission estimates to be comparable with

11 those of the IPCC. However, while Grassi et al. (2021) used only one DGVM, here 17 DGVMs

12 are used, thus providing a more robust value to be used as potential adjustment in the

13 policy context, e.g., to help assessing the collective countries' progress towards the goal of

14 the Paris Agreement and avoiding double-accounting for the sink in managed forests. In the

15 absence of this adjustment, collective progress would hence appear better than it is (Grassi

16 et al. 2021).

17 The comparison of GOBMs, data products and inversions highlights substantial discrepancy

18 in the Southern Ocean (Fig. 12, Hauck et al., 2020). The long-standing sparse data coverage

19 of $\mathrm{fCO}_{2}$ observations in the Southern compared to the Northern Hemisphere (e.g., Takahashi

20 et al., 2009) continues to exist (Bakker et al., 2016, 2021, Fig. B1) and to lead to substantially

21 higher uncertainty in the SOCEAN estimate for the Southern Hemisphere (Watson et al., 2020,

22 Gloege et al., 2021). This discrepancy, which also hampers model improvement, points to

23 the need for increased high-quality $\mathrm{fCO}_{2}$ observations especially in the Southern Ocean. At

24 the same time, model uncertainty is illustrated by the large spread of individual GOBM

25 estimates (indicated by shading in Fig. 12) and highlights the need for model improvement.

26 Further uncertainty stems from the regional distribution of the river flux adjustment term

27 being based on one model study yielding the largest riverine outgassing flux south of $20^{\circ} \mathrm{S}$

28 (Aumont et al., 2001), with a recent study questioning this distribution (Lacroix et al., 2020).

29 The diverging trends in SOCEAN from different methods is a matter of concern, which is

30 unresolved. The assessment of the net land-atmosphere exchange from DGVMs and

31 atmospheric inversions also shows substantial discrepancy, particularly for the estimate of 
1 the total land flux over the northern extra-tropic. This discrepancy highlights the difficulty to

2 quantify complex processes ( $\mathrm{CO}_{2}$ fertilisation, nitrogen deposition and fertilisers, climate

3 change and variability, land management, etc.) that collectively determine the net land $\mathrm{CO}_{2}$

4 flux. Resolving the differences in the Northern Hemisphere land sink will require the

5 consideration and inclusion of larger volumes of observations.

6 We provide metrics for the evaluation of the ocean and land models and the atmospheric

7 inversions (Figs. B2 to B4). These metrics expand the use of observations in the global

8 carbon budget, helping 1) to support improvements in the ocean and land carbon models

9 that produce the sink estimates, and 2) to constrain the representation of key underlying

10 processes in the models and to allocate the regional partitioning of the $\mathrm{CO}_{2}$ fluxes. However,

11 GOBMs skills have changed little since the introduction of the ocean model evaluation. An

12 additional simulation this year allows for direct comparison with interior ocean

13 anthropogenic carbon estimates and suggests that the models underestimate

14 anthropogenic carbon uptake and storage. This is an initial step towards the introduction of

15 a broader range of observations that we hope will support continued improvements in the

16 annual estimates of the global carbon budget.

17 We assessed before that a sustained decrease of $-1 \%$ in global emissions could be detected

18 at the 66\% likelihood level after a decade only (Peters et al., 2017). Similarly, a change in

19 behaviour of the land and/or ocean carbon sink would take as long to detect, and much

20 longer if it emerges more slowly. To continue reducing the carbon imbalance on annual to

21 decadal time scales, regionalising the carbon budget, and integrating multiple variables are

22 powerful ways to shorten the detection limit and ensure the research community can

23 rapidly identify issues of concern in the evolution of the global carbon cycle under the

24 current rapid and unprecedented changing environmental conditions.

\section{Conclusions}

26 The estimation of global $\mathrm{CO}_{2}$ emissions and sinks is a major effort by the carbon cycle

27 research community that requires a careful compilation and synthesis of measurements,

28 statistical estimates, and model results. The delivery of an annual carbon budget serves two

29 purposes. First, there is a large demand for up-to-date information on the state of the

30 anthropogenic perturbation of the climate system and its underpinning causes. A broad 
1 stakeholder community relies on the data sets associated with the annual carbon budget

2 including scientists, policy makers, businesses, journalists, and non-governmental

3 organizations engaged in adapting to and mitigating human-driven climate change. Second,

4 over the last decades we have seen unprecedented changes in the human and biophysical

5 environments (e.g., changes in the growth of fossil fuel emissions, impact of COVID-19

6 pandemic, Earth's warming, and strength of the carbon sinks), which call for frequent

7 assessments of the state of the planet, a better quantification of the causes of changes in

8 the contemporary global carbon cycle, and an improved capacity to anticipate its evolution

9 in the future. Building this scientific understanding to meet the extraordinary climate

10 mitigation challenge requires frequent, robust, transparent, and traceable data sets and

11 methods that can be scrutinized and replicated. This paper via 'living data' helps to keep

12 track of new budget updates.

\section{Data availability}

14 The data presented here are made available in the belief that their wide dissemination will

15 lead to greater understanding and new scientific insights of how the carbon cycle works,

16 how humans are altering it, and how we can mitigate the resulting human-driven climate

17 change. The free availability of these data does not constitute permission for publication of

18 the data. For research projects, if the data are essential to the work, or if an important

19 result or conclusion depends on the data, co-authorship may need to be considered for the

20 relevant data providers. Full contact details and information on how to cite the data shown

21 here are given at the top of each page in the accompanying database and summarised in

22 Table 2.

23 The accompanying database includes two Excel files organised in the following

24 spreadsheets:

25 File Global_Carbon_Budget_2021v1.0.xlsx includes the following:

26 1. Summary

27 2. The global carbon budget (1959-2020);

28 3. The historical global carbon budget (1750-2020);

29 4. Global $\mathrm{CO}_{2}$ emissions from fossil fuels and cement production by fuel type, and the percapita emissions (1959-2020); 
15 . $\mathrm{CO}_{2}$ emissions from land-use change from the individual methods and models (1959-

2 2020);

36 . Ocean $\mathrm{CO}_{2}$ sink from the individual ocean models and $\mathrm{fCO}_{2}$-based products (1959-

4 2020);

5 7. Terrestrial $\mathrm{CO}_{2}$ sink from the DGVMs (1959-2020).

6

7 File National_Carbon_Emissions_2021v1.0.xlsx includes the following:

8 1. Summary

9 2. Territorial country $\mathrm{CO}_{2}$ emissions from fossil $\mathrm{CO}_{2}$ emissions (1959-2020);

10 3. Consumption country $\mathrm{CO}_{2}$ emissions from fossil $\mathrm{CO}_{2}$ emissions and emissions transfer 11 from the international trade of goods and services (1990-2019) using CDIAC/UNFCCC 12 data as reference;

13 4. Emissions transfers (Consumption minus territorial emissions; 1990-2019);

14 5. Country definitions;

15 6. Details of disaggregated countries;

16 7. Details of aggregated countries.

17 Both spreadsheets are published by the Integrated Carbon Observation System (ICOS)

18 Carbon Portal and are available at https://doi.org/10.18160/gcp-2021 (Friedlingstein et al.,

19 2021). National emissions data are also available from the Global Carbon Atlas

20 (http://www.globalcarbonatlas.org/, last access: 21 October 2021) and from Our World in

21 Data (https://ourworldindata.org/co2-emissions, last access: 21 October 2021).

22

23

\section{Author contributions}

PF, MWJ, MOS, CLQ, RMA, DCEB, JH, GPP, WP, JP and SS designed the study, conducted the analysis, and wrote the paper with input from JGC, PC and RBJ. RMA, GPP and JIK produced the fossil fuel emissions and their uncertainties and analysed the emissions data. DG and GM provided fossil fuel emission data. JP, TG, CS and RAH provided the bookkeeping landuse change emissions. JH, LB, OG, NG, TI, LR, JS, RS and DW provided an update of the global 
1 ocean biogeochemical models. SRA, TTTC, LD, LG, YI, PL, CR, AJW and JZ provided an update

2 of the ocean $\mathrm{fCO}_{2}$ data products, with synthesis by JH. $\mathrm{MB}, \mathrm{NRB}, \mathrm{KIC}, \mathrm{MC}, \mathrm{WE}, \mathrm{RAF}, \mathrm{SRA}, \mathrm{TG}$,

$3 \mathrm{AK}, \mathrm{NL}, \mathrm{SKL}, \mathrm{DRM}, \mathrm{CIS}, \mathrm{COS}, \mathrm{SN}, \mathrm{CW}, \mathrm{TO}, \mathrm{DP}, \mathrm{GR}, \mathrm{AJS}, \mathrm{BT}, \mathrm{TT}, \mathrm{CW}$, and RW provided ocean

$4 \mathrm{fCO}_{2}$ measurements for the year 2020, with synthesis by DCEB and SDJ. PA, BD, AKJ, DK, EK,

$5 \mathrm{JK}, \mathrm{SL}, \mathrm{PCM}, \mathrm{JRM}, \mathrm{JEMSN}, \mathrm{BP}, \mathrm{HT}, \mathrm{NV}, \mathrm{AJW}, \mathrm{WY}, \mathrm{XY}$ and SZ provided an update of the

6 Dynamic Global Vegetation Models, with synthesis by SS. WP, FC, LF, ITL, JL, YN and CR

7 provided an updated atmospheric inversion, developed the protocol and produced the

8 evaluation, with synthesis by WP. RMA provided predictions of the 2021 emissions and

9 atmospheric $\mathrm{CO}_{2}$ growth rate. PL provided the predictions of the 2021 ocean and land sinks.

10 LPC, GCH, KKG, TMS and GRvdW provided forcing data for land-use change. GG, FT, and CY

11 provided data for the land-use change NGHGI mapping. PPT provided key atmospheric $\mathrm{CO}_{2}$

12 data. MWJ produced the historical record of atmospheric $\mathrm{CO}_{2}$ concentration and growth

13 rate, including the atmospheric $\mathrm{CO}_{2}$ forcing. MOS and NB produced the aerosol diffuse

14 radiative forcing for the DGVMs. IH provided the climate forcing data for the DGVMs. ER

15 provided the evaluation of the DGVMs. MWJ provided the emissions prior for use in the

16 inversion models. XD provided seasonal emissions data for years 2019-2020 for the emission

17 prior. MWJ and MOS developed a new data management pipeline which automates many

18 aspects of the data collation, analysis, plotting and synthesis. PF, MWJ, and MOS revised all

19 figures, tables, text and/or numbers to ensure the update is clear from the 2020 edition and

20 in phase with the globalcarbonatlas.org.

21

22 Competing interests. The authors declare that they have no conflict of interest. 


\section{Acknowledgements}

2 We thank all people and institutions who provided the data used in this global carbon budget

32021 and the Global Carbon Project members for their input throughout the development of

4 this publication. We thank Nigel Hawtin for producing Figure 2 and Figure 13. We thank Omar

5 Jamil and Freddy Wordingham for technical support. We thank Ed Dlugokencky for providing

6 atmospheric $\mathrm{CO}_{2}$ measurements. We thank Vivek Arora, Ian G.C. Ashton, Erik Buitenhuis,

7 Fatemeh Cheginig, Christian Ethé, Marion Gehlen, Lonneke Goddijn-Murphy, T. Holding,

8 Fabrice Lacroix, Enhui Liao, Pedro M.S. Monteiro, Naiquing Pan, Tristan Quaife, Shijie Shu,

9 Jamie D. Shutler, Jade Skye, Anthony Walker, and David K. Woolf for their involvement in the

10 development, use and analysis of the models and data-products used here. We thank Markus

11 Ritschel, Carmen Rodriguez, Claire Lo Monaco, Nicolas Metzl, Vassilis Kitidis, Sören Gutekunst,

12 Anne Willstrand Wranne, Tobias Steinhoff, Jessica N. Cross, Natalie M. Monacci, Alice Benoit-

13 Cattin, Sólveig R. Ólafsdóttir, Joe Salisbury, Doug Vandemark and Christopher W. Hunt, who

14 contributed to the provision of surface ocean $\mathrm{CO}_{2}$ observations for the year 2020 (see Table

15 A5). We also thank Benjamin Pfeil, Rocío Castaño-Primo, Camilla Landa and Maren Karlsen of

16 the Ocean Thematic Centre of the EU Integrated Carbon Observation System (ICOS) Research

17 Infrastructure, Kevin O'Brien and Eugene Burger of NOAA's Pacific Marine Environmental

18 Laboratory and Alex Kozyr of NOAA's National Centers for Environmental Information, for

19 their contribution to surface ocean $\mathrm{CO}_{2}$ data and metadata management. We thank the

20 scientists, institutions, and funding agencies responsible for the collection and quality control

21 of the data in SOCAT as well as the International Ocean Carbon Coordination Project (IOCCP),

22 the Surface Ocean Lower Atmosphere Study (SOLAS) and the Integrated Marine Biosphere

23 Research (IMBeR) program for their support. We thank data providers ObsPack 
1 GLOBALVIEWplus v6.1 and NRT v6.1.1 for atmospheric $\mathrm{CO}_{2}$ observations. We thank the

2 individuals and institutions that provided the databases used for the models evaluations used

3 here. We thank Fortunat Joos, Samar Khatiwala and Timothy DeVries for providing historical

4 data. NV thanks the whole ORCHIDEE group. YN thanks CSIRO, EC, EMPA, FMI, IPEN, JMA,

5 LSCE, NCAR, NIES, NILU, NIWA, NOAA, SIO, and TU/NIPR for providing data for NISMON-CO2.

$6 \mathrm{JL}$ thanks the Jet Propulsion Laboratory, California Institute of Technology. This is PMEL

7 contribution 5317. SDJ thanks the data management team at the Bjerknes Climate Data

8 Centre. WE thanks the Tula Foundation for funding support. Australian ocean $\mathrm{CO}_{2}$ data were

9 sourced from Australia's Integrated Marine Observing System (IMOS); IMOS is enabled by the

10 National Collaborative Research Infrastructure Strategy (NCRIS). MC thanks Anthony English,

11 Clynt Gregory and Gordon Furey (P\&O Maritime Services) and Tobias Steinhoff for support.

12 NL thanks the crew of the Cap San Lorenzo and the US IMAGO of IRD Brest for technical

13 support. GR is grateful for the skillful technical support of M. Glockzin and B. Sadkowiak. MWJ

14 thanks Anthony J. De-Gol for his technical and conceptual assistance with the development

15 of GCP-GridFED. FAOSTAT is funded by FAO member states through their contributions to the

16 FAO Regular Programme, data contributions by national experts are greatly acknowledged.

17 The views expressed in this paper are the authors' only and do not necessarily reflect those

18 of FAO. Finally, we thank all funders who have supported the individual and joint

19 contributions to this work (see Table A9), as well as the reviewers of this manuscript and

20 previous versions, and the many researchers who have provided feedback. 
2 Ahlström, A., Raupach, M. R., Schurgers, G., Smith, B., Arneth, A., Jung, M., Reichstein, M.,

3 Canadell, J. G., Friedlingstein, P., Jain, A. K., Kato, E., Poulter, B., Sitch, S., Stocker, B. D.,

4 Viovy, N., Wang, Y. P., Wiltshire, A., Zaehle, S., and Zeng, N.: The dominant role of semi-arid

5 ecosystems in the trend and variability of the land CO2 sink, 348, 895-899,

6 https://doi.org/10.1126/science.aaa1668, 2015.

7 Ahlström, A., Raupach, M. R., Schurgers, G., Smith, B., Arneth, A., Jung, M., Reichstein, M.,

8 Canadell, J. G., Friedlingstein, P., Jain, A. K., Kato, E., Poulter, B., Sitch, S., Stocker, B. D.,

9 Viovy, N., Wang, Y. P., Wiltshire, A., Zaehle, S., and Zeng, N.: The dominant role of semi-arid

10 ecosystems in the trend and variability of the land CO2 sink, 348, 895-899,

11 https://doi.org/10.1126/science.aaa1668, 2015.

12 Amador-Jiménez, M., Millner, N., Palmer, C., Pennington, R. T., and Sileci, L.: The

13 Unintended Impact of Colombia's Covid-19 Lockdown on Forest Fires, Environ Resource

14 Econ, 76, 1081-1105, https://doi.org/10.1007/s10640-020-00501-5, 2020.

15 Amante, C. and Eakins, B. W.: ETOPO1 Global Relief Model converted to PanMap layer

16 format, https://doi.org/10.1594/PANGAEA.769615, 2009.

17 Andela, N., Morton, D. C., Giglio, L., Chen, Y., van der Werf, G. R., Kasibhatla, P. S., DeFries,

18 R. S., Collatz, G. J., Hantson, S., Kloster, S., Bachelet, D., Forrest, M., Lasslop, G., Li, F.,

19 Mangeon, S., Melton, J. R., Yue, C., and Randerson, J. T.: A human-driven decline in global

20 burned area, Science, 356, 1356-1362, https://doi.org/10.1126/science.aal4108, 2017.

21 Andres, R. J., Boden, T. A., Bréon, F.-M., Ciais, P., Davis, S., Erickson, D., Gregg, J. S.,

22 Jacobson, A., Marland, G., Miller, J., Oda, T., Olivier, J. G. J., Raupach, M. R., Rayner, P., and

23 Treanton, K.: A synthesis of carbon dioxide emissions from fossil-fuel combustion,

24 Biogeosciences, 9, 1845-1871, https://doi.org/10.5194/bg-9-1845-2012, 2012.

25 Andres, R. J., Boden, T. A., and Higdon, D.: A new evaluation of the uncertainty associated

26 with CDIAC estimates of fossil fuel carbon dioxide emission, Tellus B: Chemical and Physical

27 Meteorology, 66, 23616, https://doi.org/10.3402/tellusb.v66.23616, 2014.

28 Andrew, R. M.: A comparison of estimates of global carbon dioxide emissions from fossil 
1 carbon sources, Earth Syst. Sci. Data, 12, 1437-1465, https://doi.org/10.5194/essd-12-1437-

22020,2020 a.

3 Andrew, R. M.: Timely estimates of India's annual and monthly fossil $\mathrm{CO} 2$ emissions, Earth

4 Syst. Sci. Data, 12, 2411-2421, https://doi.org/10.5194/essd-12-2411-2020, 2020 b.

5 Andrew, R. M.: Towards near real-time, monthly fossil $\mathrm{CO} 2$ emissions estimates for the

6 European Union with current-year projections, Atmospheric Pollution Research, 101229,

7 https://doi.org/10.1016/j.apr.2021.101229, 2021.

8 Andrew, R. M. and Peters, G. P.: A MULTI-REGION INPUT-OUTPUT TABLE BASED ON THE

9 GLOBAL TRADE ANALYSIS PROJECT DATABASE (GTAP-MRIO), Economic Systems Research,

10 25, 99-121, https://doi.org/10.1080/09535314.2012.761953, 2013.

11 Andrew, R. M. and Peters, G. P.: The Global Carbon Project's fossil CO2 emissions dataset

12 (2021v34), https://doi.org/10.5281/ZENODO.5569235, 2021. Aragão, L. E. O. C., Anderson, L. O., Fonseca, M. G., Rosan, T. M., Vedovato, L. B., Wagner, F. H., Silva, C. V. J., Silva Junior, C. H. L., Arai, E., Aguiar, A. P., Barlow, J., Berenguer, E., Deeter, M. N., Domingues, L. G., Gatti, L., Gloor, M., Malhi, Y., Marengo, J. A., Miller, J. B., Phillips, O. L., and Saatchi, S.: 21st Century drought-related fires counteract the decline of Amazon deforestation carbon emissions, Nat Commun, 9, 536, https://doi.org/10.1038/s41467-017$02771-y, 2018$.

Archer, D., Eby, M., Brovkin, V., Ridgwell, A., Cao, L., Mikolajewicz, U., Caldeira, K., Matsumoto, K., Munhoven, G., Montenegro, A., and Tokos, K.: Atmospheric Lifetime of Fossil Fuel Carbon Dioxide, Annu. Rev. Earth Planet. Sci., 37, 117-134, https://doi.org/10.1146/annurev.earth.031208.100206, 2009.

Arneth, A., Sitch, S., Pongratz, J., Stocker, B. D., Ciais, P., Poulter, B., Bayer, A. D., Bondeau, A., Calle, L., Chini, L. P., Gasser, T., Fader, M., Friedlingstein, P., Kato, E., Li, W., Lindeskog, M., Nabel, J. E. M. S., Pugh, T. A. M., Robertson, E., Viovy, N., Yue, C., and Zaehle, S.: Historical carbon dioxide emissions caused by land-use changes are possibly larger than assumed, Nature Geosci, 10, 79-84, https://doi.org/10.1038/ngeo2882, 2017.

Arora, V. K., Boer, G. J., Christian, J. R., Curry, C. L., Denman, K. L., Zahariev, K., Flato, G. M., 
2 Down Regulation on the Twentieth-Century Carbon Budget Simulated with the CCCma Earth

3 System Model, 22, 6066-6088, https://doi.org/10.1175/2009JCLI3037.1, 2009.

4 Asaadi, A., Arora, V. K., Melton, J. R., and Bartlett, P.: An improved parameterization of leaf

5 area index (LAI) seasonality in the Canadian Land Surface Scheme (CLASS) and Canadian

6 Terrestrial Ecosystem Model (CTEM) modelling framework, 15, 6885-6907,

7 https://doi.org/10.5194/bg-15-6885-2018, 2018.

8 Aumont, O., Orr, J. C., Monfray, P., Ludwig, W., Amiotte-Suchet, P., and Probst, J.-L.:

9 Riverine-driven interhemispheric transport of carbon, Global Biogeochem. Cycles, 15, 393-

10 405, https://doi.org/10.1029/1999GB001238, 2001.

11 Aumont, O., Ethé, C., Tagliabue, A., Bopp, L., and Gehlen, M.: PISCES-v2: an ocean

12 biogeochemical model for carbon and ecosystem studies, 8, 2465-2513,

13 https://doi.org/10.5194/gmd-8-2465-2015, 2015.

Avitabile, V., Herold, M., Heuvelink, G. B. M., Lewis, S. L., Phillips, O. L., Asner, G. P., Armston, J., Ashton, P. S., Banin, L., Bayol, N., Berry, N. J., Boeckx, P., de Jong, B. H. J., DeVries, B., Girardin, C. A. J., Kearsley, E., Lindsell, J. A., Lopez-Gonzalez, G., Lucas, R., Malhi, Y., Morel, A., Mitchard, E. T. A., Nagy, L., Qie, L., Quinones, M. J., Ryan, C. M., Ferry, S. J. W., Sunderland, T., Laurin, G. V., Gatti, R. C., Valentini, R., Verbeeck, H., Wijaya, A., and Willcock, S.: An integrated pan-tropical biomass map using multiple reference datasets, Glob Change Biol, 22, 1406-1420, https://doi.org/10.1111/gcb.13139, 2016.

Baccini, A., Walker, W., Carvalho, L., Farina, M., Sulla-Menashe, D., and Houghton, R. A.: Tropical forests are a net carbon source based on aboveground measurements of gain and loss, Science, 358, 230-234, https://doi.org/10.1126/science.aam5962, 2017.

Bakker, D. C. E., Pfeil, B., Landa, C. S., Metzl, N., O’Brien, K. M., Olsen, A., Smith, K., Cosca, C., Harasawa, S., Jones, S. D., Nakaoka, S., Nojiri, Y., Schuster, U., Steinhoff, T., Sweeney, C., Takahashi, T., Tilbrook, B., Wada, C., Wanninkhof, R., Alin, S. R., Balestrini, C. F., Barbero, L., Bates, N. R., Bianchi, A. A., Bonou, F., Boutin, J., Bozec, Y., Burger, E. F., Cai, W.-J., Castle, R. D., Chen, L., Chierici, M., Currie, K., Evans, W., Featherstone, C., Feely, R. A., Fransson, A., Goyet, C., Greenwood, N., Gregor, L., Hankin, S., Hardman-Mountford, N. J., Harlay, J., 
Hauck, J., Hoppema, M., Humphreys, M. P., Hunt, C. W., Huss, B., Ibánhez, J. S. P.,

Johannessen, T., Keeling, R., Kitidis, V., Körtzinger, A., Kozyr, A., Krasakopoulou, E., Kuwata,

3 A., Landschützer, P., Lauvset, S. K., Lefèvre, N., Lo Monaco, C., Manke, A., Mathis, J. T.,

4 Merlivat, L., Millero, F. J., Monteiro, P. M. S., Munro, D. R., Murata, A., Newberger, T., Omar,

5 A. M., Ono, T., Paterson, K., Pearce, D., Pierrot, D., Robbins, L. L., Saito, S., Salisbury, J.,

6 Schlitzer, R., Schneider, B., Schweitzer, R., Sieger, R., Skjelvan, I., Sullivan, K. F., Sutherland,

7 S. C., Sutton, A. J., Tadokoro, K., Telszewski, M., Tuma, M., van Heuven, S. M. A. C.,

8 Vandemark, D., Ward, B., Watson, A. J., and Xu, S.: A multi-decade record of high-quality

9 CO2 data in version 3 of the Surface Ocean CO2 Atlas (SOCAT), Earth Syst. Sci. Data, 8, 383-

10 413, https://doi.org/10.5194/essd-8-383-2016, 2016.

11 Bakker, D. C. E., Alin, S. R., Castaño-Primo, R., Cronin, M., Gkritzalis, T., Kozyr, A., Lauvset, S.

12 K., Metzl, N., Munro, D. R., Nakaoka, S.-I., O’Brien, K. M., Olsen, A., Omar, A. M., Pfeil, B.,

13 Pierrot, D., Rodriguez, C., Steinhoff, T., Sutton, A. J., Tilbrook, B., Wanninkhof, R., Willstrand

14 Wranne, A., Ahmed, M., Andersson, A., Apelthun, L. B., Bates, N., Battisti, R., Beaumont, L.,

15 Becker, M., Benoit-Cattin, A., Berghoff, C. F., Boutin, J., Burger, E. F., Burgers, T. M., Cantoni,

16 C., Cattrijsse, A., Chierici, M., Cross, J. N., Coppola, L., Cosca, C. E., Currie, K. I., De Carlo, E.

17 H., Else, B., Enright, M. P., Ericson, Y., Evans, W., Feely, R. A., Fiedler, B., Fransson, A., GarcíaIbáñez, M. I., Gehrung, M., Glockzin, M., González Dávila, M., Gutekunst, S., Hermes, R., Humphreys, M. P., Hunt, C. W., Ibánhez, J. S. P., Jones, S. D., Kitidis, V., Körtzinger, A., Kosugi, N., Landa, C. S., Landschützer, P., Lefèvre, N., Lo Monaco, C., Luchetta, A., Lutz, V. A., Macovei, V. A., Manke, A. B., Merlivat, L., Millero, F. J., Monacci, N. M., Negri, R. M., Newberger, T., Newton, J., Nickford, S. E., Nojiri, Y., Ohman, M., Ólafsdóttir, S. R., Sweeney, C., Ono, T., Palter, J. B., Papakyriakou, T., Peterson, W. T., Plueddemann, A. J., Qi, D., Rehder, G., Ritschel, M., Rutgersson, A., Sabine, C. L., Salisbury, J. E., Santana-Casiano, J. M., et al.: Surface Ocean CO2 Atlas Database Version 2021 (SOCATv2021) (NCEI Accession 0235360), https://doi.org/10.25921/YG69-JD96, 2021. 
1 Ballantyne, A. P., Andres, R., Houghton, R., Stocker, B. D., Wanninkhof, R., Anderegg, W.,

2 Cooper, L. A., DeGrandpre, M., Tans, P. P., Miller, J. B., Alden, C., and White, J. W. C.: Audit

3 of the global carbon budget: estimate errors and their impact on uptake uncertainty,

4 Biogeosciences, 12, 2565-2584, https://doi.org/10.5194/bg-12-2565-2015, 2015.

5 Bastos, A., O’Sullivan, M., Ciais, P., Makowski, D., Sitch, S., Friedlingstein, P., Chevallier, F.,

6 Rödenbeck, C., Pongratz, J., Luijkx, I. T., Patra, P. K., Peylin, P., Canadell, J. G., Lauerwald, R.,

7 Li, W., Smith, N. E., Peters, W., Goll, D. S., Jain, A. K., Kato, E., Lienert, S., Lombardozzi, D. L.,

8 Haverd, V., Nabel, J. E. M. S., Poulter, B., Tian, H., Walker, A. P., and Zaehle, S.: Sources of

9 Uncertainty in Regional and Global Terrestrial CO 2 Exchange Estimates, Global Biogeochem.

10 Cycles, 34, https://doi.org/10.1029/2019GB006393, 2020.

11 Bastos, A., Hartung, K., Nützel, T. B., Nabel, J. E. M. S., Houghton, R. A., and Pongratz, J.:

12 Comparison of uncertainties in land-use change fluxes from bookkeeping model

13 parameterisation, 12, 745-762, https://doi.org/10.5194/esd-12-745-2021, 2021.

14 Basu, S., Baker, D. F., Chevallier, F., Patra, P. K., Liu, J., and Miller, J. B.: The impact of

15 transport model differences on $\mathrm{CO} 2$ surface flux estimates from OCO-2 retrievals of column

16 average CO2, Atmos. Chem. Phys., 18, 7189-7215, https://doi.org/10.5194/acp-18-7189-

$17 \quad 2018,2018$.

Bauer, J. E., Cai, W.-J., Raymond, P. A., Bianchi, T. S., Hopkinson, C. S., and Regnier, P. A. G.:

The changing carbon cycle of the coastal ocean, Nature, 504, 61-70, https://doi.org/10.1038/nature12857, 2013.

Beckman, J. and Countryman, A. M.: The Importance of Agriculture in the Economy: Impacts from COVID-19, 103, 1595-1611, https://doi.org/10.1111/ajae.12212, 2021.

Bellouin, N., Rae, J., Jones, A., Johnson, C., Haywood, J., and Boucher, O.: Aerosol forcing in the Climate Model Intercomparison Project (CMIP5) simulations by HadGEM2-ES and the role of ammonium nitrate, 116, https://doi.org/10.1029/2011JD016074, 2011.

Berthet, S., Séférian, R., Bricaud, C., Chevallier, M., Voldoire, A., and Ethé, C.: Evaluation of an Online Grid-Coarsening Algorithm in a Global Eddy-Admitting Ocean Biogeochemical Model, 11, 1759-1783, https://doi.org/10.1029/2019MS001644, 2019. 
Brancalion, P. H. S., Broadbent, E. N., de-Miguel, S., Cardil, A., Rosa, M. R., Almeida, C. T.,

2 Almeida, D. R. A., Chakravarty, S., Zhou, M., Gamarra, J. G. P., Liang, J., Crouzeilles, R.,

3 Hérault, B., Aragão, L. E. O. C., Silva, C. A., and Almeyda-Zambrano, A. M.: Emerging threats

4 linking tropical deforestation and the COVID-19 pandemic, Perspectives in Ecology and

5 Conservation, 18, 243-246, https://doi.org/10.1016/j.pecon.2020.09.006, 2020.

6 Brienen, R. J. W., Phillips, O. L., Feldpausch, T. R., Gloor, E., Baker, T. R., Lloyd, J., Lopez-

7 Gonzalez, G., Monteagudo-Mendoza, A., Malhi, Y., Lewis, S. L., Vásquez Martinez, R.,

8 Alexiades, M., Álvarez Dávila, E., Alvarez-Loayza, P., Andrade, A., Aragão, L. E. O. C., Araujo-

9 Murakami, A., Arets, E. J. M. M., Arroyo, L., Aymard C., G. A., Bánki, O. S., Baraloto, C., Barroso, J., Bonal, D., Boot, R. G. A., Camargo, J. L. C., Castilho, C. V., Chama, V., Chao, K. J., Chave, J., Comiskey, J. A., Cornejo Valverde, F., da Costa, L., de Oliveira, E. A., Di Fiore, A., Erwin, T. L., Fauset, S., Forsthofer, M., Galbraith, D. R., Grahame, E. S., Groot, N., Hérault, B., Higuchi, N., Honorio Coronado, E. N., Keeling, H., Killeen, T. J., Laurance, W. F., Laurance, S., Licona, J., Magnussen, W. E., Marimon, B. S., Marimon-Junior, B. H., Mendoza, C., Neill, D. A., Nogueira, E. M., Núñez, P., Pallqui Camacho, N. C., Parada, A., Pardo-Molina, G., Peacock, J., Peña-Claros, M., Pickavance, G. C., Pitman, N. C. A., Poorter, L., Prieto, A., Quesada, C. A., Ramírez, F., Ramírez-Angulo, H., Restrepo, Z., Roopsind, A., Rudas, A., Salomão, R. P., Schwarz, M., Silva, N., Silva-Espejo, J. E., Silveira, M., Stropp, J., Talbot, J., ter Steege, H., Teran-Aguilar, J., Terborgh, J., Thomas-Caesar, R., Toledo, M., Torello-Raventos, M., Umetsu, R. K., van der Heijden, G. M. F., van der Hout, P., Guimarães Vieira, I. C., Vieira, S. A., Vilanova, E., Vos, V. A., and Zagt, R. J.: Long-term decline of the Amazon carbon sink, 519, 344-348, https://doi.org/10.1038/nature14283, 2015.

Broecker, W. S.: Ocean chemistry during glacial time, Geochimica et Cosmochimica Acta, 46, 1689-1705, https://doi.org/10.1016/0016-7037(82)90110-7, 1982.

Bruno, M. and Joos, F.: Terrestrial carbon storage during the past 200 years: A Monte Carlo Analysis of CO 2 data from ice core and atmospheric measurements, Global Biogeochem. Cycles, 11, 111-124, https://doi.org/10.1029/96GB03611, 1997. 
1 Burton, C., Betts, R., Cardoso, M., Feldpausch, T. R., Harper, A., Jones, C. D., Kelley, D. I.,

2 Robertson, E., and Wiltshire, A.: Representation of fire, land-use change and vegetation

3 dynamics in the Joint UK Land Environment Simulator vn4.9 (JULES), Geosci. Model Dev., 12,

4 179-193, https://doi.org/10.5194/gmd-12-179-2019, 2019.

5 Bushinsky, S. M., Landschützer, P., Rödenbeck, C., Gray, A. R., Baker, D., Mazloff, M. R.,

6 Resplandy, L., Johnson, K. S., and Sarmiento, J. L.: Reassessing Southern Ocean Air-Sea CO 2

7 Flux Estimates With the Addition of Biogeochemical Float Observations, Global Biogeochem.

8 Cycles, 33, 1370-1388, https://doi.org/10.1029/2019GB006176, 2019.

9 Canadell, J. G., Le Quere, C., Raupach, M. R., Field, C. B., Buitenhuis, E. T., Ciais, P., Conway,

10 T. J., Gillett, N. P., Houghton, R. A., and Marland, G.: Contributions to accelerating

11 atmospheric $\mathrm{CO} 2$ growth from economic activity, carbon intensity, and efficiency of natural

12 sinks, Proceedings of the National Academy of Sciences, 104, 18866-18870, https://doi.org/10.1073/pnas.0702737104, 2007.

14 Canadell, J. G., Monteiro, P. M. S., Costa, M. H., Cotrim da Cunha, L., Cox, P. M., Eliseev, A.

15 V., Henson, S., Ishii, M., Jaccard, S., Koven, C., Lohila, A., Patra, P. K., Piao, S., Rogelj, J.,

16 Syampungani, S., Zaehle, S., and Zickfeld, K.: Global Carbon and other Biogeochemical Cycles

17 and Feedbacks. In: Climate Change 2021: The Physical Science Basis. Contribution of

18 Working Group I to the Sixth Assessment Report of the Intergovernmental Panel on Climate

19 Change [Masson-Delmotte, V., P. Zhai, A. Pirani, S. L. Connors, C. Péan, S. Berger, N. Caud, Y.

20 Chen, L. Goldfarb, M. I. Gomis, M. Huang, K. Leitzell, E. Lonnoy, J.B.R. Matthews, T. K.

21 Maycock, T. Waterfield, O. Yelekçi, R. Yu and B. Zhou (eds.)]. Cambridge University Press. In

22 Press., 2021.

23 Cao, Z., Myers, R. J., Lupton, R. C., Duan, H., Sacchi, R., Zhou, N., Reed Miller, T., Cullen, J.

24 M., Ge, Q., and Liu, G.: The sponge effect and carbon emission mitigation potentials of the

25 global cement cycle, Nat Commun, 11, 3777, https://doi.org/10.1038/s41467-020-17583-w,

262020.

27 Carbon Monitor: CO2 Emissions Variation, available at: https://carbonmonitor.org/, last

28 access: 25 October 2021., 2021.

29 Chatfield, C.: The Holt-Winters Forecasting Procedure, 27, 264-279, 
2 Chau, T. T. T., Gehlen, M., and Chevallier, F.: QUALITY INFORMATION DOCUMENT for Global

3 Ocean Surface Carbon Product MULTIOBS_GLO_BIO_CARBON_SURFACE_REP_015_008, Le

4 Laboratoire des Sciences du Climat et de l’Environnement, 2020.

5 Chau, T. T. T., Gehlen, M., and Chevallier, F.: A seamless ensemble-based reconstruction of

6 surface ocean pCO2 and air-sea CO2 fluxes over the global coastal and open oceans, 1-30,

7 https://doi.org/10.5194/bg-2021-207, 2021.

8 Chevallier, F.: On the parallelization of atmospheric inversions of $\mathrm{CO} 2$ surface fluxes within a

9 variational framework, 6, 783-790, https://doi.org/10.5194/gmd-6-783-2013, 2013.

10 Chevallier, F., Fisher, M., Peylin, P., Serrar, S., Bousquet, P., Bréon, F.-M., Chédin, A., and

11 Ciais, P.: Inferring CO 2 sources and sinks from satellite observations: Method and

12 application to TOVS data, J. Geophys. Res., 110, D24309,

13 https://doi.org/10.1029/2005JD006390, 2005.

14 Chevallier, F., Remaud, M., O’Dell, C. W., Baker, D., Peylin, P., and Cozic, A.: Objective

15 evaluation of surface- and satellite-driven carbon dioxide atmospheric inversions, Atmos.

16 Chem. Phys., 19, 14233-14251, https://doi.org/10.5194/acp-19-14233-2019, 2019.

17 Chini, L., Hurtt, G., Sahajpal, R., Frolking, S., Klein Goldewijk, K., Sitch, S., Ganzenmüller, R.,

18 Ma, L., Ott, L., Pongratz, J., and Poulter, B.: Land-use harmonization datasets for annual

19 global carbon budgets, 13, 4175-4189, https://doi.org/10.5194/essd-13-4175-2021, 2021.

20 Ciais, P., Sabine, C., Bala, G., Bopp, L., Brovkin, V., Canadell, J. G., Chhabra, A., DeFries, R.,

21 Galloway, J., Heimann, M., Jones, C., Le Quéré, C., Myneni, R., Piao, S., Thornton, P., Willem,

22 J., Friedlingstein, P., and Munhoven, G.: Carbon and Other Biogeochemical Cycles, in Climate

23 Change 2013: The Physical Science Basis, Contribution of Working Group I to the Fifth

24 Assessment Report of the Intergovernmental Panel on Climate Change, edited by:

25 Intergovernmental Panel on Climate Change, Cambridge University Press, Cambridge, UK,

26 465-570, 2013.

27 Ciais, P., Tan, J., Wang, X., Roedenbeck, C., Chevallier, F., Piao, S.-L., Moriarty, R., Broquet,

28 G., Le Quéré, C., Canadell, J. G., Peng, S., Poulter, B., Liu, Z., and Tans, P.: Five decades of 
northern land carbon uptake revealed by the interhemispheric CO2 gradient, Nature, 568,

2 221-225, https://doi.org/10.1038/s41586-019-1078-6, 2019.

3 Ciais, P., Bastos, A., Chevallier, F., Lauerwald, R., Poulter, B., Canadell, P., Hugelius, G.,

4 Jackson, R. B., Jain, A., Jones, M., Kondo, M., Luijkx, I., Patra, P. K., Peters, W., Pongratz, J.,

5 Petrescu, A. M. R., Piao, S., Qiu, C., Von Randow, C., Regnier, P., Saunois, M., Scholes, R.,

6 Shvidenko, A., Tian, H., Yang, H., Wang, X., and Zheng, B.: Definitions and methods to

7 estimate regional land carbon fluxes for the second phase of the REgional Carbon Cycle

8 Assessment and Processes Project (RECCAP-2), 1-46, https://doi.org/10.5194/gmd-2020-

$9259,2020$.

10 Collier, N., Hoffman, F. M., Lawrence, D. M., Keppel-Aleks, G., Koven, C. D., Riley, W. J., Mu,

11 M., and Randerson, J. T.: The International Land Model Benchmarking (ILAMB) System:

12 Design, Theory, and Implementation, J. Adv. Model. Earth Syst., 10, 2731-2754, https://doi.org/10.1029/2018MS001354, 2018.

14 Conchedda, G. and Tubiello, F. N.: Drainage of organic soils and GHG emissions: Validation with country data, Biosphere - Biogeosciences, https://doi.org/10.5194/essd-2020-202, 2020.

Cooper, D. J., Watson, A. J., and Ling, R. D.: Variation of pCO2 along a North Atlantic shipping route (U.K. to the Caribbean): A year of automated observations, Marine Chemistry, 60, 147-164, https://doi.org/10.1016/S0304-4203(97)00082-0, 1998. Karion, A., Hensen, A., Arlyn Andrews, Frumau, A., Colomb, A., Scheeren, B., Law, B., Baier, B., Munger, B., Paplawsky, B., Viner, B., Stephens, B., Daube, B., Labuschagne, C., Myhre, C. L., Hanson, C., Miller, C. E., Plass-Duelmer, C., Plass-Duelmer, C., Gerbig, C., Sloop, C. D.,

24 Sweeney, C., Kubistin, D., Goto, D., Jaffe, D., Say, D., Van Dinther, D., Bowling, D., Lam, D. H.

25 Y., Dickon Young, Worthy, D., Dlugokencky, E., Kozlova, E., Gloor, E., Cuevas, E., Reyes-

26 Sanchez, E., Hintsa, E., Kort, E., Morgan, E., Obersteiner, F., Apadula, F., Francois Gheusi,

27 Meinhardt, F., Moore, F., Vitkova, G., Chen, G., Bentz, G., Manca, G., Brailsford, G., Forster,

28 G., Boenisch, H., Riris, H., Meijer, H., Timas, H., Matsueda, H., Huilin Chen, Levin, I., Lehner,

29 I., Mammarella, I., Bartyzel, J., Abshire, J. B., Elkins, J. W., Levula, J., Jaroslaw Necki, Pichon, 
1 J. M., Peischl, J., Müller-Williams, J., Turnbull, J., Miller, J. B., Lee, J., Lin, J., Josep-Anton

2 Morgui, DiGangi, J. P., Hatakka, J., Coletta, J. D., Worsey, J., Holst, J., Kominkova, K., McKain,

3 K., Saito, K., Aikin, K., Davis, K., Thoning, K., Tørseth, K., Haszpra, L., Mitchell, L., Gatti, L. V.,

4 Emmenegger, L., Lukasz Chmura, Merchant, L., Sha, M. K., Delmotte, M., et al.: Multi-

5 laboratory compilation of atmospheric carbon dioxide data for the period 1957-2019;

6 obspack_co2_1_GLOBALVIEWplus_v6.1_2021-03-01, https://doi.org/10.25925/20201204,

72021.

8 Cox, P. M., Pearson, D., Booth, B. B., Friedlingstein, P., Huntingford, C., Jones, C. D., and

9 Luke, C. M.: Sensitivity of tropical carbon to climate change constrained by carbon dioxide

10 variability, Nature, 494, 341-344, https://doi.org/10.1038/nature11882, 2013.

11 Crippa, M., Janssens-Maenhout, G., Guizzardi, D., Van Dingenen, R., and Dentener, F.:

12 Contribution and uncertainty of sectorial and regional emissions to regional and global

13 PM2.5 health impacts, 19, 5165-5186, https://doi.org/10.5194/acp-19-5165-2019, 2019.

14 Dai, A. and Trenberth, K. E.: Estimates of Freshwater Discharge from Continents: Latitudinal

15 and Seasonal Variations, 3, 660-687, https://doi.org/10.1175/1525-

$167541(2002) 003<0660:$ EOFDFC>2.0.CO;2, 2002.

17 Davis, S. J. and Caldeira, K.: Consumption-based accounting of $\mathrm{CO} 2$ emissions, Proceedings

18 of the National Academy of Sciences, 107, 5687-5692,

19 https://doi.org/10.1073/pnas.0906974107, 2010.

20 De Kauwe, M. G., Disney, M. I., Quaife, T., Lewis, P., and Williams, M.: An assessment of the 21 MODIS collection 5 leaf area index product for a region of mixed coniferous forest, Remote 22 Sensing of Environment, 115, 767-780, https://doi.org/10.1016/j.rse.2010.11.004, 2011.

23 Decharme, B., Delire, C., Minvielle, M., Colin, J., Vergnes, J.-P., Alias, A., Saint-Martin, D., 24 Séférian, R., Sénési, S., and Voldoire, A.: Recent Changes in the ISBA-CTRIP Land Surface 25 System for Use in the CNRM-CM6 Climate Model and in Global Off-Line Hydrological 26 Applications, 11, 1207-1252, https://doi.org/10.1029/2018MS001545, 2019.

27 Delire, C., Séférian, R., Decharme, B., Alkama, R., Calvet, J.-C., Carrer, D., Gibelin, A.-L., 
1 With ISBA-CTRIP: Improvements Over the Last Decade, 12, e2019MS001886,

2 https://doi.org/10.1029/2019MS001886, 2020.

3 Denman, K. L., Brasseur, G., Chidthaisong, A., Ciais, P., Cox, P. M., Dickinson, R. E.,

4 Hauglustaine, D., Heinze, C., Holland, E., Jacob, D., Lohmann, U., Ramachandran, S., Leite da

5 Silva Dias, P., Wofsy, S. C., and Zhang, X.: Couplings Between Changes in the Climate System

6 and Biogeochemistry, in: Climate Change 2007: The Physical Science Basis. Contribution of

7 Working Group I to the Fourth Assessment Report of the Intergovernmental Panel on

8 Climate Change, edited by: Solomon, S., Qin, D., Manning, M., Marquis, M., Averyt, K.,

9 Tignor, M. M. B., Miller, H. L., and Chen, Z. L., Cambridge University Press, Cambridge, UK

10 and New York, USA, 499-587, 2007.

11 Denning, A. S., Fung, I. Y., and Randall, D.: Latitudinal gradient of atmospheric $\mathrm{CO} 2$ due to

12 seasonal exchange with land biota, Nature, 376, 240-243,

13 https://doi.org/10.1038/376240a0, 1995.

14 Denvil-Sommer, A., Gehlen, M., Vrac, M., and Mejia, C.: LSCE-FFNN-v1: a two-step neural

15 network model for the reconstruction of surface ocean pCO2 over the global ocean, 12,

16 2091-2105, https://doi.org/10.5194/gmd-12-2091-2019, 2019.

17 DeVries, T.: The oceanic anthropogenic CO 2 sink: Storage, air-sea fluxes, and transports

18 over the industrial era, Global Biogeochem. Cycles, 28, 631-647, https://doi.org/10.1002/2013GB004739, 2014.

DeVries, T., Holzer, M., and Primeau, F.: Recent increase in oceanic carbon uptake driven by

21 weaker upper-ocean overturning, Nature, 542, 215-218, https://doi.org/10.1038/nature21068, 2017.

DeVries, T., Quéré, C. L., Andrews, O., Berthet, S., Hauck, J., Ilyina, T., Landschützer, P., ocean carbon sink, PNAS, 116, 11646-11651, https://doi.org/10.1073/pnas.1900371116, 2019. 
1 Jaffe, D., Dlugokencky, E., Vitkova, G., Manca, G., Huilin Chen, Lehner, I., Mammarella, I.,

2 Pichon, J. M., Müller-Williams, J., Miller, J. B., Lee, J., Hatakka, J., Holst, J., Kominkova, K.,

3 McKain, K., Thoning, K., Tørseth, K., Emmenegger, L., Sha, M. K., Delmotte, M., Fischer, M.

4 L., Schumacher, M., Leuenberger, M., Steinbacher, M., De Mazière, M., Lindauer, M.,

5 Mölder, M., Heliasz, M., Marek, M. V., Ramonet, M., Lopez, M., Laurent, O., Hermanssen, O.,

6 Trisolino, P., Cristofanelli, P., Smith, P., Bakwin, P., Bergamaschi, P., Keronen, P., Tans, P.,

7 Piacentino, S., Biraud, S. C., Conil, S., De Wekker, S., Biermann, T., Laurila, T., Aalto, T., and

8 Kazan, V.: Multi-laboratory compilation of atmospheric carbon dioxide data for the years

9 2020-2021; obspack_co2_1_NRT_v6.1.1_2021-05-17, https://doi.org/10.25925/20210517,

102021.

11 Dickson, A. G., Sabine, C. L., and Christian, J. R.: Guide to best practices for ocean CO2

12 measurement. Sidney, British Columbia, North Pacific Marine Science Organization, 191pp.

13 (PICES Special Publication 3; IOCCP Report 8). DOI: https://doi.org/10.25607/OBP-1342,

142007.

15 Dlugokencky, E. and Tans, P.: Trends in atmospheric carbon dioxide, National Oceanic and

16 Atmospheric Administration, Earth System Research Laboratory (NOAA/ESRL), available at:

17 http://www.esrl.noaa.gov/gmd/ccgg/trends/global.html, accessed: 16 November 2020.,

182020.

19 Dlugokencky, E. and Tans, P.: Trends in atmospheric carbon dioxide, National Oceanic and

20 Atmospheric Administration, Earth System Research Laboratory (NOAA/ESRL), available at:

21 http://www.esrl.noaa.gov/gmd/ccgg/trends/global.html, last access: 25 October 2021.,

222021.

23 Doney, S. C., Lima, I., Feely, R. A., Glover, D. M., Lindsay, K., Mahowald, N., Moore, J. K., and

24 Wanninkhof, R.: Mechanisms governing interannual variability in upper-ocean inorganic

25 carbon system and air-sea CO2 fluxes: Physical climate and atmospheric dust, Deep Sea

26 Research Part II: Topical Studies in Oceanography, 56, 640-655,

27 https://doi.org/10.1016/j.dsr2.2008.12.006, 2009.

28 Duce, R. A., LaRoche, J., Altieri, K., Arrigo, K. R., Baker, A. R., Capone, D. G., Cornell, S.,

29 Dentener, F., Galloway, J., Ganeshram, R. S., Geider, R. J., Jickells, T., Kuypers, M. M., 

Pedersen, T., Prospero, J., Schlitzer, R., Seitzinger, S., Sorensen, L. L., Uematsu, M., Ulloa, O.,

3 Voss, M., Ward, B., and Zamora, L.: Impacts of Atmospheric Anthropogenic Nitrogen on the Open Ocean, Science, 320, 893-897, https://doi.org/10.1126/science.1150369, 2008.

Dufour, C. O., Sommer, J. L., Gehlen, M., Orr, J. C., Molines, J., Simeon, J., and Barnier, B.:

6 Eddy compensation and controls of the enhanced sea-to-air CO 2 flux during positive phases

7 of the Southern Annular Mode, Global Biogeochem. Cycles, 27, 950-961,

8 https://doi.org/10.1002/gbc.20090, 2013.

9 Eakins, B. W. and Sharman, G. F.: National Geophysical Data Center: Volumes of the World's

10 Oceans from ETOPO1, available at:

11 https://www.ngdc.noaa.gov/mgg/global/etopo1_ocean_volumes.html, last access: 25

12 October 2021, U.S. Department of Commerce, 2010.

13 Eggleston, H. S., Buendia, L., Miwa, K., Ngara, T., and Tanabe, K.: Volume 4: Agriculture,

14 forestry and land use. in: 2006 IPCC guidelines for national greenhouse gas inventories.,

152006.

16 EIA: U.S. Energy Information Administration: Short-Term Energy Outlook, available at:

17 http://www.eia.gov/forecasts/steo/outlook, last access: 25 October 2021., 2021.

18 Erb, K.-H., Kastner, T., Luyssaert, S., Houghton, R. A., Kuemmerle, T., Olofsson, P., and

19 Haberl, H.: Bias in the attribution of forest carbon sinks, Nature Clim Change, 3, 854-856, https://doi.org/10.1038/nclimate2004, 2013. large impact of forest management and grazing on global vegetation biomass, Nature, 553, 73-76, https://doi.org/10.1038/nature25138, 2018. https://doi.org/10.1038/s41558-020-0831-z, 2020. 
1 V. I.: Natural and anthropogenic changes in atmospheric CO 2 over the last 1000 years from

2 air in Antarctic ice and firn, J. Geophys. Res., 101, 4115-4128,

3 https://doi.org/10.1029/95JD03410, 1996.

4 Eyring, V., Bony, S., Meehl, G. A., Senior, C. A., Stevens, B., Stouffer, R. J., and Taylor, K. E.:

5 Overview of the Coupled Model Intercomparison Project Phase 6 (CMIP6) experimental

6 design and organization, Geosci. Model Dev., 9, 1937-1958, https://doi.org/10.5194/gmd-9-

7 1937-2016, 2016.

8 FAO: Global Forest Resources Assessment 2020: Main report, FAO, Rome, Italy, 184 pp.,

9 https://doi.org/10.4060/ca9825en, 2020.

10 FAO: FAO: FAOSTAT Statistical Database, domains Climate Change, available at:

11 http://www.fao.org/faostat/en/\#data/GT, last accessed: 25 October 2021, 2021.

12 FAOSTAT: FAOSTAT: Food and Agriculture Organization Statistics Division, available at:

13 http://faostat.fao.org/, last access: 25 October 2021), 2021.

14 FAO/UNEP: Food and Agriculture Organisation / United Nations Environment Programme:

15 The state of food and agriculture 1981, available at:

16 https://www.fao.org/3/ap661e/ap661e.pdf, last access: 25 October 2021, 1981.

17 Fay, A. R. and McKinley, G. A.: Global open-ocean biomes: mean and temporal variability, 6,

18 273-284, https://doi.org/10.5194/essd-6-273-2014, 2014.

19 Fay, A. R., Gregor, L., Landschützer, P., McKinley, G. A., Gruber, N., Gehlen, M., lida, Y.,

20 Laruelle, G. G., Rödenbeck, C., and Zeng, J.: Harmonization of global surface ocean pCO2

21 mapped products and their flux calculations; an improved estimate of the ocean carbon

22 sink, 1-32, https://doi.org/10.5194/essd-2021-16, 2021a.

23 Fay, A. R., Gregor, L., Landschützer, P., McKinley, G. A., Gruber, N., Gehlen, M., lida, Y.,

24 Laruelle, G. G., Rödenbeck, C., Roobaert, A., and Zeng, J.: SeaFlux: harmonization of air-sea

25 CO2 fluxes from surface pCO2 data products using a standardized approach, 13, 4693-4710,

26 https://doi.org/10.5194/essd-13-4693-2021, 2021b.

27 Feng, L., Palmer, P. I., Bosch, H., and Dance, S.: Estimating surface CO2 fluxes from space- 
1 borne CO2 dry air mole fraction observations using an ensemble Kalman Filter, 15, 2009.

2 Feng, L., Palmer, P. I., Parker, R. J., Deutscher, N. M., Feist, D. G., Kivi, R., Morino, I., and

3 Sussmann, R.: Estimates of European uptake of CO2 inferred from GOSAT XCO2 retrievals:

4 sensitivity to measurement bias inside and outside Europe, Atmos. Chem. Phys., 16, 1289-

5 1302, https://doi.org/10.5194/acp-16-1289-2016, 2016.

6 Friedlingstein, P., Houghton, R. A., Marland, G., Hackler, J., Boden, T. A., Conway, T. J.,

7 Canadell, J. G., Raupach, M. R., Ciais, P., and Le Quéré, C.: Update on CO2 emissions, Nature

8 Geosci, 3, 811-812, https://doi.org/10.1038/ngeo1022, 2010.

9 Friedlingstein, P., Andrew, R. M., Rogelj, J., Peters, G. P., Canadell, J. G., Knutti, R., Luderer, 10 G., Raupach, M. R., Schaeffer, M., van Vuuren, D. P., and Le Quéré, C.: Persistent growth of 11 CO2 emissions and implications for reaching climate targets, Nature Geosci, 7, 709-715,

12 https://doi.org/10.1038/ngeo2248, 2014.

13 Friedlingstein, P., Jones, M. W., O’Sullivan, M., Andrew, R. M., Hauck, J., Peters, G. P., Peters,

14 W., Pongratz, J., Sitch, S., Le Quéré, C., Bakker, D. C. E., Canadell, J. G., Ciais, P., Jackson, R.

15 B., Anthoni, P., Barbero, L., Bastos, A., Bastrikov, V., Becker, M., Bopp, L., Buitenhuis, E.,

16 Chandra, N., Chevallier, F., Chini, L. P., Currie, K. I., Feely, R. A., Gehlen, M., Gilfillan, D.,

17 Gkritzalis, T., Goll, D. S., Gruber, N., Gutekunst, S., Harris, I., Haverd, V., Houghton, R. A.,

18 Hurtt, G., Ilyina, T., Jain, A. K., Joetzjer, E., Kaplan, J. O., Kato, E., Klein Goldewijk, K.,

19 Korsbakken, J. I., Landschützer, P., Lauvset, S. K., Lefèvre, N., Lenton, A., Lienert, S.,

20 Lombardozzi, D., Marland, G., McGuire, P. C., Melton, J. R., Metzl, N., Munro, D. R., Nabel, J.

21 E. M. S., Nakaoka, S.-I., Neill, C., Omar, A. M., Ono, T., Peregon, A., Pierrot, D., Poulter, B.,

22 Rehder, G., Resplandy, L., Robertson, E., Rödenbeck, C., Séférian, R., Schwinger, J., Smith, N.,

23 Tans, P. P., Tian, H., Tilbrook, B., Tubiello, F. N., van der Werf, G. R., Wiltshire, A. J., and

24 Zaehle, S.: Global Carbon Budget 2019, Earth Syst. Sci. Data, 11, 1783-1838,

25 https://doi.org/10.5194/essd-11-1783-2019, 2019.

26 Friedlingstein, P., O’Sullivan, M., Jones, M. W., Andrew, R. M., Hauck, J., Olsen, A., Peters, G.

27 P., Peters, W., Pongratz, J., Sitch, S., Le Quéré, C., Canadell, J. G., Ciais, P., Jackson, R. B., Alin,

28 S., Aragão, L. E. O. C., Arneth, A., Arora, V., Bates, N. R., Becker, M., Benoit-Cattin, A., Bittig,

29 H. C., Bopp, L., Bultan, S., Chandra, N., Chevallier, F., Chini, L. P., Evans, W., Florentie, L., 
Forster, P. M., Gasser, T., Gehlen, M., Gilfillan, D., Gkritzalis, T., Gregor, L., Gruber, N., Harris,

2 I., Hartung, K., Haverd, V., Houghton, R. A., Ilyina, T., Jain, A. K., Joetzjer, E., Kadono, K., Kato,

3 E., Kitidis, V., Korsbakken, J. I., Landschützer, P., Lefèvre, N., Lenton, A., Lienert, S., Liu, Z.,

4 Lombardozzi, D., Marland, G., Metzl, N., Munro, D. R., Nabel, J. E. M. S., Nakaoka, S.-I., Niwa,

5 Y., O’Brien, K., Ono, T., Palmer, P. I., Pierrot, D., Poulter, B., Resplandy, L., Robertson, E.,

6 Rödenbeck, C., Schwinger, J., Séférian, R., Skjelvan, I., Smith, A. J. P., Sutton, A. J., Tanhua, T.,

7 Tans, P. P., Tian, H., Tilbrook, B., van der Werf, G., Vuichard, N., Walker, A. P., Wanninkhof,

8 R., Watson, A. J., Willis, D., Wiltshire, A. J., Yuan, W., Yue, X., and Zaehle, S.: Global Carbon

9 Budget 2020, Earth Syst. Sci. Data, 12, 3269-3340, https://doi.org/10.5194/essd-12-3269-

$102020,2020$.

11 Friedlingstein, P., Jones, M. W., O’Sullivan, M., Andrew, R. M., Bakker, D. C. E., Hauck, J., Le

12 Quéré, C., Peters, G. P., Peters, W., Pongratz, J., Sitch, S., Canadell, J. G., Ciais, P., Jackson, R.

13 B., Anthoni, P., Bates, N. R., Becker, M., Bopp, L., Tuyet, T., Chau, T., Chevallier, F., Chini, L.

14 P., Cronin, M., Currie, K. I., Decharme, B., Djeutchouang, L. M., Dou, X., Evans, W., Feely, R.

15 A., Feng, L., Gasser, T., Gilfillan, D., Gkritzalis, T., Grassi, G., Gregor, L., Gruber, N., Gürses, Ö.,

16 Harris, I., Houghton, R. A., Hurtt, G. C., lida, Y., Ilyina, T., Luijkx, I. T., Jain, A. K., Jones, S. D.,

17 Kato, E., Kennedy, D., Klein Goldewijk, K., Knauer, J., Korsbakken, J. I., Körtzinger, A.,

18 Landschützer, P., Lauvset, S. K., Lefèvre, N., Lienert, S., Liu, J., Marland, G., McGuire, P. C.,

19 Melton, J. R., Munro, D. R., Nabel, J. E. M. S., Nakaoka, S.-I., Niwa, Y., Ono, T., Pierrot, D.,

20 Poulter, B., Rehder, G., Resplandy, L., Robertson, E., Rödenbeck, C., Schwinger, J.,

21 Schwingshackl, C., Séférian, R., Sutton, A. J., Tanhua, T., Tans, P., Tian, H., Tilbrook, B.,

22 Tubiello, F., van der Werf, G. R., Vuichard, N., Wanninkhof, R., Watson, A. J., Willis, D.,

23 Wiltshire, A. J., Wenping Yuan, Yue, C., Yue, X., Zaehle, S., and Zeng, J.: Supplemental data of

24 the Global Carbon Budget 2021, ICOS-ERIC Carbon Portal, https://doi.org/10.18160/gcp-

$252021,2021$.

26 Gasser, T. and Ciais, P.: A theoretical framework for the net land-to-atmosphere CO2 flux

27 and its implications in the definition of "emissions from land-use change", Earth Syst.

28 Dynam., 4, 171-186, https://doi.org/10.5194/esd-4-171-2013, 2013.

29 Gasser, T., Crepin, L., Quilcaille, Y., Houghton, R. A., Ciais, P., and Obersteiner, M.: Historical

30 CO2 emissions from land use and land cover change and their uncertainty, Biogeosciences, 
2 Gaubert, B., Stephens, B. B., Basu, S., Chevallier, F., Deng, F., Kort, E. A., Patra, P. K., Peters,

3 W., Rödenbeck, C., Saeki, T., Schimel, D., Van der Laan-Luijkx, I., Wofsy, S., and Yin, Y.: Global

4 atmospheric $\mathrm{CO} 2$ inverse models converging on neutral tropical land exchange, but

5 disagreeing on fossil fuel and atmospheric growth rate, Biogeosciences, 16, 117-134,

6 https://doi.org/10.5194/bg-16-117-2019, 2019.

7 Gaubert, B., Emmons, L. K., Raeder, K., Tilmes, S., Miyazaki, K., Arellano Jr., A. F., Elguindi, N.,

8 Granier, C., Tang, W., Barré, J., Worden, H. M., Buchholz, R. R., Edwards, D. P., Franke, P.,

9 Anderson, J. L., Saunois, M., Schroeder, J., Woo, J.-H., Simpson, I. J., Blake, D. R., Meinardi,

10 S., Wennberg, P. O., Crounse, J., Teng, A., Kim, M., Dickerson, R. R., He, H., Ren, X., Pusede,

11 S. E., and Diskin, G. S.: Correcting model biases of CO in East Asia: impact on oxidant

12 distributions during KORUS-AQ, 20, 14617-14647, https://doi.org/10.5194/acp-20-14617-

$132020,2020$.

14 General Administration of Customs of the People's Republic of China: Monthly statistical

15 reports, available at:

16 http://www.customs.gov.cn/customs/302249/zfxxgk/2799825/302274/302277/3512606/in

17 dex.html, last access: 25 October 2021, 2021.

18 Giglio, L., Schroeder, W., and Justice, C. O.: The collection 6 MODIS active fire detection

19 algorithm and fire products, Remote Sensing of Environment, 178, 31-41,

20 https://doi.org/10.1016/j.rse.2016.02.054, 2016.

21 Gilfillan, D. and Marland, G.: CDIAC-FF: global and national CO2 emissions from fossil fuel

22 combustion and cement manufacture: 1751-2017, 13, 1667-1680,

23 https://doi.org/10.5194/essd-13-1667-2021, 2021.

24 Gloege, L., McKinley, G. A., Landschützer, P., Fay, A. R., Frölicher, T. L., Fyfe, J. C., Ilyina, T., 25 Jones, S., Lovenduski, N. S., Rodgers, K. B., Schlunegger, S., and Takano, Y.: Quantifying

26 Errors in Observationally Based Estimates of Ocean Carbon Sink Variability, 35,

27 e2020GB006788, https://doi.org/10.1029/2020GB006788, 2021. 
1 Greenhouse Gases methodology for deriving a sea surface climatology of $\mathrm{CO} 2$ fugacity in

2 support of air-sea gas flux studies, 11, 519-541, https://doi.org/10.5194/os-11-519-2015,

32015.

4 Golar, G., Malik, A., Muis, H., Herman, A., Nurudin, N., and Lukman, L.: The social-economic

5 impact of COVID-19 pandemic: implications for potential forest degradation, Heliyon, 6,

6 e05354, https://doi.org/10.1016/j.heliyon.2020.e05354, 2020.

7 Grassi, G., House, J., Kurz, W. A., Cescatti, A., Houghton, R. A., Peters, G. P., Sanz, M. J.,

8 Viñas, R. A., Alkama, R., Arneth, A., Bondeau, A., Dentener, F., Fader, M., Federici, S.,

9 Friedlingstein, P., Jain, A. K., Kato, E., Koven, C. D., Lee, D., Nabel, J. E. M. S., Nassikas, A. A.,

10 Perugini, L., Rossi, S., Sitch, S., Viovy, N., Wiltshire, A., and Zaehle, S.: Reconciling global-

11 model estimates and country reporting of anthropogenic forest $\mathrm{CO} 2$ sinks, Nature Clim

12 Change, 8, 914-920, https://doi.org/10.1038/s41558-018-0283-x, 2018.

13 Grassi, G., Stehfest, E., Rogelj, J., van Vuuren, D., Cescatti, A., House, J., Nabuurs, G.-J., Rossi,

14 S., Alkama, R., Viñas, R. A., Calvin, K., Ceccherini, G., Federici, S., Fujimori, S., Gusti, M.,

15 Hasegawa, T., Havlik, P., Humpenöder, F., Korosuo, A., Perugini, L., Tubiello, F. N., and Popp,

16 A.: Critical adjustment of land mitigation pathways for assessing countries' climate progress,

17 Nat. Clim. Chang., 11, 425-434, https://doi.org/10.1038/s41558-021-01033-6, 2021.

18 Gregg, J. S., Andres, R. J., and Marland, G.: China: Emissions pattern of the world leader in

19 CO 2 emissions from fossil fuel consumption and cement production, Geophys. Res. Lett.,

20 35, L08806, https://doi.org/10.1029/2007GL032887, 2008.

21 Gregor, L. and Gruber, N.: OceanSODA-ETHZ: a global gridded data set of the surface ocean

22 carbonate system for seasonal to decadal studies of ocean acidification, 13, 777-808,

23 https://doi.org/10.5194/essd-13-777-2021, 2021.

24 Gregor, L., Lebehot, A. D., Kok, S., and Scheel Monteiro, P. M.: A comparative assessment of

25 the uncertainties of global surface ocean $\mathrm{CO} 2$ estimates using a machine-learning ensemble

26 (CSIR-ML6 version 2019a) - have we hit the wall?, 12, 5113-5136,

27 https://doi.org/10.5194/gmd-12-5113-2019, 2019. 
1 Gerber, M., Jacobson, A. R., Joos, F., Lindsay, K., Menemenlis, D., Mouchet, A., Müller, S. A.,

2 Sarmiento, J. L., and Takahashi, T.: Oceanic sources, sinks, and transport of atmospheric

3 CO2, 23, https://doi.org/10.1029/2008GB003349, 2009.

4 Gruber, N., Clement, D., Carter, B. R., Feely, R. A., van Heuven, S., Hoppema, M., Ishii, M.,

5 Key, R. M., Kozyr, A., Lauvset, S. K., Lo Monaco, C., Mathis, J. T., Murata, A., Olsen, A., Perez,

6 F. F., Sabine, C. L., Tanhua, T., and Wanninkhof, R.: The oceanic sink for anthropogenic CO2

7 from 1994 to 2007, 363, 1193-1199, https://doi.org/10.1126/science.aau5153, 2019.

8 Gruère, G. and Brooks, J.: Viewpoint: Characterising early agricultural and food policy

9 responses to the outbreak of COVID-19, Food Policy, 100, 102017,

10 https://doi.org/10.1016/j.foodpol.2020.102017, 2021.

11 Guan, D., Liu, Z., Geng, Y., Lindner, S., and Hubacek, K.: The gigatonne gap in China's carbon

12 dioxide inventories, Nature Clim Change, 2, 672-675,

13 https://doi.org/10.1038/nclimate1560, 2012.

14 Guo, R., Wang, J., Bing, L., Tong, D., Ciais, P., Davis, S. J., Andrew, R. M., Xi, F., and Liu, Z.:

15 Global CO2 uptake by cement from 1930 to 2019, 13, 1791-1805,

16 https://doi.org/10.5194/essd-13-1791-2021, 2021.

17 Gütschow, J., Jeffery, M. L., Gieseke, R., Gebel, R., Stevens, D., Krapp, M., and Rocha, M.:

18 The PRIMAP-hist national historical emissions time series, 8, 571-603,

19 https://doi.org/10.5194/essd-8-571-2016, 2016.

20 Gütschow, J., Günther, A., and Pflüger, M.: The PRIMAP-hist national historical emissions

21 time series (1750-2019) v2.3.1, https://doi.org/10.5281/zenodo.5494497, 2021.

22 Hall, B. D., Crotwell, A. M., Kitzis, D. R., Mefford, T., Miller, B. R., Schibig, M. F., and Tans, P.

23 P.: Revision of the World Meteorological Organization Global Atmosphere Watch

24 (WMO/GAW) CO2 calibration scale, 14, 3015-3032, https://doi.org/10.5194/amt-14-3015-

$252021,2021$.

26 Hansen, M. C., Potapov, P. V., Moore, R., Hancher, M., Turubanova, S. A., Tyukavina, A.,

27 Thau, D., Stehman, S. V., Goetz, S. J., Loveland, T. R., Kommareddy, A., Egorov, A., Chini, L.,

28 Justice, C. O., and Townshend, J. R. G.: High-Resolution Global Maps of 21st-Century Forest 
2 Hansis, E., Davis, S. J., and Pongratz, J.: Relevance of methodological choices for accounting

3 of land use change carbon fluxes, Global Biogeochem. Cycles, 29, 1230-1246,

4 https://doi.org/10.1002/2014GB004997, 2015.

5 Harris, I., Jones, P. D., Osborn, T. J., and Lister, D. H.: Updated high-resolution grids of

6 monthly climatic observations - the CRU TS3.10 Dataset: UPDATED HIGH-RESOLUTION

7 GRIDS OF MONTHLY CLIMATIC OBSERVATIONS, Int. J. Climatol., 34, 623-642,

8 https://doi.org/10.1002/joc.3711, 2014.

9 Harris, I., Osborn, T. J., Jones, P., and Lister, D.: Version 4 of the CRU TS monthly high-

10 resolution gridded multivariate climate dataset, Sci Data, 7, 109,

11 https://doi.org/10.1038/s41597-020-0453-3, 2020.

12 Hauck, J., Zeising, M., Le Quéré, C., Gruber, N., Bakker, D. C. E., Bopp, L., Chau, T. T. T.,

13 Gürses, Ö., llyina, T., Landschützer, P., Lenton, A., Resplandy, L., Rödenbeck, C., Schwinger,

14 J., and Séférian, R.: Consistency and Challenges in the Ocean Carbon Sink Estimate for the

15 Global Carbon Budget, Front. Mar. Sci., 7, 571720,

16 https://doi.org/10.3389/fmars.2020.571720, 2020.

17 Haverd, V., Smith, B., Nieradzik, L., Briggs, P. R., Woodgate, W., Trudinger, C. M., Canadell, J.

18 G., and Cuntz, M.: A new version of the CABLE land surface model (Subversion revision

19 r4601) incorporating land use and land cover change, woody vegetation demography, and a

20 novel optimisation-based approach to plant coordination of photosynthesis, Geosci. Model

21 Dev., 11, 2995-3026, https://doi.org/10.5194/gmd-11-2995-2018, 2018.

22 Heinimann, A., Mertz, O., Frolking, S., Christensen, A. E., Hurni, K., Sedano, F., Chini, L. P.,

23 Sahajpal, R., Hansen, M., and Hurtt, G.: A global view of shifting cultivation: Recent, current,

24 and future extent, PLOS ONE, 12, e0184479, https://doi.org/10.1371/journal.pone.0184479,

252017.

26 Hertwich, E. G. and Peters, G. P.: Carbon Footprint of Nations: A Global, Trade-Linked

27 Analysis, Environ. Sci. Technol., 43, 6414-6420, https://doi.org/10.1021/es803496a, 2009.

28 Hickler, T., Smith, B., Prentice, I. C., Mjöfors, K., Miller, P., Arneth, A., and Sykes, M. T.: CO2 
1 fertilization in temperate FACE experiments not representative of boreal and tropical

2 forests, 14, 1531-1542, https://doi.org/10.1111/j.1365-2486.2008.01598.x, 2008.

3 Ho, D. T., Wanninkhof, R., Schlosser, P., Ullman, D. S., Hebert, D., and Sullivan, K. F.: Toward

4 a universal relationship between wind speed and gas exchange: Gas transfer velocities

5 measured with 3He/SF6 during the Southern Ocean Gas Exchange Experiment, 116,

6 https://doi.org/10.1029/2010JC006854, 2011.

7 Hoesly, R. M., Smith, S. J., Feng, L., Klimont, Z., Janssens-Maenhout, G., Pitkanen, T., Seibert,

8 J. J., Vu, L., Andres, R. J., Bolt, R. M., Bond, T. C., Dawidowski, L., Kholod, N., Kurokawa, J., Li,

9 M., Liu, L., Lu, Z., Moura, M. C. P., O’Rourke, P. R., and Zhang, Q.: Historical (1750-2014)

10 anthropogenic emissions of reactive gases and aerosols from the Community Emissions Data

11 System (CEDS), Geosci. Model Dev., 11, 369-408, https://doi.org/10.5194/gmd-11-369-

12 2018, 2018.

13 Hong, C., Burney, J. A., Pongratz, J., Nabel, J. E. M. S., Mueller, N. D., Jackson, R. B., and

14 Davis, S. J.: Global and regional drivers of land-use emissions in 1961-2017, 589, 554-561, https://doi.org/10.1038/s41586-020-03138-y, 2021.

Hooijer, A., Page, S., Canadell, J. G., Silvius, M., Kwadijk, J., Wösten, H., and Jauhiainen, J.:

17 Current and future $\mathrm{CO} 2$ emissions from drained peatlands in Southeast Asia,

19 Houghton, R. A.: Why are estimates of the terrestrial carbon balance so different?, 9, 500-

20 509, https://doi.org/10.1046/j.1365-2486.2003.00620.x, 2003.

21 Houghton, R. A. and Nassikas, A. A.: Global and regional fluxes of carbon from land use and

22 land cover change 1850-2015: Carbon Emissions From Land Use, Global Biogeochem. Cycles,

23 31, 456-472, https://doi.org/10.1002/2016GB005546, 2017.

24 Houghton, R. A., House, J. I., Pongratz, J., van der Werf, G. R., DeFries, R. S., Hansen, M. C.,

25 Le Quéré, C., and Ramankutty, N.: Carbon emissions from land use and land-cover change,

26 Biogeosciences, 9, 5125-5142, https://doi.org/10.5194/bg-9-5125-2012, 2012.

27 Hubau, W., Lewis, S. L., Phillips, O. L., Affum-Baffoe, K., Beeckman, H., Cuní-Sanchez, A.,

28 Daniels, A. K., Ewango, C. E. N., Fauset, S., Mukinzi, J. M., Sheil, D., Sonké, B., Sullivan, M. J. 
P., Sunderland, T. C. H., Taedoumg, H., Thomas, S. C., White, L. J. T., Abernethy, K. A., Adu-

Bredu, S., Amani, C. A., Baker, T. R., Banin, L. F., Baya, F., Begne, S. K., Bennett, A. C., Chezeaux, E., Chuyong, G. B., Clark, C. J., Collins, M., Comiskey, J. A., Coomes, D. A., Dargie, G. C., de Haulleville, T., Kamdem, M. N. D., Doucet, J.-L., Esquivel-Muelbert, A., Feldpausch, T. R., Fofanah, A., Foli, E. G., Gilpin, M., Gloor, E., Gonmadje, C., Gourlet-Fleury, S., Hall, J. S., Hamilton, A. C., Harris, D. J., Hart, T. B., Hockemba, M. B. N., Hladik, A., Ifo, S. A., Jeffery, K. J., Jucker, T., Yakusu, E. K., Kearsley, E., Kenfack, D., Koch, A., Leal, M. E., Levesley, A.,

9 Lindsell, J. A., Lisingo, J., Lopez-Gonzalez, G., Lovett, J. C., Makana, J.-R., Malhi, Y., Marshall, 10 A. R., Martin, J., Martin, E. H., Mbayu, F. M., Medjibe, V. P., Mihindou, V., Mitchard, E. T. A., 11 Moore, S., Munishi, P. K. T., Bengone, N. N., Ojo, L., Ondo, F. E., Peh, K. S.-H., Pickavance, G.

12 C., Poulsen, A. D., Poulsen, J. R., Qie, L., Reitsma, J., Rovero, F., Swaine, M. D., Talbot, J.,

13 Taplin, J., Taylor, D. M., Thomas, D. W., Toirambe, B., Mukendi, J. T., Tuagben, D., Umunay,

14 P. M., et al.: Asynchronous carbon sink saturation in African and Amazonian tropical forests, 579, 80-87, https://doi.org/10.1038/s41586-020-2035-0, 2020. O’Donnell, J., Schirrmeister, L., Schuur, E. A. G., Sheng, Y., Smith, L. C., Strauss, J., and Yu, Z.: A new data set for estimating organic carbon storage to $3 \mathrm{~m}$ depth in soils of the northern circumpolar permafrost region, Earth Syst. Sci. Data, 5, 393-402, https://doi.org/10.5194/essd-5-393-2013, 2013. Humphrey, V., Zscheischler, J., Ciais, P., Gudmundsson, L., Sitch, S., and Seneviratne, S. I.: Sensitivity of atmospheric $\mathrm{CO} 2$ growth rate to observed changes in terrestrial water storage, 560, 628-631, https://doi.org/10.1038/s41586-018-0424-4, 2018. Frankenberg, C.: Soil moisture-atmosphere feedback dominates land carbon uptake variability, 592, 65-69, https://doi.org/10.1038/s41586-021-03325-5, 2021. 
1 W., Zeng, N., and Zhao, F.: Uncertainty in the response of terrestrial carbon sink to

2 environmental drivers undermines carbon-climate feedback predictions, Sci Rep, 7, 4765,

3 https://doi.org/10.1038/s41598-017-03818-2, 2017.

4 Hurtt, G., Chini, L., Sahajpal, R., Frolking, S., Bodirsky, B. L., Calvin, K., Doelman, J., Fisk, J.,

5 Fujimori, S., Goldewijk, K. K., Hasegawa, T., Havlik, P., Heinimann, A., Humpenöder, F.,

6 Jungclaus, J., Kaplan, J., Krisztin, T., Lawrence, D., Lawrence, P., Mertz, O., Pongratz, J., Popp,

7 A., Riahi, K., Shevliakova, E., Stehfest, E., Thornton, P., van Vuuren, D., and Zhang, X.:

8 input4MIPs.CMIP6.CMIP.UofMD.UofMD-landState-2-1-h,

9 https://doi.org/10.22033/ESGF/input4MIPs.1127, 2017.

10 Hurtt, G. C., Chini, L. P., Frolking, S., Betts, R. A., Feddema, J., Fischer, G., Fisk, J. P., Hibbard,

11 K., Houghton, R. A., Janetos, A., Jones, C. D., Kindermann, G., Kinoshita, T., Klein Goldewijk,

12 K., Riahi, K., Shevliakova, E., Smith, S., Stehfest, E., Thomson, A., Thornton, P., van Vuuren, D.

13 P., and Wang, Y. P.: Harmonization of land-use scenarios for the period 1500-2100: 600

14 years of global gridded annual land-use transitions, wood harvest, and resulting secondary

15 lands, Climatic Change, 109, 117-161, https://doi.org/10.1007/s10584-011-0153-2, 2011.

16 Hurtt, G. C., Chini, L., Sahajpal, R., Frolking, S., Bodirsky, B. L., Calvin, K., Doelman, J. C., Fisk,

17 J., Fujimori, S., Klein Goldewijk, K., Hasegawa, T., Havlik, P., Heinimann, A., Humpenöder, F.,

18 Jungclaus, J., Kaplan, J. O., Kennedy, J., Krisztin, T., Lawrence, D., Lawrence, P., Ma, L., Mertz,

19 O., Pongratz, J., Popp, A., Poulter, B., Riahi, K., Shevliakova, E., Stehfest, E., Thornton, P.,

20 Tubiello, F. N., van Vuuren, D. P., and Zhang, X.: Harmonization of global land use change

21 and management for the period 850-2100 (LUH2) for CMIP6, Geosci. Model Dev., 13, 5425-

22 5464, https://doi.org/10.5194/gmd-13-5425-2020, 2020.

23 IEA: International Energy Agency: Global Energy Review, available at:

24 https://www.iea.org/reports/global-energy-review-2021, last access: 25 October 2021.,

$252021 a$.

26 IEA: International Energy Agency: World Energy Outlook, available at:

27 https://www.iea.org/reports/world-energy-outlook-2021, last access: 25 October 2021.,

$282021 b$.

29 IEA/OECD: International Energy Agency/Organisation for Economic Cooperation and 
1 Development: $\mathrm{CO} 2$ emissions from fuel combustion, available at:

2 https://webstore.iea.org/co2-emissions-from-fuel-combustion-2019-highlights, last access:

325 October 2021, 2019.

4 lida, Y., Kojima, A., Takatani, Y., Nakano, T., Sugimoto, H., Midorikawa, T., and Ishii, M.:

5 Trends in pCO2 and sea-air $\mathrm{CO} 2$ flux over the global open oceans for the last two decades, J

6 Oceanogr, 71, 637-661, https://doi.org/10.1007/s10872-015-0306-4, 2015.

7 lida, Y., Takatani, Y., Kojima, A., and Ishii, M.: Global trends of ocean $\mathrm{CO} 2$ sink and ocean

8 acidification: an observation-based reconstruction of surface ocean inorganic carbon

9 variables, J Oceanogr, 77, 323-358, https://doi.org/10.1007/s10872-020-00571-5, 2021.

10 Ilyina, T., Six, K. D., Segschneider, J., Maier-Reimer, E., Li, H., and Núñez-Riboni, I.: Global

11 ocean biogeochemistry model HAMOCC: Model architecture and performance as

12 component of the MPI-Earth system model in different CMIP5 experimental realizations:

13 The Model Hamocc within Mpi-Esm in Cmip5, J. Adv. Model. Earth Syst., 5, 287-315,

14 https://doi.org/10.1029/2012MS000178, 2013.

15 IMF: International Monetary Fund: World Economic Outlook, available at:

16 http://www.imf.org, last access: 25 October 2021., 2021.

17 Inness, A., Ades, M., Agustí-Panareda, A., Barré, J., Benedictow, A., Blechschmidt, A.-M.,

18 Dominguez, J. J., Engelen, R., Eskes, H., Flemming, J., Huijnen, V., Jones, L., Kipling, Z.,

19 Massart, S., Parrington, M., Peuch, V.-H., Razinger, M., Remy, S., Schulz, M., and Suttie, M.:

20 The CAMS reanalysis of atmospheric composition, 19, 3515-3556,

21 https://doi.org/10.5194/acp-19-3515-2019, 2019.

22 IPCC: Summary for Policymakers. In: Climate Change 2021: The Physical Science Basis.

23 Contribution of Working Group I to the Sixth Assessment Report of the Intergovernmental

24 Panel on Climate Change [Masson-Delmotte, V., P. Zhai, A. Pirani, S.L. Connors, C. Péan, S.

25 Berger, N. Caud, Y. Chen, L. Goldfarb, M.I. Gomis, M. Huang, K. Leitzell, E. Lonnoy, J.B.R.

26 Matthews, T.K. Maycock, T. Waterfield, O. Yelekçi, R. Yu, and B. Zhou (eds.)]. Cambridge

27 University Press. In Press., 2021. 
1 global terrestrial ecosystems and evaluation of uncertainty, 9, 759-773,

2 https://doi.org/10.5194/bg-9-759-2012, 2012.

3 Jackson, R. B., Canadell, J. G., Le Quéré, C., Andrew, R. M., Korsbakken, J. I., Peters, G. P.,

4 and Nakicenovic, N.: Reaching peak emissions, Nature Clim Change, 6, 7-10,

5 https://doi.org/10.1038/nclimate2892, 2016.

6 Jackson, R. B., Le Quéré, C., Andrew, R. M., Canadell, J. G., Korsbakken, J. I., Liu, Z., Peters, G.

7 P., and Zheng, B.: Global energy growth is outpacing decarbonization, Environ. Res. Lett., 13,

8 120401, https://doi.org/10.1088/1748-9326/aaf303, 2018.

9 Jackson, R. B., Friedlingstein, P., Andrew, R. M., Canadell, J. G., Le Quéré, C., and Peters, G.

10 P.: Persistent fossil fuel growth threatens the Paris Agreement and planetary health,

11 Environ. Res. Lett., 14, 121001, https://doi.org/10.1088/1748-9326/ab57b3, 2019.

12 Jacobson, A. R., Mikaloff Fletcher, S. E., Gruber, N., Sarmiento, J. L., and Gloor, M.: A joint

13 atmosphere-ocean inversion for surface fluxes of carbon dioxide: 1. Methods and global-

14 scale fluxes: JOINT INVERSION-METHODS AND GLOBAL FLUXES, Global Biogeochem. Cycles,

15 21, https://doi.org/10.1029/2005GB002556, 2007.

16 Jain, A. K., Meiyappan, P., Song, Y., and House, J. I.: CO2 emissions from land-use change

17 affected more by nitrogen cycle, than by the choice of land-cover data, 19, 2893-2906,

18 https://doi.org/10.1111/gcb.12207, 2013.

19 Janssens-Maenhout, G., Crippa, M., Guizzardi, D., Muntean, M., Schaaf, E., Dentener, F.,

20 Bergamaschi, P., Pagliari, V., Olivier, J. G. J., Peters, J. A. H. W., van Aardenne, J. A., Monni,

21 S., Doering, U., Petrescu, A. M. R., Solazzo, E., and Oreggioni, G. D.: EDGAR v4.3.2 Global

22 Atlas of the three major greenhouse gas emissions for the period 1970-2012, Earth Syst. Sci.

23 Data, 11, 959-1002, https://doi.org/10.5194/essd-11-959-2019, 2019.

24 JODI: Joint Organisations Data Initiative, available at: https://www. jodidata.org, last access:

2525 October 2021, 2021.

26 Jones, M. W., Andrew, R. M., Peters, G. P., Janssens-Maenhout, G., De-Gol, A. J., Ciais, P.,

27 Patra, P. K., Chevallier, F., and Le Quéré, C.: Gridded fossil CO2 emissions and related 02

28 combustion consistent with national inventories 1959-2018, Sci Data, 8, 2, 
2 Jones, M. W., Andrew, R. M., Peters, G. P., Janssens-Maenhout, G., De-Gol, A. J., Dou, X., Liu,

3 Z., Ciais, P., Patra, P. K., Chevallier, F., and Le Quéré, C.: Gridded fossil CO2 emissions and

4 related $\mathrm{O} 2$ combustion consistent with national inventories 1959-2020,

5 https://doi.org/10.5281/zenodo.5565199, 2021b.

6 Joos, F. and Spahni, R.: Rates of change in natural and anthropogenic radiative forcing over

7 the past 20,000 years, Proceedings of the National Academy of Sciences, 105, 1425-1430,

8 https://doi.org/10.1073/pnas.0707386105, 2008.

9 Jung, M., Reichstein, M., Ciais, P., Seneviratne, S. I., Sheffield, J., Goulden, M. L., Bonan, G.,

10 Cescatti, A., Chen, J., de Jeu, R., Dolman, A. J., Eugster, W., Gerten, D., Gianelle, D., Gobron,

11 N., Heinke, J., Kimball, J., Law, B. E., Montagnani, L., Mu, Q., Mueller, B., Oleson, K., Papale,

12 D., Richardson, A. D., Roupsard, O., Running, S., Tomelleri, E., Viovy, N., Weber, U., Williams,

13 C., Wood, E., Zaehle, S., and Zhang, K.: Recent decline in the global land evapotranspiration

14 trend due to limited moisture supply, Nature, 467, 951-954, https://doi.org/10.1038/nature09396, 2010. Camps-Valls, G., Ciais, P., Friedlingstein, P., Gans, F., Ichii, K., Jain, A. K., Kato, E., Papale, D., Poulter, B., Raduly, B., Rödenbeck, C., Tramontana, G., Viovy, N., Wang, Y.-P., Weber, U., Zaehle, S., and Zeng, N.: Compensatory water effects link yearly global land CO2 sink changes to temperature, Nature, 541, 516-520, https://doi.org/10.1038/nature20780, 2017.

Kalnay, E., Kanamitsu, M., Kistler, R., Collins, W., Deaven, D., Gandin, L., Iredell, M., Saha, S., White, G., Woollen, J., Zhu, Y., Chelliah, M., Ebisuzaki, W., Higgins, W., Janowiak, J., Mo, K. C., Ropelewski, C., Wang, J., Leetmaa, A., Reynolds, R., Jenne, R., and Joseph, D.: The NCEP/NCAR 40-Year Reanalysis Project, 77, 437-472, https://doi.org/10.1175/15200477(1996)077<0437:TNYRP>2.0.CO;2, 1996.

27 Kato, E., Kinoshita, T., Ito, A., Kawamiya, M., and Yamagata, Y.: Evaluation of spatially

28 explicit emission scenario of land-use change and biomass burning using a process-based biogeochemical model, 8, 104-122, https://doi.org/10.1080/1747423X.2011.628705, 2013. 
1 Keeling, C. D., Bacastow, R. B., Bainbridge, A. E., Ekdahl, C. A., Guenther, P. R., Waterman, L.

2 S., and Chin, J. F. S.: Atmospheric carbon dioxide variations at Mauna Loa Observatory,

3 Hawaii, 28, 538-551, https://doi.org/10.1111/j.2153-3490.1976.tb00701.x, 1976.

4 Keeling, R. F. and Manning, A. C.: 5.15 - Studies of Recent Changes in Atmospheric O2

5 Content, in: Treatise on Geochemistry (Second Edition), edited by: Holland, H. D. and

6 Turekian, K. K., Elsevier, Oxford, 385-404, https://doi.org/10.1016/B978-0-08-095975-

$7 \quad 7.00420-4,2014$.

8 Keppler, L. and Landschützer, P.: Regional Wind Variability Modulates the Southern Ocean

9 Carbon Sink, Sci Rep, 9, 7384, https://doi.org/10.1038/s41598-019-43826-y, 2019.

10 Khatiwala, S., Primeau, F., and Hall, T.: Reconstruction of the history of anthropogenic CO2

11 concentrations in the ocean, Nature, 462, 346-349, https://doi.org/10.1038/nature08526,

122009.

13 Khatiwala, S., Tanhua, T., Mikaloff Fletcher, S., Gerber, M., Doney, S. C., Graven, H. D.,

14 Gruber, N., McKinley, G. A., Murata, A., Ríos, A. F., and Sabine, C. L.: Global ocean storage of

15 anthropogenic carbon, Biogeosciences, 10, 2169-2191, https://doi.org/10.5194/bg-10-

$16 \quad 2169-2013,2013$.

17 Klein Goldewijk, K., Beusen, A., Doelman, J., and Stehfest, E.: Anthropogenic land use

18 estimates for the Holocene - HYDE 3.2, Earth Syst. Sci. Data, 9, 927-953,

19 https://doi.org/10.5194/essd-9-927-2017, 2017a.

20 Klein Goldewijk, K., Dekker, S. C., and van Zanden, J. L.: Per-capita estimations of long-term

21 historical land use and the consequences for global change research, Journal of Land Use

22 Science, 1747423X.2017.1354938, https://doi.org/10.1080/1747423X.2017.1354938,

$232017 b$.

24 Kobayashi, S., Ota, Y., Harada, Y., Ebita, A., Moriya, M., Onoda, H., Onogi, K., Kamahori, H.,

25 Kobayashi, C., Endo, H., Miyaoka, K., and Takahashi, K.: The JRA-55 Reanalysis: General

26 Specifications and Basic Characteristics, Journal of the Meteorological Society of Japan, 93,

27 5-48, https://doi.org/10.2151/jmsj.2015-001, 2015. 
1 China's coal use and CO2 emissions, Nature Clim Change, 6, 687-690,

2 https://doi.org/10.1038/nclimate2963, 2016.

3 Krinner, G., Viovy, N., de Noblet-Ducoudré, N., Ogée, J., Polcher, J., Friedlingstein, P., Ciais,

4 P., Sitch, S., and Prentice, I. C.: A dynamic global vegetation model for studies of the coupled

5 atmosphere-biosphere system: DVGM FOR COUPLED CLIMATE STUDIES, Global

6 Biogeochem. Cycles, 19, https://doi.org/10.1029/2003GB002199, 2005.

7 Lacroix, F., Ilyina, T., and Hartmann, J.: Oceanic CO2 outgassing and biological production

8 hotspots induced by pre-industrial river loads of nutrients and carbon in a global modeling

9 approach, Biogeosciences, 17, 55-88, https://doi.org/10.5194/bg-17-55-2020, 2020.

10 Lacroix, F., llyina, T., Mathis, M., Laruelle, G. G., and Regnier, P.: Historical increases in land-

11 derived nutrient inputs may alleviate effects of a changing physical climate on the oceanic

12 carbon cycle, Glob Change Biol, 27, 5491-5513, https://doi.org/10.1111/gcb.15822, 2021.

13 Landschützer, P., Gruber, N., Bakker, D. C. E., Schuster, U., Nakaoka, S., Payne, M. R., Sasse,

14 T. P., and Zeng, J.: A neural network-based estimate of the seasonal to inter-annual

15 variability of the Atlantic Ocean carbon sink, Biogeosciences, 10, 7793-7815,

16 https://doi.org/10.5194/bg-10-7793-2013, 2013.

17 Landschützer, P., Gruber, N., Bakker, D. C. E., and Schuster, U.: Recent variability of the

18 global ocean carbon sink, Global Biogeochem. Cycles, 28, 927-949,

19 https://doi.org/10.1002/2014GB004853, 2014.

20 Landschützer, P., Gruber, N., Haumann, F. A., Rödenbeck, C., Bakker, D. C. E., van Heuven, S.,

21 Hoppema, M., Metzl, N., Sweeney, C., Takahashi, T., Tilbrook, B., and Wanninkhof, R.: The

22 reinvigoration of the Southern Ocean carbon sink, Science, 349, 1221-1224,

23 https://doi.org/10.1126/science.aab2620, 2015.

24 Landschützer, P., Gruber, N., and Bakker, D. C. E.: Decadal variations and trends of the global

25 ocean carbon sink: DECADAL AIR-SEA CO 2 FLUX VARIABILITY, Global Biogeochem. Cycles,

$2630,1396-1417$, https://doi.org/10.1002/2015GB005359, 2016.

27 Landschützer, P., Laruelle, G. G., Roobaert, A., and Regnier, P.: A uniform pCO2 climatology

28 combining open and coastal oceans, 12, 2537-2553, https://doi.org/10.5194/essd-12-2537- 
2020, 2020.

2

Lang, F., Ackermann, L., Huang, Y., Truong, S. C. H., Siems, S. T., and Manton, M. J.: A climatology of open and closed mesoscale cellular convection over the Southern Ocean derived from Himawari-8 observations, 1-27, https://doi.org/10.5194/acp-2021-681, 2021. Lasslop, G., Reichstein, M., Papale, D., Richardson, A. D., Arneth, A., Barr, A., Stoy, P., and Wohlfahrt, G.: Separation of net ecosystem exchange into assimilation and respiration using a light response curve approach: critical issues and global evaluation: Separation of NEE into GPP and RECO, 16, 187-208, https://doi.org/10.1111/j.1365-2486.2009.02041.x, 2010. Lawrence, D. M., Fisher, R. A., Koven, C. D., Oleson, K. W., Swenson, S. C., Bonan, G., Collier, N., Ghimire, B., van Kampenhout, L., Kennedy, D., Kluzek, E., Lawrence, P. J., Li, F., Li, H., Lombardozzi, D., Riley, W. J., Sacks, W. J., Shi, M., Vertenstein, M., Wieder, W. R., Xu, C., Ali, A. A., Badger, A. M., Bisht, G., van den Broeke, M., Brunke, M. A., Burns, S. P., Buzan, J., Clark, M., Craig, A., Dahlin, K., Drewniak, B., Fisher, J. B., Flanner, M., Fox, A. M., Gentine, P., Hoffman, F., Keppel-Aleks, G., Knox, R., Kumar, S., Lenaerts, J., Leung, L. R., Lipscomb, W. H., Lu, Y., Pandey, A., Pelletier, J. D., Perket, J., Randerson, J. T., Ricciuto, D. M., Sanderson, B. M., Slater, A., Subin, Z. M., Tang, J., Thomas, R. Q., Val Martin, M., and Zeng, X.: The Community Land Model Version 5: Description of New Features, Benchmarking, and Impact of Forcing Uncertainty, 11, 4245-4287, https://doi.org/10.1029/2018MS001583, 2019. Le Quéré, C., Rödenbeck, C., Buitenhuis, E. T., Conway, T. J., Langenfelds, R., Gomez, A., Labuschagne, C., Ramonet, M., Nakazawa, T., Metzl, N., Gillett, N., and Heimann, M.: Saturation of the Southern Ocean CO2 Sink Due to Recent Climate Change, 316, 1735-1738, https://doi.org/10.1126/science.1136188, 2007.

Le Quéré, C., Raupach, M. R., Canadell, J. G., Marland, G., Bopp, L., Ciais, P., Conway, T. J., Doney, S. C., Feely, R. A., Foster, P., Friedlingstein, P., Gurney, K., Houghton, R. A., House, J. I., Huntingford, C., Levy, P. E., Lomas, M. R., Majkut, J., Metzl, N., Ometto, J. P., Peters, G. P., Prentice, I. C., Randerson, J. T., Running, S. W., Sarmiento, J. L., Schuster, U., Sitch, S., Takahashi, T., Viovy, N., van der Werf, G. R., and Woodward, F. I.: Trends in the sources and sinks of carbon dioxide, Nature Geosci, 2, 831-836, https://doi.org/10.1038/ngeo689, 2009. Le Quéré, C., Andres, R. J., Boden, T., Conway, T., Houghton, R. A., House, J. I., Marland, G., 
Peters, G. P., van der Werf, G. R., Ahlström, A., Andrew, R. M., Bopp, L., Canadell, J. G., Ciais,

P., Doney, S. C., Enright, C., Friedlingstein, P., Huntingford, C., Jain, A. K., Jourdain, C., Kato,

E., Keeling, R. F., Klein Goldewijk, K., Levis, S., Levy, P., Lomas, M., Poulter, B., Raupach, M.

R., Schwinger, J., Sitch, S., Stocker, B. D., Viovy, N., Zaehle, S., and Zeng, N.: The global carbon budget 1959-2011, Earth Syst. Sci. Data, 5, 165-185, https://doi.org/10.5194/essd5-165-2013, 2013.

Le Quéré, C., Peters, G. P., Andres, R. J., Andrew, R. M., Boden, T. A., Ciais, P., Friedlingstein, P., Houghton, R. A., Marland, G., Moriarty, R., Sitch, S., Tans, P., Arneth, A., Arvanitis, A., Bakker, D. C. E., Bopp, L., Canadell, J. G., Chini, L. P., Doney, S. C., Harper, A., Harris, I., House, J. I., Jain, A. K., Jones, S. D., Kato, E., Keeling, R. F., Klein Goldewijk, K., Körtzinger, A., Koven, C., Lefèvre, N., Maignan, F., Omar, A., Ono, T., Park, G.-H., Pfeil, B., Poulter, B., Raupach, M. R., Regnier, P., Rödenbeck, C., Saito, S., Schwinger, J., Segschneider, J., Stocker, B. D., Takahashi, T., Tilbrook, B., van Heuven, S., Viovy, N., Wanninkhof, R., Wiltshire, A., and Zaehle, S.: Global carbon budget 2013, Earth Syst. Sci. Data, 6, 235-263, https://doi.org/10.5194/essd-6-235-2014, 2014. Le Quéré, C., Moriarty, R., Andrew, R. M., Peters, G. P., Ciais, P., Friedlingstein, P., Jones, S. D., Sitch, S., Tans, P., Arneth, A., Boden, T. A., Bopp, L., Bozec, Y., Canadell, J. G., Chini, L. P., Chevallier, F., Cosca, C. E., Harris, I., Hoppema, M., Houghton, R. A., House, J. I., Jain, A. K., Johannessen, T., Kato, E., Keeling, R. F., Kitidis, V., Klein Goldewijk, K., Koven, C., Landa, C. S., Landschützer, P., Lenton, A., Lima, I. D., Marland, G., Mathis, J. T., Metzl, N., Nojiri, Y., Olsen, A., Ono, T., Peng, S., Peters, W., Pfeil, B., Poulter, B., Raupach, M. R., Regnier, P., Rödenbeck, C., Saito, S., Salisbury, J. E., Schuster, U., Schwinger, J., Séférian, R., Segschneider, J., Steinhoff, T., Stocker, B. D., Sutton, A. J., Takahashi, T., Tilbrook, B., van der Werf, G. R., Viovy, N., Wang, Y.-P., Wanninkhof, R., Wiltshire, A., and Zeng, N.: Global carbon budget 2014, Earth Syst. Sci. Data, 7, 47-85, https://doi.org/10.5194/essd-7-47-2015, 2015a. Friedlingstein, P., Peters, G. P., Andres, R. J., Boden, T. A., Houghton, R. A., House, J. I., Keeling, R. F., Tans, P., Arneth, A., Bakker, D. C. E., Barbero, L., Bopp, L., Chang, J., Chevallier, F., Chini, L. P., Ciais, P., Fader, M., Feely, R. A., Gkritzalis, T., Harris, I., Hauck, J., Ilyina, T., 

van der Werf, G. R., van Heuven, S., Vandemark, D., Viovy, N., Wiltshire, A., Zaehle, S., and https://doi.org/10.5194/essd-7-349-2015, 2015b.

Le Quéré, C., Andrew, R. M., Canadell, J. G., Sitch, S., Korsbakken, J. I., Peters, G. P., D., Anthoni, P., Barbero, L., Bopp, L., Chevallier, F., Chini, L. P., Ciais, P., Currie, K., Delire, C., Doney, S. C., Friedlingstein, P., Gkritzalis, T., Harris, I., Hauck, J., Haverd, V., Hoppema, M., Klein Goldewijk, K., Jain, A. K., Kato, E., Körtzinger, A., Landschützer, P., Lefèvre, N., Lenton, A., Lienert, S., Lombardozzi, D., Melton, J. R., Metzl, N., Millero, F., Monteiro, P. M. S., Munro, D. R., Nabel, J. E. M. S., Nakaoka, S., O’Brien, K., Olsen, A., Omar, A. M., Ono, T., Pierrot, D., Poulter, B., Rödenbeck, C., Salisbury, J., Schuster, U., Schwinger, J., Séférian, R., Skjelvan, I., Stocker, B. D., Sutton, A. J., Takahashi, T., Tian, H., Tilbrook, B., van der LaanLuijkx, I. T., van der Werf, G. R., Viovy, N., Walker, A. P., Wiltshire, A. J., and Zaehle, S.: Global Carbon Budget 2016, Earth Syst. Sci. Data, 8, 605-649, https://doi.org/10.5194/essd8-605-2016, 2016.

Le Quéré, C., Andrew, R. M., Friedlingstein, P., Sitch, S., Pongratz, J., Manning, A. C., Korsbakken, J. I., Peters, G. P., Canadell, J. G., Jackson, R. B., Boden, T. A., Tans, P. P., Andrews, O. D., Arora, V. K., Bakker, D. C. E., Barbero, L., Becker, M., Betts, R. A., Bopp, L., Chevallier, F., Chini, L. P., Ciais, P., Cosca, C. E., Cross, J., Currie, K., Gasser, T., Harris, I., Hauck, J., Haverd, V., Houghton, R. A., Hunt, C. W., Hurtt, G., Ilyina, T., Jain, A. K., Kato, E., Kautz, M., Keeling, R. F., Klein Goldewijk, K., Körtzinger, A., Landschützer, P., Lefèvre, N., Lenton, A., Lienert, S., Lima, I., Lombardozzi, D., Metzl, N., Millero, F., Monteiro, P. M. S., Munro, D. R., Nabel, J. E. M. S., Nakaoka, S., Nojiri, Y., Padin, X. A., Peregon, A., Pfeil, B., Pierrot, D., Poulter, B., Rehder, G., Reimer, J., Rödenbeck, C., Schwinger, J., Séférian, R., Skjelvan, I., Stocker, B. D., Tian, H., Tilbrook, B., Tubiello, F. N., van der Laan-Luijkx, I. T., van der Werf, G. R., van Heuven, S., Viovy, N., Vuichard, N., Walker, A. P., Watson, A. J., 
2 Le Quéré, C., Andrew, R. M., Friedlingstein, P., Sitch, S., Hauck, J., Pongratz, J., Pickers, P. A.,

3 Korsbakken, J. I., Peters, G. P., Canadell, J. G., Arneth, A., Arora, V. K., Barbero, L., Bastos, A.,

4 Bopp, L., Chevallier, F., Chini, L. P., Ciais, P., Doney, S. C., Gkritzalis, T., Goll, D. S., Harris, I.,

5 Haverd, V., Hoffman, F. M., Hoppema, M., Houghton, R. A., Hurtt, G., Ilyina, T., Jain, A. K.,

6 Johannessen, T., Jones, C. D., Kato, E., Keeling, R. F., Goldewijk, K. K., Landschützer, P.,

7 Lefèvre, N., Lienert, S., Liu, Z., Lombardozzi, D., Metzl, N., Munro, D. R., Nabel, J. E. M. S.,

8 Nakaoka, S., Neill, C., Olsen, A., Ono, T., Patra, P., Peregon, A., Peters, W., Peylin, P., Pfeil, B.,

9 Pierrot, D., Poulter, B., Rehder, G., Resplandy, L., Robertson, E., Rocher, M., Rödenbeck, C.,

10 Schuster, U., Schwinger, J., Séférian, R., Skjelvan, I., Steinhoff, T., Sutton, A., Tans, P. P., Tian,

11 H., Tilbrook, B., Tubiello, F. N., van der Laan-Luijkx, I. T., van der Werf, G. R., Viovy, N.,

12 Walker, A. P., Wiltshire, A. J., Wright, R., Zaehle, S., and Zheng, B.: Global Carbon Budget

13 2018, Earth Syst. Sci. Data, 10, 2141-2194, https://doi.org/10.5194/essd-10-2141-2018,

$142018 b$.

15 Le Quéré, C., Korsbakken, J. I., Wilson, C., Tosun, J., Andrew, R., Andres, R. J., Canadell, J. G., 16 Jordan, A., Peters, G. P., and van Vuuren, D. P.: Drivers of declining CO2 emissions in 18

17 developed economies, Nat. Clim. Chang., 9, 213-217, https://doi.org/10.1038/s41558-019-

18 0419-7, 2019.

19 Le Quéré, C., Peters, G. P., Friedlingstein, P., Andrew, R. M., Canadell, J. G., Davis, S. J.,

20 Jackson, R. B., and Jones, M. W.: Fossil CO2 emissions in the post-COVID-19 era, Nat. Clim.

21 Chang., 11, 197-199, https://doi.org/10.1038/s41558-021-01001-0, 2021.

$22 \mathrm{Li}, \mathrm{H}$. and Ilyina, T.: Current and Future Decadal Trends in the Oceanic Carbon Uptake Are

23 Dominated by Internal Variability, Geophys. Res. Lett., 45, 916-925,

24 https://doi.org/10.1002/2017GL075370, 2018.

25 Li, W., Ciais, P., Peng, S., Yue, C., Wang, Y., Thurner, M., Saatchi, S. S., Arneth, A., Avitabile,

26 V., Carvalhais, N., Harper, A. B., Kato, E., Koven, C., Liu, Y. Y., Nabel, J. E. M. S., Pan, Y.,

27 Pongratz, J., Poulter, B., Pugh, T. A. M., Santoro, M., Sitch, S., Stocker, B. D., Viovy, N.,

28 Wiltshire, A., Yousefpour, R., and Zaehle, S.: Land-use and land-cover change carbon

29 emissions between 1901 and 2012 constrained by biomass observations, Biogeosciences, 
2 Liao, E., Resplandy, L., Liu, J., and Bowman, K. W.: Amplification of the Ocean Carbon Sink

3 During El Niños: Role of Poleward Ekman Transport and Influence on Atmospheric CO2, 34,

4 e2020GB006574, https://doi.org/10.1029/2020GB006574, 2020.

5 Lienert, S. and Joos, F.: A Bayesian ensemble data assimilation to constrain model

6 parameters and land-use carbon emissions, Biogeosciences, 15, 2909-2930,

7 https://doi.org/10.5194/bg-15-2909-2018, 2018.

8 Liu, J., Baskaran, L., Bowman, K., Schimel, D., Bloom, A. A., Parazoo, N. C., Oda, T., Carroll, D.,

9 Menemenlis, D., Joiner, J., Commane, R., Daube, B., Gatti, L. V., McKain, K., Miller, J.,

10 Stephens, B. B., Sweeney, C., and Wofsy, S.: Carbon Monitoring System Flux Net Biosphere

11 Exchange 2020 (CMS-Flux NBE 2020), 13, 299-330, https://doi.org/10.5194/essd-13-299-

$12 \quad 2021,2021$.

13 Liu, Z., Guan, D., Wei, W., Davis, S. J., Ciais, P., Bai, J., Peng, S., Zhang, Q., Hubacek, K.,

14 Marland, G., Andres, R. J., Crawford-Brown, D., Lin, J., Zhao, H., Hong, C., Boden, T. A., Feng,

15 K., Peters, G. P., Xi, F., Liu, J., Li, Y., Zhao, Y., Zeng, N., and He, K.: Reduced carbon emission

16 estimates from fossil fuel combustion and cement production in China, Nature, 524, 335-

17 338, https://doi.org/10.1038/nature14677, 2015.

18 Liu, Z., Ciais, P., Deng, Z., Davis, S. J., Zheng, B., Wang, Y., Cui, D., Zhu, B., Dou, X., Ke, P., Sun,

19 T., Guo, R., Zhong, H., Boucher, O., Bréon, F.-M., Lu, C., Guo, R., Xue, J., Boucher, E., Tanaka,

20 K., and Chevallier, F.: Carbon Monitor, a near-real-time daily dataset of global CO2 emission

21 from fossil fuel and cement production, Sci Data, 7, 392, https://doi.org/10.1038/s41597020-00708-7, 2020a.

23 Liu, Z., Ciais, P., Deng, Z., Lei, R., Davis, S. J., Feng, S., Zheng, B., Cui, D., Dou, X., Zhu, B., Guo, 24 R., Ke, P., Sun, T., Lu, C., He, P., Wang, Y., Yue, X., Wang, Y., Lei, Y., Zhou, H., Cai, Z., Wu, Y., 25 Guo, R., Han, T., Xue, J., Boucher, O., Boucher, E., Chevallier, F., Tanaka, K., Wei, Y., Zhong, 26 H., Kang, C., Zhang, N., Chen, B., Xi, F., Liu, M., Bréon, F.-M., Lu, Y., Zhang, Q., Guan, D., 27 Gong, P., Kammen, D. M., He, K., and Schellnhuber, H. J.: Near-real-time monitoring of 28 global CO2 emissions reveals the effects of the COVID-19 pandemic, Nat Commun, 11, 5172, https://doi.org/10.1038/s41467-020-18922-7, 2020b. 
1 Ma, L., Hurtt, G. C., Chini, L. P., Sahajpal, R., Pongratz, J., Frolking, S., Stehfest, E., Klein

2 Goldewijk, K., O'Leary, D., and Doelman, J. C.: Global rules for translating land-use change

3 (LUH2) to land-cover change for CMIP6 using GLM2, Geosci. Model Dev., 13, 3203-3220,

4 https://doi.org/10.5194/gmd-13-3203-2020, 2020.

5 Maki, T., Ikegami, M., Fujita, T., Hirahara, T., Yamada, K., Mori, K., Takeuchi, A., Tsutsumi, Y.,

6 Suda, K., and Conway, T. J.: New technique to analyse global distributions of CO2

7 concentrations and fluxes from non-processed observational data, 62, 797-809,

8 https://doi.org/10.1111/j.1600-0889.2010.00488.x, 2010.

9 MapBiomas: MapBiomas Collection 5, available at:

10 https://plataforma.brasil.mapbiomas.org/, last access: 21 October 2021, 2021.

11 Marland, G.: Uncertainties in Accounting for CO 2 From Fossil Fuels, 12, 136-139,

12 https://doi.org/10.1111/j.1530-9290.2008.00014.x, 2008.

13 Marland, G., Hamal, K., and Jonas, M.: How Uncertain Are Estimates of CO2 Emissions?, 13,

14 4-7, https://doi.org/10.1111/j.1530-9290.2009.00108.x, 2009.

15 Masarie, K. A. and Tans, P. P.: Extension and integration of atmospheric carbon dioxide data

16 into a globally consistent measurement record, J. Geophys. Res., 100, 11593,

17 https://doi.org/10.1029/95JD00859, 1995.

18 Mather, A.: The transition from deforestation to reforestation in Europe., 35-52, 2001.

19 Matricardi, E. A. T., Skole, D. L., Costa, O. B., Pedlowski, M. A., Samek, J. H., and Miguel, E. P.:

20 Long-term forest degradation surpasses deforestation in the Brazilian Amazon, 369, 1378-

21 1382, https://doi.org/10.1126/science.abb3021, 2020.

22 Mauritsen, T., Bader, J., Becker, T., Behrens, J., Bittner, M., Brokopf, R., Brovkin, V.,

23 Claussen, M., Crueger, T., Esch, M., Fast, I., Fiedler, S., Fläschner, D., Gayler, V., Giorgetta,

24 M., Goll, D. S., Haak, H., Hagemann, S., Hedemann, C., Hohenegger, C., Ilyina, T., Jahns, T.,

25 Jimenéz-de-la-Cuesta, D., Jungclaus, J., Kleinen, T., Kloster, S., Kracher, D., Kinne, S., Kleberg,

26 D., Lasslop, G., Kornblueh, L., Marotzke, J., Matei, D., Meraner, K., Mikolajewicz, U., Modali,

27 K., Möbis, B., Müller, W. A., Nabel, J. E. M. S., Nam, C. C. W., Notz, D., Nyawira, S.-S.,

28 Paulsen, H., Peters, K., Pincus, R., Pohlmann, H., Pongratz, J., Popp, M., Raddatz, T. J., Rast, 
1 S., Redler, R., Reick, C. H., Rohrschneider, T., Schemann, V., Schmidt, H., Schnur, R.,

2 Schulzweida, U., Six, K. D., Stein, L., Stemmler, I., Stevens, B., von Storch, J.-S., Tian, F., Voigt,

3 A., Vrese, P., Wieners, K.-H., Wilkenskjeld, S., Winkler, A., and Roeckner, E.: Developments in

4 the MPI-M Earth System Model version 1.2 (MPI-ESM1.2) and Its Response to Increasing

5 CO2, 11, 998-1038, https://doi.org/10.1029/2018MS001400, 2019.

6 McGrath, M. J., Luyssaert, S., Meyfroidt, P., Kaplan, J. O., Bürgi, M., Chen, Y., Erb, K., Gimmi,

7 U., McInerney, D., Naudts, K., Otto, J., Pasztor, F., Ryder, J., Schelhaas, M.-J., and Valade, A.:

8 Reconstructing European forest management from 1600 to 2010, 12, 4291-4316,

9 https://doi.org/10.5194/bg-12-4291-2015, 2015.

10 McKinley, G. A., Pilcher, D. J., Fay, A. R., Lindsay, K., Long, M. C., and Lovenduski, N. S.:

11 Timescales for detection of trends in the ocean carbon sink, Nature, 530, 469-472,

12 https://doi.org/10.1038/nature16958, 2016.

13 McKinley, G. A., Fay, A. R., Eddebbar, Y. A., Gloege, L., and Lovenduski, N. S.: External

14 Forcing Explains Recent Decadal Variability of the Ocean Carbon Sink, AGU Advances, 1, https://doi.org/10.1029/2019AV000149, 2020.

McNeil, B. I.: Anthropogenic CO2 Uptake by the Ocean Based on the Global

17 Chlorofluorocarbon Data Set, 299, 235-239, https://doi.org/10.1126/science.1077429, 2003.

Meiyappan, P., Jain, A. K., and House, J. I.: Increased influence of nitrogen limitation on CO 2 emissions from future land use and land use change, Global Biogeochem. Cycles, 29, 15241548, https://doi.org/10.1002/2015GB005086, 2015. L.: CLASSIC v1.0: the open-source community successor to the Canadian Land Surface Scheme (CLASS) and the Canadian Terrestrial Ecosystem Model (CTEM) - Part 1: Model framework and site-level performance, Geosci. Model Dev., 13, 2825-2850, https://doi.org/10.5194/gmd-13-2825-2020, 2020. 
1 1017, https://doi.org/10.1038/nature07949, 2009.

2 Mikaloff Fletcher, S. E., Gruber, N., Jacobson, A. R., Doney, S. C., Dutkiewicz, S., Gerber, M., 3 Follows, M., Joos, F., Lindsay, K., Menemenlis, D., Mouchet, A., Müller, S. A., and Sarmiento,

4 J. L.: Inverse estimates of anthropogenic $\mathrm{CO} 2$ uptake, transport, and storage by the ocean:

5 AIR-SEA EXCHANGE OF ANTHROPOGENIC CARBON, Global Biogeochem. Cycles, 20,

6 https://doi.org/10.1029/2005GB002530, 2006.

7 Myneni, R. B., Ramakrishna, R., Nemani, R., and Running, S. W.: Estimation of global leaf

8 area index and absorbed par using radiative transfer models, IEEE Trans. Geosci. Remote

9 Sensing, 35, 1380-1393, https://doi.org/10.1109/36.649788, 1997.

10 Naegler, T.: Reconciliation of excess 14C-constrained global CO2 piston velocity estimates,

11 61, 372-384, https://doi.org/10.1111/j.1600-0889.2008.00408.x, 2009.

12 Nakamura, T., Yamazaki, K., Iwamoto, K., Honda, M., Miyoshi, Y., Ogawa, Y., and Ukita, J.: A

13 negative phase shift of the winter AO/NAO due to the recent Arctic sea-ice reduction in late

14 autumn, 120, 3209-3227, https://doi.org/10.1002/2014JD022848, 2015.

15 Narayanan, B., Aguiar, A., and McDougall, R.: Global Trade, Assistance, and Production: The

16 GTAP 9 Data Base, Cent. Glob. Trade Anal. Purdue Univ., 2015 September, available at:

17 https:// www.gtap.agecon.purdue.edu/databases/v9/default.asp, last access: 25 October

$18 \quad 2021,2021$.

19 NBS: National Bureau of Statistics (NBS): National Data (online database), National Bureau

20 of Statistics, available at: http://data.stats.gov.cn/, last access: 25 October 2021, 2021.

21 NCEP: National Centers for Environmental Prediction. ONI Index. Cold \& Warm Episodes by

22 Season, available at:

23 https://origin.cpc.ncep.noaa.gov/products/analysis_monitoring/ensostuff/ONI_v5.php, last

24 access: 25 October 2021, 2021.

25 Nightingale, P. D., Liss, P. S., and Schlosser, P.: Measurements of air-sea gas transfer during

26 an open ocean algal bloom, 27, 2117-2120, https://doi.org/10.1029/2000GL011541, 2000.

27 Niwa, Y., Fujii, Y., Sawa, Y., lida, Y., Ito, A., Satoh, M., Imasu, R., Tsuboi, K., Matsueda, H., and 

inversion, Geosci. Model Dev., 10, 2201-2219, https://doi.org/10.5194/gmd-10-2201-2017,

42017.

5 Niwa, Y., Langenfelds, R., Krummel, P., Loh, Zoe, Worthy, Doug, Hatakka, Juha, Aalto, Tuula,

6 Ramonet, Michel, Delmotte, Marc, Schmidt, Martina, Gheusi, Francois, Mihalopoulos, N.,

7 Morgui, J.A., Andrews, Arlyn, Dlugokencky, Ed, Lee, John, Sweeney, Colm, Thoning, Kirk,

8 Tans, Pieter, De Wekker, Stephan, Fischer, Marc L., Jaffe, Dan, McKain, Kathryn, Viner, Brian,

9 Miller, John B., Karion, Anna, Miller, Charles, Sloop, Christopher D., Saito, Kazuyuki, Aoki,

10 Shuji, Morimoto, Shinji, Goto, Daisuke, Steinbacher, Martin, Myhre, Cathrine Lund,

11 Hermanssen, Ove, Stephens, Britton, Keeling, Ralph, Afshar, Sara, Paplawsky, Bill, Cox,

12 Adam, Walker, Stephen, Schuldt, Kenneth, Mukai, Hitoshi, Machida, Toshinobu, Sasakawa,

13 Motoki, Nomura, Shohei, Ito, Akihiko, lida, Yosuke, and Jones, Matthew W.: Long-term

14 global CO2 fluxes estimated by NICAM-based Inverse Simulation for Monitoring CO2 (NISMON-CO2) (ver.2020.1), https://doi.org/10.17595/20201127.001, 2020. Obermeier, W. A., Nabel, J. E. M. S., Loughran, T., Hartung, K., Bastos, A., Havermann, F.,

17 Anthoni, P., Arneth, A., Goll, D. S., Lienert, S., Lombardozzi, D., Luyssaert, S., McGuire, P. C.,

18 Melton, J. R., Poulter, B., Sitch, S., Sullivan, M. O., Tian, H., Walker, A. P., Wiltshire, A. J.,

19 Zaehle, S., and Pongratz, J.: Modelled land use and land cover change emissions - a spatiotemporal comparison of different approaches, 12, 635-670, https://doi.org/10.5194/esd12-635-2021, 2021.

O’Rourke, P. R., Smith, S. J., Mott, A., Ahsan, H., McDuffie, E. E., Crippa, M., Klimont, Z., McDonald, B., Wang, S., Nicholson, M. B., Feng, L., and Hoesly, R. M.: CEDS v_2021_04_21 Release Emission Data, https://doi.org/10.5281/zenodo.4741285, 2021. Dunne, J. P., Dutay, J.-C., Graven, H., Griffies, S. M., John, J. G., Joos, F., Levin, I., Lindsay, K., 
1 O'Sullivan, M., Zhang, Y., Bellouin, N., Harris, I., Mercado, L. M., Sitch, S., Ciais, P., and

2 Friedlingstein, P.: (under review) Aerosol-light interactions reduce the carbon budget

3 imbalance, Environmental Research Letters, 2021.

4 Palmer, P. I., Feng, L., Baker, D., Chevallier, F., Bösch, H., and Somkuti, P.: Net carbon

5 emissions from African biosphere dominate pan-tropical atmospheric $\mathrm{CO} 2$ signal, Nat

6 Commun, 10, 3344, https://doi.org/10.1038/s41467-019-11097-w, 2019.

7 Pan, Y., Birdsey, R. A., Fang, J., Houghton, R., Kauppi, P. E., Kurz, W. A., Phillips, O. L.,

8 Shvidenko, A., Lewis, S. L., Canadell, J. G., Ciais, P., Jackson, R. B., Pacala, S. W., McGuire, A.

9 D., Piao, S., Rautiainen, A., Sitch, S., and Hayes, D.: A Large and Persistent Carbon Sink in the

10 World's Forests, Science, 333, 988-993, https://doi.org/10.1126/science.1201609, 2011.

11 Patra, P. K., Takigawa, M., Watanabe, S., Chandra, N., Ishijima, K., and Yamashita, Y.:

12 Improved Chemical Tracer Simulation by MIROC4.0-based Atmospheric Chemistry-Transport

13 Model (MIROC4-ACTM), SOLA, 14, 91-96, https://doi.org/10.2151/sola.2018-016, 2018.

14 Pendrill, F., Persson, U. M., Godar, J., Kastner, T., Moran, D., Schmidt, S., and Wood, R.:

15 Agricultural and forestry trade drives large share of tropical deforestation emissions, Global

16 Environmental Change, 56, 1-10, https://doi.org/10.1016/j.gloenvcha.2019.03.002, 2019.

17 Peters, G. P., Andrew, R., and Lennox, J.: Constructing an environmentally-extended multi-

18 regional input-output table using the GTAP database, Economic Systems Research, 23, 131-

19 152, https://doi.org/10.1080/09535314.2011.563234, 2011a.

20 Peters, G. P., Minx, J. C., Weber, C. L., and Edenhofer, O.: Growth in emission transfers via

21 international trade from 1990 to 2008, Proceedings of the National Academy of Sciences,

22 108, 8903-8908, https://doi.org/10.1073/pnas.1006388108, 2011b.

23 Peters, G. P., Davis, S. J., and Andrew, R.: A synthesis of carbon in international trade,

24 Biogeosciences, 9, 3247-3276, https://doi.org/10.5194/bg-9-3247-2012, 2012a.

25 Peters, G. P., Marland, G., Le Quéré, C., Boden, T., Canadell, J. G., and Raupach, M. R.: Rapid

26 growth in CO2 emissions after the 2008-2009 global financial crisis, Nature Clim Change, 2,

27 2-4, https://doi.org/10.1038/nclimate1332, 2012b. 
Peters, G. P., Andrew, R. M., Boden, T., Canadell, J. G., Ciais, P., Le Quéré, C., Marland, G.,

2 Raupach, M. R., and Wilson, C.: The challenge to keep global warming below $2{ }^{\circ} \mathrm{C}$, Nature

Clim Change, 3, 4-6, https://doi.org/10.1038/nclimate1783, 2013.

Peters, G. P., Le Quéré, C., Andrew, R. M., Canadell, J. G., Friedlingstein, P., Ilyina, T.,

Peters, G. P., Andrew, R. M., Canadell, J. G., Friedlingstein, P., Jackson, R. B., Korsbakken, J. emerging climate policies, Nat. Clim. Chang., 10, 3-6, https://doi.org/10.1038/s41558-0190659-6, 2020.

Petrescu, A. M. R., Peters, G. P., Janssens-Maenhout, G., Ciais, P., Tubiello, F. N., Grassi, G., D., Solazzo, E., Kiesow, A., Bastos, A., Pongratz, J., Nabel, J. E. M. S., Conchedda, G., Pilli, R., Andrew, R. M., Schelhaas, M.-J., and Dolman, A. J.: European anthropogenic AFOLU greenhouse gas emissions: a review and benchmark data, Earth Syst. Sci. Data, 12, 9611001, https://doi.org/10.5194/essd-12-961-2020, 2020.

Pfeil, B., Olsen, A., Bakker, D. C. E., Hankin, S., Koyuk, H., Kozyr, A., Malczyk, J., Manke, A., Metzl, N., Sabine, C. L., Akl, J., Alin, S. R., Bates, N., Bellerby, R. G. J., Borges, A., Boutin, J., Brown, P. J., Cai, W.-J., Chavez, F. P., Chen, A., Cosca, C., Fassbender, A. J., Feely, R. A., González-Dávila, M., Goyet, C., Hales, B., Hardman-Mountford, N., Heinze, C., Hood, M., Hoppema, M., Hunt, C. W., Hydes, D., Ishii, M., Johannessen, T., Jones, S. D., Key, R. M., Körtzinger, A., Landschützer, P., Lauvset, S. K., Lefèvre, N., Lenton, A., Lourantou, A., Merlivat, L., Midorikawa, T., Mintrop, L., Miyazaki, C., Murata, A., Nakadate, A., Nakano, Y., Nakaoka, S., Nojiri, Y., Omar, A. M., Padin, X. A., Park, G.-H., Paterson, K., Perez, F. F., Pierrot, D., Poisson, A., Ríos, A. F., Santana-Casiano, J. M., Salisbury, J., Sarma, V. V. S. S., Schlitzer, R., Schneider, B., Schuster, U., Sieger, R., Skjelvan, I., Steinhoff, T., Suzuki, T., Takahashi, T., Tedesco, K., Telszewski, M., Thomas, H., Tilbrook, B., Tjiputra, J., Vandemark, D., Veness, T., Wanninkhof, R., Watson, A. J., Weiss, R., Wong, C. S., and Yoshikawa-Inoue, 
2 Piao, S., Ciais, P., Friedlingstein, P., de Noblet-Ducoudré, N., Cadule, P., Viovy, N., and Wang,

3 T.: Spatiotemporal patterns of terrestrial carbon cycle during the 20th century, 23,

4 https://doi.org/10.1029/2008GB003339, 2009.

5 Piao, S., Huang, M., Liu, Z., Wang, X., Ciais, P., Canadell, J. G., Wang, K., Bastos, A.,

6 Friedlingstein, P., Houghton, R. A., Le Quéré, C., Liu, Y., Myneni, R. B., Peng, S., Pongratz, J.,

7 Sitch, S., Yan, T., Wang, Y., Zhu, Z., Wu, D., and Wang, T.: Lower land-use emissions

8 responsible for increased net land carbon sink during the slow warming period, Nature

9 Geosci, 11, 739-743, https://doi.org/10.1038/s41561-018-0204-7, 2018.

10 Pongratz, J., Reick, C. H., Houghton, R. A., and House, J. I.: Terminology as a key uncertainty

11 in net land use and land cover change carbon flux estimates, Earth Syst. Dynam., 5, 177-

12 195, https://doi.org/10.5194/esd-5-177-2014, 2014.

13 Potapov, P., Hansen, M. C., Laestadius, L., Turubanova, S., Yaroshenko, A., Thies, C., Smith,

14 W., Zhuravleva, I., Komarova, A., Minnemeyer, S., and Esipova, E.: The last frontiers of

15 wilderness: Tracking loss of intact forest landscapes from 2000 to 2013, 3, e1600821,

16 https://doi.org/10.1126/sciadv.1600821, 2017.

17 Poulter, B., Frank, D. C., Hodson, E. L., and Zimmermann, N. E.: Impacts of land cover and

18 climate data selection on understanding terrestrial carbon dynamics and the $\mathrm{CO} 2$ airborne

19 fraction, Biogeosciences, 8, 2027-2036, https://doi.org/10.5194/bg-8-2027-2011, 2011.

20 Poulter, B., Freeborn, P. H., Jolly, W. M., and Varner, J. M.: COVID-19 lockdowns drive

21 decline in active fires in southeastern United States, PNAS, 118,

22 https://doi.org/10.1073/pnas.2105666118, 2021.

23 Prather, M.: Interactive comment on "Carbon dioxide and climate impulse response

24 functions for the computation of greenhouse gas metrics: a multi-model analysis" by F. Joos

25 et al., 6, 2012.

26 Prentice, I. C., Farquhar, G. D., Fasham, M. J. R., Goulden, M. L., Heimann, M., Jaramillo, V.

27 J., Kheshgi, H. S., Le Quéré, C., Scholes, R. J., and Wallace, D. W. R.: The Carbon Cycle and

28 Atmospheric Carbon Dioxide, in Climate Change 2001: The Scientific Basis. Contribution of 
1 Working Group I to the Third Assessment Report of the Intergovernmental Panel on Climate

2 Change, edited by: Houghton, J. T., Ding, Y., Griggs, D. J., Noguer, M., van der Linden, P. J.,

3 Dai, X., Maskell, K., and Johnson, C. A., Cambridge University Press, Cambridge, United

4 Kingdom and New York, NY, USA, 183-237, 2001.

5 Price, J. T. and Warren, R.: Literature Review of the Potential of "Blue Carbon" Activities to

6 Reduce Emissions, available at: https://avoid-net-uk.cc.ic.ac.uk/wp-

7 content/uploads/delightful-downloads/2016/03/Literature-review-of-the-potential-of-blue-

8 carbon-activities-to-reduce-emissions-AVOID2-WPE2.pdf, last access: 25 October 2021,

92016.

10 Qin, Y., Xiao, X., Wigneron, J.-P., Ciais, P., Brandt, M., Fan, L., Li, X., Crowell, S., Wu, X.,

11 Doughty, R., Zhang, Y., Liu, F., Sitch, S., and Moore, B.: Carbon loss from forest degradation

12 exceeds that from deforestation in the Brazilian Amazon, Nat. Clim. Chang., 11, 442-448, https://doi.org/10.1038/s41558-021-01026-5, 2021.

14 Qiu, C., Ciais, P., Zhu, D., Guenet, B., Peng, S., Petrescu, A. M. R., Lauerwald, R., Makowski,

15 D., Gallego-Sala, A. V., Charman, D. J., and Brewer, S. C.: Large historical carbon emissions from cultivated northern peatlands, 7, eabf1332, https://doi.org/10.1126/sciadv.abf1332, 2021.

Raupach, M. R., Marland, G., Ciais, P., Le Quere, C., Canadell, J. G., Klepper, G., and Field, C. B.: Global and regional drivers of accelerating $\mathrm{CO} 2$ emissions, Proceedings of the National Academy of Sciences, 104, 10288-10293, https://doi.org/10.1073/pnas.0700609104, 2007. Regnier, P., Friedlingstein, P., Ciais, P., Mackenzie, F. T., Gruber, N., Janssens, I. A., Laruelle, G. G., Lauerwald, R., Luyssaert, S., Andersson, A. J., Arndt, S., Arnosti, C., Borges, A. V., Dale, A. W., Gallego-Sala, A., Goddéris, Y., Goossens, N., Hartmann, J., Heinze, C., Ilyina, T., Joos, F., LaRowe, D. E., Leifeld, J., Meysman, F. J. R., Munhoven, G., Raymond, P. A., Spahni, R., Suntharalingam, P., and Thullner, M.: Anthropogenic perturbation of the carbon fluxes from land to ocean, Nature Geosci, 6, 597-607, https://doi.org/10.1038/ngeo1830, 2013.

27 Reick, C. H., Gayler, V., Goll, D., Hagemann, S., Heidkamp, M., Nabel, J. E. M. S., Raddatz, T., 28 Roeckner, E., Schnur, R., and Wilkenskjeld, S.: JSBACH 3 - The land component of the MPI Earth System Model: documentation of version 3.2, https://doi.org/10.17617/2.3279802, 
12021.

2 Remaud, M., Chevallier, F., Cozic, A., Lin, X., and Bousquet, P.: On the impact of recent

3 developments of the LMDz atmospheric general circulation model on the simulation of $\mathrm{CO} 2$

4 transport, 11, 4489, https://doi.org/10.5194/gmd-11-4489-2018, 2018.

5 Resplandy, L., Keeling, R. F., Rödenbeck, C., Stephens, B. B., Khatiwala, S., Rodgers, K. B.,

6 Long, M. C., Bopp, L., and Tans, P. P.: Revision of global carbon fluxes based on a

7 reassessment of oceanic and riverine carbon transport, Nature Geosci, 11, 504-509,

8 https://doi.org/10.1038/s41561-018-0151-3, 2018.

9 Rhein, M., Rintoul, S. R., Aoki, S., Campos, E., Chambers, D., Feely, R. A., Gulev, S., Johnson,

10 G. C., Josey, S. A., Kostianoy, A., Mauritzen, C., Roemmich, D., and Talley, L. D.:

11 Observations: Ocean, edited by: Stocker, T. F., Qin, D., Plattner, G.-K., Tignor, M., Allen, S. K.,

12 Boschung, J., Nauels, A., Xia, Y., Bex, V., and Midgley, P. M., Cambridge University Press,

$13255-316,2013$.

14 Rodenbeck, C., Houweling, S., Gloor, M., and Heimann, M.: CO2 flux history 1982-2001

15 inferred from atmospheric data using a global inversion of atmospheric transport, 46, 2003.

16 Rödenbeck, C., Keeling, R. F., Bakker, D. C. E., Metzl, N., Olsen, A., Sabine, C., and Heimann,

17 M.: Global surface-ocean pCO2 and sea-air $\mathrm{CO} 2$ flux variability from an observation-driven

18 ocean mixed-layer scheme, 9, 193-216, https://doi.org/10.5194/os-9-193-2013, 2013.

19 Rödenbeck, C., Bakker, D. C. E., Metzl, N., Olsen, A., Sabine, C., Cassar, N., Reum, F., Keeling,

20 R. F., and Heimann, M.: Interannual sea-air CO2 flux variability from an observation-driven

21 ocean mixed-layer scheme, 11, 4599-4613, https://doi.org/10.5194/bg-11-4599-2014,

222014.

23 Rödenbeck, C., Bakker, D. C. E., Gruber, N., lida, Y., Jacobson, A. R., Jones, S., Landschützer,

24 P., Metzl, N., Nakaoka, S., Olsen, A., Park, G.-H., Peylin, P., Rodgers, K. B., Sasse, T. P.,

25 Schuster, U., Shutler, J. D., Valsala, V., Wanninkhof, R., and Zeng, J.: Data-based estimates of

26 the ocean carbon sink variability - first results of the Surface Ocean CO2 Mapping

27 intercomparison (SOCOM), Biogeosciences, 12, 7251-7278, https://doi.org/10.5194/bg-12-

28 7251-2015, 2015. 
1 Rödenbeck, C., Zaehle, S., Keeling, R., and Heimann, M.: History of El Niño impacts on the

2 global carbon cycle 1957-2017: a quantification from atmospheric CO2 data, 373,

320170303, https://doi.org/10.1098/rstb.2017.0303, 2018.

4 Roobaert, A., Laruelle, G. G., Landschützer, P., and Regnier, P.: Uncertainty in the global

5 oceanic $\mathrm{CO} 2$ uptake induced by wind forcing: quantification and spatial analysis, 15, 1701-

6 1720, https://doi.org/10.5194/bg-15-1701-2018, 2018.

7 Rosan, T. M., Goldewijk, K. K., Ganzenmüller, R., O’Sullivan, M., Pongratz, J., Mercado, L. M.,

8 Aragao, L. E. O. C., Heinrich, V., Randow, C. V., Wiltshire, A., Tubiello, F. N., Bastos, A.,

9 Friedlingstein, P., and Sitch, S.: A multi-data assessment of land use and land cover

10 emissions from Brazil during 2000-2019, Environ. Res. Lett., 16, 074004,

11 https://doi.org/10.1088/1748-9326/ac08c3, 2021.

12 Rypdal, K., Paciornik, N., Eggleston, S., Goodwin, J., Irving, W., Penman, J., and Woodfield,

13 M.: Volume 1: Introduction to the 2006 Guidelines in: 2006 IPCC guidelines for national

14 greenhouse gas inventories., 2006.

15 Saatchi, S. S., Harris, N. L., Brown, S., Lefsky, M., Mitchard, E. T. A., Salas, W., Zutta, B. R.,

16 Buermann, W., Lewis, S. L., Hagen, S., Petrova, S., White, L., Silman, M., and Morel, A.:

17 Benchmark map of forest carbon stocks in tropical regions across three continents,

18 Proceedings of the National Academy of Sciences, 108, 9899-9904,

19 https://doi.org/10.1073/pnas.1019576108, 2011.

20 Sabine, C. L., Feely, R. A., Gruber, N., Key, R. M., Lee, K., Bullister, J. L., Wanninkhof, R.,

21 Wong, C. S., Wallace, D. W. R., Tilbrook, B., Millero, F. J., Peng, T.-H., Kozyr, A., Ono, T., and

22 Rios, A. F.: The Oceanic Sink for Anthropogenic CO2, 305, 367-371,

23 https://doi.org/10.1126/science.1097403, 2004.

24 Sarmiento, J. L., Orr, J. C., and Siegenthaler, U.: A perturbation simulation of CO2 uptake in

25 an ocean general circulation model, 97, 3621-3645, https://doi.org/10.1029/91JC02849,

261992.

27 Sato, M., Hansen, J. E., McCormick, M. P., and Pollack, J. B.: Stratospheric aerosol optical

28 depths, 1850-1990, 98, 22987-22994, https://doi.org/10.1029/93JD02553, 1993. 
Saunois, M., Stavert, A. R., Poulter, B., Bousquet, P., Canadell, J. G., Jackson, R. B., Raymond,

2 P. A., Dlugokencky, E. J., Houweling, S., Patra, P. K., Ciais, P., Arora, V. K., Bastviken, D.,

3 Bergamaschi, P., Blake, D. R., Brailsford, G., Bruhwiler, L., Carlson, K. M., Carrol, M., Castaldi,

4 S., Chandra, N., Crevoisier, C., Crill, P. M., Covey, K., Curry, C. L., Etiope, G., Frankenberg, C.,

5 Gedney, N., Hegglin, M. I., Höglund-Isaksson, L., Hugelius, G., Ishizawa, M., Ito, A., Janssens-

6 Maenhout, G., Jensen, K. M., Joos, F., Kleinen, T., Krummel, P. B., Langenfelds, R. L., Laruelle,

7 G. G., Liu, L., Machida, T., Maksyutov, S., McDonald, K. C., McNorton, J., Miller, P. A.,

8 Melton, J. R., Morino, I., Müller, J., Murguia-Flores, F., Naik, V., Niwa, Y., Noce, S., O’Doherty,

9 S., Parker, R. J., Peng, C., Peng, S., Peters, G. P., Prigent, C., Prinn, R., Ramonet, M., Regnier,

10 P., Riley, W. J., Rosentreter, J. A., Segers, A., Simpson, I. J., Shi, H., Smith, S. J., Steele, L. P.,

11 Thornton, B. F., Tian, H., Tohjima, Y., Tubiello, F. N., Tsuruta, A., Viovy, N., Voulgarakis, A.,

12 Weber, T. S., van Weele, M., van der Werf, G. R., Weiss, R. F., Worthy, D., Wunch, D., Yin, Y.,

13 Yoshida, Y., Zhang, W., Zhang, Z., Zhao, Y., Zheng, B., Zhu, Q., Zhu, Q., and Zhuang, Q.: The

14 Global Methane Budget 2000-2017, Earth Syst. Sci. Data, 12, 1561-1623,

https://doi.org/10.5194/essd-12-1561-2020, 2020.

Schimel, D., Alves, D., Enting, I. G., Heimann, M., Joos, F., Raynaud, D., Wigley, T., Prater, M., Derwent, R., Ehhalt, D., Fraser, P., Sanhueza, E., Zhou, X., Jonas, P., Charlson, R., Rodhe, H., Sadasivan, S., Shine, K. P., Fouquart, Y., Ramaswamy, V., Solomon, S., Srinivasan, J., Albritton, D., Derwent, R., Isaksen, I., Lal, M., and Wuebbles, D.: Radiative Forcing of Climate Change, in: Climate Change 1995 The Science of Climate Change, Contribution of Working Group I to the Second Assessment Report of the Intergovernmental Panel on Climate Change, edited by: Houghton, J. T., Meira Rilho, L. G., Callander, B. A., Harris, N., Kattenberg, A., and Maskell, K., Cambridge University Press, Cambridge, United Kingdom and New York, NY, USA, 1995.

Schimel, D., Stephens, B. B., and Fisher, J. B.: Effect of increasing CO 2 on the terrestrial carbon cycle, Proc Natl Acad Sci USA, 112, 436-441, https://doi.org/10.1073/pnas.1407302112, 2015.

Schourup-Kristensen, V., Sidorenko, D., Wolf-Gladrow, D. A., and Völker, C.: A skill assessment of the biogeochemical model REcoM2 coupled to the Finite Element Sea IceOcean Model (FESOM 1.3), Geosci. Model Dev., 7, 2769-2802, 
2 Schuh, A. E., Jacobson, A. R., Basu, S., Weir, B., Baker, D., Bowman, K., Chevallier, F., Crowell,

3 S., Davis, K. J., Deng, F., Denning, S., Feng, L., Jones, D., Liu, J., and Palmer, P. I.: Quantifying

4 the Impact of Atmospheric Transport Uncertainty on $\mathrm{CO} 2$ Surface Flux Estimates, Global

5 Biogeochem. Cycles, 33, 484-500, https://doi.org/10.1029/2018GB006086, 2019.

6 Schwinger, J., Goris, N., Tjiputra, J. F., Kriest, I., Bentsen, M., Bethke, I., llicak, M., Assmann,

7 K. M., and Heinze, C.: Evaluation of NorESM-OC (versions 1 and 1.2), the ocean carbon-cycle

8 stand-alone configuration ofthe Norwegian Earth System Model (NorESM1), Geosci. Model

9 Dev., 9, 2589-2622, https://doi.org/10.5194/gmd-9-2589-2016, 2016.

10 Séférian, R., Nabat, P., Michou, M., Saint-Martin, D., Voldoire, A., Colin, J., Decharme, B.,

11 Delire, C., Berthet, S., Chevallier, M., Sénési, S., Franchisteguy, L., Vial, J., Mallet, M.,

12 Joetzjer, E., Geoffroy, O., Guérémy, J.-F., Moine, M.-P., Msadek, R., Ribes, A., Rocher, M.,

13 Roehrig, R., Salas-y-Mélia, D., Sanchez, E., Terray, L., Valcke, S., Waldman, R., Aumont, O.,

14 Bopp, L., Deshayes, J., Éthé, C., and Madec, G.: Evaluation of CNRM Earth System Model,

15 CNRM-ESM2-1: Role of Earth System Processes in Present-Day and Future Climate, 11, 4182-4227, https://doi.org/10.1029/2019MS001791, 2019.

Sellar, A. A., Jones, C. G., Mulcahy, J. P., Tang, Y., Yool, A., Wiltshire, A., O'Connor, F. M., Stringer, M., Hill, R., Palmieri, J., Woodward, S., Mora, L., Kuhlbrodt, T., Rumbold, S. T., Kelley, D. I., Ellis, R., Johnson, C. E., Walton, J., Abraham, N. L., Andrews, M. B., Andrews, T., Archibald, A. T., Berthou, S., Burke, E., Blockley, E., Carslaw, K., Dalvi, M., Edwards, J., Folberth, G. A., Gedney, N., Griffiths, P. T., Harper, A. B., Hendry, M. A., Hewitt, A. J., Johnson, B., Jones, A., Jones, C. D., Keeble, J., Liddicoat, S., Morgenstern, O., Parker, R. J., Predoi, V., Robertson, E., Siahaan, A., Smith, R. S., Swaminathan, R., Woodhouse, M. T.,

24 Zeng, G., and Zerroukat, M.: UKESM1: Description and Evaluation of the U.K. Earth System Model, J. Adv. Model. Earth Syst., 11, 4513-4558, https://doi.org/10.1029/2019MS001739, 2019.

27 Shu, S., Jain, A. K., Koven, C. D., and Mishra, U.: Estimation of Permafrost SOC Stock and

28 Turnover Time Using a Land Surface Model With Vertical Heterogeneity of Permafrost Soils, 34, e2020GB006585, https://doi.org/10.1029/2020GB006585, 2020. 
1 Silva Junior, C. H. L., Pessôa, A. C. M., Carvalho, N. S., Reis, J. B. C., Anderson, L. O., and

2 Aragão, L. E. O. C.: The Brazilian Amazon deforestation rate in 2020 is the greatest of the

3 decade, Nat Ecol Evol, 5, 144-145, https://doi.org/10.1038/s41559-020-01368-x, 2021.

4 Sitch, S., Huntingford, C., Gedney, N., Levy, P. E., Lomas, M., Piao, S. L., Betts, R., Ciais, P.,

5 Cox, P., Friedlingstein, P., Jones, C. D., Prentice, I. C., and Woodward, F. I.: Evaluation of the

6 terrestrial carbon cycle, future plant geography and climate-carbon cycle feedbacks using

7 five Dynamic Global Vegetation Models (DGVMs): Uncertainty In Land Carbon Cycle

8 Feedbacks, 14, 2015-2039, https://doi.org/10.1111/j.1365-2486.2008.01626.x, 2008.

9 Smith, B., Wårlind, D., Arneth, A., Hickler, T., Leadley, P., Siltberg, J., and Zaehle, S.:

10 Implications of incorporating $\mathrm{N}$ cycling and $\mathrm{N}$ limitations on primary production in an

11 individual-based dynamic vegetation model, Biogeosciences, 11, 2027-2054,

12 https://doi.org/10.5194/bg-11-2027-2014, 2014.

13 Stephens, B. B., Gurney, K. R., Tans, P. P., Sweeney, C., Peters, W., Bruhwiler, L., Ciais, P.,

14 Ramonet, M., Bousquet, P., Nakazawa, T., Aoki, S., Machida, T., Inoue, G., Vinnichenko, N.,

15 Lloyd, J., Jordan, A., Heimann, M., Shibistova, O., Langenfelds, R. L., Steele, L. P., Francey, R.

16 J., and Denning, A. S.: Weak Northern and Strong Tropical Land Carbon Uptake from Vertical

17 Profiles of Atmospheric CO2, Science, 316, 1732-1735,

18 https://doi.org/10.1126/science.1137004, 2007.

19 Stocker, T., Qin, D., and Platner, G.-K.: Climate Change 2013: The Physical Science Basis.

20 Contribution of Working Group I to the Fifth Assessment Report of the Intergovernmental

21 Panel on Climate Change, edited by: Intergovernmental Panel on Climate Change,

22 Cambridge University Press, Cambridge, 2013.

23 Sweeney, C., Gloor, E., Jacobson, A. R., Key, R. M., McKinley, G., Sarmiento, J. L., and

24 Wanninkhof, R.: Constraining global air-sea gas exchange for CO2 with recent bomb 14C

25 measurements, 21, https://doi.org/10.1029/2006GB002784, 2007.

26 SX Coal: Monthly coal consumption estimates, available at: http://www.sxcoal.com/, last

27 access: 25 October 2021, 2021.

28 Takahashi, T., Sutherland, S. C., Wanninkhof, R., Sweeney, C., Feely, R. A., Chipman, D. W., 
1 Hales, B., Friederich, G., Chavez, F., Sabine, C., Watson, A., Bakker, D. C. E., Schuster, U.,

2 Metzl, N., Yoshikawa-Inoue, H., Ishii, M., Midorikawa, T., Nojiri, Y., Körtzinger, A., Steinhoff,

3 T., Hoppema, M., Olafsson, J., Arnarson, T. S., Tilbrook, B., Johannessen, T., Olsen, A.,

4 Bellerby, R., Wong, C. S., Delille, B., Bates, N. R., and de Baar, H. J. W.: Climatological mean

5 and decadal change in surface ocean pCO2, and net sea-air $\mathrm{CO} 2$ flux over the global oceans,

6 Deep Sea Research Part II: Topical Studies in Oceanography, 56, 554-577,

7 https://doi.org/10.1016/j.dsr2.2008.12.009, 2009.

8 Thomason, L. W., Ernest, N., Millán, L., Rieger, L., Bourassa, A., Vernier, J.-P., Manney, G.,

9 Luo, B., Arfeuille, F., and Peter, T.: A global space-based stratospheric aerosol climatology: 1979-2016, 10, 469-492, https://doi.org/10.5194/essd-10-469-2018, 2018.

11 Tian, H., Xu, X., Lu, C., Liu, M., Ren, W., Chen, G., Melillo, J., and Liu, J.: Net exchanges of

$12 \mathrm{CO} 2, \mathrm{CH} 4$, and $\mathrm{N} 2 \mathrm{O}$ between China's terrestrial ecosystems and the atmosphere and their contributions to global climate warming, 116, https://doi.org/10.1029/2010JG001393, 2011.

14 Tian, H., Chen, G., Lu, C., Xu, X., Hayes, D. J., Ren, W., Pan, S., Huntzinger, D. N., and Wofsy,

15 S. C.: North American terrestrial $\mathrm{CO} 2$ uptake largely offset by $\mathrm{CH} 4$ and N2O emissions: toward a full accounting of the greenhouse gas budget, Climatic Change, 129, 413-426, https://doi.org/10.1007/s10584-014-1072-9, 2015. Todd-Brown, K. E. O., Randerson, J. T., Post, W. M., Hoffman, F. M., Tarnocai, C., Schuur, E. A. G., and Allison, S. D.: Causes of variation in soil carbon simulations from CMIP5 Earth system models and comparison with observations, Biogeosciences, 10, 1717-1736, https://doi.org/10.5194/bg-10-1717-2013, 2013. Tohjima, Y., Mukai, H., Machida, T., Hoshina, Y., and Nakaoka, S.-I.: Global carbon budgets estimated from atmospheric $02 / \mathrm{N} 2$ and $\mathrm{CO} 2$ observations in the western Pacific region over a 15-year period, 19, 9269-9285, https://doi.org/10.5194/acp-19-9269-2019, 2019.

25 Tubiello, F. N., Conchedda, G., Wanner, N., Federici, S., Rossi, S., and Grassi, G.: Carbon

26 emissions and removals from forests: new estimates, 1990-2020, 13, 1681-1691,

27 https://doi.org/10.5194/essd-13-1681-2021, 2021. 
1 available at: http://unstats.un.org/unsd/ snaama/Introduction.asp, last access: 25 October

$22021,2021$.

3 UNFCCC: National Inventory Submissions, available at: https://unfccc.int/ghg-inventories-

4 annex-i-parties/2021, last access: 25 October 2021., 2021a.

5 UNFCCC: Nationally determined contributions under the Paris Agreement. Synthesis report

6 by the secretariat, available at: https://unfccc.int/documents/306848, last access: 25

7 October 2021, 2021b.

8 Vale, M. M., Berenguer, E., Argollo de Menezes, M., Viveiros de Castro, E. B., Pugliese de

9 Siqueira, L., and Portela, R. de C. Q.: The COVID-19 pandemic as an opportunity to weaken

10 environmental protection in Brazil, Biological Conservation, 255, 108994,

11 https://doi.org/10.1016/j.biocon.2021.108994, 2021.

12 van der Laan-Luijkx, I. T., van der Velde, I. R., van der Veen, E., Tsuruta, A., Stanislawska, K., 13 Babenhauserheide, A., Zhang, H. F., Liu, Y., He, W., Chen, H., Masarie, K. A., Krol, M. C., and

14 Peters, W.: The CarbonTracker Data Assimilation Shell (CTDAS) v1.0: implementation and

15 global carbon balance 2001-2015, Geosci. Model Dev., 10, 2785-2800,

16 https://doi.org/10.5194/gmd-10-2785-2017, 2017.

17 van der Velde, I. R., Miller, J. B., Schaefer, K., van der Werf, G. R., Krol, M. C., and Peters, W.:

18 Terrestrial cycling of $13 \mathrm{CO} 2$ by photosynthesis, respiration, and biomass burning in SiBCASA,

19 11, 6553-6571, https://doi.org/10.5194/bg-11-6553-2014, 2014.

20 van der Velde, I. R., van der Werf, G. R., Houweling, S., Maasakkers, J. D., Borsdorff, T.,

21 Landgraf, J., Tol, P., van Kempen, T. A., van Hees, R., Hoogeveen, R., Veefkind, J. P., and

22 Aben, I.: Vast CO2 release from Australian fires in 2019-2020 constrained by satellite, 597,

23 366-369, https://doi.org/10.1038/s41586-021-03712-y, 2021.

24 van der Werf, G. R., Randerson, J. T., Giglio, L., Collatz, G. J., Mu, M., Kasibhatla, P. S.,

25 Morton, D. C., DeFries, R. S., Jin, Y., and van Leeuwen, T. T.: Global fire emissions and the

26 contribution of deforestation, savanna, forest, agricultural, and peat fires (1997-2009),

27 Atmos. Chem. Phys., 10, 11707-11735, https://doi.org/10.5194/acp-10-11707-2010, 2010.

28 van der Werf, G. R., Randerson, J. T., Giglio, L., van Leeuwen, T. T., Chen, Y., Rogers, B. M., 
Mu, M., van Marle, M. J. E., Morton, D. C., Collatz, G. J., Yokelson, R. J., and Kasibhatla, P. S.:

2 Global fire emissions estimates during 1997-2016, Earth Syst. Sci. Data, 9, 697-720,

3 https://doi.org/10.5194/essd-9-697-2017, 2017.

4 Viovy, N.: CRUNCEP data set, available at:

5 ftp://nacp.ornl.gov/synthesis/2009/frescati/temp/land_use_change/original/readme.htm,

6 last access: 25 October 2021, 2016.

7 Vuichard, N., Messina, P., Luyssaert, S., Guenet, B., Zaehle, S., Ghattas, J., Bastrikov, V., and

8 Peylin, P.: Accounting for carbon and nitrogen interactions in the global terrestrial

9 ecosystem model ORCHIDEE (trunk version, rev 4999): multi-scale evaluation of gross

10 primary production, Geosci. Model Dev., 12, 4751-4779, https://doi.org/10.5194/gmd-12-

11 4751-2019, 2019.

12 Walker, A. P., Quaife, T., Bodegom, P. M., De Kauwe, M. G., Keenan, T. F., Joiner, J., Lomas,

13 M. R., MacBean, N., Xu, C., Yang, X., and Woodward, F. I.: The impact of alternative trait-

14 scaling hypotheses for the maximum photosynthetic carboxylation rate ( $\mathrm{V} \mathrm{cmax}$ ) on global

15 gross primary production, New Phytol, 215, 1370-1386, https://doi.org/10.1111/nph.14623, 2017.

Walker, A. P., De Kauwe, M. G., Bastos, A., Belmecheri, S., Georgiou, K., Keeling, R. F., McMahon, S. M., Medlyn, B. E., Moore, D. J. P., Norby, R. J., Zaehle, S., Anderson-Teixeira, K. J., Battipaglia, G., Brienen, R. J. W., Cabugao, K. G., Cailleret, M., Campbell, E., Canadell, J. G.,

20 Ciais, P., Craig, M. E., Ellsworth, D. S., Farquhar, G. D., Fatichi, S., Fisher, J. B., Frank, D. C.,

21 Graven, H., Gu, L., Haverd, V., Heilman, K., Heimann, M., Hungate, B. A., Iversen, C. M., Joos,

22 F., Jiang, M., Keenan, T. F., Knauer, J., Körner, C., Leshyk, V. O., Leuzinger, S., Liu, Y.,

23 MacBean, N., Malhi, Y., McVicar, T. R., Penuelas, J., Pongratz, J., Powell, A. S., Riutta, T.,

24 Sabot, M. E. B., Schleucher, J., Sitch, S., Smith, W. K., Sulman, B., Taylor, B., Terrer, C., Torn,

25 M. S., Treseder, K. K., Trugman, A. T., Trumbore, S. E., van Mantgem, P. J., Voelker, S. L., Whelan, M. E., and Zuidema, P. A.: Integrating the evidence for a terrestrial carbon sink caused by increasing atmospheric CO2, 229, 2413-2445, https://doi.org/10.1111/nph.16866, 2021.

Wanninkhof, R.: Relationship between wind speed and gas exchange over the ocean, 97, 
2 Wanninkhof, R.: Relationship between wind speed and gas exchange over the ocean

3 revisited, 12, 351-362, https://doi.org/10.4319/lom.2014.12.351, 2014.

4 Wanninkhof, R., Park, G.-H., Takahashi, T., Sweeney, C., Feely, R., Nojiri, Y., Gruber, N.,

5 Doney, S. C., McKinley, G. A., Lenton, A., Le Quéré, C., Heinze, C., Schwinger, J., Graven, H.,

6 and Khatiwala, S.: Global ocean carbon uptake: magnitude, variability and trends,

7 Biogeosciences, 10, 1983-2000, https://doi.org/10.5194/bg-10-1983-2013, 2013.

8 Watson, A. J., Schuster, U., Shutler, J. D., Holding, T., Ashton, I. G. C., Landschützer, P.,

9 Woolf, D. K., and Goddijn-Murphy, L.: Revised estimates of ocean-atmosphere $\mathrm{CO} 2$ flux are

10 consistent with ocean carbon inventory, Nat Commun, 11, 4422,

11 https://doi.org/10.1038/s41467-020-18203-3, 2020.

12 Watson, R. T., Rohde, H., Oeschger, H., and Siegenthaler, U.: Greenhouse Gases and

13 Aerosols, in: Climate Change: The IPCC Scientific Assessment. Intergovernmental Panel on

14 Climate Change (IPCC), edited by: Houghton, J. T., Jenkins, G. J., and Ephraums, J. J.,

15 Cambridge University Press, Cambridge, 140, 1990.

16 Weiss, R. F. and Price, B. A.: Nitrous oxide solubility in water and seawater, Marine

17 Chemistry, 8, 347-359, https://doi.org/10.1016/0304-4203(80)90024-9, 1980.

18 Wenzel, S., Cox, P. M., Eyring, V., and Friedlingstein, P.: Projected land photosynthesis

19 constrained by changes in the seasonal cycle of atmospheric CO2, Nature, 538, 499-501,

20 https://doi.org/10.1038/nature19772, 2016.

21 Wilkenskjeld, S., Kloster, S., Pongratz, J., Raddatz, T., and Reick, C. H.: Comparing the

22 influence of net and gross anthropogenic land-use and land-cover changes on the carbon

23 cycle in the MPI-ESM, Biogeosciences, 11, 4817-4828, https://doi.org/10.5194/bg-11-4817-

$242014,2014$.

25 Wiltshire, A. J., Burke, E. J., Chadburn, S. E., Jones, C. D., Cox, P. M., Davies-Barnard, T.,

26 Friedlingstein, P., Harper, A. B., Liddicoat, S., Sitch, S., and Zaehle, S.: JULES-CN: a coupled

27 terrestrial carbon-nitrogen scheme (JULES vn5.1), 14, 2161-2186,

28 https://doi.org/10.5194/gmd-14-2161-2021, 2021. 
1 Woodward, F. I. and Lomas, M. R.: Vegetation dynamics - simulating responses to climatic

2 change, Biol. Rev., 79, 643-670, https://doi.org/10.1017/S1464793103006419, 2004.

3 Wright, R. M., Le Quéré, C., Buitenhuis, E., Pitois, S., and Gibbons, M. J.: Role of jellyfish in

4 the plankton ecosystem revealed using a global ocean biogeochemical model, 18, 1291-

5 1320, https://doi.org/10.5194/bg-18-1291-2021, 2021.

6 Xi, F., Davis, S. J., Ciais, P., Crawford-Brown, D., Guan, D., Pade, C., Shi, T., Syddall, M., Lv, J., 7 Ji, L., Bing, L., Wang, J., Wei, W., Yang, K.-H., Lagerblad, B., Galan, I., Andrade, C., Zhang, Y.,

8 and Liu, Z.: Substantial global carbon uptake by cement carbonation, Nature Geosci, 9, 880-

9 883, https://doi.org/10.1038/ngeo2840, 2016.

10 Xia, J., Chen, Y., Liang, S., Liu, D., and Yuan, W.: Global simulations of carbon allocation

11 coefficients for deciduous vegetation types, 67, 28016,

12 https://doi.org/10.3402/tellusb.v67.28016, 2015.

13 Yin, X.: Responses of leaf nitrogen concentration and specific leaf area to atmospheric $\mathrm{CO} 2$

14 enrichment: a retrospective synthesis across 62 species: Leaf response to atmospheric co 2

15 enrichment, 8, 631-642, https://doi.org/10.1046/j.1365-2486.2002.00497.x, 2002.

16 Yuan, W., Liu, D., Dong, W., Liu, S., Zhou, G., Yu, G., Zhao, T., Feng, J., Ma, Z., Chen, J., Chen,

17 Y., Chen, S., Han, S., Huang, J., Li, L., Liu, H., Liu, S., Ma, M., Wang, Y., Xia, J., Xu, W., Zhang,

18 Q., Zhao, X., and Zhao, L.: Multiyear precipitation reduction strongly decreases carbon

19 uptake over northern China, 119, 881-896, https://doi.org/10.1002/2014JG002608, 2014.

20 Yue, C., Ciais, P., Luyssaert, S., Li, W., McGrath, M. J., Chang, J., and Peng, S.: Representing

21 anthropogenic gross land use change, wood harvest, and forest age dynamics in a global

22 vegetation model ORCHIDEE-MICT v8.4.2, 11, 409-428, https://doi.org/10.5194/gmd-11-

23 409-2018, 2018.

24 Yue, X. and Unger, N.: The Yale Interactive terrestrial Biosphere model version 1.0:

25 description, evaluation and implementation into NASA GISS ModelE2, Geosci. Model Dev., 8,

26 2399-2417, https://doi.org/10.5194/gmd-8-2399-2015, 2015.

27 Zaehle, S. and Friend, A. D.: Carbon and nitrogen cycle dynamics in the O-CN land surface

28 model: 1. Model description, site-scale evaluation, and sensitivity to parameter estimates: 
1 Site-scale evaluation of a C-N model, Global Biogeochem. Cycles, 24,

2 https://doi.org/10.1029/2009GB003521, 2010.

3 Zaehle, S., Ciais, P., Friend, A. D., and Prieur, V.: Carbon benefits of anthropogenic reactive

4 nitrogen offset by nitrous oxide emissions, Nature Geosci, 4, 601-605,

5 https://doi.org/10.1038/ngeo1207, 2011.

6 Zeng, J., Nojiri, Y., Landschützer, P., Telszewski, M., and Nakaoka, S.: A Global Surface Ocean

7 fCO2 Climatology Based on a Feed-Forward Neural Network, 31, 1838-1849,

8 https://doi.org/10.1175/JTECH-D-13-00137.1, 2014.

9 Zheng, B., Chevallier, F., Yin, Y., Ciais, P., Fortems-Cheiney, A., Deeter, M. N., Parker, R. J.,

10 Wang, Y., Worden, H. M., and Zhao, Y.: Global atmospheric carbon monoxide budget 2000-

112017 inferred from multi-species atmospheric inversions, 26, 2019.

12 Zheng, B., Ciais, P., Chevallier, F., Chuvieco, E., Chen, Y., and Yang, H.: Increasing forest fire

13 emissions despite the decline in global burned area, 7, eabh2646,

14 https://doi.org/10.1126/sciadv.abh2646, 2021.

15 Zscheischler, J., Mahecha, M. D., Avitabile, V., Calle, L., Carvalhais, N., Ciais, P., Gans, F.,

16 Gruber, N., Hartmann, J., Herold, M., Ichii, K., Jung, M., Landschützer, P., Laruelle, G. G.,

17 Lauerwald, R., Papale, D., Peylin, P., Poulter, B., Ray, D., Regnier, P., Rödenbeck, C., Roman-

18 Cuesta, R. M., Schwalm, C., Tramontana, G., Tyukavina, A., Valentini, R., van der Werf, G.,

19 West, T. O., Wolf, J. E., and Reichstein, M.: Reviews and syntheses: An empirical

20 spatiotemporal description of the global surface-atmosphere carbon fluxes: opportunities

21 and data limitations, Biogeosciences, 14, 3685-3703, https://doi.org/10.5194/bg-14-3685-

$22 \quad 2017,2017$. 
https://doi.org/10.5194/essd-2021-386

Preprint. Discussion started: 4 November 2021

(c) Author(s) 2021. CC BY 4.0 License.

\section{Tables}

\begin{tabular}{|l|l|l|l|}
\hline \multicolumn{3}{|c|}{ Table 1. Factors used to convert carbon in various units (by convention, Unit 1 = Unit $2 \times$ conversion). } \\
\hline Unit 1 & Unit 2 & Conversion & Source \\
\hline $\begin{array}{l}\text { GtC (gigatonnes of } \\
\text { carbon) }\end{array}$ & ppm (parts per million) (a) & 2.124 (b) & 1 SI unit conversion \\
\hline $\begin{array}{l}\text { GtC (gigatonnes of } \\
\text { carbon) }\end{array}$ & PgC (petagrams of carbon) & 3.664 & $\begin{array}{l}44.01 / 12.011 \text { in mass } \\
\text { equivalent }\end{array}$ \\
\hline $\begin{array}{l}\text { GtCO2 (gigatonnes of } \\
\text { carbon dioxide) }\end{array}$ & $\begin{array}{l}\text { GtC (gigatonnes of } \\
\text { carbon) }\end{array}$ & 1000 & Sl unit conversion \\
\hline $\begin{array}{l}\text { GtC (gigatonnes of } \\
\text { carbon) }\end{array}$ & $\begin{array}{l}\text { MtC (megatonnes of } \\
\text { carbon) }\end{array}$ & $2012)$ \\
\hline
\end{tabular}

(a) Measurements of atmospheric $\mathrm{CO} 2$ concentration have units of dry-air mole fraction. 'ppm' is an abbreviation for micromole/mol, dry air.

(b) The use of a factor of 2.124 assumes that all the atmosphere is well mixed within one year. In reality, only the troposphere is well mixed and the growth rate of $\mathrm{CO} 2$ concentration in the less well-mixed stratosphere is not measured by sites from the NOAA network. Using a factor of 2.124 makes the approximation that the growth rate of $\mathrm{CO} 2$ concentration in the stratosphere equals that of the troposphere on a yearly basis. 
1

\begin{tabular}{l|l|}
$\begin{array}{l}\text { Table 2. How to cite the individual } \\
\text { components of the global carbon budget } \\
\text { presented here. }\end{array}$ & \\
\hline Component & Primary reference \\
\hline $\begin{array}{l}\text { Global fossil CO2 emissions (EFOS), total and by fuel } \\
\text { type }\end{array}$ & Andrew and Peters (2021) \\
\hline National territorial fossil CO2 emissions (EFOS) & Gilfillan and Marland (2021), UNFCCC (2021a) \\
\hline $\begin{array}{l}\text { National consumption-based fossil CO2 emissions } \\
\text { (EFOS) by country (consumption) }\end{array}$ & $\begin{array}{l}\text { Peters et al. (2011b) updated as described in this } \\
\text { paper }\end{array}$ \\
\hline Net land-use change flux (ELUC) & $\begin{array}{l}\text { This paper (see Table 4 for individual model } \\
\text { references). }\end{array}$ \\
\hline $\begin{array}{l}\text { Growth rate in atmospheric CO2 concentration } \\
\text { (GATM) }\end{array}$ & Dlugokencky and Tans (2021) \\
\hline Ocean and land CO2 sinks (SOCEAN and SLAND) & $\begin{array}{l}\text { This paper (see Table } 4 \text { for individual model } \\
\text { references). }\end{array}$ \\
\hline
\end{tabular}


https://doi.org/10.5194/essd-2021-386

Preprint. Discussion started: 4 November 2021

(c) Author(s) 2021. CC BY 4.0 License.

Table 3. Main methodological changes in the global carbon budget since 2017. Methodological changes introduced in one year are kept for the following years unless noted. Empty cells mean there were no methodological changes introduced that year. Table A7 lists methodological changes from the first global carbon budget publication up to 2016.

\begin{tabular}{|c|c|c|c|c|c|c|c|}
\hline \multirow{2}{*}{$\begin{array}{c}\text { Publication } \\
\text { year }\end{array}$} & \multicolumn{2}{|c|}{ Fossil fuel emissions } & \multirow[t]{2}{*}{ LUC emissions } & \multicolumn{3}{|c|}{ Reservoirs } & \multirow[t]{2}{*}{$\begin{array}{l}\text { Uncertainty \& } \\
\text { other changes }\end{array}$} \\
\hline & Global & $\begin{array}{l}\text { Country } \\
\text { (territorial) }\end{array}$ & & Atmosphere & Ocean & Land & \\
\hline $\begin{array}{l}\text { Le Quéré et al. } \\
\text { (2018a) } \\
\text { GCB2017 }\end{array}$ & $\begin{array}{l}\text { Projection } \\
\text { includes India- } \\
\text { specific data }\end{array}$ & & $\begin{array}{c}\text { Average of two } \\
\text { bookkeeping } \\
\text { models; use of } \\
12 \text { DGVMs }\end{array}$ & & $\begin{array}{c}\text { Based on eight } \\
\text { models that } \\
\text { match the } \\
\text { observed sink } \\
\text { for the 1990s; } \\
\text { no longer } \\
\text { normalised }\end{array}$ & $\begin{array}{c}\text { Based on } 15 \\
\text { models that } \\
\text { meet } \\
\text { observation- } \\
\text { based criteria } \\
\text { (see Sect. 2.5) }\end{array}$ & $\begin{array}{l}\text { Land multi- } \\
\text { model average } \\
\text { now used in } \\
\text { main carbon } \\
\text { budget, with } \\
\text { the carbon } \\
\text { imbalance } \\
\text { presented } \\
\text { separately; } \\
\text { new table of } \\
\text { key } \\
\text { uncertainties }\end{array}$ \\
\hline $\begin{array}{l}\text { Le Quéré et al. } \\
\text { (2018b) } \\
\text { GCB2018 }\end{array}$ & $\begin{array}{l}\text { Revision in } \\
\text { cement } \\
\text { emissions; } \\
\text { Projection } \\
\text { includes EU- } \\
\text { specific data }\end{array}$ & $\begin{array}{l}\text { Aggregation of } \\
\text { overseas } \\
\text { territories into } \\
\text { governing } \\
\text { nations for } \\
\text { total of } 213 \\
\text { countries a }\end{array}$ & $\begin{array}{c}\text { Average of two } \\
\text { bookkeeping } \\
\text { models; use of } \\
16 \text { DGVMs }\end{array}$ & $\begin{array}{l}\text { Use of four } \\
\text { atmospheric } \\
\text { inversions }\end{array}$ & $\begin{array}{c}\text { Based on } \\
\text { seven models }\end{array}$ & $\begin{array}{l}\text { Based on } 16 \\
\text { models; } \\
\text { revised } \\
\text { atmospheric } \\
\text { forcing from } \\
\text { CRUNCEP to } \\
\text { CRU-JRA-55 }\end{array}$ & $\begin{array}{l}\text { Introduction of } \\
\text { metrics for } \\
\text { evaluation of } \\
\text { individual } \\
\text { models using } \\
\text { observations }\end{array}$ \\
\hline $\begin{array}{l}\text { Friedlingstein } \\
\text { et al. (2019) } \\
\text { GCB2019 }\end{array}$ & $\begin{array}{c}\text { Global } \\
\text { emissions } \\
\text { calculated as } \\
\text { sum of all } \\
\text { countries plus } \\
\text { bunkers, } \\
\text { rather than } \\
\text { taken directly } \\
\text { from CDIAC. }\end{array}$ & & $\begin{array}{c}\text { Average of two } \\
\text { bookkeeping } \\
\text { models; use of } \\
15 \text { DGVMs }\end{array}$ & $\begin{array}{c}\text { Use of three } \\
\text { atmospheric } \\
\text { inversions }\end{array}$ & $\begin{array}{l}\text { Based on nine } \\
\text { models }\end{array}$ & $\begin{array}{l}\text { Based on } 16 \\
\text { models }\end{array}$ & \\
\hline $\begin{array}{l}\text { Friedlingstein } \\
\text { et al. (2020) } \\
\text { GCB2020 }\end{array}$ & $\begin{array}{c}\text { Cement } \\
\text { carbonation } \\
\text { now included } \\
\text { in the EFOS } \\
\text { estimate, } \\
\text { reducing EFOS } \\
\text { by about } \\
0.2 \text { GtC yr- } 1 \text { for } \\
\text { the last decade }\end{array}$ & $\begin{array}{c}\text { India's } \\
\text { emissions from } \\
\text { Andrew (2020: } \\
\text { India); } \\
\text { Corrections to } \\
\text { Netherland } \\
\text { Antilles and } \\
\text { Aruba and } \\
\text { Soviet } \\
\text { emissions } \\
\text { before } 1950 \text { as } \\
\text { per Andrew } \\
\text { (2020: CO2); }\end{array}$ & $\begin{array}{l}\text { Average of } \\
\text { three } \\
\text { bookkeeping } \\
\text { models; use of } \\
17 \text { DGVMs. } \\
\text { Estimate of } \\
\text { gross land use } \\
\text { sources and } \\
\text { sinks provided }\end{array}$ & $\begin{array}{l}\text { Use of six } \\
\text { atmospheric } \\
\text { inversions }\end{array}$ & $\begin{array}{c}\text { Based on nine } \\
\text { models. River } \\
\text { flux revised } \\
\text { and } \\
\text { partitioned } \\
\text { NH, Tropics, SH }\end{array}$ & $\begin{array}{l}\text { Based on } 17 \\
\text { models }\end{array}$ & \\
\hline
\end{tabular}


https://doi.org/10.5194/essd-2021-386

Preprint. Discussion started: 4 November 2021

(c) Author(s) 2021. CC BY 4.0 License.

\begin{tabular}{|c|c|c|c|c|c|}
\hline & & $\begin{array}{l}\text { China's coal } \\
\text { emissions in } \\
2019 \text { derived } \\
\text { from official } \\
\text { statistics, } \\
\text { emissions now } \\
\text { shown for } \\
\text { EU27 instead } \\
\text { of } \\
\text { EU28.Projectio } \\
n \text { for } 2020 \\
\text { based on } \\
\text { assessment of } \\
\text { four } \\
\text { approaches. }\end{array}$ & & & \\
\hline $\begin{array}{l}\text { Friedlingstein } \\
\text { et al. (2021) } \\
\text { GCB2021 (This } \\
\text { study) }\end{array}$ & $\begin{array}{c}\text { Projections are } \\
\text { no longer an } \\
\text { assessment of } \\
\text { four } \\
\text { approaches. }\end{array}$ & $\begin{array}{l}\text { Official data } \\
\text { included for a } \\
\text { number of } \\
\text { additional } \\
\text { countries, new } \\
\text { estimates for } \\
\text { South Korea, } \\
\text { added } \\
\text { emissions from } \\
\text { lime } \\
\text { production in } \\
\text { China. }\end{array}$ & $\begin{array}{l}\text { ELUC estimate } \\
\text { compared to } \\
\text { the estimates } \\
\text { adopted in } \\
\text { national GHG } \\
\text { inventories } \\
\text { (NGHGI) }\end{array}$ & $\begin{array}{l}\text { Average of } \\
\text { means of eight } \\
\text { models and } \\
\text { means of } \\
\text { seven data- } \\
\text { products. } \\
\text { Current year } \\
\text { prediction of } \\
\text { SOCEAN using } \\
\text { a feed-forward } \\
\text { neural network } \\
\text { method }\end{array}$ & $\begin{array}{c}\text { Current year } \\
\text { prediction of } \\
\text { SLAND using a } \\
\text { feed-forward } \\
\text { neural network } \\
\text { method }\end{array}$ \\
\hline
\end{tabular}

1 
https://doi.org/10.5194/essd-2021-386

Preprint. Discussion started: 4 November 2021

(c) Author(s) 2021. CC BY 4.0 License.

\begin{tabular}{|c|c|c|}
\hline $\begin{array}{l}\text { Model/data } \\
\text { name }\end{array}$ & Reference & $\begin{array}{l}\text { Change from Global Carbon Budget } 2020 \text { (Friedlingstein et al., } \\
\text { 2020) }\end{array}$ \\
\hline \multicolumn{3}{|c|}{ Bookkeeping models for land-use change emissions } \\
\hline BLUE & Hansis et al. (2015) & $\begin{array}{l}\text { No change to model, but simulations performed with updated } \\
\text { LUH2 forcing. }\end{array}$ \\
\hline $\begin{array}{l}\text { updated } \\
\text { H\&N2017 }\end{array}$ & Houghton and Nassikas (2017) & $\begin{array}{l}\text { Adjustment to treatment of harvested wood products. Update } \\
\text { to FRA2020 and } 2021 \text { FAOSTAT for forest cover and land-use } \\
\text { areas. Forest loss in excess of increases in cropland and } \\
\text { pastures represented an increase in shifting cultivation. } \\
\text { Extratropical peatland drainage emissions added (based on Qiu } \\
\text { et al., 2021). }\end{array}$ \\
\hline OSCAR & Gasser et al. (2020) & $\begin{array}{l}\text { Update to OSCAR3.1.2, which provides finer resolution (96 } \\
\text { countries/regions). LUH2-TRENDYv8 input data replaced by } \\
\text { LUH2-TRENDYv10. FRA2015 (Houghton \& Nassikas, 2017) still } \\
\text { used as a second driving dataset, with emissions from FRA2015 } \\
\text { extended to 2020. Constraining based on this year's budget } \\
\text { data. }\end{array}$ \\
\hline \multicolumn{3}{|c|}{ Dynamic global vegetation models } \\
\hline CABLE-POP & Haverd et al. (2018) & changes in parameterisation, minor bug fixes \\
\hline CLASSIC & Melton et al. (2020) (a) & Non-structural carbohydrates are now explicitly simulated. \\
\hline CLM5.0 & Lawrence et al. (2019) & No Change. \\
\hline DLEM & Tian et al. (2015) (b) & Updated algorithms for land use change processes. \\
\hline IBIS & Yuan et al. (2014) (c) & $\begin{array}{l}\text { Several changes in parameterisation; Dynamic carbon } \\
\text { allocation scheme. }\end{array}$ \\
\hline ISAM & Meiyappan et al. (2015) (d) & $\begin{array}{l}\text { ISAM now accounting for vertically-resolved soil } \\
\text { biogeochemistry (carbon and nitrogen) module (Shu et al., } \\
\text { 2020) }\end{array}$ \\
\hline ISBA-CTRIP & Delire et al. (2020) (e) & $\begin{array}{l}\text { Updated spinup protocol + model name updated (SURFEXv8 in } \\
\text { GCB2017) + inclusion of crop harvesting module }\end{array}$ \\
\hline JSBACH & Reick et al. (2021) (f) & Wood product pools per plant functional type. \\
\hline JULES-ES & Wiltshire et al. (2021) (g) & Version 1.1 Inclusion of interactive fire Burton et al., (2019) \\
\hline LPJ-GUESS & Smith et al. (2014) (h) & No code change. Using updated LUH2 and climate forcings. \\
\hline LPJ & Poulter et al. (2011) (i) & Updated soil data from FAO to HWSD v2.0 \\
\hline
\end{tabular}


https://doi.org/10.5194/essd-2021-386

Preprint. Discussion started: 4 November 2021

(c) Author(s) 2021. CC BY 4.0 License.

\begin{tabular}{|c|c|c|}
\hline LPX-Bern & Lienert and Joos (2018) & No Change. \\
\hline OCN & Zaehle and Friend (2010) (j) & No change (uses r294). \\
\hline ORCHIDEEv3 & Vuichard et al. (2019) (k) & Updated growth respiration scheme (revision 7267) \\
\hline SDGVM & Walker et al. (2017) (I) & $\begin{array}{l}\text { No changes from version used in Friedlingstein et al. (2019), } \\
\text { except for properly switching from grasslands to pasture in the } \\
\text { blending of the ESA data with LUH2; this change affects mostly } \\
\text { the semi-arid lands. }\end{array}$ \\
\hline VISIT & Kato et al. (2013) (m) & Minor bug fix on $\mathrm{CH} 4$ emissions of recent few years. \\
\hline YIBs & Yue and Unger (2015) & $\begin{array}{l}\text { Inclusion of nutrient limit with down regulation approach of } \\
\text { Arora et al. (2009) }\end{array}$ \\
\hline \multicolumn{3}{|c|}{ Global ocean biogeochemistry models } \\
\hline $\begin{array}{l}\text { NEMO- } \\
\text { PlankTOM12 }\end{array}$ & Wright et al. (2021) (n) & $\begin{array}{l}\text { Updated biochemical model to include } 12 \text { functional types. } \\
\text { Change to spin-up, now using a looped } 1990 .\end{array}$ \\
\hline $\begin{array}{l}\text { MICOM-HAMOCC } \\
\text { (NorESM-OCV1.2) }\end{array}$ & Schwinger et al. (2016) & No change \\
\hline $\begin{array}{l}\text { MPIOM- } \\
\text { HAMOCC6 }\end{array}$ & Lacroix et al. (2021) & $\begin{array}{l}\text { Added riverine fluxes; cmip6 model version including } \\
\text { modifications and bug-fixes in HAMOCC and MPIOM }\end{array}$ \\
\hline $\begin{array}{l}\text { NEMO3.6- } \\
\text { PISCESv2-gas } \\
\text { (CNRM) }\end{array}$ & Berthet et al. (2019) (o) & $\begin{array}{l}\text { small bug fixes; updated model-spin-up (new forcings); atm } \\
\text { forcing is now JRA55-Do including } 2020 \text { year and varying } \\
\text { riverine freshwater inputs }\end{array}$ \\
\hline $\begin{array}{l}\text { FESOM-2.1- } \\
\text { RECOM2 }\end{array}$ & Hauck et al. (2020) (p) & $\begin{array}{l}\text { Updated physical model version FESOM2.1, and including } 2 \text { nd } \\
\text { zooplankton and } 2 \text { nd detritus group. Used new atmospheric } \\
\text { CO2 time series provided by GCB }\end{array}$ \\
\hline $\begin{array}{l}\text { MOM6-COBALT } \\
\text { (Princeton) }\end{array}$ & Liao et al. (2020) & $\begin{array}{l}\text { Adjustment of the piston velocity prefactor ( } 0.337 \mathrm{cph} / \mathrm{m} 2 / \mathrm{s} 2 \\
\text { to } 0.251 \mathrm{cph} / \mathrm{m} 2 / \mathrm{s} 2) \text {. MOM6 update from GitHub version } \\
\text { b748b1b (2018-10-03) to version 69a096b (2021-02-24). } \\
\text { Updated model spin-up and simulation using JRA55-do v1.5. } \\
\text { Used new atmospheric CO2 time series provided by GCB. }\end{array}$ \\
\hline CESM-ETHZ & Doney et al. (2009) & $\begin{array}{l}\text { No change in the model. Used new atmospheric } \mathrm{CO} 2 \text { time } \\
\text { series provided by GCB }\end{array}$ \\
\hline $\begin{array}{l}\text { NEMO-PISCES } \\
\text { (IPSL) }\end{array}$ & Aumont et al. (2015) & No change \\
\hline
\end{tabular}

ocean fCO2-based data products

\begin{tabular}{l|l|l}
\hline $\begin{array}{l}\text { Landschützer } \\
\text { (MPI-SOMFFN) }\end{array}$ & Landschützer et al. (2016) & $\begin{array}{l}\text { update to SOCATv2021 measurements and time period 1982- } \\
2020 ; \\
\text { domain as well as the Arctic Ocean extension described in } \\
\text { Landschützer et al. (2020) }\end{array}$ \\
\hline $\begin{array}{l}\text { Rödenbeck (Jena- } \\
\text { MLS) }\end{array}$ & $\begin{array}{l}\text { update to SOCATv2021 measurements, time period extended } \\
\text { to 1957-2020, involvement of a multi-linear regression for } \\
\text { extrapolation (combined with an explicitly interannual } \\
\text { correction), use of OCIM (deVries, 2014) as decadal prior, } \\
\text { carbonate chemistry parameterization now time-dependent, } \\
\text { grid resolution increased to 2.5*2 degrees, adjustable degrees }\end{array}$ \\
\hline Rödenbeck et al. (2014) &
\end{tabular}




\begin{tabular}{|l|l|l|}
\hline & & $\begin{array}{l}\text { of freedom now also covering shallow areas and Arctic, some } \\
\text { numerical revisions }\end{array}$ \\
\hline CMEMS-LSCE- & Chau et al. (2021) & $\begin{array}{l}\text { Update to SOCATv2021 measurements and time period 1985- } \\
\text { 2020. The CMEMS-LSCE-FFNNv2 product now covers both the } \\
\text { open ocean and coastal regions (see in Chau et al. } 2021 \text { for } \\
\text { FFNNv2 }\end{array}$ \\
\hline CSIR-ML6 & Gregor et al. (2019) & $\begin{array}{l}\text { Updated to SOCATV2021. Reconstruction now spans the period } \\
\text { 1985 - 2020 and includes updates using the SeaFlux protocols } \\
\text { (Fay et al., 2021b) }\end{array}$ \\
\hline Watson et al & Watson et al. (2020) & $\begin{array}{l}\text { Updated to SOCAT v2021. A monthly climatology of the skin } \\
\text { temperature deviation as calculated for years 2003-2011 is now } \\
\text { used in place of a single global average figure. SOM calculation } \\
\text { updated to treat the Arctic as a separate biome. }\end{array}$ \\
\hline NIES-NN & Zeng et al. (2014) & New this year \\
\hline JMA-MLR & lida et al. (2021) & New this year \\
\hline OS-ETHZ-GRaCER & Gregor and Gruber (2021) & New this year \\
\hline
\end{tabular}

Atmospheric inversions

\begin{tabular}{|l|l|l|}
\hline CAMS & Chevallier et al. (2005) (q) & No change. \\
\hline $\begin{array}{l}\text { CarbonTracker } \\
\text { Europe (CTE) }\end{array}$ & van der Laan-Luijkx et al. (2017) & No change. \\
\hline Jena CarboScope & Rödenbeck et al. (2018) (r) & No change. \\
\hline UoE in-situ & Feng et al., (2016) (s) & Fossil fuels now from GCP-GridFEDv2021.2 \\
\hline NISMON-CO2 & Niwa et al., (2017) (t) & Some inversion parameters were changed. \\
\hline CMS-Flux & Liu et al., (2021) & New this year \\
\hline
\end{tabular}

(a) see also Asaadi et al. (2018).

(b) see also Tian et al. (2011)

(c) the dynamic carbon allocation scheme was presented by Xia et al. (2015)

(d) see also Jain et al. (2013). Soil biogeochemistry is updated based on Shu et al. (2020)

(e) see also Decharme et al. (2019) and Seferian et al. (2019)

(f) Mauritsen et al. (2019)

(g) see also Sellar et al. (2019) and Burton et al., (2019). JULES-ES is the Earth System configuration of the Joint UK Land Environment Simulator as used in the UK Earth System Model (UKESM).

(h) to account for the differences between the derivation of shortwave radiation from CRU cloudiness and DSWRF from CRUJRA, the photosynthesis scaling parameter aa was modified (-15\%) to yield similar results. 
https://doi.org/10.5194/essd-2021-386

Preprint. Discussion started: 4 November 2021

(c) Author(s) 2021. CC BY 4.0 License.

(i) compared to published version, decreased LPJ wood harvest efficiency so that $50 \%$ of biomass was removed offsite compared to $85 \%$ used in the 2012 budget. Residue management of managed grasslands increased so that 100 $\%$ of harvested grass enters the litter pool.

(j) see also Zaehle et al. (2011).

(k) see also Zaehle and Friend (2010) and Krinner et al. (2005)

(I) see also Woodward and Lomas (2004)

(m) see also Ito and Inatomi (2012).

(n) see also Buitenhuis et al. (2013)

(o) see also Séférian et al. (2019)

(p) see also Schourup-Kristensen et al (2014)

(q) see also Remaud (2018)

(r) see also Rödenbeck et al. (2003)

(s) see also Feng et al. (2009) and Palmer et al. (2019)

(t) see also Niwa et al. (2020) 
https://doi.org/10.5194/essd-2021-386

Preprint. Discussion started: 4 November 2021

(c) Author(s) 2021. CC BY 4.0 License.

1

2 Table 5. Comparison of results from the bookkeeping method and budget residuals with results from the 3 DGVMs and inverse estimates for different periods, the last decade, and the last year available. All values 4 are in GtCyr-1. The DGVM uncertainties represent $\pm 1 \sigma$ of the decadal or annual (for 2020 only) estimates 5 from the individual DGVMs: for the inverse models the range of available results is given. All values are 6 rounded to the nearest $0.1 \mathrm{GtC}$ and therefore columns do not necessarily add to zero.

\begin{tabular}{|c|c|c|c|c|c|c|c|}
\hline \multicolumn{8}{|c|}{ Mean (GtC/yг) } \\
\hline & $1960 \mathrm{~s}$ & 1970 s & $1980 \mathrm{~s}$ & $1990 \mathrm{~s}$ & $2000 \mathrm{~s}$ & $\begin{array}{l}2011- \\
2020\end{array}$ & 2020 \\
\hline \multicolumn{8}{|l|}{ Land-use change emissions (ELUC) } \\
\hline Bookkeeping methods - net flux (1a) & $1.6 \pm 0.7$ & $1.3 \pm 0.7$ & $1.2 \pm 0.7$ & $1.3 \pm 0.7$ & $1.2 \pm 0.7$ & $1.1 \pm 0.7$ & $0.9 \pm 0.7$ \\
\hline Bookkeeping methods - source & $3.4 \pm 0.9$ & $3.3 \pm 0.8$ & $3.4 \pm 0.8$ & $3.6 \pm 0.6$ & $3.7 \pm 0.6$ & $3.8 \pm 0.6$ & $3.6 \pm 0.6$ \\
\hline Bookkeeping methods - sink & $-1.9 \pm 0.4$ & $-2 \pm 0.4$ & $-2.1 \pm 0.3$ & $-2.3 \pm 0.4$ & $-2.5 \pm 0.4$ & $-2.7 \pm 0.4$ & $-2.8 \pm 0.4$ \\
\hline DGVMs-net flux (1b) & $1.6 \pm 0.5$ & $1.3 \pm 0.4$ & $1.4 \pm 0.5$ & $1.4 \pm 0.5$ & $1.4 \pm 0.5$ & $1.5 \pm 0.5$ & $1.4 \pm 0.7$ \\
\hline \multicolumn{8}{|l|}{ Terrestrial sink (SLAND) } \\
\hline $\begin{array}{l}\text { Residual sink from global budget (EFOS+ELUC-GATM- } \\
\text { SOCEAN) ( } 2 a \text { ) }\end{array}$ & $1.8 \pm 0.8$ & $1.9 \pm 0.8$ & $1.6 \pm 0.9$ & $2.5 \pm 0.9$ & $2.7 \pm 0.9$ & $2.8 \pm 0.9$ & $2.1 \pm 0.9$ \\
\hline DGVMs (2b) & $1.2 \pm 0.5$ & $2 \pm 0.5$ & $1.8 \pm 0.5$ & $2.3 \pm 0.4$ & $2.6 \pm 0.5$ & $3.1 \pm 0.6$ & $2.9 \pm 1$ \\
\hline \multicolumn{8}{|l|}{ Total land fluxes (SLAND-ELUC) } \\
\hline GCB2021 Budget (2b-1a) & $-0.4 \pm 0.8$ & $0.8 \pm 0.8$ & $0.5 \pm 0.9$ & $1 \pm 0.8$ & $1.4 \pm 0.9$ & $1.9 \pm 0.9$ & $2 \pm 1.2$ \\
\hline Budget constraint (2a-1a) & $0.2 \pm 0.4$ & $0.6 \pm 0.5$ & $0.3 \pm 0.5$ & $1.2 \pm 0.5$ & $1.5 \pm 0.6$ & $1.7 \pm 0.6$ & $1.3 \pm 0.6$ \\
\hline DGVMs-net (2b-1b) & $-0.4 \pm 0.6$ & $0.7 \pm 0.4$ & $0.3 \pm 0.4$ & $0.9 \pm 0.4$ & $1.2 \pm 0.4$ & $1.6 \pm 0.6$ & $1.5 \pm 0.8$ \\
\hline Inversions* & -- & -- & $\begin{array}{l}0.5-0.6 \\
(2)\end{array}$ & $\begin{array}{l}0.9-1.2 \\
(3)\end{array}$ & $\begin{array}{c}1.3-1.8 \\
(3)\end{array}$ & $1.3-2(6)$ & $\begin{array}{c}-0.1-1.3 \\
(6)\end{array}$ \\
\hline
\end{tabular}


https://doi.org/10.5194/essd-2021-386

Preprint. Discussion started: 4 November 2021

(c) Author(s) 2021. CC BY 4.0 License.

1

2 Table 6. Decadal mean in the five components of the anthropogenic $\mathrm{CO}$ budget for different periods, and 3 last year available. All values are in $\mathrm{GtC}$ yr-1, and uncertainties are reported as $\pm 1 \sigma$. Fossil $\mathrm{CO}_{2}$ emissions

4 include cement carbonation. The table also shows the budget imbalance $\left(B_{I M}\right)$, which provides a measure of 5 the discrepancies among the nearly independent estimates and has an uncertainty exceeding $\pm 1 \mathrm{GtC}^{-1}$. A 6 positive imbalance means the emissions are overestimated and/or the sinks are too small. All values are

7 rounded to the nearest $0.1 \mathrm{GtC}$ and therefore columns do not necessarily add to zero.

\begin{tabular}{|c|c|c|c|c|c|c|c|c|}
\hline \multicolumn{9}{|c|}{ Mean (GtC/yr) } \\
\hline & $1960 \mathrm{~s}$ & 1970 s & $1980 \mathrm{~s}$ & $1990 \mathrm{~s}$ & $2000 s$ & $2011-2020$ & 2020 & 2021 (Projection) \\
\hline \multicolumn{9}{|l|}{ Total emissions (EFOS + ELUC) } \\
\hline Fossil CO2 emissions (EFOS)* & $3 \pm 0.2$ & $4.7 \pm 0.2$ & $5.5 \pm 0.3$ & $6.3 \pm 0.3$ & $7.7 \pm 0.4$ & $9.5 \pm 0.5$ & $9.3 \pm 0.5$ & $9.7 \pm 0.5$ \\
\hline Land-use change emissions (ELUC) & $1.6 \pm 0.7$ & $1.3 \pm 0.7$ & $1.2 \pm 0.7$ & $1.3 \pm 0.7$ & $1.2 \pm 0.7$ & $1.1 \pm 0.7$ & $0.9 \pm 0.7$ & $0.8 \pm 0.7$ \\
\hline Total emissions & $4.6 \pm 0.7$ & $5.9 \pm 0.7$ & $6.7 \pm 0.8$ & $7.7 \pm 0.8$ & $9 \pm 0.8$ & $10.6 \pm 0.8$ & $10.2 \pm 0.8$ & $10.5 \pm 0.9$ \\
\hline \multicolumn{9}{|l|}{ Partitioning } \\
\hline Growth rate in atmos CO2 (GATM) & $1.7 \pm 0.07$ & $2.8 \pm 0.07$ & $3.4 \pm 0.02$ & $3.1 \pm 0.02$ & $4 \pm 0.02$ & $5.1 \pm 0.02$ & $5 \pm 0.2$ & $4.2 \pm 0.4$ \\
\hline Ocean sink (SOCEAN) & $1.1 \pm 0.4$ & $1.3 \pm 0.4$ & $1.8 \pm 0.4$ & $2 \pm 0.4$ & $2.2 \pm 0.4$ & $2.8 \pm 0.4$ & $3 \pm 0.4$ & $2.9 \pm 0.4$ \\
\hline Terrestrial sink (SLAND) & $1.2 \pm 0.5$ & $2 \pm 0.5$ & $1.8 \pm 0.5$ & $2.3 \pm 0.4$ & $2.6 \pm 0.5$ & $3.1 \pm 0.6$ & $2.9 \pm 1$ & $3.3 \pm 1$ \\
\hline \multicolumn{9}{|l|}{ Budget Imbalance } \\
\hline $\begin{array}{l}\text { BIM=EFOS+ELUC- } \\
(\text { GATM+SOCEAN+SLAND) }\end{array}$ & 0.6 & -0.2 & -0.2 & 0.2 & 0.1 & -0.3 & -0.8 & 0.1 \\
\hline
\end{tabular}

- Fossil emissions excluding the cement carbonation sink amount to $3.1 \pm 0.2 \mathrm{GtC} / \mathrm{yr}, 4.7 \pm 0.2 \mathrm{GtC} / \mathrm{yr}, 5.5 \pm 0.3 \mathrm{GtC} / \mathrm{yr}, 6.4 \pm 0.3 \mathrm{GtC} / \mathrm{yr}, 7.9 \pm 0.4$ 8 GtC/yr, and $9.7 \pm 0.5 \mathrm{GtC} / \mathrm{yr}$ for the decades 1960 s to 2010 s respectively and to $9.5 \pm 0.5 \mathrm{GtC} / \mathrm{yr}$ for 2020 . 
Table 7. Comparison of the projection with realised fossil CO2 emissions (EFOS). The 'Actual' values are first the estimate available using actual data, and the 'Projected' values refers to estimates made before the end of the year for each publication. Projections based on a different method from that described here during 2008-2014 are available in Le Quéré et al., (2016). All values are adjusted for leap years.

\begin{tabular}{|c|c|c|c|c|c|c|c|c|c|c|c|c|}
\hline & \multicolumn{2}{|c|}{ World } & \multicolumn{2}{|c|}{ China } & \multicolumn{2}{|c|}{ USA } & \multicolumn{2}{|c|}{ EU28 (h) } & \multicolumn{2}{|c|}{ India } & \multicolumn{2}{|c|}{ Rest of World } \\
\hline & $\begin{array}{c}\text { Project } \\
\text { ed }\end{array}$ & Actual & $\begin{array}{l}\text { Projec } \\
\text { ted }\end{array}$ & Actual & $\begin{array}{l}\text { Projec } \\
\text { ted }\end{array}$ & Actual & $\begin{array}{l}\text { Projec } \\
\text { ted }\end{array}$ & Actual & $\begin{array}{l}\text { Projec } \\
\text { ted }\end{array}$ & Actual & $\begin{array}{l}\text { Projec } \\
\text { ted }\end{array}$ & Actual \\
\hline & $-0.6 \%$ & & $-3.9 \%$ & & $-1.5 \%$ & & & & & & $1.2 \%$ & \\
\hline (a) & $\begin{array}{c}(-1.6 \text { to } \\
0.5)\end{array}$ & $0.06 \%$ & $\begin{array}{c}(-4.6 \text { to } \\
-1.1)\end{array}$ & $-0.7 \%$ & $\begin{array}{c}(-5.5 \text { to } \\
0.3)\end{array}$ & $-2.5 \%$ & - & - & - & - & $\begin{array}{c}(-0.2 \text { to } \\
2.6)\end{array}$ & $1.2 \%$ \\
\hline & $-0.2 \%$ & & $-0.5 \%$ & & $-1.7 \%$ & & & & & & $1.0 \%$ & \\
\hline (b) & $\begin{array}{c}(-1.0 \text { to } \\
+1.8)\end{array}$ & $0.20 \%$ & $\begin{array}{c}(-3.8 \text { to } \\
+1.3)\end{array}$ & $-0.3 \%$ & $\begin{array}{c}(-4.0 \text { to } \\
+0.6)\end{array}$ & $-2.1 \%$ & - & - & - & - & $\begin{array}{c}(-0.4 \text { to } \\
+2.5)\end{array}$ & $1.3 \%$ \\
\hline & $2.0 \%$ & & $3.5 \%$ & & $-0.4 \%$ & & & & $2.00 \%$ & & $1.6 \%$ & \\
\hline 2017 (c) & $\begin{array}{c}(+0.8 \text { to } \\
+3.0)\end{array}$ & $1.6 \%$ & $\begin{array}{l}(+0.7 \text { to } \\
+5.4)\end{array}$ & $1.5 \%$ & $\begin{array}{c}(-2.7 \text { to } \\
+1.0)\end{array}$ & $-0.5 \%$ & - & - & $\begin{array}{c}(+0.2 \text { to } \\
+3.8)\end{array}$ & $3.9 \%$ & $\begin{array}{c}\text { (0.0 to } \\
+3.2)\end{array}$ & $1.9 \%$ \\
\hline & $2.7 \%$ & & $4.7 \%$ & & $2.5 \%$ & & $-0.7 \%$ & & $6.3 \%$ & & $1.8 \%$ & \\
\hline (d) & $\begin{array}{c}(+1.8 \text { to } \\
+3.7)\end{array}$ & $2.1 \%$ & $\begin{array}{c}(+2.0 \text { to } \\
+7.4)\end{array}$ & $2.3 \%$ & $\begin{array}{c}(+0.5 \text { to } \\
+4.5)\end{array}$ & $2.8 \%$ & $\begin{array}{c}(-2.6 \text { to } \\
+1.3)\end{array}$ & $-2.1 \%$ & $\begin{array}{c}(+4.3 \text { to } \\
+8.3)\end{array}$ & $8.0 \%$ & $\begin{array}{c}(+0.5 \text { to } \\
+3.0)\end{array}$ & $1.7 \%$ \\
\hline & $0.5 \%$ & & $2.6 \%$ & & $-2.4 \%$ & & $-1.7 \%$ & & $1.8 \%$ & & $0.5 \%$ & \\
\hline $\begin{array}{c}2019 \\
\text { (e) }\end{array}$ & $\begin{array}{c}(-0.3 \text { to } \\
+1.4)\end{array}$ & $0.1 \%$ & $\begin{array}{c}(+0.7 \text { to } \\
+4.4)\end{array}$ & $2.2 \%$ & $\begin{array}{c}(-4.7 \text { to } \\
-0.1)\end{array}$ & $-2.6 \%$ & $\begin{array}{c}(-5.1 \% \\
\text { to } \\
+1.8 \%)\end{array}$ & $-4.3 \%$ & $\begin{array}{c}(-0.7 \text { to } \\
+3.7)\end{array}$ & $1.0 \%$ & $\begin{array}{c}(-0.8 \text { to } \\
+1.8)\end{array}$ & $0.5 \%$ \\
\hline $2020(f)$ & $-6.7 \%$ & $-5.4 \%$ & $-1.7 \%$ & $1.4 \%$ & $-12.2 \%$ & $-10.6 \%$ & $\begin{array}{l}-11.3 \% \\
\text { (EU27) }\end{array}$ & $-10.9 \%$ & $-9.1 \%$ & $-7.3 \%$ & $-7.4 \%$ & $-7.0 \%$ \\
\hline & $4.9 \%$ & & $4.0 \%$ & & $7.6 \%$ & & $7.6 \%$ & & $12.6 \%$ & & $2.9 \%$ & \\
\hline $\begin{array}{c}2021 \\
\text { (g) }\end{array}$ & $\begin{array}{c}(4.1 \% \\
\text { to } \\
5.7 \%)\end{array}$ & & $\begin{array}{c}(2.1 \% \\
\text { to } \\
5.8 \%)\end{array}$ & & $\begin{array}{c}(5.3 \% \\
\text { to } \\
10.0 \%)\end{array}$ & & $\begin{array}{c}(5.6 \% \\
\text { to } \\
9.5 \%)\end{array}$ & & $\begin{array}{c}(10.7 \% \\
\text { to } \\
13.6 \%)\end{array}$ & & $\begin{array}{c}(1.8 \% \\
\text { to } \\
4.1 \%)\end{array}$ & \\
\hline
\end{tabular}

(a) Jackson et al. (2016) and Le Quéré et al. (2015a). (b) Le Quéré et al. (2016). (c) Le Quéré et al. (2018a). (d) Le Quéré et al. (2018b). (e) Friedlingstein et al., (2019), (f) Friedlingstein et al., (2020), (g) This study (median of four reported estimates, Section 3.4.1.2)

(h) EU28 until 2019, EU27 from 2020 
https://doi.org/10.5194/essd-2021-386

Preprint. Discussion started: 4 November 2021

(c) Author(s) 2021. CC BY 4.0 License.

1

Table 8. Cumulative $\mathrm{CO}_{2}$ for different time periods in gigatonnes of carbon (GtC). All uncertainties are reported as $\pm 1 \sigma$. Fossil $\mathrm{CO}_{2}$ emissions include cement carbonation. The budget imbalance ( $\mathrm{B}_{\mathrm{IM}}$ ) provides a measure of the discrepancies among the nearly independent estimates. All values are rounded to the nearest $5 \mathrm{GtC}$ and therefore columns do not necessarily add to zero.

$1750-2020 \quad 1850-2014 \quad 1850-2020 \quad 1960-2020 \quad 1850-2021$

\begin{tabular}{l|ccccc}
\hline \multicolumn{2}{l}{ Emissions } & \multicolumn{5}{l}{} \\
\hline Fossil CO2 emissions (EFOS) & $460 \pm 25$ & $400 \pm 20$ & $455 \pm 25$ & $375 \pm 20$ & $465 \pm 25$ \\
\hline Land-use change emissions (ELUC) & $235 \pm 75$ & $195 \pm 60$ & $200 \pm 65$ & $80 \pm 45$ & $205 \pm 65$ \\
\hline Total emissions & $690 \pm 80$ & $595 \pm 65$ & $660 \pm 65$ & $455 \pm 45$ & $670 \pm 65$ \\
\hline Partitioning & & & & & \\
\hline Growth rate in atmos CO2 (GATM) & $290 \pm 5$ & $235 \pm 5$ & $270 \pm 5$ & $205 \pm 5$ & $270 \pm 5$ \\
\hline Ocean sink (SOCEAN) & $180 \pm 35$ & $150 \pm 30$ & $170 \pm 35$ & $115 \pm 25$ & $170 \pm 35$ \\
\hline Terrestrial sink (SLAND) & $215 \pm 50$ & $180 \pm 40$ & $195 \pm 45$ & $135 \pm 25$ & $200 \pm 45$ \\
\hline Budget imbalance & & & & & \\
\hline BIM=EFOS+ELUC-(GATM+SOCEAN+SLAND) & 10 & 30 & 25 & 0 & 25 \\
\hline
\end{tabular}


https://doi.org/10.5194/essd-2021-386

Preprint. Discussion started: 4 November 2021

(c) Author(s) 2021. CC BY 4.0 License.

Table 9. Major known sources of uncertainties in each component of the Global Carbon Budget, defined as input data or processes that have a demonstrated effect of at least $\pm 0.3 \mathrm{GtC}$ yr-1.

\begin{tabular}{|c|c|c|c|c|}
\hline $\begin{array}{l}\text { Source of } \\
\text { uncertainty }\end{array}$ & $\begin{array}{l}\text { Time scale } \\
\text { (years) }\end{array}$ & Location & Status & Evidence \\
\hline \multicolumn{5}{|c|}{ Fossil CO2 emissions (EFOS; Section 2.1) } \\
\hline energy statistics & $\begin{array}{l}\text { annual to } \\
\text { decadal }\end{array}$ & $\begin{array}{c}\text { global, but } \\
\text { mainly China \& } \\
\text { major } \\
\text { developing } \\
\text { countries }\end{array}$ & see Sect. 2.1 & (Korsbakken et al., 2016, Guan et al., 2012) \\
\hline $\begin{array}{l}\text { carbon content } \\
\text { of coal }\end{array}$ & $\begin{array}{l}\text { annual to } \\
\text { decadal }\end{array}$ & $\begin{array}{c}\text { global, but } \\
\text { mainly China \& } \\
\text { major } \\
\text { developing } \\
\text { countries }\end{array}$ & see Sect. 2.1 & (Liu et al., 2015) \\
\hline $\begin{array}{l}\text { system } \\
\text { boundary }\end{array}$ & $\begin{array}{l}\text { annual to } \\
\text { decadal }\end{array}$ & all countries & see Sect. 2.1 & (Andrew, 2020) \\
\hline \multicolumn{5}{|c|}{ Net land-use change flux (ELUC; section 2.2) } \\
\hline $\begin{array}{l}\text { land-cover and } \\
\text { land-use change } \\
\text { statistics }\end{array}$ & continuous & $\begin{array}{l}\text { global; in } \\
\text { particular } \\
\text { tropics }\end{array}$ & see Sect. 2.2 & (Houghton et al., 2012; Gasser et al., 2020) \\
\hline $\begin{array}{l}\text { sub-grid-scale } \\
\text { transitions }\end{array}$ & $\begin{array}{l}\text { annual to } \\
\text { decadal }\end{array}$ & global & see Table A1 & (Wilkenskjeld et al., 2014) \\
\hline $\begin{array}{l}\text { vegetation } \\
\text { biomass }\end{array}$ & $\begin{array}{l}\text { annual to } \\
\text { decadal }\end{array}$ & $\begin{array}{l}\text { global; in } \\
\text { particular } \\
\text { tropics }\end{array}$ & see Table A1 & (Houghton et al., 2012) \\
\hline $\begin{array}{l}\text { forest } \\
\text { degradation } \\
\text { (fire, selective } \\
\text { logging) }\end{array}$ & $\begin{array}{l}\text { annual to } \\
\text { decadal }\end{array}$ & tropics & & (Aragão et al., 2018; Qin et al., 2020) \\
\hline $\begin{array}{l}\text { wood and crop } \\
\text { harvest }\end{array}$ & $\begin{array}{l}\text { annual to } \\
\text { decadal }\end{array}$ & global; SE Asia & see Table A1 & (Arneth et al., 2017, Erb et al., 2018) \\
\hline peat burning (a) & $\begin{array}{l}\text { multi-decadal } \\
\text { trend }\end{array}$ & global & see Table A1 & (van der Werf et al., 2010, 2017) \\
\hline $\begin{array}{l}\text { loss of } \\
\text { additional sink } \\
\text { capacity }\end{array}$ & $\begin{array}{l}\text { multi-decadal } \\
\text { trend }\end{array}$ & global & $\begin{array}{l}\text { not included; } \\
\text { see Appendix } \\
\text { D1.4 }\end{array}$ & $\begin{array}{c}\text { (Pongratz et al, 2014, Gasser et al, 2020; } \\
\text { Obermeier et al., 2021) }\end{array}$ \\
\hline \multicolumn{5}{|c|}{ Atmospheric growth rate (GATM; section 2.3 ) no demonstrated uncertainties larger than $\pm 0.3 \mathrm{GtC}$ yr-1 (b) } \\
\hline \multicolumn{5}{|c|}{ Ocean sink (SOCEAN; section 2.4) } \\
\hline
\end{tabular}


https://doi.org/10.5194/essd-2021-386

Preprint. Discussion started: 4 November 2021

(c) Author(s) 2021. CC BY 4.0 License.

\begin{tabular}{|c|c|c|c|c|}
\hline $\begin{array}{l}\text { sparsity in } \\
\text { surface fCO2 } \\
\text { observations }\end{array}$ & $\begin{array}{c}\text { mean, decadal } \\
\text { variability and } \\
\text { trend }\end{array}$ & $\begin{array}{c}\text { global, in } \\
\text { particular } \\
\text { southern } \\
\text { hemisphere }\end{array}$ & see Sect 3.5.2 & $\begin{array}{l}\text { (Gloege et al., 2021, Denvil-Sommer et al., } \\
\text { 2021, Bushinsky et al., 2019) }\end{array}$ \\
\hline $\begin{array}{l}\text { riverine carbon } \\
\text { outgassing and } \\
\text { its } \\
\text { anthropogenic } \\
\text { perturbation }\end{array}$ & $\begin{array}{c}\text { annual to } \\
\text { decadal }\end{array}$ & $\begin{array}{c}\text { global, in } \\
\text { particular } \\
\text { partitioning } \\
\text { between } \\
\text { Tropics and } \\
\text { South }\end{array}$ & $\begin{array}{c}\text { see Sect. } 2.4 \\
\text { (anthropogenic } \\
\text { perturbations } \\
\text { not included) }\end{array}$ & $\begin{array}{c}\text { (Aumont et al., 2001, Resplandy et al., 2018, } \\
\text { Lacroix et al., 2020) }\end{array}$ \\
\hline $\begin{array}{l}\text { interior ocean } \\
\text { anthropogenic } \\
\text { carbon storage }\end{array}$ & $\begin{array}{c}\text { annual to } \\
\text { decadal }\end{array}$ & global & see Sect 3.5.5 & (Gruber et al., 2019) \\
\hline $\begin{array}{l}\text { near-surface } \\
\text { temperature } \\
\text { and salinity } \\
\text { gradients }\end{array}$ & $\begin{array}{l}\text { mean on all } \\
\text { time-scales }\end{array}$ & global & see Sect. 3.8.2 & (Watson et al., 2020) \\
\hline
\end{tabular}

Land sink (SLAND; section 2.5)

\begin{tabular}{|c|c|c|c|c|}
\hline $\begin{array}{l}\text { strength of } \mathrm{CO} 2 \\
\text { fertilisation }\end{array}$ & $\begin{array}{l}\text { multi-decadal } \\
\text { trend }\end{array}$ & global & see Sect. 2.5 & (Wenzel et al., 2016; Walker et al., 2021) \\
\hline $\begin{array}{l}\text { response to } \\
\text { variability in } \\
\text { temperature } \\
\text { and rainfall } \\
\text { nutrient } \\
\text { limitation and } \\
\text { supply }\end{array}$ & $\begin{array}{l}\text { annual to } \\
\text { decadal }\end{array}$ & $\begin{array}{l}\text { global; in } \\
\text { particular } \\
\text { tropics }\end{array}$ & see Sect. 2.5 & $\begin{array}{l}\text { (Cox et al., 2013; Jung et al., 2017; Humphrey } \\
\text { et al., 2018; 2021) }\end{array}$ \\
\hline tree mortality & annual & $\begin{array}{l}\text { global in } \\
\text { particular } \\
\text { tropics }\end{array}$ & see Sect. 2.5 & (Hubau et al., 2021; Brienen et al., 2020) \\
\hline $\begin{array}{l}\text { response to } \\
\text { diffuse radiation }\end{array}$ & annual & global & see Sect. 2.5 & (Mercado et al., 2009; O'Sullivan et al., 2021) \\
\hline \multicolumn{5}{|c|}{ a As result of interactions between land-use and climate } \\
\hline \multicolumn{5}{|c|}{$\begin{array}{l}\text { b The uncertainties in GATM have been estimated as } \pm 0.2 \mathrm{GtC} y r-1 \text {, although the conversion of the growth rate into a } \\
\text { global annual flux assuming instantaneous mixing throughout the atmosphere introduces additional errors that have } \\
\text { not yet been quantified. }\end{array}$} \\
\hline
\end{tabular}




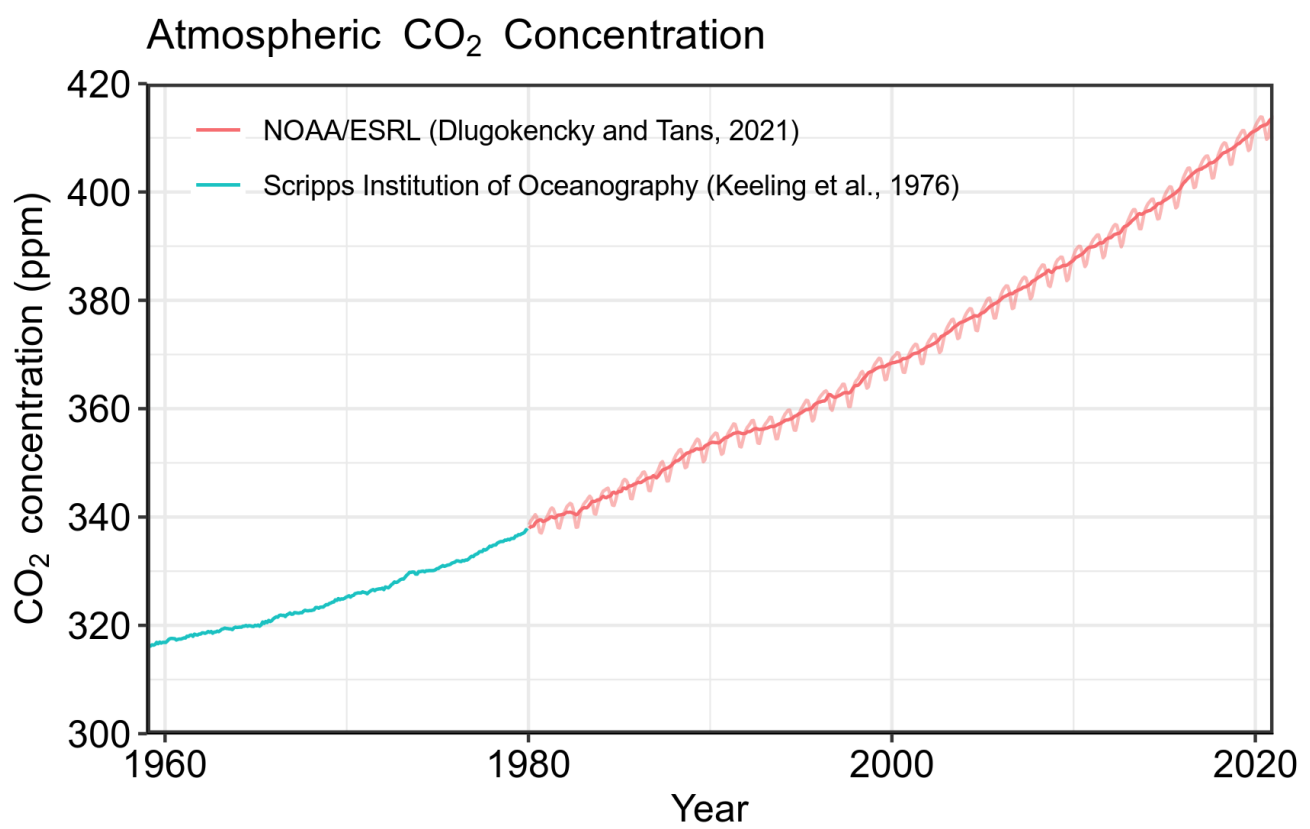

2

3 Figure 1. Surface average atmospheric $\mathrm{CO}_{2}$ concentration (ppm). Since 1980, monthly data are

4 from NOAA/ESRL (Dlugokencky and Tans, 2021) and are based on an average of direct

5 atmospheric $\mathrm{CO}_{2}$ measurements from multiple stations in the marine boundary layer (Masarie and

6 Tans, 1995). The 1958-1979 monthly data are from the Scripps Institution of Oceanography, based

7 on an average of direct atmospheric $\mathrm{CO}_{2}$ measurements from the Mauna Loa and South Pole

8 stations (Keeling et al., 1976). To account for the difference of mean $\mathrm{CO}_{2}$ and seasonality between

9 the NOAA/ESRL and the Scripps station networks used here, the Scripps surface average (from two

10 stations) was de-seasonalised and adjusted to match the NOAA/ESRL surface average (from

11 multiple stations) by adding the mean difference of $0.667 \mathrm{ppm}$, calculated here from overlapping

12 data during 1980-2012. 


\section{The global carbon cycle}

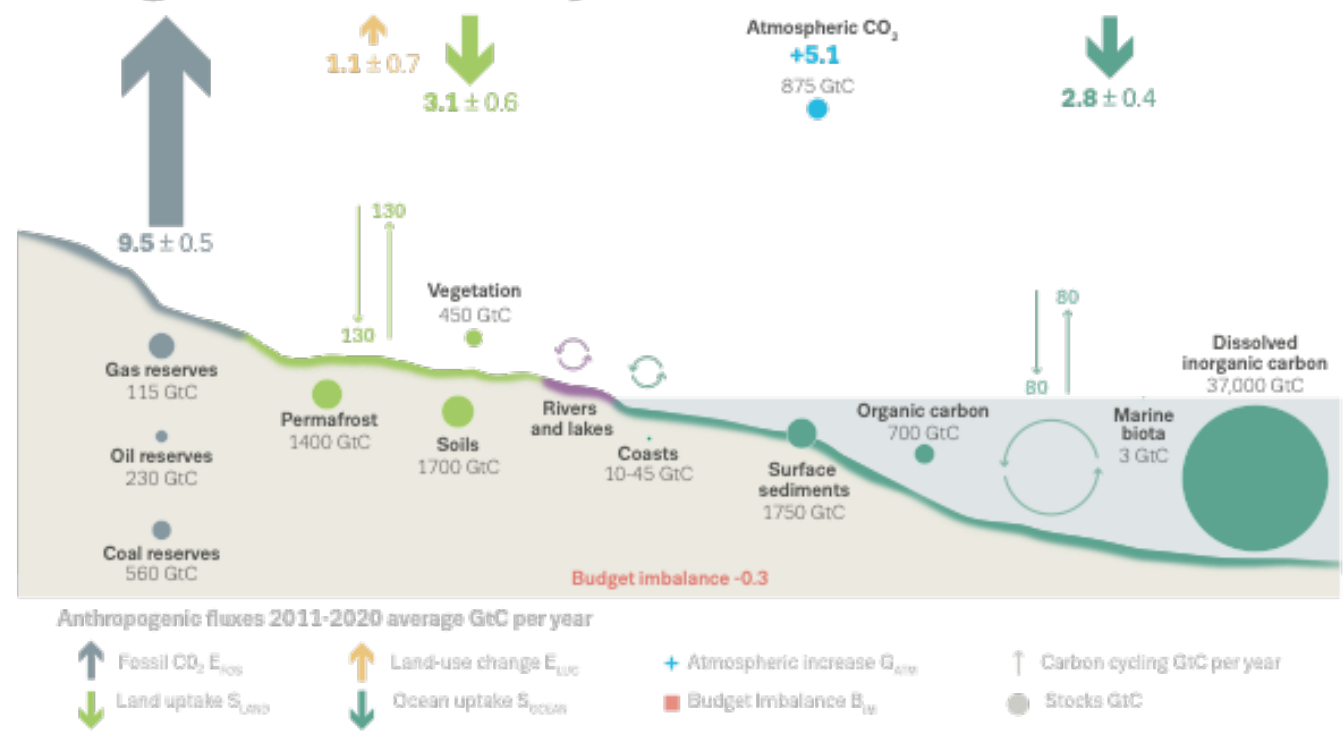

Figure 2. Schematic representation of the overall perturbation of the global carbon cycle caused by anthropogenic activities, averaged globally for the decade 2011-2020. See legends for the corresponding arrows and units. The uncertainty in the atmospheric $\mathrm{CO}_{2}$ growth rate is very small $\left.\left( \pm 0.02 \mathrm{GtC}^{-1}\right)^{-1}\right)$ and is neglected for the figure. The anthropogenic perturbation occurs on top of an active carbon cycle, with fluxes and stocks represented in the background and taken from Canadell et al. (2021) for all numbers, except for the carbon stocks in coasts which is from a literature review of coastal marine sediments (Price and Warren, 2016). 

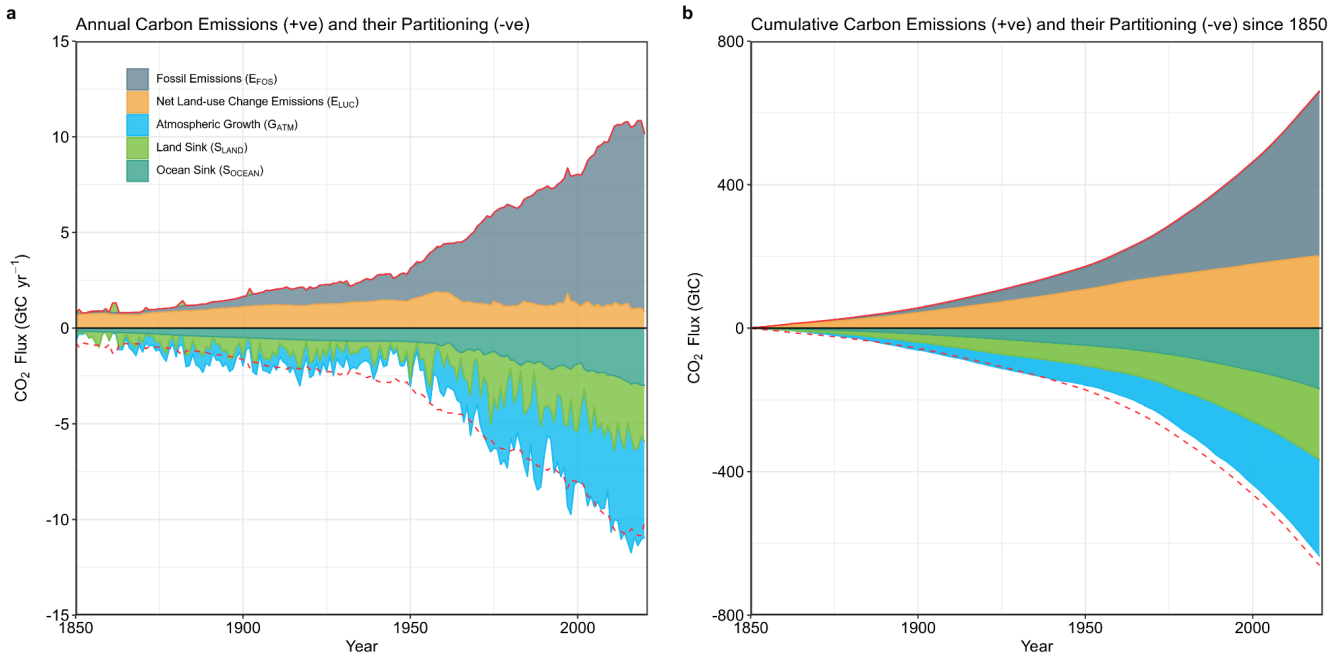

2 Figure 3. Combined components of the global carbon budget illustrated in Fig. 2 as a function of

time, for fossil $\mathrm{CO}_{2}$ emissions (EFos, including a small sink from cement carbonation; grey) and

emissions from land-use change ( $E_{L U c}$; brown), as well as their partitioning among the atmosphere

5 ( $\mathrm{G}_{\text {ATM }}$; cyan), ocean (SOCEAN; blue), and land (S $\mathrm{S}_{\text {LAND }}$; green). Panel (a) shows annual estimates of

each flux and panel (b) the cumulative flux (the sum of all prior annual fluxes) since the year 1850.

The partitioning is based on nearly independent estimates from observations (for $\mathrm{G}_{\text {ATM }}$ ) and from process model ensembles constrained by data (for SOCEAN and SLAND) and does not exactly add up to the sum of the emissions, resulting in a budget imbalance $\left(B I_{M}\right)$ which is represented by the difference between the bottom red line (mirroring total emissions) and the sum of carbon fluxes

11 in the ocean, land, and atmosphere reservoirs. All data are in GtC $\mathrm{yr}^{-1}$ (panel a) and GtC (panel b).

12 The Efos estimates are primarily from (Gilfillan and Marland, 2021), with uncertainty of about $\pm 5 \%$

$13( \pm 1 \sigma)$. The Eluc estimates are from three bookkeeping models (Table 4) with uncertainties of about

$14 \pm 0.7 \mathrm{GtC}_{\mathrm{yr}}{ }^{-1}$. The $\mathrm{G}_{\text {ATM }}$ estimates prior to 1959 are from Joos and Spahni (2008) with uncertainties

15 equivalent to about $\pm 0.1-0.15 \mathrm{GtC}_{\mathrm{yr}}^{-1}$ and from Dlugokencky and Tans (2021) since 1959 with

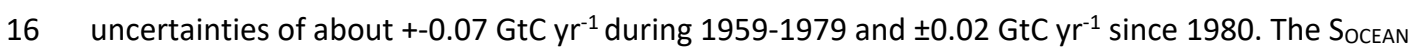

17 estimate is the average from Khatiwala et al. (2013) and DeVries (2014) with uncertainty of about

$18 \pm 30 \%$ prior to 1959 , and the average of an ensemble of models and an ensemble of $\mathrm{fCO}_{2}$ data

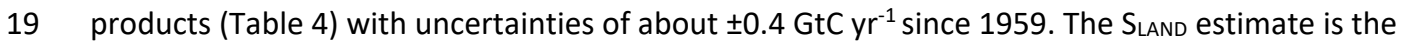

20 average of an ensemble of models (Table 4) with uncertainties of about $\pm 1 \mathrm{GtC}^{-1}{ }^{-1}$. See the text

21 for more details of each component and their uncertainties. 

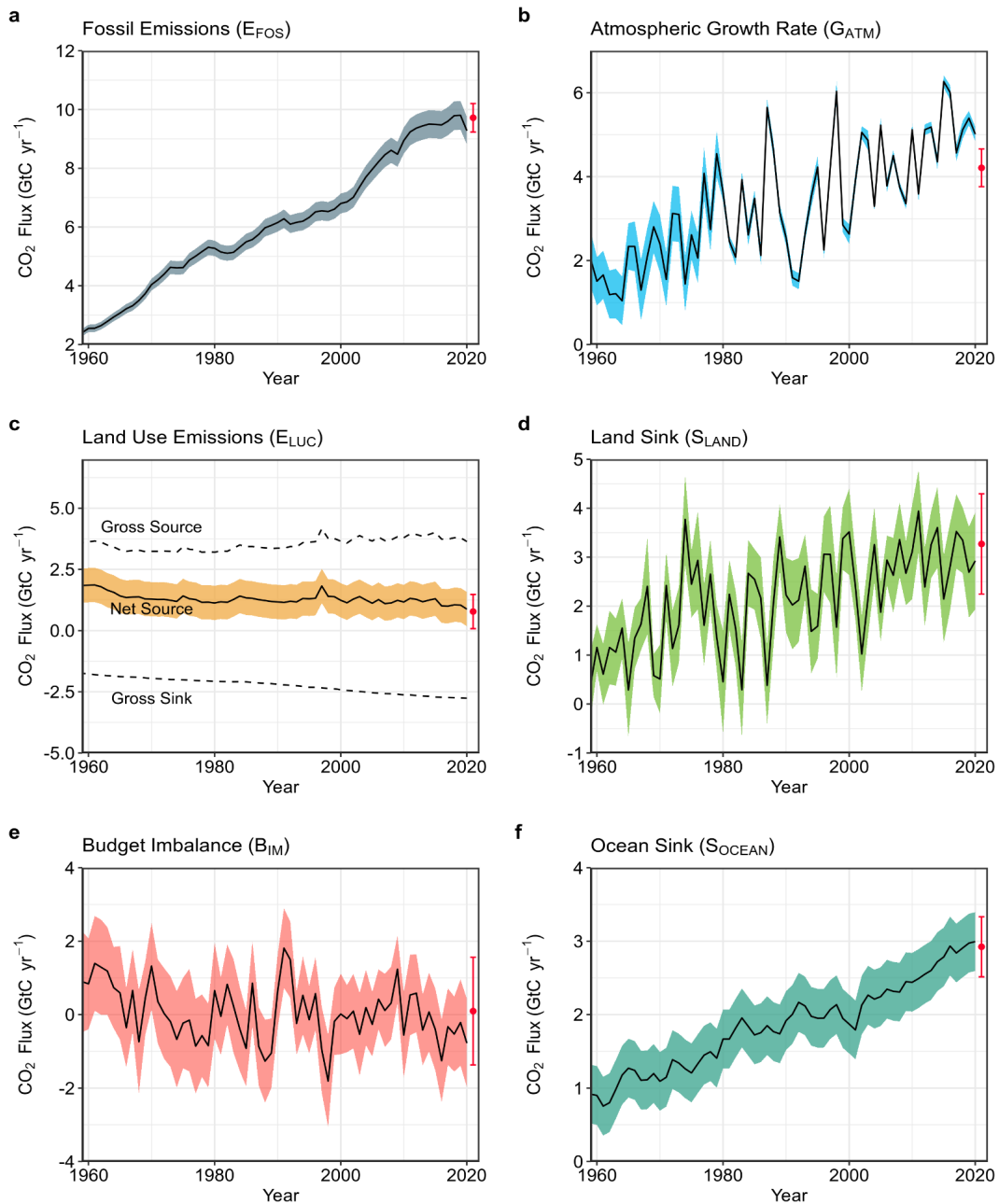

3 Figure 4. Components of the global carbon budget and their uncertainties as a function of time,

4 presented individually for (a) fossil $\mathrm{CO}_{2}$ emissions ( $\mathrm{E}_{\mathrm{FOS}}$ ), (b) growth rate in atmospheric $\mathrm{CO}_{2}$

5 concentration $\left(G_{A T M}\right)$, (c) emissions from land-use change ( $\left.E_{L U C}\right)$, (d) the land $\mathrm{CO}_{2} \operatorname{sink}\left(\mathrm{S}_{\mathrm{LAND}}\right)$, (e)

6 the ocean $\mathrm{CO}_{2} \operatorname{sink}$ (SOCEAN), ( $\mathrm{f}$ ) the budget imbalance that is not accounted for by the other terms.

7 Positive values of S SAND and SOCEAN represent a flux from the atmosphere to land or the ocean. All

8 data are in $\mathrm{GtC} \mathrm{yr}^{-1}$ with the uncertainty bounds representing \pm 1 standard deviation in shaded

9 colour. Data sources are as in Fig. 3. The red dots indicate our projections for the year 2021 and the red error bars the uncertainty in the projections (see methods). 
a

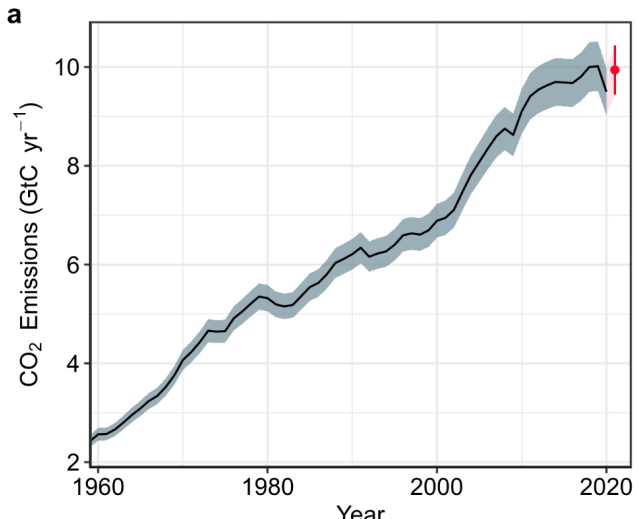

C

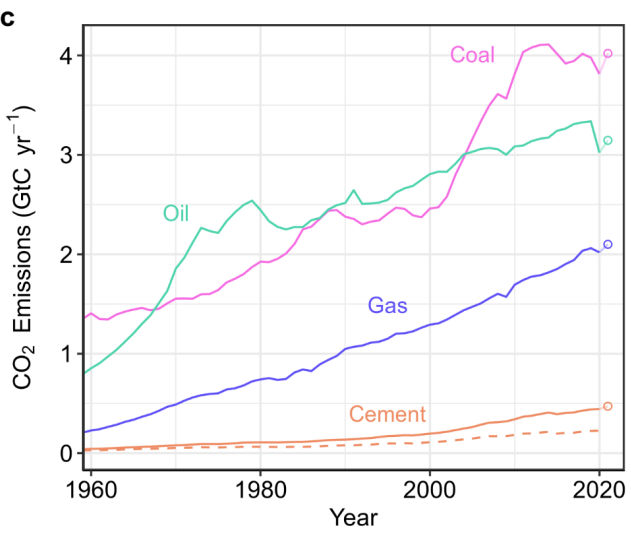

b
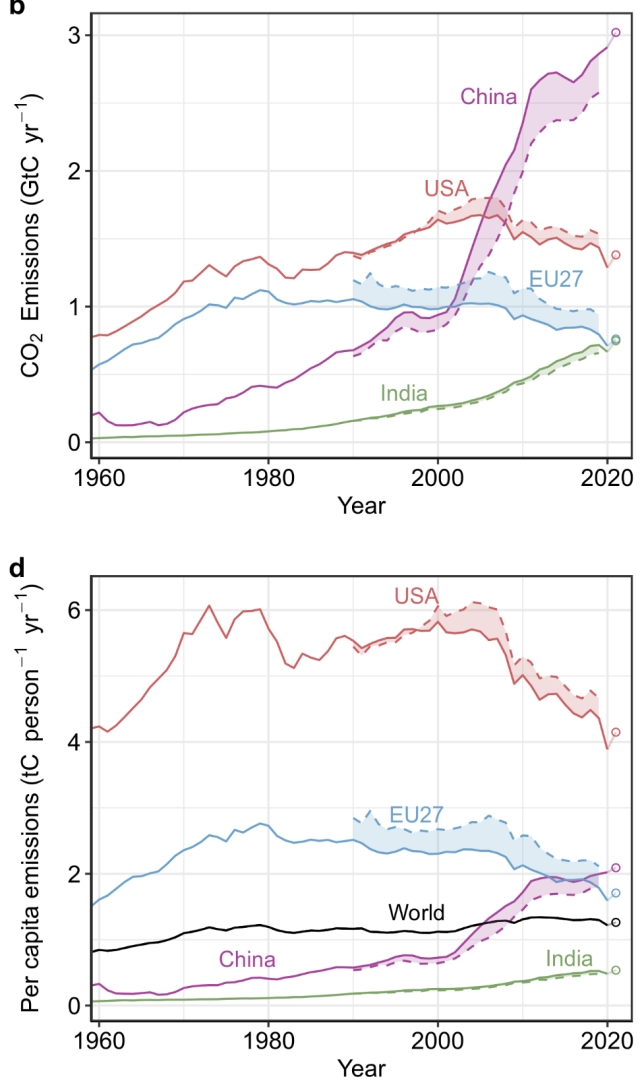

1

2

Figure 5. Fossil $\mathrm{CO}_{2}$ emissions for (a) the globe, including an uncertainty of $\pm 5 \%$ (grey shading) and a projection through the year 2021 (red dot and uncertainty range), (b) territorial (solid lines) and consumption (dashed lines) emissions for the top three country emitters (USA, China, India) and for the European Union (EU27), (c) global emissions by fuel type, including coal, oil, gas, and cement, and cement minus cement carbonation (dashed), and (d) per-capita emissions the world and for the large emitters as in panel (b). Territorial emissions are primarily from Gilfillan and Marland (2021) except national data for the USA and EU27 for 1990-2018, which are reported by the countries to the UNFCCC as detailed in the text; consumption-based emissions are updated from Peters et al. (2011b). See Section 2.1 and Appendix C.1 for details of the calculations and data sources. 

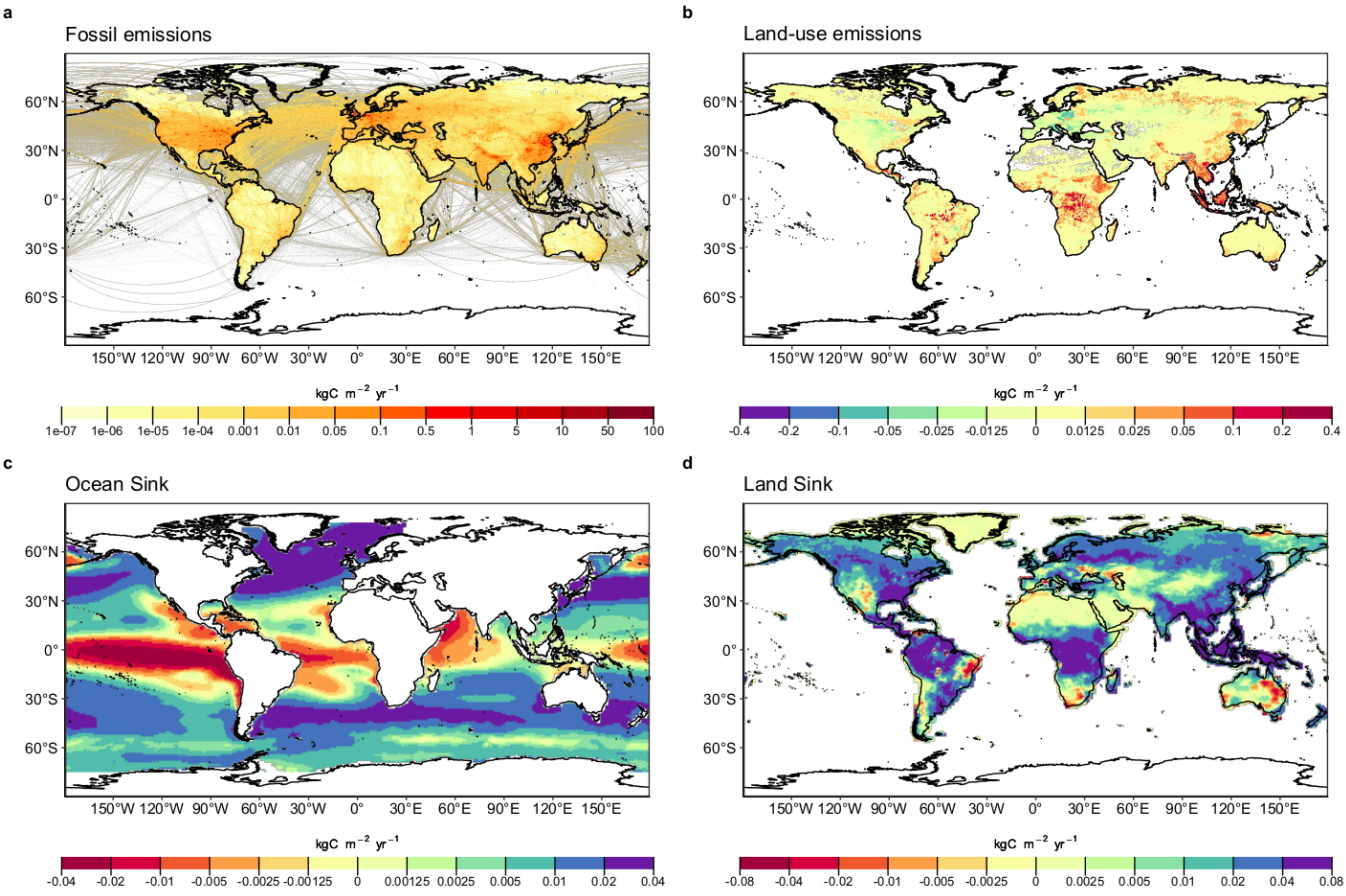

Figure 6. The 2011-2020 decadal mean components of the global carbon budget, presented for (a)

3 fossil $\mathrm{CO}_{2}$ emissions ( $\mathrm{E}_{\mathrm{FOS}}$ ), (b) land-use change emissions ( $\left.\mathrm{E}_{\mathrm{LUC}}\right)$, (c) the ocean $\mathrm{CO}_{2}$ sink (SoceAN), and

4 (d) the land $\mathrm{CO}_{2} \operatorname{sink}\left(\mathrm{S}_{\mathrm{LAND}}\right.$ ). Positive values for $\mathrm{E}_{\mathrm{FOS}}$ and $\mathrm{E}_{\mathrm{LUC}}$ represent a flux to the atmosphere,

5 whereas positive values of SOCEAN and SLAND represent a flux from the atmosphere to the ocean or the land. In all panels, yellow/red (green/blue) colours represent a flux from (into) the land/ocean to (from) the atmosphere. All units are in $\mathrm{kgC} \mathrm{m}^{-2} \mathrm{yr}^{-1}$. Note the different scales in each panel. $\mathrm{E}_{\mathrm{FOS}}$ data shown is from GCP-GridFEDv2021.2. ELUC data shown is only from BLUE as the updated

9 H\&N2017 and OSCAR do not resolve gridded fluxes. SOCEAN data shown is the average of GOBMs

10 and data-products means, using GOBMs simulation A, no adjustment for bias and drift applied to

11 the gridded fields (see Sections 2.4). SLAND data shown is the average of DGVMs for simulation S2

12 (see Sections 2.5). 
a

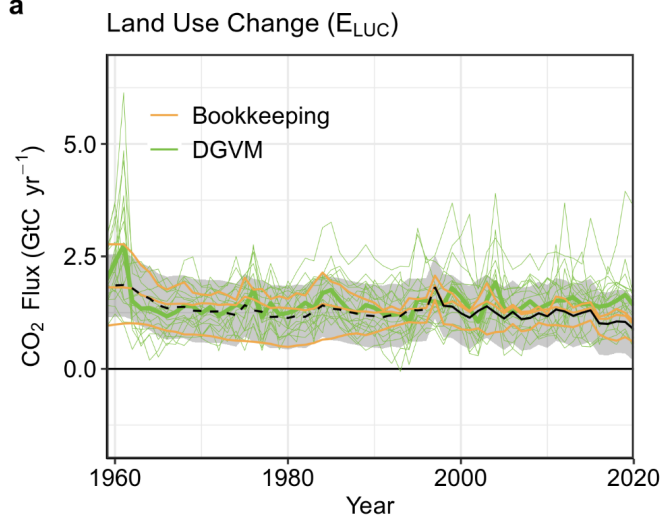

C

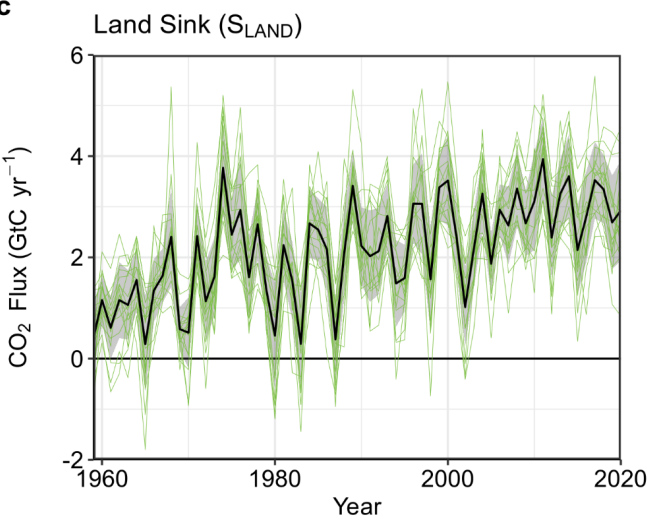

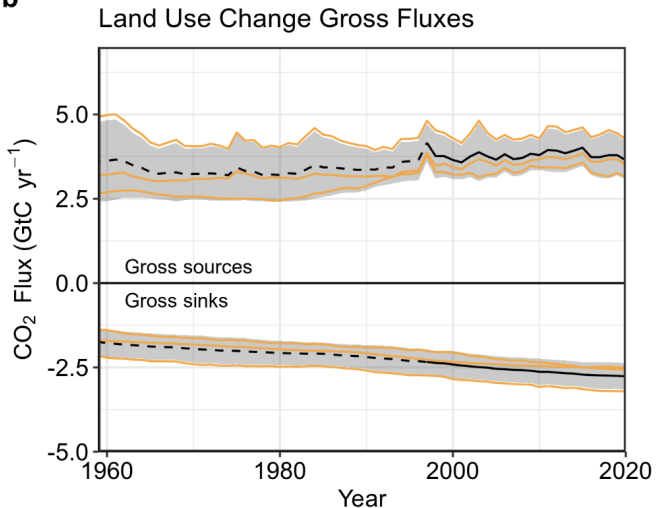

d

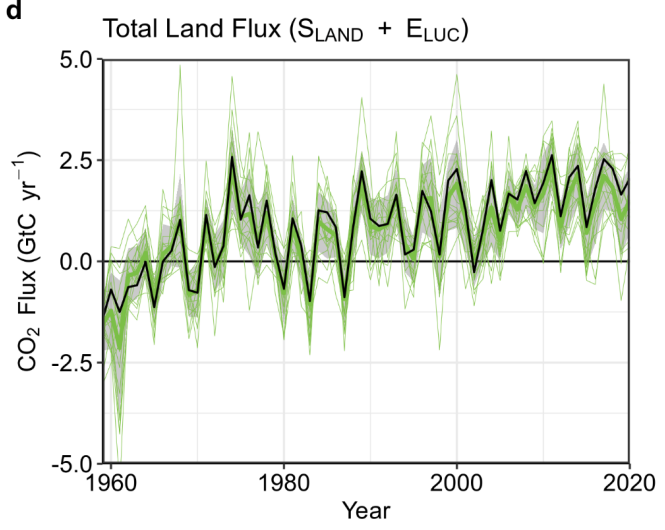

1

2 Figure 7. $\mathrm{CO}_{2}$ exchanges between the atmosphere and the terrestrial biosphere as used in the global carbon budget (black with $\pm 1 \sigma$ uncertainty in grey shading in all panels). (a) $\mathrm{CO}_{2}$ emissions

from land-use change (ELuc) with estimates from the three bookkeeping models (yellow lines) and

DGVMs models (green) shown individually, with DGVMs ensemble means (dark green). The dashed line identifies the pre-satellite period before the inclusion of peatland burning. (b) $\mathrm{CO}_{2}$ gross sinks (positive, from regrowth after agricultural abandonment and wood harvesting) and gross sources (negative, from decaying material left dead on site, products after clearing of natural vegetation for agricultural purposes, wood harvesting, and for BLUE, degradation from primary to secondary land through usage of natural vegetation as rangeland, and also from emissions from peat drainage and peat burning) from the three bookkeeping models (yellow 2 lines). The sum of the gross sinks and sources is $E_{\text {LUC }}$ shown in panel(a). (c) Land $\mathrm{CO}_{2} \operatorname{sink}\left(\mathrm{S}_{\text {LAND }}\right.$ ) 3 with individual DGVMs estimates (green). (d) Total atmosphere-land $\mathrm{CO}_{2}$ fluxes ( $\mathrm{S}_{\mathrm{LAND}}-\mathrm{E}_{\mathrm{LUC}}$ ), with 4 individual DGVMs (green) and their multi-model mean (dark green). 

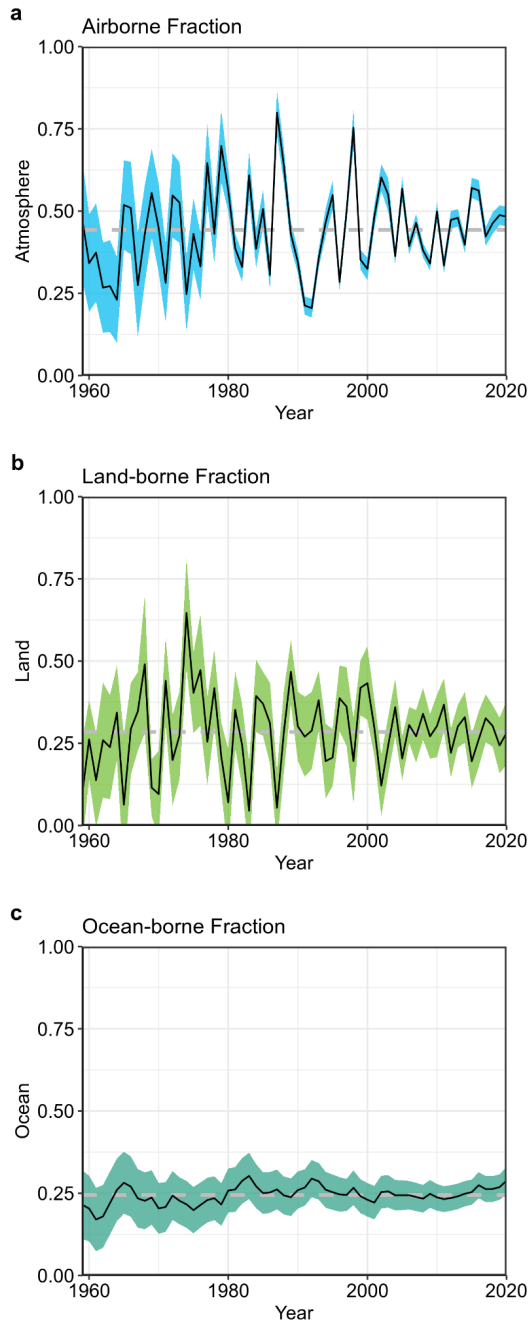

2 Figure 8. The partitioning of total anthropogenic $\mathrm{CO}_{2}$ emissions ( $\left.E_{F O S}+E_{L U C}\right)$ across (a) the

3 atmosphere (airborne fraction), (b) land (land-borne fraction), and (c) ocean (ocean-borne

4 fraction). Black lines represent the central estimate, and the coloured shading represents the

5 uncertainty. The grey dashed lines represent the long-term average of the airborne (44\%), land-

6 borne (28\%) and ocean-borne (24\%) fractions during 1959-2020. 


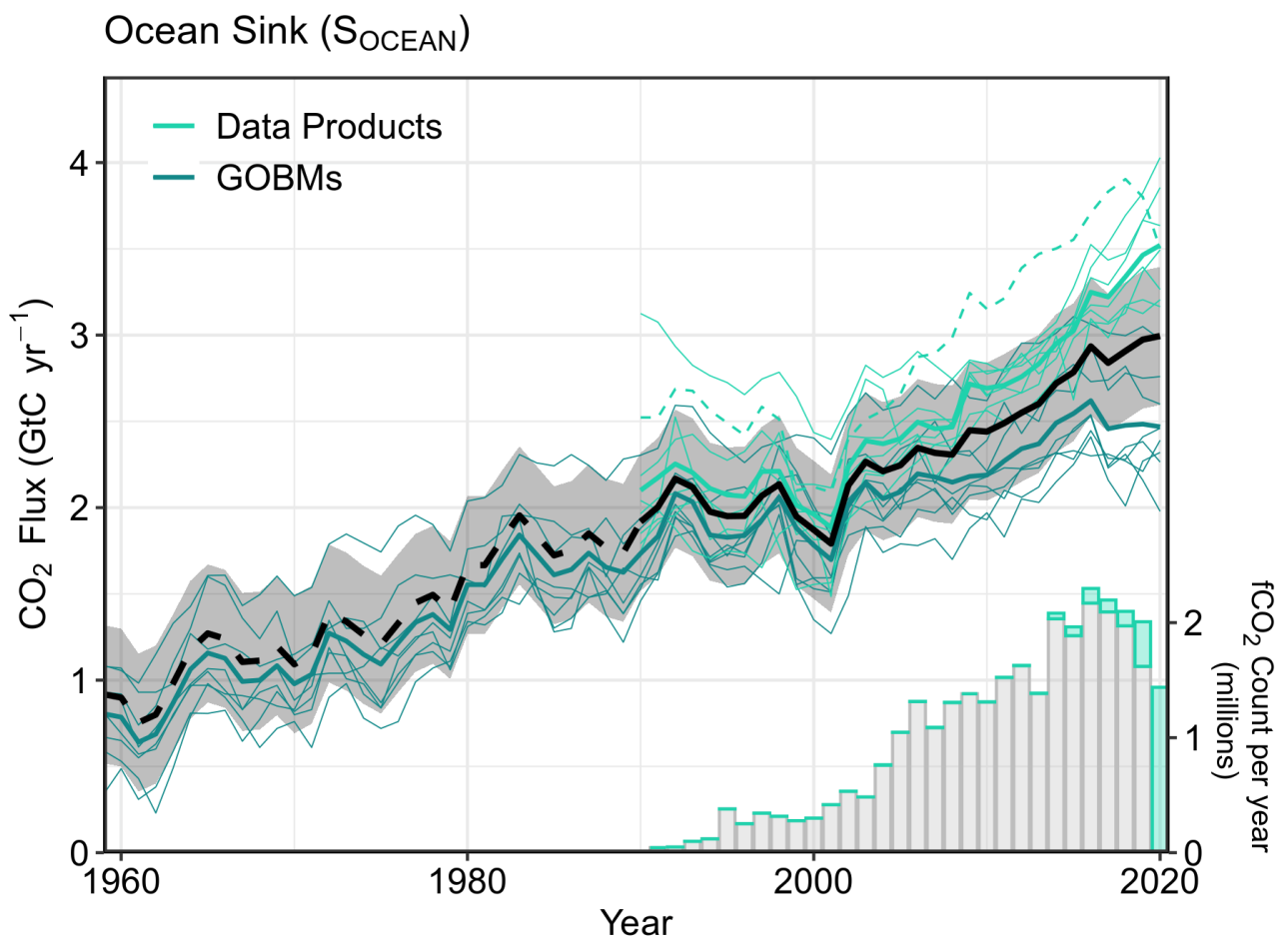

2 Figure 9. Comparison of the anthropogenic atmosphere-ocean $\mathrm{CO}_{2}$ flux showing the budget values

3 of SOCEAN (black; with the uncertainty in grey shading), individual ocean models (teal), and the

4 ocean $\mathrm{fCO}_{2}$-based data products (cyan; with Watson et al. (2020) in dashed line as not used for

5 ensemble mean). The $\mathrm{fCO}_{2}$-based data products were adjusted for the pre-industrial ocean source

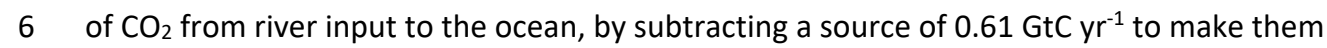

7 comparable to SOCEAN (see Section 2.4). Bar-plot in the lower right illustrates the number of $\mathrm{fCO}_{2}$

8 observations in the SOCAT V2021 database (Bakker et al., 2021). Grey bars indicate the number of

9 data points in SOCAT V2020, and coloured bars the newly added observations in v2021. 
$\mathrm{CO}_{2}$ effect

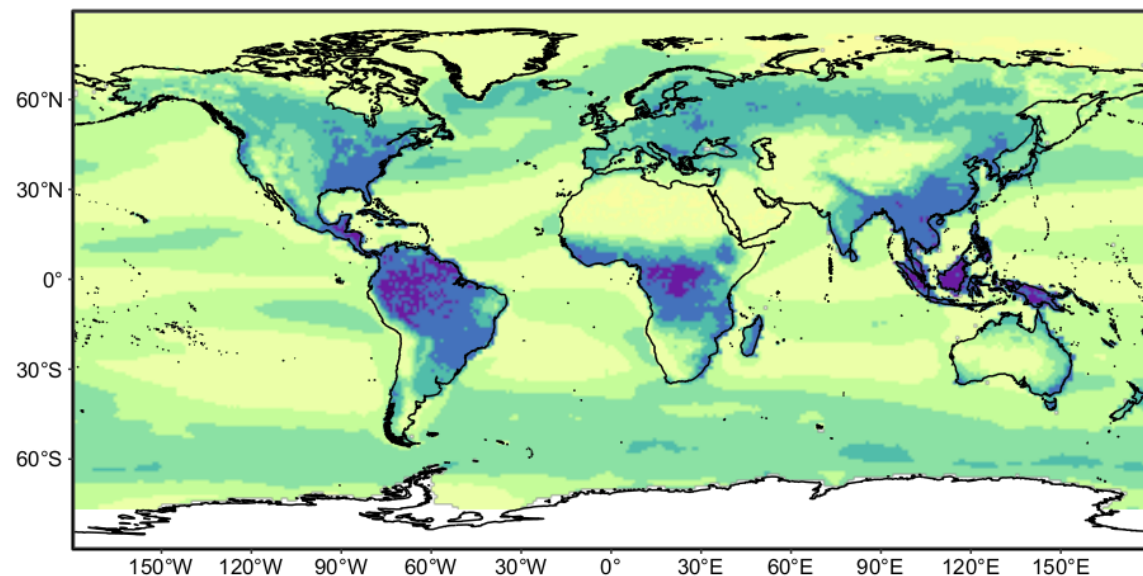

$\mathrm{kgC} \mathrm{m}^{-2} \mathrm{yr}^{-1}$

b Climate effect
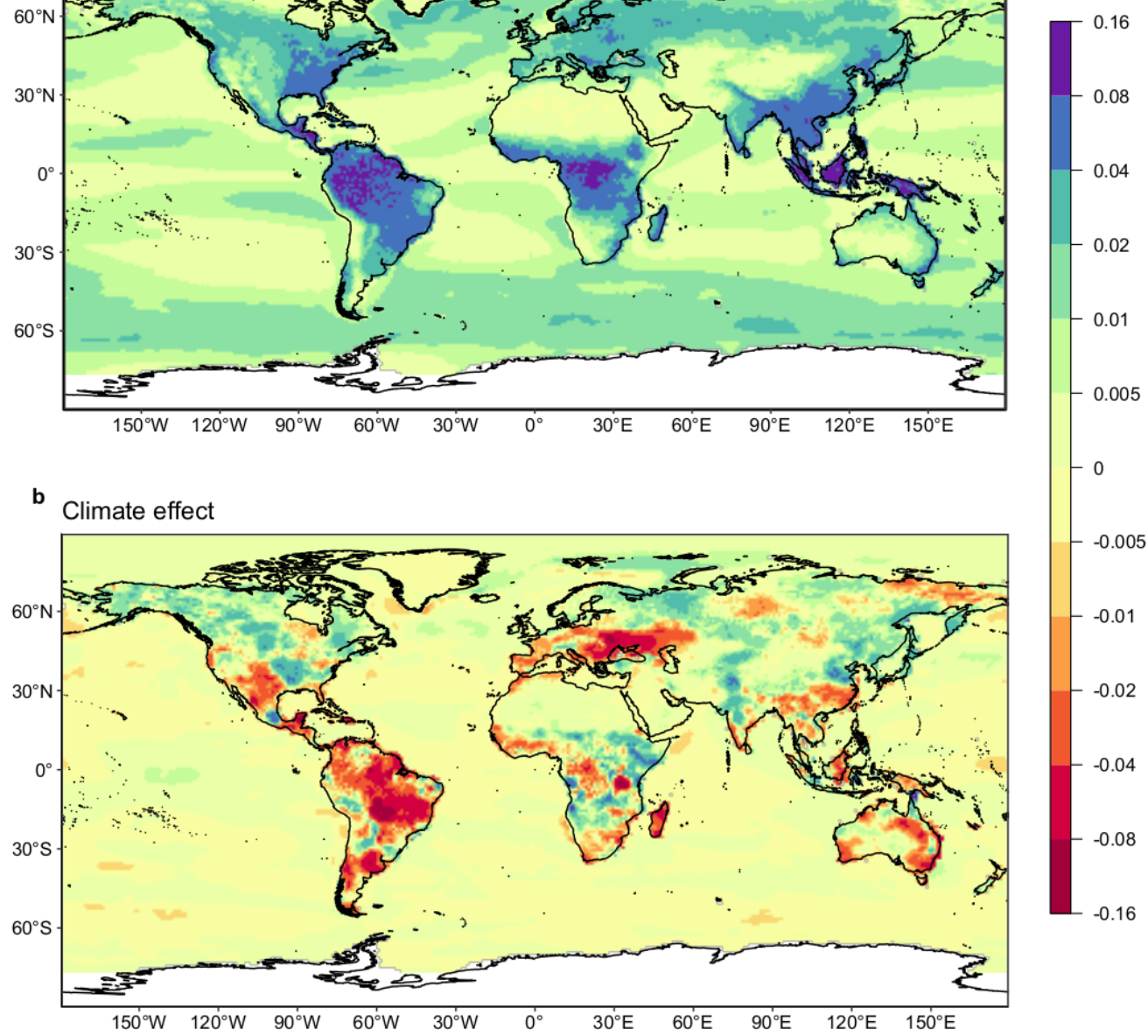

2 Figure 10. Attribution of the atmosphere-ocean (SOCEAN) and atmosphere-land ( $\left.\mathrm{S}_{\mathrm{LAND}}\right) \mathrm{CO}_{2}$ fluxes to

3 (a) increasing atmospheric $\mathrm{CO}_{2}$ concentrations and (b) changes in climate, averaged over the

4 previous decade 2011-2020. All data shown is from the processed-based GOBMs and DGVMs. The

5 sum of ocean $\mathrm{CO}_{2}$ and climate effects will not equal the ocean sink shown in Figure 6 which

6 includes the $\mathrm{fCO}_{2}$-based data products. See Appendix C.3.2 and C.4.1 for attribution methodology.

7 Units are in $\mathrm{kgC} \mathrm{m}^{-2} \mathrm{yr}^{-1}$ (note the non-linear colour scale). 


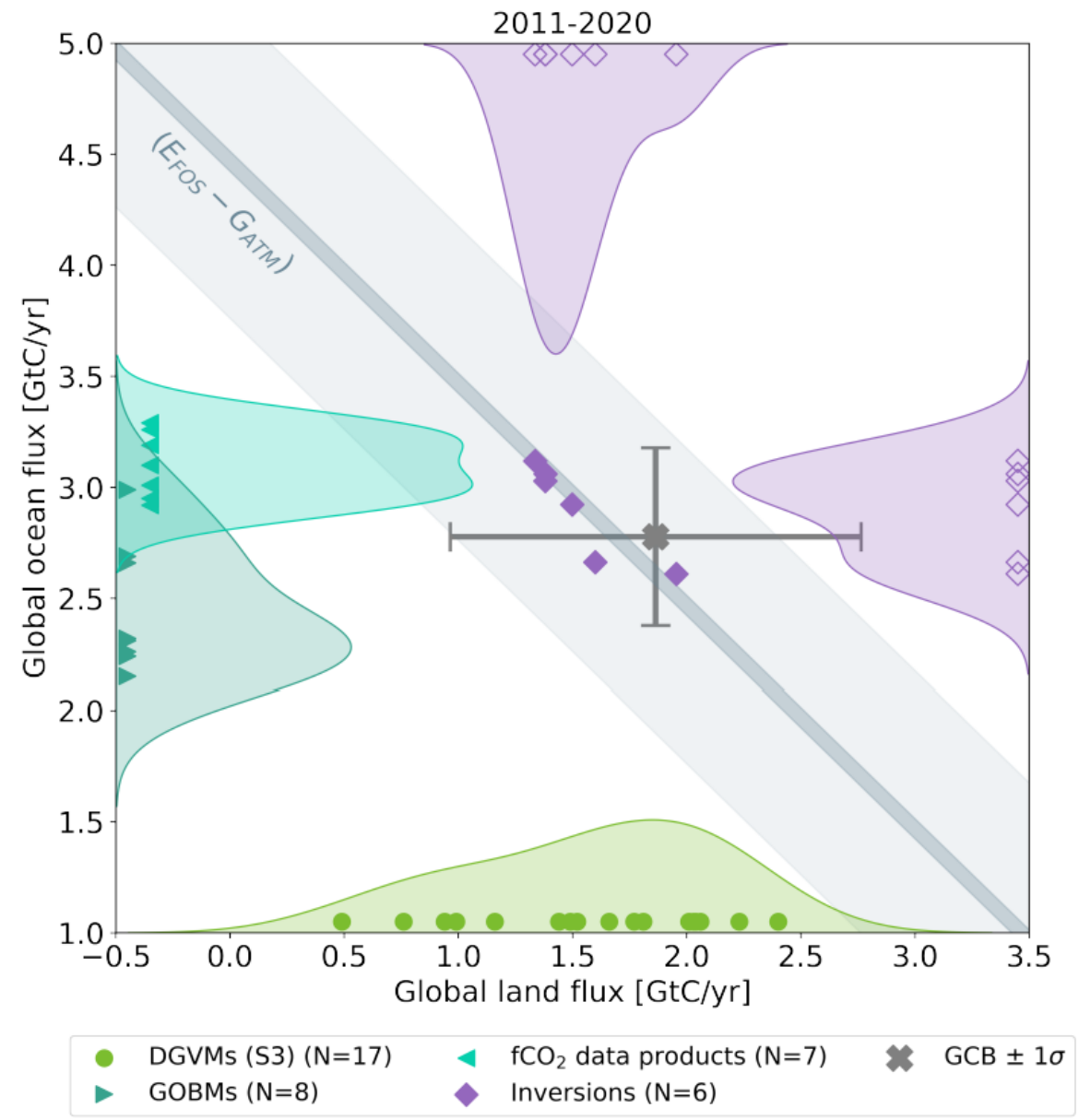

2 Figure 11. The 2011-2020 decadal mean net atmosphere-ocean and atmosphere-land fluxes

3 derived from the ocean models and $\mathrm{fCO}_{2}$ products ( $y$-axis, right and left pointing blue triangles

4 respectively), and from the DGVMs (x-axis, green symbols), and the same fluxes estimated from

5 the six inversions (purple symbols on secondary $x$-and $y$-axis). The grey central point is the mean

$6( \pm 1 \sigma)$ of SOCEAN and (SLAND $-E_{L U C}$ ) as assessed in this budget. The shaded distributions show the

7 density of the ensemble of individual estimates. The grey diagonal band represents the fossil fuel

8 emissions minus the atmospheric growth rate from this budget ( $\left.E_{F O S}-G_{A T M}\right)$. Note that positive

9 values are $\mathrm{CO}_{2}$ sinks. 
Annual Carbon Fluxes to (-ve) or from (+ve) the Atmosphere
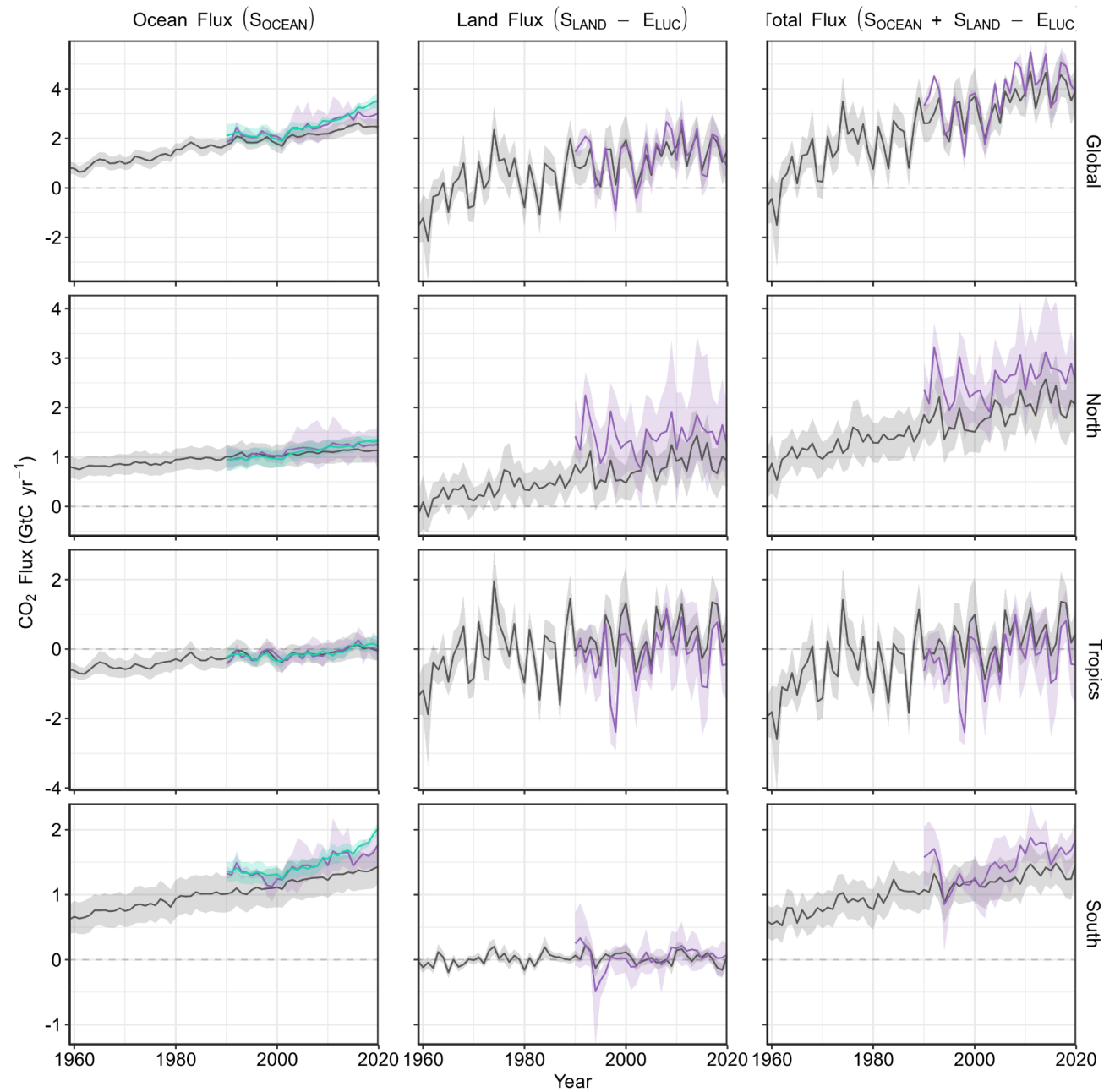

- Process - based models (DGVMs and GOBMs) — Inversions — Data products

1

2 Figure 12. $\mathrm{CO}_{2}$ fluxes between the atmosphere and the Earth's surface separated between land

3 and oceans, globally and in three latitude bands. The ocean flux is SOCEAN and the land flux is the

4 net atmosphere-land fluxes from the DGVMs. The latitude bands are (top row) global, ( $2^{\text {nd }}$ row)

5 north $\left(>30^{\circ} \mathrm{N}\right),\left(3^{\text {rd }}\right.$ row) tropics $\left(30^{\circ} \mathrm{S}-30^{\circ} \mathrm{N}\right)$, and (bottom row) south $\left(<30^{\circ} \mathrm{S}\right)$, and over ocean (left column), land (middle column), and total (right column). Estimates are shown for: process-based models (DGVMs for land, GOBMs for oceans); inversion models (land and ocean); and $\mathrm{fCO}_{2}$-based data products (ocean only). Positive values indicate a flux from the atmosphere to the land or the ocean. Mean estimates from the combination of the process models for the land and oceans are 
1 shown (black line) with \pm 1 standard deviation $(1 \sigma)$ of the model ensemble (grey shading). For the

2 total uncertainty in the process-based estimate of the total sink, uncertainties are summed in

3 quadrature. Mean estimates from the atmospheric inversions are shown (purple lines) with their

4 full spread (purple shading). Mean estimates from the $\mathrm{fCO}_{2}$-based data products are shown for the

5 ocean domain (light blue lines) with their $\pm 1 \sigma$ spread (light blue shading). The global SocEan (upper

6 left) and the sum of SOCEAN in all three regions represents the anthropogenic atmosphere-to-ocean

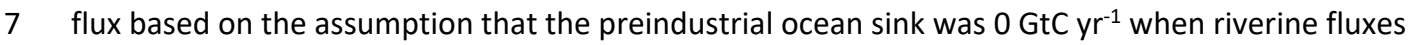

8 are not considered. This assumption does not hold at the regional level, where preindustrial fluxes

9 can be significantly different from zero. Hence, the regional panels for SocEAN represent a

10 combination of natural and anthropogenic fluxes. Bias-correction and area-weighting were only

11 applied to global Socean; hence the sum of the regions is slightly different from the global estimate

$12\left(<0.06 \mathrm{GtC}^{-1}\right)^{-1}$. 


\section{Anthropogenic carbon flows}

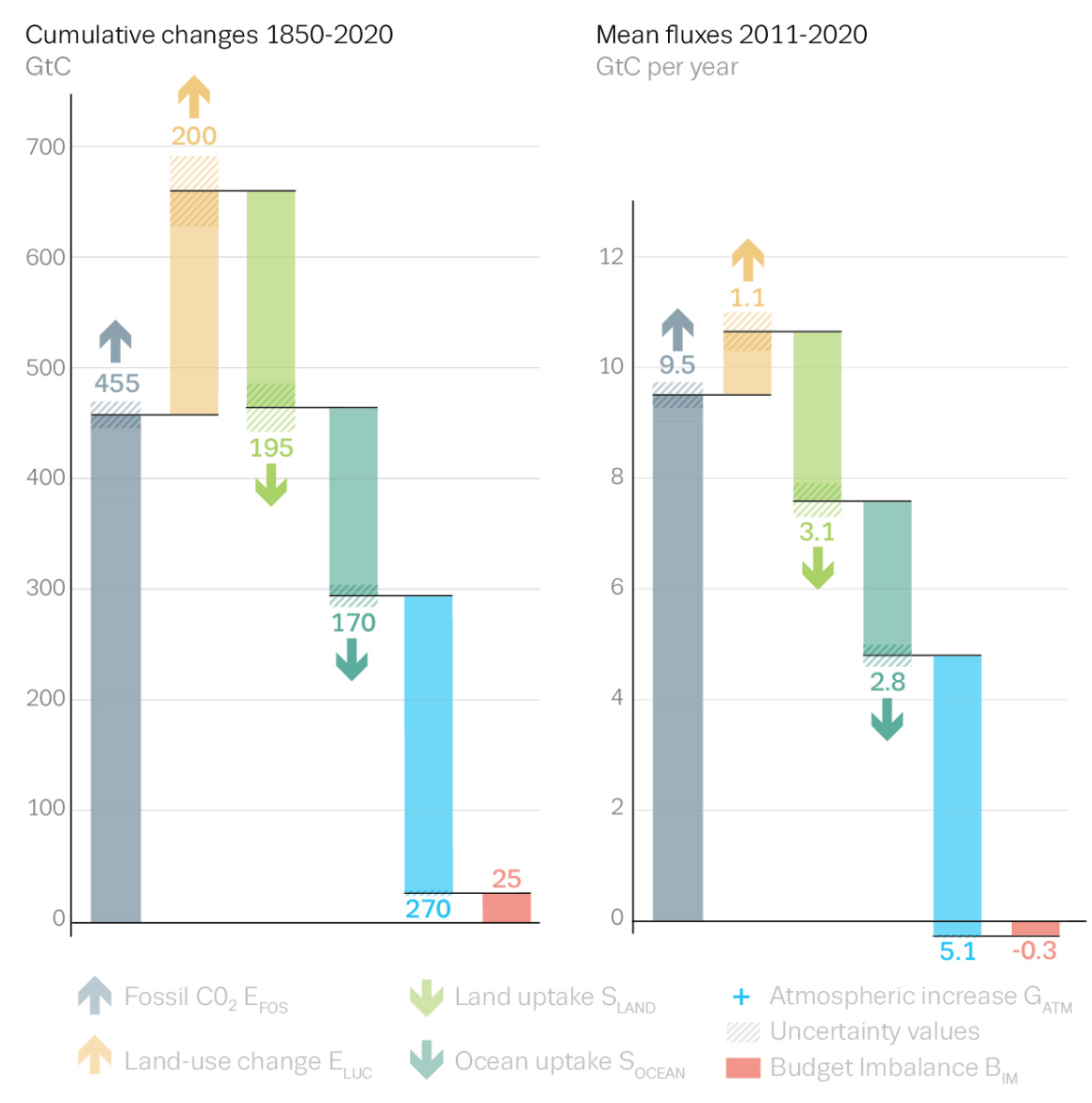

Figure 13. Cumulative changes over the 1850-2020 period (left) and average fluxes over the 2011-2020 period (right) for the anthropogenic perturbation of the global carbon cycle. See the caption of Figure 3 for key information and the methods in text for full details. 

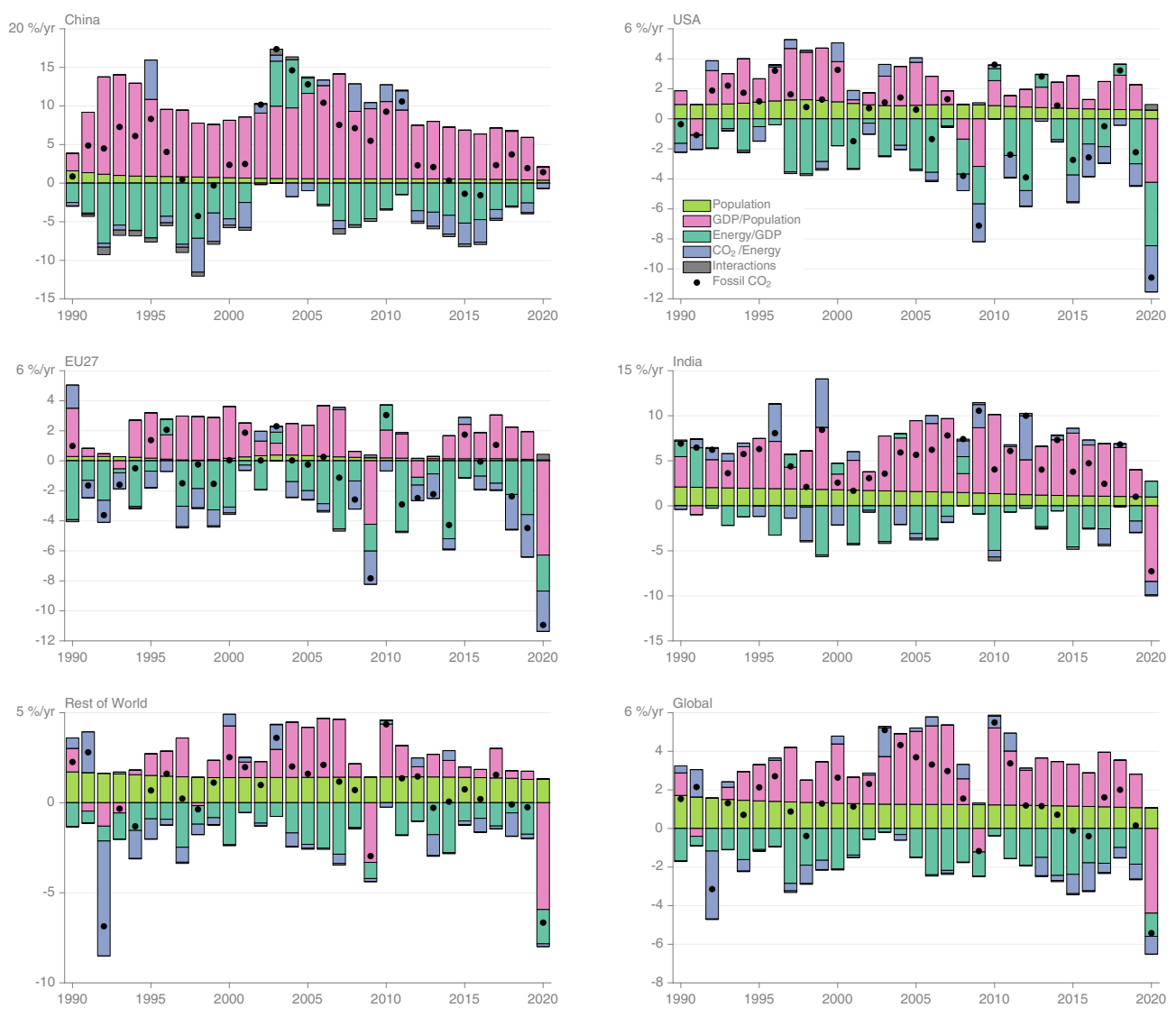

4 Figure 14. Kaya decomposition of the main drivers of fossil $\mathrm{CO}_{2}$ emissions, considering population,

5 GDP per person, Energy per GDP, and $\mathrm{CO}_{2}$ emissions per energy, for China (top left), USA (top right), EU27 (middle left), India (middle right), Rest of the World (bottom left), and World (bottom right). Black dots are the annual fossil $\mathrm{CO}_{2}$ emissions growth rate, coloured bars are the contributions from the different drivers. A general trend is that population and GDP growth put upward pressure on emissions, while energy per GDP and more recently $\mathrm{CO}_{2}$ emissions per energy

10 put downward pressure on emissions. The changes during 2020 led to a stark contrast to previous 11 years, with different drivers in each region. 


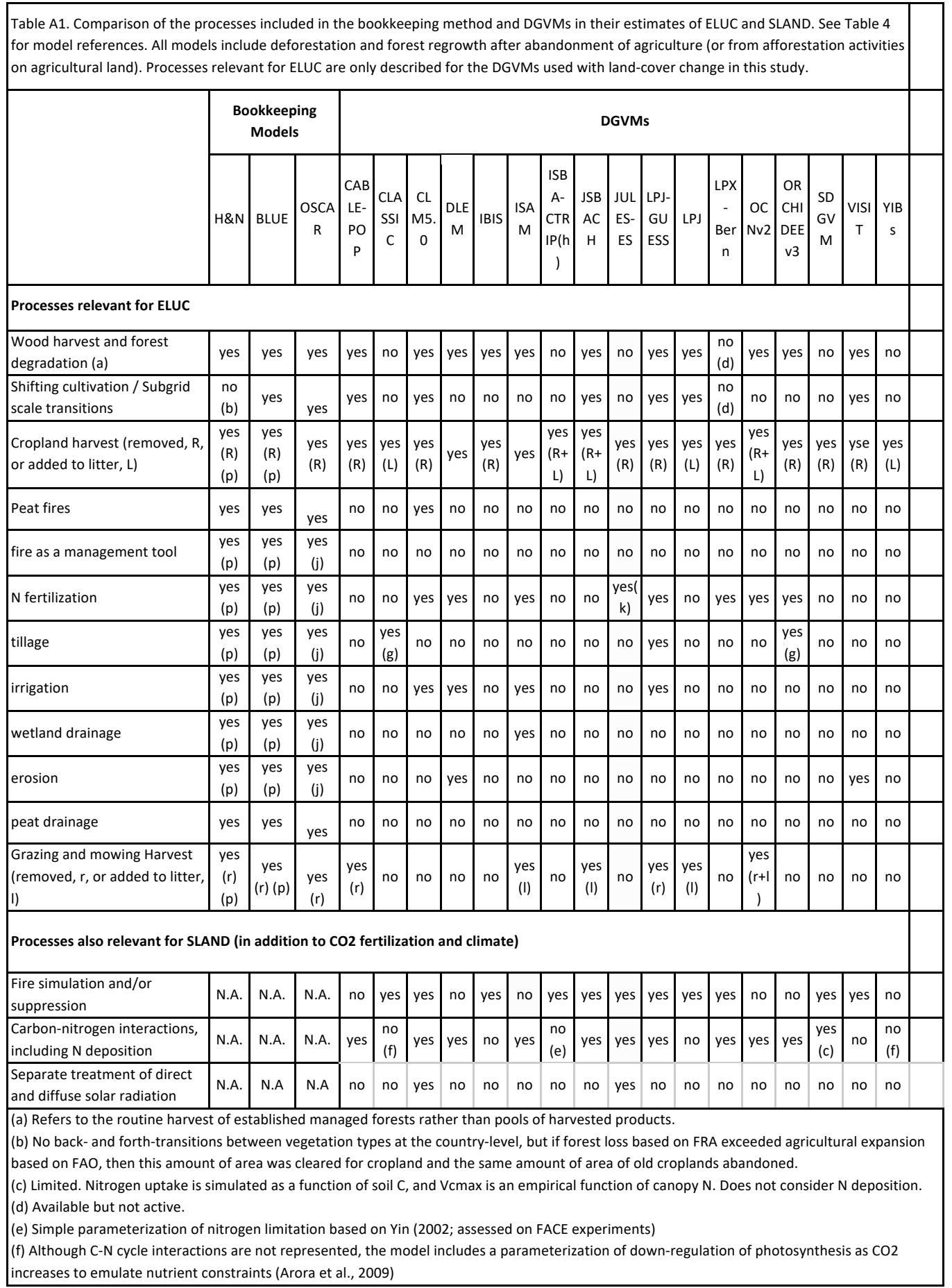


https://doi.org/10.5194/essd-2021-386

Preprint. Discussion started: 4 November 2021

(c) Author(s) 2021. CC BY 4.0 License.

(g) Tillage is represented over croplands by increased soil carbon decomposition rate and reduced humification of litter to soil carbon. (h) ISBA-CTRIP corresponds to SURFEXv8 in GCB2018

(i) Bookkeeping models include the effect of $\mathrm{CO} 2$-fertilization as captured by present-day carbon densities, but not as an effect transient in time. (j) as far as the DGVMs that OSCAR is calibrated to include it

(k) perfect fertilisation assumed, i.e. crops are not nitrogen limited and the implied fertiliser diagnosed

(m) fire intensity responds to climate and $\mathrm{CO} 2$, but no fire suppression

1

(z) Process captured implicitly by use of observed carbon densities. 
https://doi.org/10.5194/essd-2021-386

Preprint. Discussion started: 4 November 2021

(c) Author(s) 2021. CC BY 4.0 License.

Table A2. Comparison of the processes and model set up for the Global Ocean Biogeochemistry Models for their estimates of SOCEAN. See Table 4 for model references.

\begin{tabular}{|c|c|c|c|c|c|c|c|c|}
\hline & $\begin{array}{c}\text { NEMO- } \\
\text { PlankTOM1 } \\
2\end{array}$ & $\begin{array}{l}\text { NEMO- } \\
\text { PISCES } \\
\text { (IPSL) }\end{array}$ & $\begin{array}{c}\text { MICOM- } \\
\text { HAMOCC } \\
\text { (NorESM1- } \\
\text { OCv1.2) }\end{array}$ & $\begin{array}{l}\text { MPIOM- } \\
\text { HAMOCC6 }\end{array}$ & $\begin{array}{l}\text { FESOM-2.1- } \\
\text { REcoM2 }\end{array}$ & $\begin{array}{l}\text { NEMO3.6- } \\
\text { PISCESv2- } \\
\text { gas (CNRM) }\end{array}$ & $\begin{array}{c}\text { MOM6- } \\
\text { COBALT } \\
\text { (Princeton) }\end{array}$ & CESM-ETHZ \\
\hline \multicolumn{9}{|c|}{ SPIN-UP procedure } \\
\hline $\begin{array}{l}\text { Initialisation of } \\
\text { carbon chemistry }\end{array}$ & $\begin{array}{l}\text { GLODAPv1 } \\
\text { corrected for } \\
\text { anthropogeni } \\
\text { c carbon } \\
\text { from Sabine } \\
\text { et al. (2004) }\end{array}$ & GLODAPv2 & $\begin{array}{l}\text { GLODAP v1 } \\
\text { (preindustrial } \\
\text { DIC) }\end{array}$ & \begin{tabular}{|l} 
initialization \\
from \\
previous \\
model \\
simulations \\
\end{tabular} & \begin{tabular}{|l|} 
GLODAPv2 \\
alkalinity and \\
preindustrial \\
DIC
\end{tabular} & GLODAPv2 & $\begin{array}{l}\text { GLODAPv2 } \\
\text { for Alkalinity } \\
\text { and DIC. } \\
\text { DIC is } \\
\text { corrected to } \\
1959 \text { level } \\
\text { for } \\
\text { simulation A } \\
\text { and C and } \\
\text { corrected to } \\
\text { pre-industrial } \\
\text { level for } \\
\text { simulation B } \\
\text { using } \\
\text { Khatiwala et } \\
\text { al. (2009, } \\
2013 \text { ) }\end{array}$ & $\begin{array}{l}\text { GLODAPv2 } \\
\text { preindustrial }\end{array}$ \\
\hline $\begin{array}{l}\text { Preindustrial spin- } \\
\text { up prior to } 1850 ? \\
\text { If yes, how long? }\end{array}$ & $\begin{array}{l}\text { spin-up } \\
1750-1947\end{array}$ & $\begin{array}{l}\text { spin-up } \\
\text { starting in } \\
1836 \text { with } 3 \\
\text { loops of } \\
\text { JRA55 }\end{array}$ & $\begin{array}{l}1000 \text { year } \\
\text { spin up }\end{array}$ & $\begin{array}{l}\text { yes, } \sim 2000 \\
\text { years }\end{array}$ & 50 years & $\begin{array}{l}\text { long spin-up } \\
(>1000 \\
\text { years })\end{array}$ & $\begin{array}{l}\text { Other } \\
\text { biogeochemi } \\
\text { cal tracers } \\
\text { are initialized } \\
\text { from a } \\
\text { GFDL- } \\
\text { ESM2M } \\
\text { spin-up (> } \\
1000 \text { years) }\end{array}$ & $\begin{array}{l}\text { spinup 1655- } \\
1849\end{array}$ \\
\hline $\begin{array}{l}\text { atmospheric } \\
\text { forcing for pre- } \\
\text { industrial spin-up }\end{array}$ & $\begin{array}{l}\text { looping } \\
\text { NCEP year } \\
1990\end{array}$ & JRA55 & $\begin{array}{l}\text { CORE-I } \\
\text { (normal } \\
\text { year) forcing }\end{array}$ & $\begin{array}{l}\text { spinup with } \\
\text { omip } \\
\text { climatology } \\
\text { to reach } \\
\text { steady state } \\
\text { with the } \\
\text { rivers }\end{array}$ & $\begin{array}{l}\text { JRA55-do } \\
\text { v.1.5.0 } \\
\text { repeated } \\
\text { year } 1961\end{array}$ & JRA55-do & $\begin{array}{l}\text { GFDL- } \\
\text { ESM2M } \\
\text { internal } \\
\text { forcing }\end{array}$ & $\begin{array}{l}\text { COREv2 } \\
\text { forcing until } \\
1835 \text {, three } \\
\text { cycles of } \\
\text { conditions } \\
\text { from 1949- } \\
\text { 2009. from } \\
\text { 1835-1850: } \\
\text { JRA forcing }\end{array}$ \\
\hline $\begin{array}{l}\text { atmospheric } \\
\text { forcing for } \\
\text { historical spin-up } \\
1850-1958 \text { for } \\
\text { simulation A }\end{array}$ & $\begin{array}{l}\text { 1750-1947: } \\
\text { looping } \\
\text { NCEP year } \\
\text { 1990; 1948- } \\
\text { 2020: NCEP }\end{array}$ & $\begin{array}{l}\text { 1836-1958: } \\
\text { looping full } \\
\text { JRA55 } \\
\text { reanalysis }\end{array}$ & $\begin{array}{l}\text { CORE-I } \\
\text { (normal } \\
\text { year) forcing; } \\
\text { from } 1948 \\
\text { onwards } \\
\text { NCEP-R1 } \\
\text { with CORE-II } \\
\text { corrections }\end{array}$ & $\begin{array}{l}\text { NCEP } 6 \\
\text { hourly cyclic } \\
\text { forcing (10 } \\
\text { years } \\
\text { starting from } \\
1948) \text { with } \\
\text { co2 at } 278 \\
\text { ppm and } \\
\text { rivers }\end{array}$ & $\begin{array}{l}\text { JRA55-do- } \\
\text { v1.5.0 } \\
\text { repeated } \\
\text { year } 1961\end{array}$ & $\begin{array}{l}\text { JRA55-do } \\
\text { cycling year } \\
1958\end{array}$ & $\begin{array}{l}\text { JRA55-do- } \\
\text { v1.5 repeat } \\
\text { year } 1959 \\
\text { (71 years) }\end{array}$ & $\begin{array}{l}\text { JRA55 } \\
\text { version 1.3, } \\
\text { repeat cycle } \\
\text { between } \\
1958-2018 .\end{array}$ \\
\hline $\begin{array}{l}\text { atmospheric CO2 } \\
\text { for historical spin- } \\
\text { up } 1850-1958 \text { for } \\
\text { simulation A }\end{array}$ & $\begin{array}{l}\text { provided by } \\
\text { the GCP; } \\
\text { converted to } \\
\text { pCO2 } \\
\text { temperature } \\
\text { formulation } \\
\text { (Sarmiento } \\
\text { et al., 1992), } \\
\text { monthly }\end{array}$ & $\begin{array}{l}\text { xCO2 as } \\
\text { provided by } \\
\text { the GCB, } \\
\text { global mean, } \\
\text { annual } \\
\text { resolution, } \\
\text { converted to } \\
\text { pCO2 with } \\
\text { sea-level }\end{array}$ & $\begin{array}{l}\text { xCO2 as } \\
\text { provided by } \\
\text { the GCB, } \\
\text { converted to } \\
\text { pCO2 with } \\
\text { sea level } \\
\text { pressure and } \\
\text { water vapor } \\
\text { correction }\end{array}$ & $\begin{array}{l}\text { provided by } \\
\text { the GCB }\end{array}$ & $\begin{array}{l}\mathrm{xCO} 2 \text { as } \\
\text { provided by } \\
\text { the GCB, } \\
\text { converted to } \\
\text { pCO2 with } \\
\text { sea-level } \\
\text { pressure and } \\
\text { water vapour } \\
\text { pressure, }\end{array}$ & $\begin{array}{l}\text { xCO2 as } \\
\text { provided by } \\
\text { the GCB, } \\
\text { converted to } \\
\text { pCO2 with } \\
\text { constant } \\
\text { sea-level } \\
\text { pressure and } \\
\text { water vapour }\end{array}$ & $\begin{array}{l}\text { xCO2 at year } \\
1959 \text { level } \\
(315 \text { ppm), } \\
\text { converted to } \\
\text { pCO2 with } \\
\text { sea-level } \\
\text { pressure and } \\
\text { water vapour } \\
\text { pressure, }\end{array}$ & $\begin{array}{l}\text { xCO2 as } \\
\text { provided by } \\
\text { the GCB } \\
\text { (new version } \\
2021 \text { ), } \\
\text { converted to } \\
\text { pCO2 with } \\
\text { atmospheric } \\
\text { pressure, }\end{array}$ \\
\hline
\end{tabular}


https://doi.org/10.5194/essd-2021-386

Preprint. Discussion started: 4 November 2021

(c) Author(s) 2021. CC BY 4.0 License.

\begin{tabular}{|c|c|c|c|c|c|c|c|c|}
\hline & resolution & $\begin{array}{l}\text { pressure and } \\
\text { water vapour } \\
\text { pressure }\end{array}$ & & & $\begin{array}{l}\text { global mean, } \\
\text { monthly } \\
\text { resolution }\end{array}$ & $\begin{array}{l}\text { pressure, } \\
\text { global mean, } \\
\text { yearly } \\
\text { resolution }\end{array}$ & $\begin{array}{l}\text { global mean, } \\
\text { yearly } \\
\text { resolution }\end{array}$ & $\begin{array}{l}\text { and locally } \\
\text { determined } \\
\text { water vapour } \\
\text { pressure } \\
\text { from SST } \\
\text { and SSS } \\
\text { (100\% } \\
\text { saturation) }\end{array}$ \\
\hline $\begin{array}{l}\text { atmospheric } \\
\text { forcing for control } \\
\text { spin-up 1850- } \\
1958 \text { for } \\
\text { simulation B }\end{array}$ & $\begin{array}{l}\text { 1750-2020: } \\
\text { looping } \\
\text { NCEP } 1990\end{array}$ & $\begin{array}{l}\text { 1836-1958: } \\
\text { looping full } \\
\text { JRA55 } \\
\text { reanalysis }\end{array}$ & $\begin{array}{l}\text { CORE-I } \\
\text { (normal } \\
\text { year) forcing }\end{array}$ & $\begin{array}{l}\text { NCEP } 1957 \\
\text { fixed forcing, } \\
\text { co2 } 2=278 \text { and } \\
\text { rivers }\end{array}$ & $\begin{array}{l}\text { JRA55-do- } \\
\text { v1.5.0 repeat } \\
\text { year } 1961\end{array}$ & $\begin{array}{l}\text { JRA55-do } \\
\text { cycling year } \\
1958\end{array}$ & $\begin{array}{l}\text { JRA55-do- } \\
\text { v1.5 repeat } \\
\text { year } 1959 \\
\text { (71 years) }\end{array}$ & $\begin{array}{l}\text { normal year } \\
\text { forcing } \\
\text { created from } \\
\text { JRA-55 } \\
\text { version 1.3, } \\
\text { NYF = } \\
\text { climatology } \\
\text { with } \\
\text { anomalies } \\
\text { from the year } \\
2001\end{array}$ \\
\hline $\begin{array}{l}\text { atmospheric CO2 } \\
\text { for control spin-up } \\
1850-1958 \text { for } \\
\text { simulation B }\end{array}$ & $\begin{array}{l}\text { constant } \\
278 p p m ; \\
\text { converted to } \\
\text { pCO2 } \\
\text { temperature } \\
\text { formulation } \\
\text { (Sarmiento } \\
\text { et al., 1992), } \\
\text { monthly } \\
\text { resolution }\end{array}$ & $\begin{array}{l}\text { xCO2 of } \\
286.46 p p m, \\
\text { converted to } \\
\text { pCO2 with } \\
\text { constant } \\
\text { sea-level } \\
\text { pressure and } \\
\text { water vapour } \\
\text { pressure }\end{array}$ & $\begin{array}{l}\text { xCO2 of } 278 \\
\text { ppm, } \\
\text { converted to } \\
\text { pCO2 with } \\
\text { seal level } \\
\text { pressure and } \\
\text { water vapor } \\
\text { correction }\end{array}$ & $\begin{array}{l}278, \text { no } \\
\text { conversion, } \\
\text { assuming } \\
\text { constant } \\
\text { standard sea } \\
\text { level } \\
\text { pressure }\end{array}$ & $\begin{array}{l}\text { xCO2 of } \\
278 p p m, \\
\text { converted to } \\
\text { pCO2 with } \\
\text { sea-level } \\
\text { pressure and } \\
\text { water vapour } \\
\text { pressure }\end{array}$ & $\begin{array}{l}\text { xCO2 of } \\
286.46 p p m, \\
\text { converted to } \\
\text { pCO2 with } \\
\text { constant } \\
\text { sea-level } \\
\text { pressure and } \\
\text { water vapour } \\
\text { pressure }\end{array}$ & $\begin{array}{l}\text { xCO2 of } \\
278 p p m, \\
\text { converted to } \\
\text { pCO2 with } \\
\text { sea-level } \\
\text { pressure and } \\
\text { water vapour } \\
\text { pressure }\end{array}$ & $\begin{array}{l}\text { xCO2 as } \\
\text { provided by } \\
\text { the GCB for } \\
1850 \text {, } \\
\text { converted to } \\
\text { pCO2 with } \\
\text { atmospheric } \\
\text { pressure, } \\
\text { and locally } \\
\text { determined } \\
\text { water vapour } \\
\text { pressure } \\
\text { from SST } \\
\text { and SSS } \\
\text { (100\% } \\
\text { saturation) }\end{array}$ \\
\hline \multicolumn{9}{|l|}{ simulation $\mathrm{A}$} \\
\hline $\begin{array}{l}\text { Atmospheric } \\
\text { forcing for } \\
\text { simulation A }\end{array}$ & NCEP & $\begin{array}{l}\text { JRA55-v1.4 } \\
\text { then } 1.5 \text { for } \\
2020 .\end{array}$ & $\begin{array}{l}\text { NCEP-R1 } \\
\text { with CORE-II } \\
\text { corrections }\end{array}$ & $\begin{array}{l}\text { till1948: } \\
\text { continue } \\
\text { from } \\
\text { A_spinup } \\
\text { with cyclic } \\
\text { NCEP } \\
\text { forcing } \\
(1948+10) \\
\text { and } \\
\text { increasing } \\
\text { CO2 => } \\
\text { GCBA-1777- } \\
\text { 1948 } \\
-1948-2020 \text { : } \\
\text { with transient } \\
\text { NCEP } \\
\text { forcing and } \\
\text { transient } \\
\text { monthly CO2 }\end{array}$ & $\begin{array}{l}\text { JRA55-do- } \\
\text { v1.5.0 } \\
\\
\\
\\
\end{array}$ & JRA55-do & $\begin{array}{l}\text { JRA55-do- } \\
\text { v1.5.0 1959- } \\
2019 \text { and } \\
\text { JRA55-do- } \\
\text { v1.5.0.1b for } \\
2020\end{array}$ & $\begin{array}{l}\text { JRA-55 } \\
\text { version } 1.3\end{array}$ \\
\hline $\begin{array}{l}\text { atmospheric } \mathrm{CO} 2 \\
\text { for simulation } \mathrm{A}\end{array}$ & $\begin{array}{l}\text { provided by } \\
\text { the GCP; } \\
\text { converted to } \\
\text { pCO2 } \\
\text { temperature } \\
\text { formulation } \\
\text { (Sarmiento } \\
\text { et al., 1992), } \\
\text { monthly } \\
\text { resolution }\end{array}$ & $\begin{array}{l}\text { xCO2 as } \\
\text { provided by } \\
\text { the GCB, } \\
\text { global mean, } \\
\text { annual } \\
\text { resolution, } \\
\text { converted to } \\
\text { pCO2 with } \\
\text { sea-level } \\
\text { pressure and }\end{array}$ & $\begin{array}{l}\mathrm{xCO} 2 \text { as } \\
\text { provided by } \\
\text { the GCB, } \\
\text { converted to } \\
\text { pCO2 with } \\
\text { sea level } \\
\text { pressure and } \\
\text { water vapor } \\
\text { correction }\end{array}$ & & $\begin{array}{l}\mathrm{xCO} 2 \text { as } \\
\text { provided by } \\
\text { the GCB, } \\
\text { converted to } \\
\text { pCO2 with } \\
\text { sea-level } \\
\text { pressure and } \\
\text { water vapour } \\
\text { pressure, } \\
\text { global mean, }\end{array}$ & $\begin{array}{l}\mathrm{xCO} 2 \text { as } \\
\text { provided by } \\
\text { the GCB, } \\
\text { converted to } \\
\text { pCO2 with } \\
\text { constant } \\
\text { sea-level } \\
\text { pressure and } \\
\text { water vapour } \\
\text { pressure, }\end{array}$ & $\begin{array}{l}\text { xCO2 as } \\
\text { provided by } \\
\text { the GCB, } \\
\text { converted to } \\
\text { pCO2 with } \\
\text { sea-level } \\
\text { pressure and } \\
\text { water vapour } \\
\text { pressure, } \\
\text { global mean, }\end{array}$ & $\begin{array}{l}\text { xCO2 as } \\
\text { provided by } \\
\text { the GCB } \\
\text { (new version } \\
2021 \text { ), } \\
\text { converted to } \\
\text { pCO2 with } \\
\text { atmospheric } \\
\text { pressure, } \\
\text { and locally }\end{array}$ \\
\hline
\end{tabular}


https://doi.org/10.5194/essd-2021-386

Preprint. Discussion started: 4 November 2021

(c) Author(s) 2021. CC BY 4.0 License.

\begin{tabular}{|c|c|c|c|c|c|c|c|c|}
\hline & & $\begin{array}{l}\text { water vapour } \\
\text { pressure }\end{array}$ & & & $\begin{array}{l}\text { monthly } \\
\text { resolution }\end{array}$ & $\begin{array}{l}\text { global mean, } \\
\text { yearly } \\
\text { resolution }\end{array}$ & $\begin{array}{l}\text { yearly } \\
\text { resolution }\end{array}$ & $\begin{array}{l}\text { determined } \\
\text { water vapour } \\
\text { pressure } \\
\text { from SST } \\
\text { and SSS } \\
\text { (100\% } \\
\text { saturation) }\end{array}$ \\
\hline \multicolumn{9}{|l|}{ simulation B } \\
\hline $\begin{array}{l}\text { Atmospheric } \\
\text { forcing for } \\
\text { simulation B }\end{array}$ & NCEP 1990 & N/A & $\begin{array}{l}\text { CORE-I } \\
\text { (normal } \\
\text { year) forcing }\end{array}$ & $\begin{array}{l}\text { 1948-2020: } \\
\text { continue with } \\
\text { B_spinup } \\
\text { with fixed } \\
\text { NCEP } \\
\text { forcing } 1957 \text {, } \\
\text { co2=278 and } \\
\text { rivers }\end{array}$ & \begin{tabular}{|l|} 
JRA55-do- \\
v1.5.0 repeat \\
year 1961 \\
\end{tabular} & $\begin{array}{l}\text { JRA55-do } \\
\text { cycling year } \\
1958\end{array}$ & $\begin{array}{l}\text { JRA55-do- } \\
\text { v1.5.0 repeat } \\
\text { year } 1959\end{array}$ & $\begin{array}{l}\text { normal year } \\
\text { forcing } \\
\text { created from } \\
\text { JRA-55 } \\
\text { version 1.3, } \\
\text { NYF = } \\
\text { climatology } \\
\text { with } \\
\text { anomalies } \\
\text { from the year } \\
2001\end{array}$ \\
\hline $\begin{array}{l}\text { atmospheric } \mathrm{CO} 2 \\
\text { for simulation } \mathrm{B}\end{array}$ & $\begin{array}{l}\text { constant } \\
278 p p m ; \\
\text { converted to } \\
\text { pCO2 } \\
\text { temperature } \\
\text { formulation } \\
\text { (Sarmiento } \\
\text { et al., 1992), } \\
\text { monthly } \\
\text { resolution }\end{array}$ & N/A & $\begin{array}{l}\text { xCO2 of } 278 \\
\text { ppm, } \\
\text { converted to } \\
\text { pCO2 with } \\
\text { sea level } \\
\text { pressure and } \\
\text { water vapor } \\
\text { correction }\end{array}$ & & $\begin{array}{l}\text { xCO2 of } \\
\text { 278ppm, } \\
\text { converted to } \\
\text { pCO2with } \\
\text { sea-level } \\
\text { pressure and } \\
\text { water vapour } \\
\text { pressure }\end{array}$ & $\begin{array}{l}\text { xCO2 of } \\
286.46 p p m, \\
\text { converted to } \\
\text { pCO2 with } \\
\text { constant } \\
\text { sea-level } \\
\text { pressure and } \\
\text { water vapour } \\
\text { pressure }\end{array}$ & $\begin{array}{l}\text { xCO2 of } \\
278 p p m, \\
\text { converted to } \\
\text { pCO2 with } \\
\text { sea-level } \\
\text { pressure and } \\
\text { water vapour } \\
\text { pressure }\end{array}$ & $\begin{array}{l}\text { xCO2 as } \\
\text { provided by } \\
\text { the GCB for } \\
1850, \\
\text { converted to } \\
\text { pCO2 with } \\
\text { atmospheric } \\
\text { pressure, } \\
\text { and locally } \\
\text { determined } \\
\text { water vapour } \\
\text { pressure } \\
\text { from SST } \\
\text { and SSS } \\
\text { (100\% } \\
\text { saturation) } \\
\end{array}$ \\
\hline \multicolumn{9}{|l|}{ model specifics } \\
\hline $\begin{array}{l}\text { Physical ocean } \\
\text { model }\end{array}$ & $\begin{array}{l}\text { NEMOv3.6- } \\
\text { ORCA2 }\end{array}$ & $\begin{array}{l}\text { NEMOv3.6- } \\
\text { eORCA1L75 }\end{array}$ & $\begin{array}{l}\text { MICOM } \\
\text { (NorESM1- } \\
\text { OCv1.2) }\end{array}$ & MPIOM & FESOM-2.1 & $\begin{array}{l}\text { NEMOv3.6- } \\
\text { GELATOv6- } \\
\text { eORCA1L75 }\end{array}$ & MOM6-SIS2 & $\begin{array}{l}\text { CESMv1.3 } \\
\text { (ocean } \\
\text { model based } \\
\text { on POP2) }\end{array}$ \\
\hline $\begin{array}{l}\text { Biogeochemistry } \\
\text { model }\end{array}$ & PlankTOM12 & PISCESv2 & $\begin{array}{l}\text { HAMOCC } \\
\text { (NorESM1- } \\
\text { OCv1.2) }\end{array}$ & HAMOCC6 & REcoM-2-M & $\begin{array}{l}\text { PISCESv2- } \\
\text { gas }\end{array}$ & COBALTv2 & $\begin{array}{l}\text { BEC } \\
\text { (modified \& } \\
\text { extended) }\end{array}$ \\
\hline $\begin{array}{l}\text { Horizontal } \\
\text { resolution }\end{array}$ & $\begin{array}{l}20 \text { lon, } 0.3 \text { to } \\
1.50 \text { lat }\end{array}$ & $\begin{array}{l}1^{\circ} \text { lon, } 0.3 \text { to } \\
1^{\circ} \text { lat }\end{array}$ & $\begin{array}{l}1^{\circ} \text { lon, } 0.17 \\
\text { to } 0.25 \text { lat } \\
\text { (nominally } \\
1^{\circ} \text { ) }\end{array}$ & $1.5^{\circ}$ & $\begin{array}{l}\text { unstructured } \\
\text { multi- } \\
\text { resolution } \\
\text { mesh. } \\
\text { CORE- } \\
\text { mesh, with } \\
20-120 \mathrm{~km} \\
\text { resolution. } \\
\text { Highest } \\
\text { resolution } \\
\text { north of } 50 \mathrm{~N}, \\
\text { intermediate } \\
\text { in the } \\
\text { equatorial } \\
\text { belt and } \\
\text { Southern } \\
\text { Ocean, } \\
\text { lowest in the } \\
\text { subtropical } \\
\text { gyres }\end{array}$ & $\begin{array}{l}1^{\circ} \text { lon, } 0.3 \text { to } \\
1^{\circ} \text { lat }\end{array}$ & $\begin{array}{l}0.5^{\circ} \text { lon, } 0.25 \\
\text { to } 0.5^{\circ} \text { lat }\end{array}$ & $\begin{array}{l}\text { Lon: } 1.125^{\circ} \text {, } \\
\text { Lat varying } \\
\text { from } 0.53^{\circ} \text { in } \\
\text { the } \\
\text { extratropics } \\
\text { to } 0.27^{\circ} \text { near } \\
\text { the equator }\end{array}$ \\
\hline
\end{tabular}


https://doi.org/10.5194/essd-2021-386

Preprint. Discussion started: 4 November 2021

(c) Author(s) 2021. CC BY 4.0 License.

\begin{tabular}{|c|c|c|c|c|c|c|c|c|}
\hline Vertical resolution & 31 levels & $\begin{array}{l}75 \text { levels, } 1 \mathrm{~m} \\
\text { at the } \\
\text { surface }\end{array}$ & $\begin{array}{l}51 \text { isopycnic } \\
\text { layers }+2 \\
\text { layers } \\
\text { representing } \\
\text { a bulk mixed } \\
\text { layer }\end{array}$ & $\begin{array}{l}40 \text { levels, } \\
\text { layer } \\
\text { thickness } \\
\text { increase with } \\
\text { depth }\end{array}$ & $\begin{array}{l}46 \text { levels, } 10 \\
\mathrm{~m} \text { spacing in } \\
\text { the top } 100 \\
\mathrm{~m}\end{array}$ & $\begin{array}{l}75 \text { levels, } 1 \mathrm{~m} \\
\text { at surface }\end{array}$ & $\begin{array}{l}75 \text { levels } \\
\text { hybrid } \\
\text { coordinates, } \\
2 \text { m at } \\
\text { surface }\end{array}$ & $\begin{array}{l}60 \text { levels (z- } \\
\text { coordinates) }\end{array}$ \\
\hline $\begin{array}{l}\text { Total ocean area } \\
\text { on native grid } \\
(\mathrm{km} 2)\end{array}$ & $3.6080 \mathrm{E}+08$ & $3.6270 \mathrm{E}+08$ & $3.6006 \mathrm{E}+08$ & $3.6598 \mathrm{E}+08$ & $3.6475 \mathrm{E}+08$ & $3.6270 \mathrm{E}+14$ & $3.6110 \mathrm{E}+08$ & $3.5926 \mathrm{E}+08$ \\
\hline $\begin{array}{l}\text { Ocean area on } \\
\text { native grid }(\mathrm{km} 2) \text { - } \\
\text { NORTH }\end{array}$ & $6.2646 \mathrm{E}+07$ & & $6.2049 E+07$ & $6.4440 \mathrm{E}+07$ & & $6.3971 \mathrm{E}+13$ & & \\
\hline $\begin{array}{l}\text { Ocean area on } \\
\text { native grid }(\mathrm{km} 2) \text { - } \\
\text { TROPICS }\end{array}$ & $1.1051 \mathrm{E}+08$ & & $1.9037 \mathrm{E}+08$ & $1.9248 E+08$ & & 1.9025E+14 & & \\
\hline $\begin{array}{l}\text { Ocean area on } \\
\text { native grid }(\mathrm{km} 2) \text { - } \\
\text { SOUTH }\end{array}$ & $1.8766 \mathrm{E}+08$ & & $1.0765 \mathrm{E}+08$ & $1.0986 \mathrm{E}+08$ & & $1.0848 \mathrm{E}+14$ & & \\
\hline $\begin{array}{l}\text { gas-exchange } \\
\text { parameterization }\end{array}$ & $\begin{array}{l}\text { Quadratic } \\
\text { exchange } \\
\text { formulation } \\
\text { (function of T } \\
\left.+0.3^{*} U^{\wedge} 2\right)^{*} \\
(\mathrm{Sc} / 660)^{\wedge}- \\
0.5) ; \\
\text { Wanninkhof } \\
(1992, \\
\text { Equation 8); } \\
\text { Sweeney et } \\
\text { al. (2007) }\end{array}$ & $\begin{array}{l}\text { see Orr et al. } \\
\text { (2017): kw } \\
\text { parameterize } \\
\text { d from } \\
\text { Wanninkhof } \\
(1992) \text {, with } \\
\text { kw }=a^{*} \\
(S c / 660)^{\wedge}- \\
0.5)^{*} 2^{*}(1- \\
\text { f_ice) with a } \\
\text { from } \\
\text { Wanninkhof } \\
\text { (2014) }\end{array}$ & $\begin{array}{l}\text { see Orr et al. } \\
\text { (2017): kw } \\
\text { parameterize } \\
\text { d from } \\
\text { Wanninkhof } \\
(1992) \text {, with } \\
\text { kw }=a^{*} \\
(\mathrm{Sc} / 660)^{\wedge} \text { - } \\
0.5)^{*} 2^{*}(1- \\
\text { f_ice) with } \\
a=0.337 \\
\text { following the } \\
\text { OCMIP2 } \\
\text { protocols }\end{array}$ & $\begin{array}{l}\text { Gas transfer } \\
\text { velocity } \\
\text { formulation } \\
\text { and } \\
\text { parameter } \\
\text { setup of } \\
\text { Wanninkhof } \\
(2014), \\
\text { including } \\
\text { updated } \\
\text { Schmidt } \\
\text { number } \\
\text { parameteriza } \\
\text { tions for CO2 } \\
\text { to comply } \\
\text { with OMIP } \\
\text { protocol (Orr } \\
\text { et al., 2017) }\end{array}$ & $\begin{array}{l}\text { see Orr et al. } \\
\text { (2017): kw } \\
\text { parameterize } \\
\text { d from } \\
\text { Wanninkhof } \\
(1992) \text {, with } \\
\text { kw = a* } \\
(\text { Sc/660 })^{\wedge} \text { - } \\
0.5)^{*} 2^{*}(1- \\
\text { f_ice) with a } \\
\text { from } \\
\text { Wanninkhof } \\
(2014) \\
\end{array}$ & $\begin{array}{l}\text { see Orr et al. } \\
\text { (2017): kw } \\
\text { parameterize } \\
\text { d from } \\
\text { Wanninkhof } \\
(1992) \text {, with } \\
\text { kw }=a^{*} \\
(S c / 660)^{\wedge}- \\
0.5)^{*} 2^{*}(1- \\
\text { f_ice) with a } \\
\text { from } \\
\text { Wanninkhof } \\
\text { (2014) }\end{array}$ & $\begin{array}{l}\text { see Orr et al. } \\
\text { (2017): kw } \\
\text { parameterize } \\
\text { d from } \\
\text { Wanninkhof } \\
(1992) \text {, with } \\
\text { kw }=a^{*} \\
(S c / 660)^{\wedge} \text { - } \\
0.5)^{*} 2^{*}(1- \\
\text { f_ice) with a } \\
\text { from } \\
\text { Wanninkhof } \\
(2014)\end{array}$ & $\begin{array}{l}\text { Gas } \\
\text { exchange is } \\
\text { parameterize } \\
\text { d using the } \\
\text { Wanninkhof } \\
\text { (1992) } \\
\text { quadratic } \\
\text { windspeed } \\
\text { dependency } \\
\text { formulation, } \\
\text { but with the } \\
\text { coefficient } \\
\text { scaled down } \\
\text { to reflect the } \\
\text { recent } 14 C \\
\text { inventories. } \\
\text { Concretely, } \\
\text { we used a } \\
\text { coefficent a } \\
\text { of } 0: 31 \mathrm{~cm} \\
\text { hr-1 s2 } \mathrm{m}-2 \\
\text { to read kw }= \\
0: 31 \mathrm{ws} 2 \\
(1-\text {-fice) } \\
(\text { Sc }=660)^{\wedge}\{- \\
1 / 2\}\end{array}$ \\
\hline time-step & 96 mins & $45 \mathrm{~min}$ & $3200 \mathrm{sec}$ & 60 mins & $45 \mathrm{~min}$ & $15 \mathrm{~min}$ & $30 \mathrm{~min}$ & $3757 \mathrm{sec}$ \\
\hline output frequency & Monthly & monthly & monthly/daily & monthly & monthly & monthly & monthly & monthly \\
\hline $\begin{array}{l}\text { CO2 chemistry } \\
\text { routines }\end{array}$ & $\begin{array}{l}\text { Following } \\
\text { Broecker et } \\
\text { al. (1982) }\end{array}$ & mocsy & $\begin{array}{l}\text { Following } \\
\text { Dickson et } \\
\text { al. (2007) }\end{array}$ & $\begin{array}{l}\text { as in llyina et } \\
\text { al. (2013) } \\
\text { adapted to } \\
\text { comply with } \\
\text { OMIP } \\
\text { protocol (Orr } \\
\text { et al., 2017). }\end{array}$ & mocsy & mocsy & mocsy & $\begin{array}{l}\text { OCMIP2 (Orr } \\
\text { et al., 2017) }\end{array}$ \\
\hline $\begin{array}{l}\text { river carbon input } \\
(\mathrm{PgC} / \mathrm{yr})\end{array}$ & $\begin{array}{l}60.24 \\
\text { Tmol/yr; } \\
0.723 \mathrm{PgC} / \mathrm{yr}\end{array}$ & $0.61 \mathrm{PgC} y-1$ & 0 & $0.77 \mathrm{PgC} / \mathrm{yr}$ & 0 & $\begin{array}{l}\sim 0.611 \mathrm{PgC} \\
\mathrm{y}-1\end{array}$ & $\begin{array}{l}\sim 0.15 \mathrm{PgC} y- \\
1\end{array}$ & $\begin{array}{l}0.33 \mathrm{Pg} \mathrm{C} \mathrm{yr}- \\
1\end{array}$ \\
\hline $\begin{array}{l}\text { burial/net flux into } \\
\text { the sediment } \\
\text { (PgC/yr) }\end{array}$ & $0.723 \mathrm{PgC} / \mathrm{yr}$ & 0.59 GtC y-1 & around 0.54 & $\begin{array}{l}\text { around } 0.44 \\
\mathrm{PgC/yr}\end{array}$ & 0 & $\begin{array}{l}\sim 0.656 \mathrm{GtC} \\
\mathrm{y}-1\end{array}$ & $\begin{array}{l}\sim 0.18 \mathrm{PgC} y- \\
1\end{array}$ & $\begin{array}{l}0.21 \mathrm{Pg} \mathrm{C} \mathrm{yr}- \\
1\end{array}$ \\
\hline
\end{tabular}


Table A3: Description of ocean data-products used for assessment of SOCEAN. See Table 4 for references.

\begin{tabular}{|c|c|c|c|c|c|c|c|c|}
\hline & Jena-MLS & MPI-SOMFFN & $\begin{array}{l}\text { CMEMS-LSCE- } \\
\text { FFNN }\end{array}$ & CSIR-ML6 & Watson et al & NIES-NN & JMA-MLR & OS-ETHZ-GRaCER \\
\hline Method & $\begin{array}{l}\text { Spatio- } \\
\text { temporal } \\
\text { interpolation } \\
\text { (update of } \\
\text { Rödenbeck } \\
\text { et al., 2013, } \\
\text { version } \\
\text { oc_v2021). } \\
\text { Specifically, } \\
\text { the sea-air } \\
\text { cO2 fluxes } \\
\text { and the } \\
\text { pcO2 field } \\
\text { are } \\
\text { numerically } \\
\text { linked to } \\
\text { each other } \\
\text { and to the } \\
\text { spatio- } \\
\text { temporal } \\
\text { field of } \\
\text { ocean- } \\
\text { internal } \\
\text { carbon } \\
\text { sources/sinks } \\
\text { through } \\
\text { process } \\
\text { parametrizati } \\
\text { ons, and the } \\
\text { ocean- } \\
\text { internal } \\
\text { sources/sink } \\
\text { field is then } \\
\text { fit to the } \\
\text { socATv2021 } \\
\text { pcO2 data } \\
\text { (Bakker et } \\
\text { al., 2021). } \\
\text { The fit } \\
\text { includes a } \\
\text { multi-linear } \\
\text { regression } \\
\text { against } \\
\text { environment } \\
\text { al drivers to } \\
\text { bridge data } \\
\text { gaps, and } \\
\text { interannually } \\
\text { explicit } \\
\text { corrections } \\
\text { signals more } \\
\text { completely. }\end{array}$ & 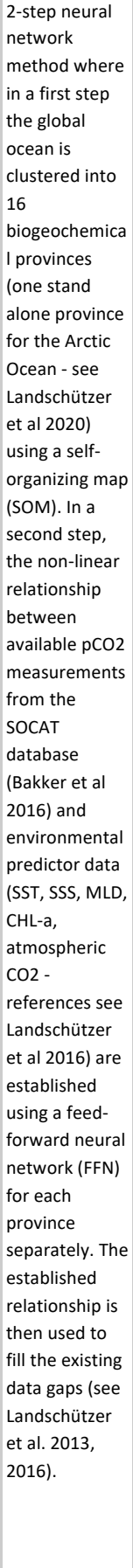 & $\begin{array}{l}\text { An ensemble } \\
\text { of neural } \\
\text { network } \\
\text { models trained } \\
\text { on } 100 \\
\text { subsampled } \\
\text { datasets from } \\
\text { the Surface } \\
\text { Ocean CO2 } \\
\text { Atlas v2021 } \\
\text { (SOCATv2021, } \\
\text { Bakker et al. } \\
2021 \text { ). Like the } \\
\text { original data, } \\
\text { subsamples } \\
\text { are distributed } \\
\text { after } \\
\text { interpolation } \\
\text { on } 1 \times 1 \text { grid } \\
\text { cells along ship } \\
\text { tracks. Sea } \\
\text { surface } \\
\text { salinity, } \\
\text { temperature, } \\
\text { sea surface } \\
\text { height, mixed } \\
\text { layer depth, } \\
\text { atmospheric } \\
\text { cO2 mole } \\
\text { fraction, } \\
\text { chlorophyll-a, } \\
\text { pcO2 } \\
\text { climatology, } \\
\text { latitude and } \\
\text { longitude are } \\
\text { used as } \\
\text { predictors. The } \\
\text { models are } \\
\text { used to } \\
\text { reconstruct } \\
\text { sea surface } \\
\text { pCO2 and } \\
\text { convert to air- } \\
\text { sea CO2 fluxes } \\
\text { (see the } \\
\text { proposed } \\
\text { ensemble- } \\
\text { based } \\
\text { approach and } \\
\text { analysis in } \\
\text { Chau et al. } \\
\text { 2020, } 2021 \text { ). }\end{array}$ & 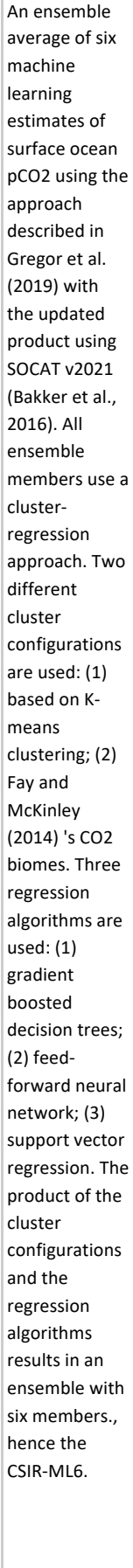 & $\begin{array}{l}\text { Derived from } \\
\text { the } \\
\text { SOCAT(v2021) } \\
\text { pCO2 } \\
\text { database, but } \\
\text { corrected to } \\
\text { the subskin } \\
\text { temperature } \\
\text { of the ocean as } \\
\text { measured by } \\
\text { satellite, using } \\
\text { the } \\
\text { methodology } \\
\text { described by } \\
\text { Goddijn- } \\
\text { Murphy et al. } \\
\text { (2015). A } \\
\text { correction to } \\
\text { the flux } \\
\text { calculation is } \\
\text { also applied } \\
\text { for the cool } \\
\text { and salty } \\
\text { surface skin. In } \\
\text { other respects } \\
\text { the product } \\
\text { uses } \\
\text { interpolation } \\
\text { of the data } \\
\text { using the two } \\
\text { step neural } \\
\text { network based } \\
\text { on MPI- } \\
\text { somFFN :in } \\
\text { the first step } \\
\text { the ocean is } \\
\text { divided into a } \\
\text { monthly } \\
\text { climatology of } \\
\text { and SST, SSS, } \\
\text { mixed layer } \\
\text { biogeochemica } \\
\text { depth(MLD) } \\
\text { and } \\
\text { I provinces } \\
\text { using a SOM, } \\
\text { In the second } \\
\text { step a feed- } \\
\text { forward neural } \\
\text { network in each } \\
\text { establishes } \\
\text { non-linear } \\
\text { relionships } \\
\text { men pCO2 } \\
\text { maric }\end{array}$ & $\begin{array}{l}\text { A feed forward } \\
\text { neural network } \\
\text { model was } \\
\text { used to } \\
\text { reconstruct } \\
\text { monthly global } \\
\text { surface ocean } \\
\text { CO2 } \\
\text { concentrations } \\
1 \times 1 \text { degree } \\
\text { meshes and } \\
\text { estimate air- } \\
\text { sea CO2 fluxes. } \\
\text { The target } \\
\text { variable is the } \\
\text { per cruise } \\
\text { weighted fCO2 } \\
\text { mean of } \\
\text { SOCAT } 2021 . \\
\text { Feature } \\
\text { variables } \\
\text { include sea } \\
\text { surface } \\
\text { temperature } \\
\text { (SST), salinity, } \\
\text { chlorophyll-a, } \\
\text { mixed layer } \\
\text { depth, and the } \\
\text { monthly } \\
\text { nomaly of SST. } \\
\text { See Zeng et al. } \\
\text { (2014) } \\
\\
\\
\end{array}$ & $\begin{array}{l}\text { Fields of total } \\
\text { alkalinity (TA) } \\
\text { were } \\
\text { estimated by } \\
\text { using a } \\
\text { multiple linear } \\
\text { regressions } \\
\text { (MLR) method } \\
\text { based on } \\
\text { GLODAPv2.202 } \\
1 \text { and satellite } \\
\text { observation } \\
\text { data. } \\
\text { TA = f(SSDH, } \\
\text { SSS) } \\
\text { SOCATV2021 } \\
\text { fCO2 data } \\
\text { were } \\
\text { converted to } \\
\text { total dissolved } \\
\text { inorganic } \\
\text { carbon (DIC) } \\
\text { concentrations } \\
\text { in combination } \\
\text { with the TA, } \\
\text { and then fields } \\
\text { of DIC were } \\
\text { estimated by } \\
\text { using a MLR } \\
\text { method based } \\
\text { on the DIC and } \\
\text { satellite } \\
\text { observation } \\
\text { data. } \\
\text { DIC = f(SSDH, } \\
\text { SST, SSS, } \\
\text { log(Chl), } \\
\text { log(MLD), } \\
\text { time) }\end{array}$ & $\begin{array}{l}\text { OceanSODA- } \\
\text { ETHZ's } \\
\text { Geospatial } \\
\text { Random } \\
\text { Cluster } \\
\text { Ensemble } \\
\text { Regression is a } \\
\text { two-step } \\
\text { cluster- } \\
\text { regression } \\
\text { approach, } \\
\text { where multiple } \\
\text { clustering } \\
\text { instances with } \\
\text { slight } \\
\text { variations are } \\
\text { run to create } \\
\text { an ensemble } \\
\text { of estimates } \\
\text { (n_membersd= } \\
16 \text { ). We use K- } \\
\text { means } \\
\text { clustering } \\
\text { (n_clusters=21 } \\
\text { ) for the } \\
\text { clustering step } \\
\text { and a } \\
\text { combination of } \\
\text { Gradient } \\
\text { boosted trees } \\
\text { (n_members=8 } \\
\text { ) and Feed- } \\
\text { forward } \\
\text { neural- } \\
\text { networks } \\
\text { (n_members=8 } \\
\text { ) to estimate } \\
\text { SOCAT v2021 } \\
\text { fCO2. } \\
\text { Clustering is } \\
\text { performed on } \\
\text { the following } \\
\text { variables: } \\
\text { SOcoM_pCO2 } \\
\text { _climatology, } \\
\text { SST_clim, } \\
\text { MLD_clim, } \\
\text { CHL_clim. } \\
\text { Regression is } \\
\text { performed on } \\
\text { the following } \\
\text { variables: } \\
\text { xCO2atm, SST, } \\
\text { SST_anomaly, } \\
\text { SSS, CHL, MLD, } \\
\text { u10_wind, } \\
\text { v10_wind, sea- }\end{array}$ \\
\hline
\end{tabular}


https://doi.org/10.5194/essd-2021-386

Preprint. Discussion started: 4 November 2021

(c) Author(s) 2021. CC BY 4.0 License.

\begin{tabular}{|c|c|c|c|c|c|c|c|c|}
\hline & & & & & $\begin{array}{l}\text { of the } 16 \\
\text { provinces. } \\
\text { Further } \\
\text { description in } \\
\text { Watson et al. } \\
(2020) \text {. }\end{array}$ & & & $\begin{array}{l}\text { ice changes, } \\
\text { SSH (note that } \\
\text { the latter two } \\
\text { variables are } \\
\text { an update } \\
\text { from Gregor } \\
\text { and Gruber, } \\
\text { 2021). }\end{array}$ \\
\hline $\begin{array}{l}\text { Gas-exchange } \\
\text { parameterizati } \\
\text { on }\end{array}$ & 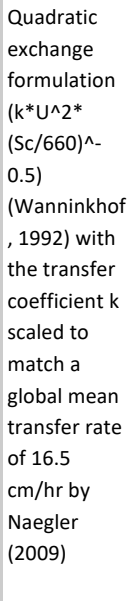 & $\begin{array}{l}\text { Quadratic } \\
\text { exchange } \\
\text { formulation } \\
\left(\mathrm{k}^{*} \mathrm{U}^{\wedge} 2^{*}\right. \\
\left.(\mathrm{Sc} / 660)^{\wedge}-0.5\right) \\
\text { (Wanninkhof, } \\
\text { 1992) with the } \\
\text { transfer } \\
\text { coefficient k } \\
\text { scaled to } \\
\text { match a global } \\
\text { mean transfer } \\
\text { rate of } 16.5 \\
\text { cm/hr } \\
\text { (calculated } \\
\text { myself over } \\
\text { the full period } \\
1982-2020)\end{array}$ & $\begin{array}{l}\text { Quadratic } \\
\text { exchange } \\
\text { formulation } \\
\left(\mathrm{k}^{*} \mathrm{U}^{\wedge} 2^{*}\right. \\
\left.(\mathrm{Sc} / 660)^{\wedge}-0.5\right) \\
\text { (Wanninkhof., } \\
2014) \text { with the } \\
\text { transfer } \\
\text { coefficient k } \\
\text { scaled to } \\
\text { match a global } \\
\text { mean transfer } \\
\text { rate of } 16.5 \\
\mathrm{~cm} / \mathrm{hr} \\
\text { (Naegler, } \\
2009) .\end{array}$ & $\begin{array}{l}\text { Quadratic } \\
\text { formulation kw } \\
=\mathrm{a} * \mathrm{U} 10^{\wedge} 2 * \\
(\mathrm{Sc} / 660)^{\wedge} 0.5 \\
\text { (). We use } \\
\text { scaled kw for } \\
\text { ERA5 } \\
\text { reanalysis } \\
\text { wind data, } \\
\text { which is scaled } \\
\text { globally to } 16.5 \\
\text { cm/hr (after } \\
\text { Naegler 2009) } \\
\text { like in Fay and } \\
\text { Gregor et al. } \\
\text { (2021) } \\
\text { https://doi.org } \\
/ 10.5194 / \text { essd- } \\
\text { 2021-16 }\end{array}$ & $\begin{array}{l}\text { Nightingale et } \\
\text { al. }(2000) \\
\text { formulation : } \\
\mathrm{K}=\left((\mathrm{Sc} / 600)^{\wedge} \text { - }\right. \\
0.5)^{*}\left(0.333^{*} \mathrm{U}\right. \\
\left.+0.222^{*} \mathrm{U}^{\wedge} 2\right)\end{array}$ & $\begin{array}{l}\mathrm{KW}=0.251 * W n \\
\mathrm{~d} * \mathrm{Wnd} / \mathrm{sqrt}(\mathrm{Sc} \\
/ 660.0) \\
\text { (Wanninkhof, } \\
\text { 2014) }\end{array}$ & $\begin{array}{l}\text { Quadratic } \\
\text { exchange } \\
\text { formulation } \\
\left(\mathrm{k}^{*} \mathrm{U}^{\wedge} 2^{*}\right. \\
\left.(\mathrm{Sc} / 660)^{\wedge}-0.5\right) \\
\text { (Wanninkhof., } \\
2014) \text { with the } \\
\text { transfer } \\
\text { coefficient k } \\
\text { scaled to } \\
\text { match a global } \\
\text { mean transfer } \\
\text { rate of } 16.5 \\
\text { cm/hr } \\
\text { (Naegler, } \\
\text { 2009) under } \\
\text { fitted to the } \\
\text { JRA55 wind } \\
\text { field. }\end{array}$ & $\begin{array}{l}\text { Quadratic } \\
\text { formulation of } \\
\text { bulk air-sea } \\
\text { CO2 flux: } \\
\text { kw }=a^{*} \cup 10^{\wedge} 2 \\
*(\mathrm{Sc} / 660)^{\wedge} 0.5 \\
\text { We use } \\
\text { individually } \\
\text { scaled kw's for } \\
\text { JRA55, ERA5, } \\
\text { and NCEP-R1, } \\
\text { which are all } \\
\text { scaled globally } \\
\text { to } 16.5 \mathrm{~cm} / \mathrm{hr} \\
\text { (after Naegler, } \\
2009) \text {. See Fay } \\
\text { and Gregor et } \\
\text { al. (2021) }\end{array}$ \\
\hline Wind product & $\begin{array}{l}\text { JMA55-do } \\
\text { reanalysis }\end{array}$ & ERA 5 & ERA5 & ERA5 & $\begin{array}{l}\text { CCMP wind } \\
\text { product, } 0.25 \text { x } \\
0.25 \text { degrees } x \\
\text { 6-hourly, from } \\
\text { which we } \\
\text { calculate mean } \\
\text { and mean } \\
\text { square winds } \\
\text { over } 1 \text { x } 1 \\
\text { degree and } 1 \\
\text { month } \\
\text { intervals. } \\
\text { CCMP product } \\
\text { does not cover } \\
\text { years } 1985- \\
1987, \text { for } \\
\text { which we use a } \\
\text { monthly } \\
\text { climatology } \\
\text { calculated as } \\
\text { the means of } \\
1988-1991 .\end{array}$ & \begin{tabular}{|l} 
ERA5 \\
EA \\
\end{tabular} & JRA55 & $\begin{array}{l}\text { JRA55, ERA5, } \\
\text { NCEP1 }\end{array}$ \\
\hline $\begin{array}{l}\text { Spatial } \\
\text { resolution }\end{array}$ & $\begin{array}{l}2.5 \text { degrees } \\
\text { longitude * } 2 \\
\text { degrees } \\
\text { latitude }\end{array}$ & 1x1 degree & $1 \times 1$ degree & $1 \times 1$ & $1 \times 1$ degree & 1x1 degree & 1x1 degree & $1 \times 1$ degree \\
\hline
\end{tabular}


https://doi.org/10.5194/essd-2021-386

Preprint. Discussion started: 4 November 2021

(c) Author(s) 2021. CC BY 4.0 License.

\begin{tabular}{|c|c|c|c|c|c|c|c|c|}
\hline $\begin{array}{l}\text { Temporal } \\
\text { resolution }\end{array}$ & daily & monthly & monthly & monthly & monthly & monthly & monthly & monthly \\
\hline $\begin{array}{l}\text { Atmospheric } \\
\mathrm{CO} 2\end{array}$ & $\begin{array}{l}\text { Spatially and } \\
\text { temporally } \\
\text { varying field } \\
\text { based on } \\
\text { atmospheric } \\
\text { CO2 data } \\
\text { from } 169 \\
\text { stations } \\
\text { (Jena } \\
\text { CarboScope } \\
\text { atmospheric } \\
\text { inversion } \\
\text { SEXTALL_V20 } \\
\text { 21) }\end{array}$ & $\begin{array}{l}\text { atmospheric } \\
\text { pCO2_wet } \\
\text { calculated } \\
\text { from the } \\
\text { NOAA ESRL } \\
\text { marine } \\
\text { boundary layer } \\
\text { xCO2 and the } \\
\text { NCEP sea level } \\
\text { pressure with } \\
\text { the moisture } \\
\text { correction by } \\
\text { Dickson et al } \\
2007 \text { (details } \\
\text { and references } \\
\text { can be } \\
\text { obtained from } \\
\text { Appendix A3 in } \\
\text { Landschützer } \\
\text { et al 2013) }\end{array}$ & $\begin{array}{l}\text { Spatially and } \\
\text { monthly } \\
\text { varying fields } \\
\text { of atmospheric } \\
\text { pCO2 } \\
\text { computed } \\
\text { from CO2 mole } \\
\text { fraction ( } \\
\text { Chevallier, } \\
2013 \text {; CO2 } \\
\text { atmospheric } \\
\text { inversion from } \\
\text { the Copernicus } \\
\text { Atmosphere } \\
\text { Monitoring } \\
\text { Service ), and } \\
\text { atmospheric } \\
\text { dry-air } \\
\text { pressure which } \\
\text { is derived from } \\
\text { monthly } \\
\text { surface } \\
\text { pressure } \\
\text { (ERA5) and } \\
\text { water vapour } \\
\text { pressure fitted } \\
\text { by Weiss and } \\
\text { Price (1980) } \\
\end{array}$ & $\begin{array}{l}\text { The NOAA's } \\
\text { marine } \\
\text { boundary layer } \\
\text { product for the } \\
\text { mole fraction } \\
\text { of carbon } \\
\text { dioxide (xCO2) } \\
\text { is linearly } \\
\text { interpolated } \\
\text { onto a } 1^{\circ} \times 1^{\circ} \\
\text { grid and } \\
\text { resampled } \\
\text { from weekly to } \\
\text { monthly. } \\
\text { Basically, } x \text { CO2 } \\
\text { is multiplied by } \\
\text { ERA5 mean sea } \\
\text { level pressure } \\
\text { (MSLP), and a } \\
\text { water vapour } \\
\text { pressure } \\
\text { correction is } \\
\text { applied to } \\
\text { MSLP using the } \\
\text { equation from } \\
\text { Dickson et al. } \\
\text { ( } 2007 \text { ). This } \\
\text { results in } \\
\text { monthly } 1^{\circ} \times 1^{\circ} \\
\text { atmospheric } \\
\text { pCO2. }\end{array}$ & $\begin{array}{l}\text { Atmospheric } \\
\text { pCO2 (wet) } \\
\text { calculated } \\
\text { from NOAA } \\
\text { marine } \\
\text { boundary layer } \\
\text { XCO2 and } \\
\text { NCEP sea level } \\
\text { pressure, with } \\
\text { pH2O } \\
\text { calculated } \\
\text { from Cooper et } \\
\text { al. (1998). } \\
\text { (2019 XCO2 } \\
\text { marine } \\
\text { boundary } \\
\text { values were } \\
\text { not available } \\
\text { at submission } \\
\text { so we used } \\
\text { preliminary } \\
\text { values, } \\
\text { estimated } \\
\text { from } 2018 \\
\text { values and } \\
\text { increase at } \\
\text { Mauna Loa.) } \\
\end{array}$ & $\begin{array}{l}\text { NOAA } \\
\text { Greenhouse } \\
\text { Gas Marine } \\
\text { Boundary } \\
\text { Layer } \\
\text { Reference. } \\
\text { https://gml.no } \\
\text { aa.gov/ccgg/m } \\
\text { bl/mbl.html } \\
\end{array}$ & $\begin{array}{l}\text { Atmospheric } \\
\text { xCO2 fields of } \\
\text { JMA-GSAM } \\
\text { inversion } \\
\text { model (Maki et } \\
\text { al. 2010; } \\
\text { Nakamura et } \\
\text { al. 2015) were } \\
\text { used. They } \\
\text { were } \\
\text { converted to } \\
\text { pCO2 by using } \\
\text { JRA55 sea level } \\
\text { pressure. xCO2 } \\
\text { fields in 2020 } \\
\text { were not } \\
\text { available at } \\
\text { this stage, and } \\
\text { we use } \\
\text { observation } \\
\text { data of } \\
\text { obspack_co2_- } \\
1 \text { __NRT_v6.1.1_ } \\
\text { 2021-05-17 (Di } \\
\text { Sarra et al. } \\
\text { 2021) to } \\
\text { estimate the } \\
\text { increase from } \\
\text { 2019 to } 2020 \text {. }\end{array}$ & $\begin{array}{l}\text { NOAA's marine } \\
\text { boundary layer } \\
\text { product for } \\
\text { xCO2 is linearly } \\
\text { interpolated } \\
\text { onto a } 1 \times 1 \\
\text { degree grid } \\
\text { and resampled } \\
\text { from weekly to } \\
\text { monthly. xCO2 } \\
\text { is multiplied by } \\
\text { ERA5 mean sea } \\
\text { level pressure, } \\
\text { where the } \\
\text { latter } \\
\text { corrected for } \\
\text { water vapour } \\
\text { pressure using } \\
\text { Dickson et al. } \\
\text { (2007). This } \\
\text { results in } \\
\text { monthly } 1 \times 1 \\
\text { degree } \\
\text { pCO2atm. }\end{array}$ \\
\hline $\begin{array}{l}\text { Total ocean } \\
\text { area on native } \\
\text { grid }(\mathbf{k m} 2)\end{array}$ & $3.63 E+08$ & $3.63 \mathrm{E}+08$ & $3.46 E+08$ & $3.48 E+08$ & $3.51 E+08$ & $\begin{array}{l}3.28 \mathrm{E}+08 \\
(3.23 \mathrm{E}+08 \text { to } \\
3.35 \mathrm{E}+08, \\
\text { depending on } \\
\text { ice cover) }\end{array}$ & $\begin{array}{l}3.05 \mathrm{E}+08 \\
(2.98 \mathrm{E}+08 \text { to } \\
3.15 \mathrm{E}+08 \\
\text { depending on } \\
\text { ice cover) }\end{array}$ & $3.55 E+08$ \\
\hline $\begin{array}{l}\text { method to } \\
\text { extend product } \\
\text { to full global } \\
\text { ocean } \\
\text { coverage }\end{array}$ & & $\begin{array}{l}\text { Arctic and } \\
\text { marginal seas } \\
\text { added } \\
\text { following } \\
\text { Landschützer } \\
\text { et al. (2020). } \\
\text { previously } \\
\text { applied coastal } \\
\text { cut (1degree } \\
\text { off coast) was } \\
\text { dropped }\end{array}$ & & & & & $\begin{array}{l}\text { We used the } \\
\text { same method } \\
\text { as Fay et al. } \\
\text { (2021a) }\end{array}$ & $\begin{array}{l}\text { Method has } \\
\text { near full } \\
\text { coverage }\end{array}$ \\
\hline $\begin{array}{l}\text { Ocean area on } \\
\text { native grid } \\
(\mathbf{k m 2}) \text { - NORTH }\end{array}$ & & & $5.4545 \mathrm{E}+07$ & $5.0528 \mathrm{E}+07$ & $5.0700 E+07$ & & $\begin{array}{l}3.90 \mathrm{E}+07 \\
(3.75 \mathrm{E}+07 \text { to } \\
4.09 \mathrm{E}+07, \\
\text { depending on } \\
\text { ice cover) }\end{array}$ & $5.9771 \mathrm{E}+07$ \\
\hline $\begin{array}{l}\text { Ocean area on } \\
\text { native grid } \\
\text { (km2) - } \\
\text { TROPICS }\end{array}$ & & & $1.8875 \mathrm{E}+08$ & $1.8933 \mathrm{E}+08$ & $1.9230 \mathrm{E}+08$ & & $1.74 \mathrm{E}+08$ & $1.8779 \mathrm{E}+08$ \\
\hline
\end{tabular}


https://doi.org/10.5194/essd-2021-386

Preprint. Discussion started: 4 November 2021

(c) Author(s) 2021. CC BY 4.0 License.

\begin{tabular}{l|l|l|l|l|l|l|} 
& & $1.0241 \mathrm{E}+08$ & $1.0767 \mathrm{E}+08$ & $1.0868 \mathrm{E}+08$ & & $\begin{array}{l}9.20 \mathrm{E}+07 \\
(8.47 \mathrm{E}+07 \text { to } \\
1.02 \mathrm{E}+08,\end{array}$ \\
$\begin{array}{l}\text { Ocean area on } \\
\text { native grid } \\
\text { (km2) - SOUTH }\end{array}$ & & & & & & $\begin{array}{l}1.0705 \mathrm{E}+08 \\
\text { depending on } \\
\text { ice cover) }\end{array}$ \\
\hline
\end{tabular}

1

2

3 
https://doi.org/10.5194/essd-2021-386

Preprint. Discussion started: 4 November 2021

(c) Author(s) 2021. CC BY 4.0 License.

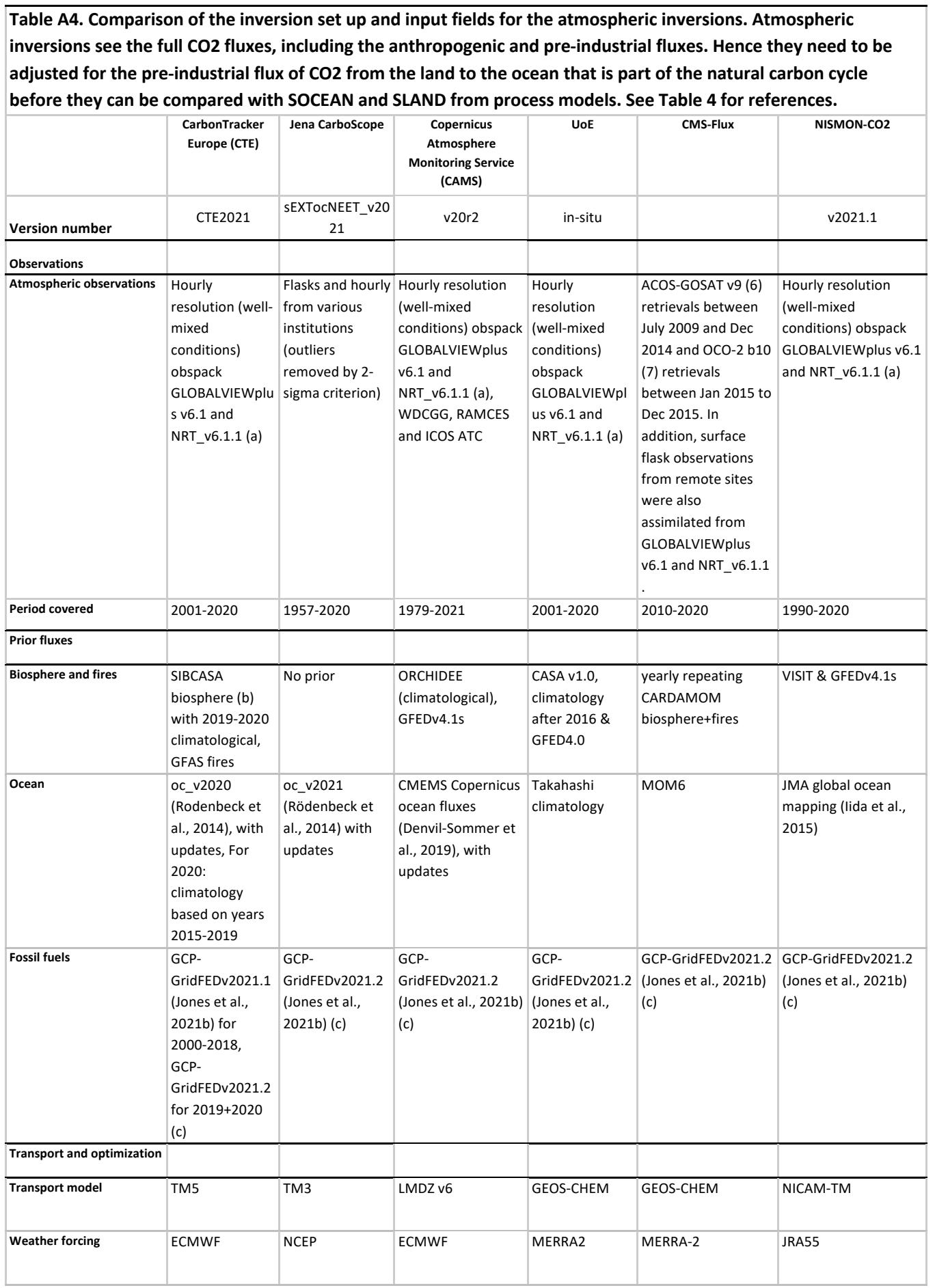


https://doi.org/10.5194/essd-2021-386

Preprint. Discussion started: 4 November 2021

(c) Author(s) 2021. CC BY 4.0 License.

\begin{tabular}{|l|l|l|l|l|l|l|}
\hline Horizontal Resolution & $\begin{array}{l}\text { Global: } 3^{\circ} \times 2^{\circ}, \\
\text { Europe: } 1^{\circ} \times 1^{\circ}, \\
\text { North America: } \\
1^{\circ} \times 1^{\circ}\end{array}$ & Global: $4^{\circ} \times 5^{\circ}$ & $\begin{array}{l}\text { Global: } 3.75^{\circ} \times \\
1.875^{\circ}\end{array}$ & Global: $4^{\circ} \times 5^{\circ}$ & Global: $4^{\circ} \times 5^{\circ}$ & isocahedral grid: \\
$\sim 225 \mathrm{~km}$ \\
\hline Optimization & $\begin{array}{l}\text { Ensemble } \\
\text { Kalman filter }\end{array}$ & $\begin{array}{l}\text { Conjugate } \\
\text { gradient (re- } \\
\text { ortho- } \\
\text { normalization) } \\
\text { (d) }\end{array}$ & Variational & $\begin{array}{l}\text { Ensemble } \\
\text { Kalman filter }\end{array}$ & Variational & Variational \\
\hline
\end{tabular}

(a) (Cox et al., 2021; Di Sarra et al., 2021)

(b) (van der Velde et al., 2014)

(c) GCP-GridFEDv2021.2 (Jones et al., 2021b) is an update through the year 2020 of the GCP-GridFED dataset presented by Jones et al. (2021a)

(d) ocean prior not optimised

1

2

3

4

5

6

7

8

9

10 
Table A5 Attribution of fCO2 measurements for the year 2020 included in SOCATv2021 (Bakker et al., 2016, 2021) to inform ocean fCO2-based data products.

\begin{tabular}{|c|c|c|c|c|c|}
\hline Platform name & Regions & \begin{tabular}{c|} 
No. of \\
measurements
\end{tabular} & Principal Investigators & $\begin{array}{l}\text { No. of data } \\
\text { sets }\end{array}$ & Platform type \\
\hline 1 degree & North Atlantic, Coastal & 8,652 & Gutekunst, S. & 2 & Ship \\
\hline Allure of the Seas & $\begin{array}{l}\text { North Atlantic, Tropical Atlantic, } \\
\text { Coastal }\end{array}$ & 19,321 & Wanninkhof, R.; Pierrot, D. & 8 & Ship \\
\hline Atlantic Explorer & North Atlantic & 15,665 & Bates, N. & 11 & Ship \\
\hline Atlantic Sail & North Atlantic, Coastal & 25,082 & Steinhoff, T.; Körtzinger, A. & 6 & Ship \\
\hline Aurora Australis & Southern Ocean & 14,316 & Tilbrook, B. & 1 & Ship \\
\hline $\begin{array}{l}\text { Bjarni } \\
\text { Saemundsson }\end{array}$ & Coastal & 3,269 & Benoit-Cattin A.; Ólafsdóttir, S. R. & 1 & Ship \\
\hline BlueFin & $\begin{array}{l}\text { North Pacific, Tropical Pacific, } \\
\text { Coastal }\end{array}$ & 76,505 & Alin, S. R.; Feely, R. A. & 12 & Ship \\
\hline Cap San Lorenzo & Tropical Atlantic, Coastal & 12,417 & Lefèvre, $\mathrm{N}$. & 2 & Ship \\
\hline Celtic Explorer & North Atlantic, Coastal & 18,617 & Cronin, M. & 6 & Ship \\
\hline Colibri & $\begin{array}{l}\text { North Atlantic, Tropical Atlantic, } \\
\text { Coastal }\end{array}$ & 13,402 & Lefèvre, $\mathrm{N}$. & 2 & Ship \\
\hline Equinox & North Atlantic, Coastal & 25,052 & Wanninkhof, R.; Pierrot, D. & 11 & Ship \\
\hline F. G. Walton Smith & Coastal & 10,460 & $\begin{array}{l}\text { Rodriguez, C.; Millero, F. J.; Pierrot, D.; } \\
\text { Wanninkhof, R. }\end{array}$ & 6 & Ship \\
\hline Finnmaid & Coastal & 253,894 & Rehder, G.; Glockzin, M. & 11 & Ship \\
\hline Flora & Tropical Pacific & 4,099 & Wanninkhof, R.; Pierrot, D. & 2 & Ship \\
\hline G.O. Sars & Arctic, North Atlantic, Coastal & 75,833 & Skjelvan, I. & 7 & Ship \\
\hline $\begin{array}{l}\text { GAKOA_149W_60 } \\
N\end{array}$ & Coastal & 68 & Cross, J. N.; Monacci, N. M. & 3 & Mooring \\
\hline Gulf Challenger & Coastal & 2,717 & Salisbury, J.; Vandemark, D.; Hunt, C. & 3 & Ship \\
\hline Healy & Arctic, North Pacific, Coastal & 16,943 & $\begin{array}{l}\text { Sweeney, C.; Newberger, T.; } \\
\text { Sutherland, S. C.; Munro, D. R. }\end{array}$ & 4 & Ship \\
\hline Henry B. Bigelow & North Atlantic, Coastal & 14,436 & Wanninkhof, R.; Pierrot, D. & 4 & Ship \\
\hline Heron Island & Coastal & 768 & Tilbrook B. & 1 & Mooring \\
\hline James Clark Ross & Southern Ocean & 2,000 & Kitidis, V. & 1 & Ship \\
\hline James Cook & $\begin{array}{l}\text { North Atlantic, Tropical Atlantic, } \\
\text { Coastal }\end{array}$ & 46,710 & Theetaert, $\mathrm{H}$. & 1 & Ship \\
\hline KC_BUOY & Coastal & 1,983 & Evans, W. & 1 & Mooring \\
\hline Laurence M. Gould & Southern Ocean & 25,414 & $\begin{array}{l}\text { Sweeney, C.; Newberger, T.; } \\
\text { Sutherland, S. C.; Munro, D. R. }\end{array}$ & 4 & Ship \\
\hline Maria. S. Merian & Tropical Atlantic, Coastal & 35,806 & Ritschel, M. & 1 & Ship \\
\hline Marion Dufresne & Southern Ocean, Indian & 4,709 & Lo Monaco, C.; Metzl, N. & 1 & Ship \\
\hline $\begin{array}{l}\text { Nathaniel B. } \\
\text { Palmer }\end{array}$ & Southern Ocean, Tropical Pacific & 34,357 & $\begin{array}{l}\text { Sweeney, C.; Newberger, T.; } \\
\text { Sutherland, S. C.; Munro, D. R. }\end{array}$ & 3 & Ship \\
\hline New Century 2 & $\begin{array}{l}\text { North Pacific, Tropical Pacific, } \\
\text { Tropical Atlantic, North Atlantic, } \\
\text { Coastal }\end{array}$ & 27,793 & Nakaoka, S.-I. & 14 & Ship \\
\hline Nuka Arctica & North Atlantic, Coastal & 26,576 & Becker, M.; Olsen, A. & 6 & Ship \\
\hline Oscar Dyson & Arctic, North Pacific, Coastal & 28,196 & Alin, S. R.; Feely, R. A. & 6 & Ship \\
\hline $\begin{array}{l}\text { Quadra Island } \\
\text { Field Station }\end{array}$ & Coastal & 78,098 & Evans, W. & 1 & Mooring \\
\hline Ronald H. Brown & $\begin{array}{l}\text { Southern Ocean, Tropical Atlantic, } \\
\text { North Atlantic, Coastal }\end{array}$ & 51,611 & Wanninkhof, R.; Pierrot, D. & 6 & Ship \\
\hline
\end{tabular}


https://doi.org/10.5194/essd-2021-386

Preprint. Discussion started: 4 November 2021

(c) Author(s) 2021. CC BY 4.0 License.

\begin{tabular}{|c|c|c|c|c|c|}
\hline Saildrone1030 & $\begin{array}{l}\text { North Atlantic, Tropical Atlantic, } \\
\text { Coastal }\end{array}$ & 4,080 & $\begin{array}{l}\text { Skjelvan, I.; Fiedler, B.; Pfeil, B.; Jones, } \\
\text { S. D. }\end{array}$ & 1 & Saildrone \\
\hline Sea Explorer & $\begin{array}{l}\text { Southern Ocean, Tropical Atlantic, } \\
\text { North Atlantic, Coastal }\end{array}$ & 89,896 & Landschützer, P.; Tanhua, T. & 6 & Ship \\
\hline Sikuliaq & Arctic, North Pacific, Coastal & 36,278 & $\begin{array}{l}\text { Sweeney, C.; Newberger, T.; } \\
\text { Sutherland, S. C.; Munro, D. R. }\end{array}$ & 10 & Ship \\
\hline Simon Stevin & Coastal & 16,448 & Gkritzalis, T. & 4 & Ship \\
\hline Soyo Maru & Coastal & 46,280 & Ono, $\mathrm{T}$. & 2 & Ship \\
\hline Tangaroa & Southern Ocean, Tropical Pacific & 121,135 & Currie, K. I. & 13 & Ship \\
\hline TAO110W_ON & Tropical Pacific & 1,518 & Sutton, A. J. & 3 & Mooring \\
\hline Tavastland & Coastal & 4,214 & Willstrand Wranne, A., Steinhoff, T. & 5 & Ship \\
\hline $\begin{array}{l}\text { Thomas } G \text {. } \\
\text { Thompson }\end{array}$ & Southern Ocean, Tropical Atlantic & 1,317 & Alin, S. R.; Feely, R. A. & 1 & Ship \\
\hline Trans Carrier & Coastal & 24,135 & Omar, A. M. & 13 & Ship \\
\hline Trans Future 5 & Southern Ocean, Coastal & 16,404 & Nakaoka, S.-I.; Nojiri, Y. & 15 & Ship \\
\hline Wakataka Maru & North Pacific, Coastal & 101,327 & Tadokoro, K.; Ono, T. & 7 & Ship \\
\hline
\end{tabular}

1

2

3

4

5

6

7

8

9

10

11

12

13

14

15

16 
Table A6. Aircraft measurement programs archived by Cooperative Global Atmospheric Data Integration Project (CGADIP; Cox et al., 2021) that contribute to the evaluation of the atmospheric inversions (Figure B4).

\begin{tabular}{|c|c|c|c|c|}
\hline $\begin{array}{l}\text { Site } \\
\text { code }\end{array}$ & $\begin{array}{l}\text { Measurement program name in } \\
\text { Obspack }\end{array}$ & Specific doi & Data providers & $\begin{array}{l}\text { used in } \\
2021\end{array}$ \\
\hline AAO & $\begin{array}{l}\text { Airborne Aerosol Observatory, Bondville, } \\
\text { Illinois }\end{array}$ & & Sweeney, C.; Dlugokencky, E.J. & yes \\
\hline ACG & Alaska Coast Guard & & $\begin{array}{l}\text { Sweeney, C.; McKain, K.; Karion, A.; } \\
\text { Dlugokencky, E.J. }\end{array}$ & yes \\
\hline ACT & $\begin{array}{l}\text { Atmospheric Carbon and Transport - } \\
\text { America }\end{array}$ & & $\begin{array}{l}\text { Sweeney, C.; Dlugokencky, E.J.; Baier, B; } \\
\text { Montzka, S.; Davis, K. }\end{array}$ & yes \\
\hline ALF & Alta Floresta & & Gatti, L.V.; Gloor, E.; Miller, J.B.; & yes \\
\hline AOA & $\begin{array}{l}\text { Aircraft Observation of Atmospheric trace } \\
\text { gases by JMA }\end{array}$ & & ghg_obs@met.kishou.go.jp & yes \\
\hline BGI & Bradgate, lowa & & Sweeney, C.; Dlugokencky, E.J. & yes \\
\hline BNE & Beaver Crossing, Nebraska & & Sweeney, C.; Dlugokencky, E.J. & yes \\
\hline BRZ & Berezorechka, Russia & & Sasakama, N.; Machida, T. & yes \\
\hline CAR & Briggsdale, Colorado & & Sweeney, C.; Dlugokencky, E.J. & yes \\
\hline CMA & Cape May, New Jersey & & Sweeney, C.; Dlugokencky, E.J. & yes \\
\hline CON & $\begin{array}{l}\text { CONTRAIL (Comprehensive Observation } \\
\text { Network for TRace gases by AlrLiner) }\end{array}$ & $\begin{array}{l}\text { http://dx.doi.org/10.17595/201 } \\
80208.001\end{array}$ & Machida, T.; Matsueda, H.; Sawa, Y. Niwa, Y. & yes \\
\hline CRV & $\begin{array}{l}\text { Carbon in Arctic Reservoirs Vulnerability } \\
\text { Experiment (CARVE) }\end{array}$ & & $\begin{array}{l}\text { Sweeney, C.; Karion, A.; Miller, J.B.; Miller, C.E.; } \\
\text { Dlugokencky, E.J. }\end{array}$ & yes \\
\hline DND & Dahlen, North Dakota & & Sweeney, C.; Dlugokencky, E.J. & yes \\
\hline ESP & Estevan Point, British Columbia & & Sweeney, C.; Dlugokencky, E.J. & yes \\
\hline ETL & East Trout Lake, Saskatchewan & & Sweeney, C.; Dlugokencky, E.J. & yes \\
\hline FWI & Fairchild, Wisconsin & & Sweeney, C.; Dlugokencky, E.J. & yes \\
\hline GSFC & $\begin{array}{l}\text { NASA Goddard Space Flight Center Aircraft } \\
\text { Campaign }\end{array}$ & & Kawa, S.R.; Abshire, J.B.; Riris, H. & yes \\
\hline HAA & Molokai Island, Hawaii & & Sweeney, C.; Dlugokencky, E.J. & yes \\
\hline HFM & Harvard University Aircraft Campaign & & Wofsy, S.C. & yes \\
\hline HIL & Homer, Illinois & & Sweeney, C.; Dlugokencky, E.J. & yes \\
\hline HIP & HIPPO (HIAPER Pole-to-Pole Observations) & $\begin{array}{l}\text { https://doi.org/10.3334/CDIAC/ } \\
\text { HIPPO_010 }\end{array}$ & $\begin{array}{l}\text { Wofsy, S.C.; Stephens, B.B.; Elkins, J.W.; Hintsa, } \\
\text { E.J.; Moore, F. }\end{array}$ & yes \\
\hline $\begin{array}{l}\text { IAGOS } \\
- \\
\text { CARIBI } \\
\text { C }\end{array}$ & $\begin{array}{l}\text { In-service Aircraft for a Global Observing } \\
\text { System }\end{array}$ & & $\begin{array}{l}\text { Obersteiner, F.; Boenisch., H; Gehrlein, T.; Zahn, } \\
\text { A.; Schuck, T. }\end{array}$ & yes \\
\hline INX & INFLUX (Indianapolis Flux Experiment) & & $\begin{array}{l}\text { Sweeney, C.; Dlugokencky, E.J.; Shepson, P.B.; } \\
\text { Turnbull, J. }\end{array}$ & yes \\
\hline LEF & Park Falls, Wisconsin & & Sweeney, C.; Dlugokencky, E.J. & yes \\
\hline NHA & Offshore Portsmouth, New Hampshire (Isles & & Sweeney, C.; Dlugokencky, E.J. & yes \\
\hline
\end{tabular}


https://doi.org/10.5194/essd-2021-386

Preprint. Discussion started: 4 November 2021

(C) Author(s) 2021. CC BY 4.0 License.

\begin{tabular}{|l|l|l|l|l|}
\hline & of Shoals) & & \\
\hline OIL & Oglesby, lllinois & & Sweeney, C.; Dlugokencky, E.J. & yes \\
\hline PFA & Poker Flat, Alaska & & Sweeney, C.; Dlugokencky, E.J. & yes \\
\hline RBA-B & Rio Branco & & Gatti, L.V.; Gloor, E.; Miller, J.B. & yes \\
\hline RTA & Rarotonga & & Sweeney, C.; Dlugokencky, E.J. & yes \\
\hline SCA & Charleston, South Carolina & & Sweeney, C.; Dlugokencky, E.J. & yes \\
\hline SGP & Southern Great Plains, Oklahoma & & Sweeney, C.; Dlugokencky, E.J; Biraud, S. & yes \\
\hline TAB & Tabatinga & & Gatti, L.V.; Gloor, E.; Miller, J.B. & yes \\
\hline TGC & Offshore Corpus Christi, Texas & Sweeney, C.; Dlugokencky, E.J. & yes \\
\hline THD & Trinidad Head, California & Sweeney, C.; Dlugokencky, E.J. & yes \\
\hline WBI & West Branch, lowa & Sweeney, C.; Dlugokencky, E.J. & yes \\
\hline
\end{tabular}




\begin{tabular}{|c|c|c|c|c|c|c|c|c|}
\hline \multicolumn{9}{|c|}{$\begin{array}{l}\text { Table A7. Main methodological changes in the glob } \\
\text { changes introduced in one year are kept for the fol } \\
\text { no methodological changes introduced that year. }\end{array}$} \\
\hline \multirow{2}{*}{$\begin{array}{l}\text { Publication } \\
\text { year }\end{array}$} & \multicolumn{3}{|c|}{ Fossil fuel emissions } & \multirow[t]{2}{*}{$\begin{array}{c}\text { LUC } \\
\text { emissions }\end{array}$} & \multicolumn{3}{|c|}{ Reservoirs } & \multirow{2}{*}{$\begin{array}{l}\text { Uncertainty } \\
\text { \& other } \\
\text { changes }\end{array}$} \\
\hline & Global & $\begin{array}{l}\text { Country } \\
\text { (territorial) }\end{array}$ & $\begin{array}{c}\text { Country } \\
\text { (consumption) }\end{array}$ & & Atmosphere & Ocean & Land & \\
\hline 2006 (a) & & $\begin{array}{l}\text { Split in } \\
\text { regions }\end{array}$ & & & & & & \\
\hline 2007 (b) & & & & \begin{tabular}{|l|} 
ELUC based \\
on FAO-FRA \\
$2005 ;$ \\
constant \\
ELUC for 2006
\end{tabular} & $\begin{array}{l}1959-1979 \\
\text { data from } \\
\text { Mauna Loa; } \\
\text { data after } \\
1980 \text { from } \\
\text { global } \\
\text { average }\end{array}$ & $\begin{array}{l}\text { Based on one } \\
\text { ocean model } \\
\text { tuned to } \\
\text { reproduced } \\
\text { observed } \\
1990 \text { s sink }\end{array}$ & & $\begin{array}{l} \pm 1 \sigma \text { provided } \\
\text { for all } \\
\text { components }\end{array}$ \\
\hline 2008 (c) & & & & $\begin{array}{l}\text { Constant } \\
\text { ELUC for } 2007\end{array}$ & & & & \\
\hline 2009 (d) & & \begin{tabular}{|l|} 
Split \\
between \\
Annex B and \\
non-Annex B
\end{tabular} & $\begin{array}{l}\text { Results from } \\
\text { an } \\
\text { independent } \\
\text { study } \\
\text { discussed }\end{array}$ & $\begin{array}{l}\text { Fire-based } \\
\text { emission } \\
\text { anomalies } \\
\text { used for } \\
2006-2008\end{array}$ & & $\begin{array}{l}\text { Based on four } \\
\text { ocean models } \\
\text { normalised to } \\
\text { observations } \\
\text { with constant } \\
\text { delta }\end{array}$ & $\begin{array}{l}\text { First use of } \\
\text { five DGVMs } \\
\text { to compare } \\
\text { with budget } \\
\text { residual }\end{array}$ & \\
\hline 2010 (e) & $\begin{array}{l}\text { Projection for } \\
\text { current year } \\
\text { based on GDP }\end{array}$ & $\begin{array}{l}\text { Emissions for } \\
\text { top emitters }\end{array}$ & & $\begin{array}{l}\text { ELUC updated } \\
\text { with FAO-FRA } \\
2010\end{array}$ & & & & \\
\hline 2011 (f) & & & $\begin{array}{l}\text { Split between } \\
\text { Annex B and } \\
\text { non-Annex B }\end{array}$ & & & & & \\
\hline 2012 (g) & & $\begin{array}{l}129 \\
\text { countries } \\
\text { from } 1959\end{array}$ & $\begin{array}{l}129 \text { countries } \\
\text { and regions } \\
\text { from } 1990- \\
2010 \text { based on } \\
\text { GTAP } 8.0\end{array}$ & $\begin{array}{l}\text { ELUC for } \\
1997-2011 \\
\text { includes } \\
\text { interannual } \\
\text { anomalies } \\
\text { from fire- } \\
\text { based } \\
\text { emissions }\end{array}$ & $\begin{array}{l}\text { All years from } \\
\text { global } \\
\text { average }\end{array}$ & \begin{tabular}{|l} 
Based on 5 \\
ocean models \\
normalised to \\
observations \\
with ratio
\end{tabular} & $\begin{array}{l}\text { Ten DGVMs } \\
\text { available for } \\
\text { SLAND; First } \\
\text { use of four } \\
\text { models to } \\
\text { compare with } \\
\text { ELUC }\end{array}$ & \\
\hline $2013(\mathrm{~h})$ & & $\begin{array}{l}250 \\
\text { countriesb }\end{array}$ & $\begin{array}{l}134 \text { countries } \\
\text { and regions } \\
1990-2011 \\
\text { based on } \\
\text { GTAP8.1, with } \\
\text { detailed } \\
\text { estimates for } \\
\text { years } 1997, \\
2001,2004, \\
\text { and } 2007\end{array}$ & \begin{tabular}{|l|} 
ELUC for 2012 \\
estimated \\
from 2001- \\
2010 average
\end{tabular} & & $\begin{array}{l}\text { Based on six } \\
\text { models } \\
\text { compared } \\
\text { with two } \\
\text { data-products } \\
\text { to year } 2011\end{array}$ & \begin{tabular}{|l|} 
Coordinated \\
DGVM \\
experiments \\
for SLAND \\
and ELUC
\end{tabular} & \begin{tabular}{|l} 
Confidence \\
levels; \\
cumulative \\
emissions; \\
budget from \\
1750
\end{tabular} \\
\hline 2014 (i) & $\begin{array}{l}\text { Three years } \\
\text { of BP data }\end{array}$ & $\begin{array}{l}\text { Three years } \\
\text { of BP data }\end{array}$ & $\begin{array}{l}\text { Extended to } \\
2012 \text { with } \\
\text { updated GDP } \\
\text { data }\end{array}$ & \begin{tabular}{|l} 
ELUC for \\
$1997-2013$ \\
includes \\
interannual \\
anomalies \\
from fire- \\
based \\
emissions
\end{tabular} & & $\begin{array}{l}\text { Based on } \\
\text { seven models }\end{array}$ & $\begin{array}{l}\text { Based on ten } \\
\text { models }\end{array}$ & \begin{tabular}{|l} 
Inclusion of \\
breakdown of \\
the sinks in \\
three latitude \\
bands and \\
comparison \\
with three \\
atmospheric \\
inversions
\end{tabular} \\
\hline
\end{tabular}




\begin{tabular}{|c|c|c|c|c|c|c|c|}
\hline $2015(j)$ & \begin{tabular}{|l|} 
Projection for \\
current year \\
based Jan- \\
Aug data
\end{tabular} & \begin{tabular}{|l|} 
National \\
emissions \\
from \\
UNFCCC \\
extended to \\
2014 also \\
provided \\
\end{tabular} & \begin{tabular}{|l|} 
Detailed \\
estimates \\
introduced for \\
2011 based on \\
GTAP9
\end{tabular} & & \begin{tabular}{|l|} 
Based on \\
eight models
\end{tabular} & \begin{tabular}{|l|} 
Based on ten \\
models with \\
assessment of \\
minimum \\
realism \\
\\
\end{tabular} & \begin{tabular}{|l} 
The decadal \\
uncertainty \\
for the DGVM \\
ensemble \\
mean now \\
uses $\pm 1 \sigma$ of \\
the decadal \\
spread across \\
models
\end{tabular} \\
\hline $2016(k)$ & $\begin{array}{l}\text { Two years of } \\
\text { BP data }\end{array}$ & \begin{tabular}{|l|} 
Added three \\
small \\
countries; \\
China's \\
emissions \\
from 1990 \\
from BP data \\
(this release \\
only) \\
\end{tabular} & & $\begin{array}{l}\text { Preliminary } \\
\text { ELUC using } \\
\text { FRA-2015 } \\
\text { shown for } \\
\text { comparison; } \\
\text { use of five } \\
\text { DGVMs }\end{array}$ & $\begin{array}{l}\text { Based on } \\
\text { seven models }\end{array}$ & \begin{tabular}{|l|} 
Based on \\
fourteen \\
models
\end{tabular} & \begin{tabular}{|l|} 
Discussion of \\
projection for \\
full budget \\
for current \\
year
\end{tabular} \\
\hline \multicolumn{8}{|c|}{ a Raupach et al. (2007) } \\
\hline \multicolumn{8}{|c|}{ b Canadell et al. (2007) } \\
\hline \multicolumn{8}{|c|}{ c GCP (2008) } \\
\hline \multicolumn{8}{|c|}{ d Le Quéré et al. (2009) } \\
\hline \multicolumn{8}{|c|}{ e Friedlingstein et al. (2010) } \\
\hline \multicolumn{8}{|c|}{ f Peters et al. (2012b) } \\
\hline \multicolumn{8}{|c|}{ g Le Quéré et al. (2013), Peters et al. (2013) } \\
\hline \multicolumn{8}{|c|}{ h Le Quéré et al. (2014) } \\
\hline \multicolumn{8}{|c|}{ i Le Quéré et al. (2015a) } \\
\hline \multicolumn{8}{|c|}{ j Le Quéré et al. (2015b) } \\
\hline
\end{tabular}


Table A8: Mapping of scientific land flux definitions to the definition of the LULUCF net flux used in national reporting Note that estimates are based on the global carbon budget estimates from Friedlingstein et al (2020), which estimated higher emissions from the net land-use change flux (ELUC) and a larger natural terrestrial sink Non-intact lands are a proxy for "managed lands" in the country reporting

\begin{tabular}{|c|c|c|c|c|}
\hline & & & $2000-2009$ & $2010-2019$ \\
\hline $\begin{array}{l}\text { ELUC from bookkeeping } \\
\text { estimates (from Tab. 5) }\end{array}$ & & & 1.44 & 1.61 \\
\hline \multirow{5}{*}{ SLAND } & Total & from DGVMs & -2.90 & -3.40 \\
\hline & on non-forest lands & from DGVMs & -1.05 & -1.38 \\
\hline & on non-intact forest & from DGVMs & -1.39 & -1.54 \\
\hline & \multirow{2}{*}{$\begin{array}{l}\text { on intact land (intact forest only } \\
\text { for DGVMs) }\end{array}$} & from DGVMs & -0.46 & -0.49 \\
\hline & & from cohort-based ORCHIDEE & -1.29 & -1.47 \\
\hline \multirow{2}{*}{$\begin{array}{l}\text { SLAND on non-intact } \\
\text { lands plus ELUC }\end{array}$} & & $\begin{array}{l}\text { from DGVMs and bookkeeping } \\
\text { ELUC }\end{array}$ & 0.05 & 0.08 \\
\hline & & from cohort-based ORCHIDEE & 1.00 & 0.61 \\
\hline $\begin{array}{l}\text { National greenhouse gas } \\
\text { inventories (LULUCF) }\end{array}$ & & & 0.00 & -0.31 \\
\hline FAOSTAT (LULUCF) & & & 0.39 & 0.20 \\
\hline
\end{tabular}


Table A9. Funding supporting the production of the various components of the global carbon budget in addition to the authors' supporting institutions (see also acknowledgements).

\begin{tabular}{|c|c|}
\hline Funder and grant number (where relevant) & Author Initials \\
\hline Australia, Integrated Marine Observing System (IMOS) & BT \\
\hline Australian National Environment Science Program (NESP) & JGC \\
\hline Belgium, FWO (Flanders Research Foundation, contract IRI I001019N) & TG \\
\hline $\begin{array}{l}\text { BNP Paribas Foundation through Climate \& Biodiversity initiative, philanthropic grant for } \\
\text { developments of the Global Carbon Atlas }\end{array}$ & PC \\
\hline Canada, Tula Foundation & WE \\
\hline China, National Natural Science Foundation (grant no. 41975155) & $X Y$ \\
\hline Commonwealth Scientific and Industrial Organization (CSIRO) - Climate Science Centre & JGC, JK \\
\hline $\begin{array}{l}\text { EC Copernicus Atmosphere Monitoring Service implemented by ECMWF on behalf of the } \\
\text { European Commission }\end{array}$ & FC \\
\hline EC Copernicus Marine Environment Monitoring Service implemented by Mercator Ocean & TTTC \\
\hline EC H2020 (4C; grant no 821003) & $\begin{array}{l}\text { PF, RMA, SS, GPP, PC, JIK, TI, LB, PL, LG, } \\
\text { SL, NG }\end{array}$ \\
\hline EC H2O20 (CHE; grant no 776186) & MWJ \\
\hline EC H2O20 (CoCO2: grant no. 958927) & RMA, GPP \\
\hline EC H2020 (COMFORT: grant no. 820989) & DCEB, LG \\
\hline EC H2020 (CONSTRAIN: grant no 820829) & RS, PMF, TG \\
\hline EC H2O20 (CRESCENDO: grant no. 641816) & RS, EJ AJPS, TI \\
\hline EC H2020 (ESM2025 - Earth System Models for the Future; grant agreement No 101003536). & RS, TG, TI, LB, BD \\
\hline EC H2020 (EuroSea: grant no. 862626) & SDJ \\
\hline EC H2020 (JERICO-S3: grant no. 871153) & GR \\
\hline EC H2020 (QUINCY; grant no 647204) & SZ \\
\hline EC H2020 (RINGO: grant no. 730944) & DCEB \\
\hline EC H2020 (VERIFY: grant no. 776810) & MWJ, RMA, GPP, PC, JIK, NV, GG \\
\hline Efg International & TT \\
\hline EFG International & TT \\
\hline $\begin{array}{l}\text { European Space Agency Climate Change Initiative ESA-CCI RECCAP2 project } 655 \\
\text { (ESRIN/4000123002/18/I-NB) }\end{array}$ & $\mathrm{PF}, \mathrm{SS}, \mathrm{PC}$ \\
\hline European Space Agency OceanSODA project (grant no. 4000112091/14/I-LG) & LG \\
\hline France, ICOS (Integrated Carbon Observation System) France & NL \\
\hline France, Institut de Recherche pour le Développement (IRD) & NL \\
\hline $\begin{array}{l}\text { Germany, Blue Ocean and Federal Ministry of Education (BONUS INTEGRAL; Grant No. } \\
\text { 03F0773A) }\end{array}$ & GR \\
\hline $\begin{array}{l}\text { Germany, Deutsche Forschungsgemeinschaft (DFG) under Germany's Excellence Strategy - EXC } \\
2037 \text { 'Climate, Climatic Change, and Society' - Project Number: } 390683824\end{array}$ & $\mathrm{TI}$ \\
\hline Germany, Federal Ministry for Education and Research (BMBF) & GR \\
\hline Germany, GEOMAR Helmholtz Centre for Ocean Research & SKL \\
\hline $\begin{array}{l}\text { Germany, German Federal Ministry of Education and Research under project "DArgo2025" } \\
\text { (03F0857C) }\end{array}$ & AK \\
\hline Germany, Helmholtz Association ATMO programme & PA \\
\hline $\begin{array}{l}\text { Germany, Helmholtz Young Investigator Group Marine Carbon and Ecosystem Feedbacks in the } \\
\text { Earth System (MarESys), grant number VH-NG-1301 }\end{array}$ & $\mathrm{JH}, \mathrm{OG}$ \\
\hline Germany, ICOS (Integrated Carbon Observation System) Germany & GR, NL \\
\hline Hapag-Lloyd & TT \\
\hline
\end{tabular}




\begin{tabular}{|c|c|}
\hline Ireland, Marine Institute & MC \\
\hline $\begin{array}{l}\text { Japan, Environment Research and Technology Development Fund of the Ministry of the } \\
\text { Environment (JPMEERF21S20810) }\end{array}$ & YN \\
\hline $\begin{array}{l}\text { Japan, Global Environmental Research Coordination System, Ministry of the Environment (grant } \\
\text { number E1751) }\end{array}$ & SN, TO, CW \\
\hline Kuehne + Nagel International AG & TT \\
\hline Mediterranean Shipping Company (MSc) & TT \\
\hline Monaco, Fondation Prince Albert II de Monaco & TT \\
\hline Monaco, Yacht Club de Monaco & TT \\
\hline NASA Interdisciplinary Research in Earth Science Program. & BP \\
\hline Netherlands Organization for Scientific Research (NWO; grant no. SH-312, 17616) & WP \\
\hline New Zealand, NIWA MBIE Core funding & KIC \\
\hline Norway, Norwegian Research Council (grant no. 270061) & JS \\
\hline $\begin{array}{l}\text { Norway, Research Council of Norway, ICOS (Integrated Carbon Observation System) Norway } \\
\text { and OTC (Ocean Thematic Centre) (grant no. 245927) }\end{array}$ & SKL, MB, SDJ \\
\hline PEAK6 Investments & SKL \\
\hline Saildrone Inc. & SKL \\
\hline South Africa, Department of Science and Innovation & LD \\
\hline South Africa, National Science Foundation & LD \\
\hline Swiss National Science Foundation (grant no. 200020_172476) & SL \\
\hline UK Royal Society (grant no. RP\R1\191063) & CLQ \\
\hline UK, CLASS ERC funding & TG \\
\hline UK, National Centre for Atmospheric Science (NCAS) & PCM \\
\hline UK, Natural Environment Research Council (SONATA: grant no. NE/P021417/1) & DW \\
\hline UK, Natural Environmental Research Council (NE/R016518/1) & LF \\
\hline UK, Newton Fund, Met Office Climate Science for Service Partnership Brazil (CSSP Brazil) & AJWi \\
\hline UK, Royal Society: The European Space Agency OCEANFLUX projects & AJWa \\
\hline UK, University of Reading Research Endowment Trust Fund & PCM \\
\hline $\begin{array}{l}\text { USA, Department of Commerce, Office of Oceanic and Atmospheric Research (OAR)'s / National } \\
\text { Oceanic and Atmospheric Administration (NOAA)'s Global Ocean Monitoring and Observation } \\
\text { Program (GOMO) }\end{array}$ & DRM, CS, DP, RW, SRA, RAF, AJS, NRB \\
\hline $\begin{array}{l}\text { USA, Department of Commerce, Office of Oceanic and Atmospheric Research (OAR)'s / National } \\
\text { Oceanic and Atmospheric Administration (NOAA)'s Ocean Acidification Program }\end{array}$ & DP, RW, SRA, RAF, AJS \\
\hline USA, Department of Energy, Office of Science and BER prg. (grant no. DE-SC000 0016323) & AKJ \\
\hline USA, Department of Energy, SciDac (DESC0012972) & GCH, LPC \\
\hline $\begin{array}{l}\text { USA, NASA Carbon Monitoring System probram and OCO Science team program } \\
\text { (80NM0018F0583). }\end{array}$ & $\mathrm{JL}$ \\
\hline USA, NASA Interdisciplinary Research in Earth Science (IDS) (80NSSC17K0348) & GCH, LPC \\
\hline USA, National Science Foundation (grant number 1903722) & HT \\
\hline USA, National Science Foundation (grant number PLR 1543457) & DRM, CS \\
\hline $\begin{array}{l}\text { USA, Princeton University Environmental Institute and the NASA OCO2 science team, grant } \\
\text { number 80NSSC18K0893. }\end{array}$ & LR \\
\hline \multicolumn{2}{|l|}{ Computing resources } \\
\hline bwHPC, High Performance Computing Network of the State of Baden-Württemberg, Germany & PA \\
\hline $\begin{array}{l}\text { Cheyenne supercomputer, Computational and Information Systems Laboratory (CISL) at } \\
\text { National Center for Atmospheric Research (NCAR) }\end{array}$ & DK \\
\hline Deutsches Klimarechenzentrum (allocation bm0891) & JEMSN, JP \\
\hline MRI (FUJITSU Server PRIMERGY CX2550M5) & YN \\
\hline
\end{tabular}


https://doi.org/10.5194/essd-2021-386

Preprint. Discussion started: 4 November 2021

(C) Author(s) 2021. CC BY 4.0 License.

\begin{tabular}{|l|l|}
\hline Netherlands Organization for Scientific Research (NWO; NWO-2021.010) & ITL \\
\hline NIES (SX-Aurora) & YN \\
\hline NIES supercomputer system & EK \\
\hline supercomputer 'Gadi' of the National Computational Infrastructure (NCI), Australia & JK \\
\hline Supercomputing time was provided by the Météo-France/DSI supercomputing center. & RS, BD \\
\hline TGCC under allocation 2019-A0070102201 made by GENCI & FC \\
\hline UEA High Performance Computing Cluster, UK & MWJ, CLQ, DRW \\
\hline $\begin{array}{l}\text { UNINETT Sigma2, National Infrastructure for High Performance Computing and Data Storage in } \\
\text { Norway (NN2980K/NS2980K) }\end{array}$ & JS \\
\hline
\end{tabular}




\section{Appendix B. Supplementary Figures}

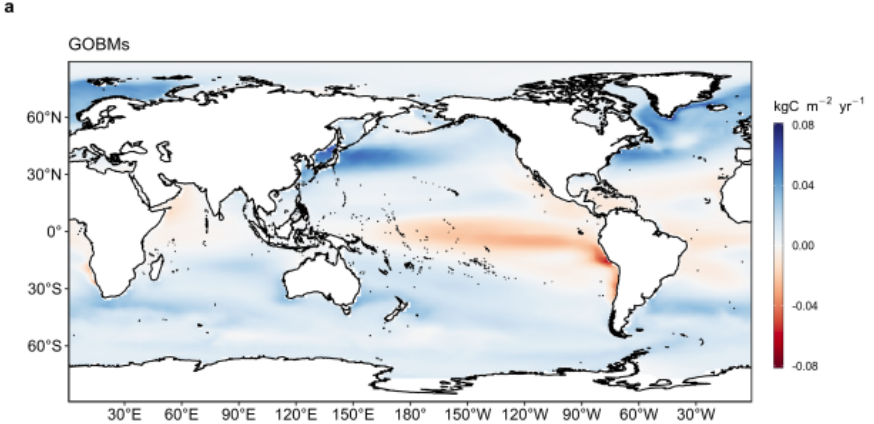

b

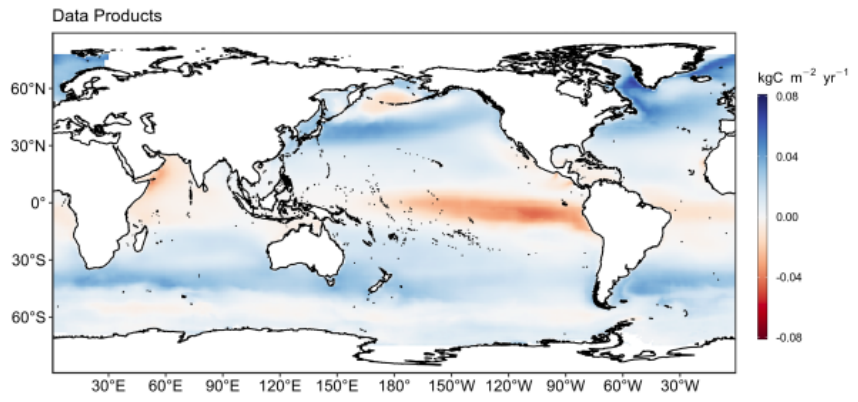

c

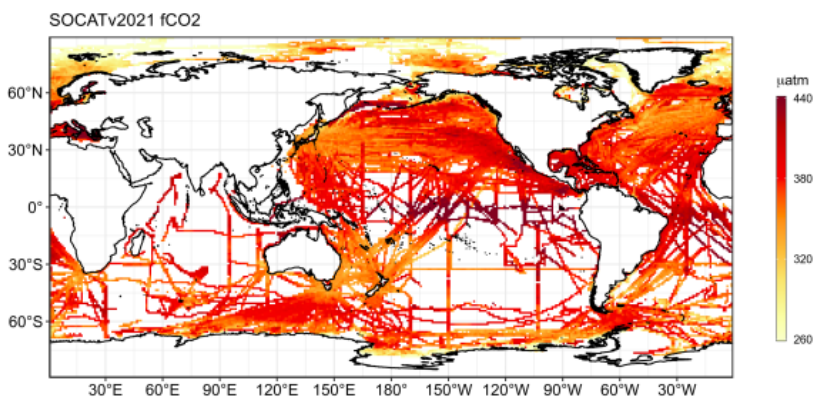

3 Figure B1. Ensemble mean air-sea $\mathrm{CO}_{2}$ flux from a) global ocean biogeochemistry models and b)

$4 \mathrm{fCO}_{2}$ based data products, averaged over 2011-2020 period $\left(\mathrm{kgC} \mathrm{m}^{-2} \mathrm{yr}^{-1}\right)$. Positive numbers

5 indicate a flux into the ocean. c) gridded SOCAT v2021 $\mathrm{fCO}_{2}$ measurements, averaged over the

6 2011-2020 period ( $\mu$ atm). In (a) model simulation A is shown. The data-products represent the

7 contemporary flux, i.e. including outgassing of riverine carbon, which is estimated to amount to

$80.615 \mathrm{GtC} \mathrm{yr}^{-1}$ globally. 

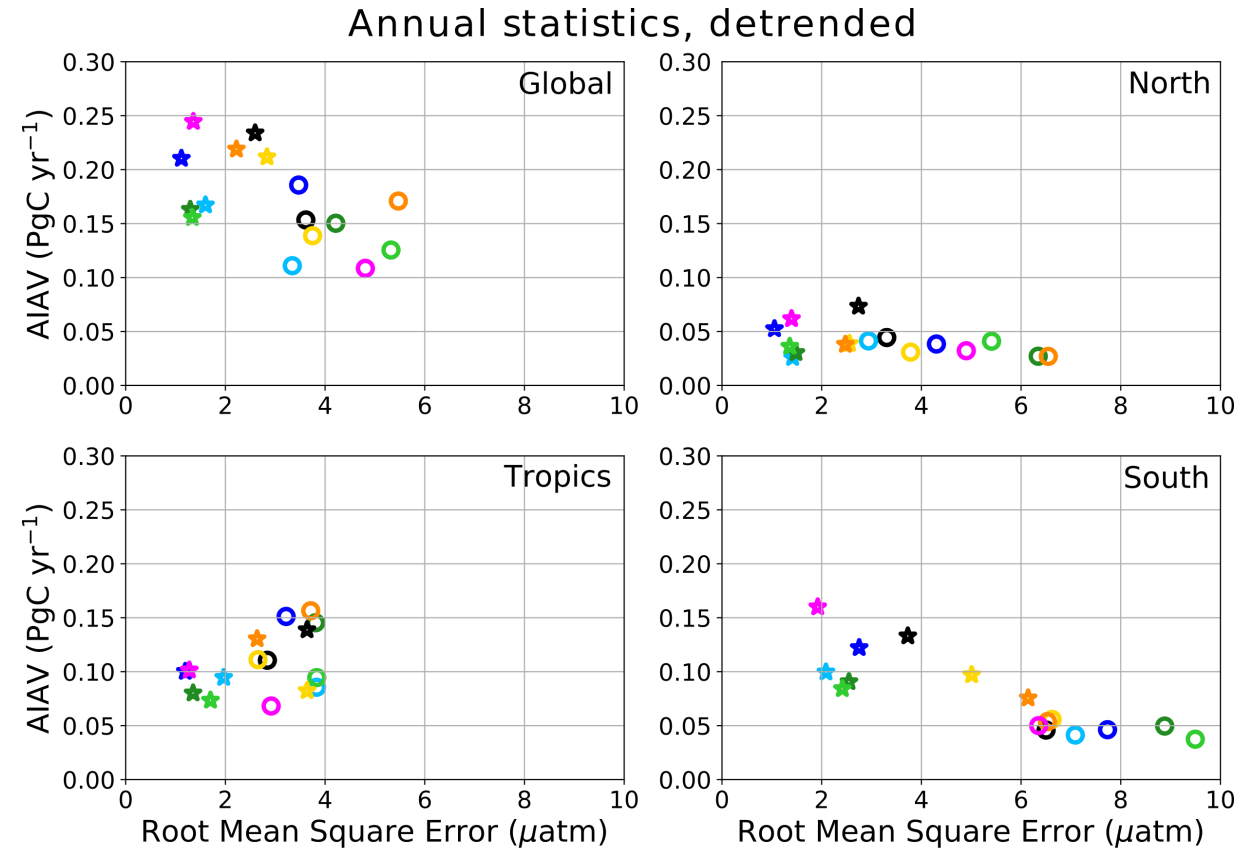

\begin{tabular}{|c|c|c|c|}
\hline 0 & IPSL-PISCES & $\star$ & Jena-MLS \\
\hline 0 & CNRM & $\star$ & MPI-SOMFFN \\
\hline 0 & NorESM & $\star$ & CMEMS \\
\hline 0 & NEMO-PlankTOM5 & $\star$ & CSIR-ML6 \\
\hline 0 & FESOM2.1-RECOM & $\star$ & OS-ETHZ-GRaCER \\
\hline ० & MOM6-COBALT & $\star$ & NIES-NN \\
\hline ० & CESM-ETH & $\star$ & JMA-MLR \\
\hline 0 & $\mathrm{MPI}$ & $\star$ & Watson \\
\hline
\end{tabular}

4 Figure B2. Evaluation of the GOBMs and data products using the root mean squared error (RMSE)

5 for the period 1990 to 2020 , between the individual surface ocean $\mathrm{fCO}_{2}$ mapping schemes and the

6 SOCAT v2021 database. The y-axis shows the amplitude of the interannual variability (A-IAV, taken

7 as the standard deviation of a detrended time series calculated as a 12-months running mean over

8 the monthly flux time series, Rödenbeck et al., 2015). Results are presented for the globe, north

$9\left(>30^{\circ} \mathrm{N}\right)$, tropics $\left(30^{\circ} \mathrm{S}-30^{\circ} \mathrm{N}\right)$, and south $\left(<30^{\circ} \mathrm{S}\right)$ for the GOBMs (see legend circles) and for the

$10 \mathrm{fCO}_{2}$-based data products (star symbols). The $\mathrm{fCO}_{2}$-based data products use the SOCAT database

11 and therefore are not independent from the data (see section 2.4.1). 

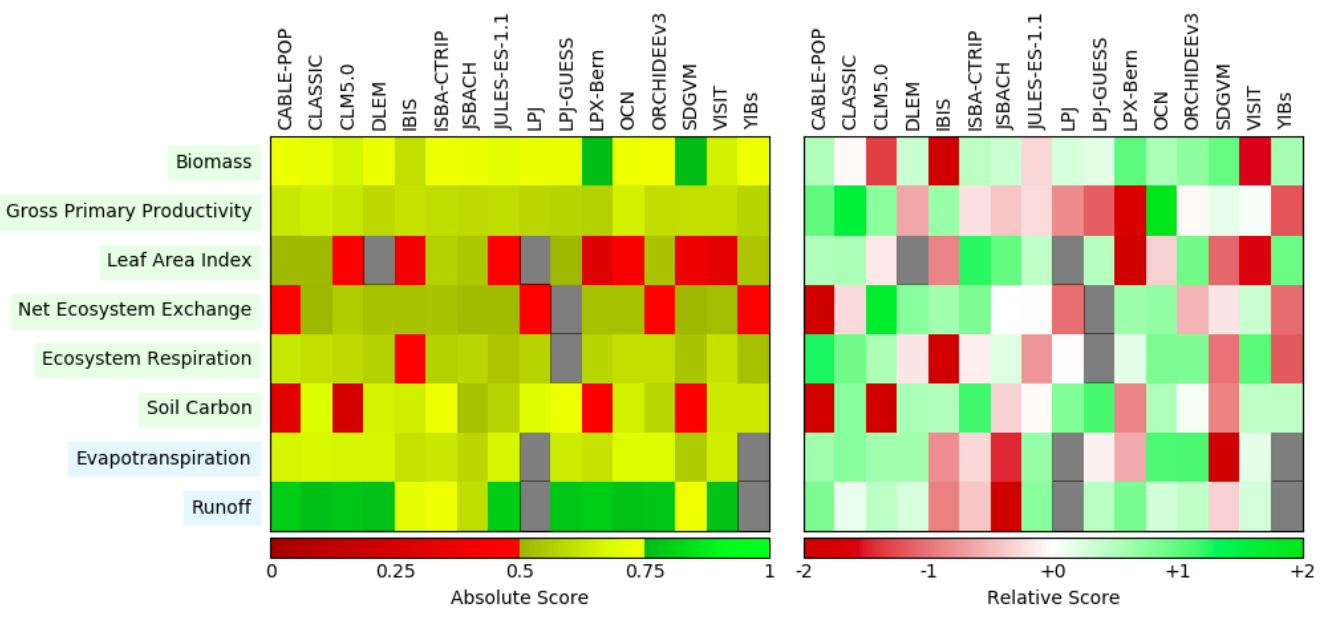

Figure B3. Evaluation of the DGVMs using the International Land Model Benchmarking system

3 (ILAMB; Collier et al., 2018) (left) absolute skill scores and (right) skill scores relative to other

4 models. The benchmarking is done with observations for vegetation biomass (Saatchi et al., 2011;

5 and GlobalCarbon unpublished data; Avitabile et al., 2016), GPP (Jung et al., 2010; Lasslop et al.,

6 2010), leaf area index (De Kauwe et al., 2011; Myneni et al., 1997), net ecosystem exchange (Jung

7 et al., 2010;Lasslop et al., 2010), ecosystem respiration (Jung et al., 2010;Lasslop et al., 2010), soil

8 carbon (Hugelius et al., 2013;Todd-Brown et al., 2013), evapotranspiration (De Kauwe et al.,

9 2011), and runoff (Dai and Trenberth, 2002). For each model-observation comparison a series of

10 error metrics are calculated, scores are then calculated as an exponential function of each error

11 metric, finally for each variable the multiple scores from different metrics and observational data

12 sets are combined to give the overall variable scores shown in the left panel. Overall variable

13 scores increase from 0 to 1 with improvements in model performance. The set of error metrics vary with data set and can include metrics based on the period mean, bias, root mean squared error, spatial distribution, interannual variability and seasonal cycle. The relative skill score shown in the right panel is a Z-score, which indicates in units of standard deviation the model scores

17 relative to the multi-model mean score for a given variable. Grey boxes represent missing model data. 

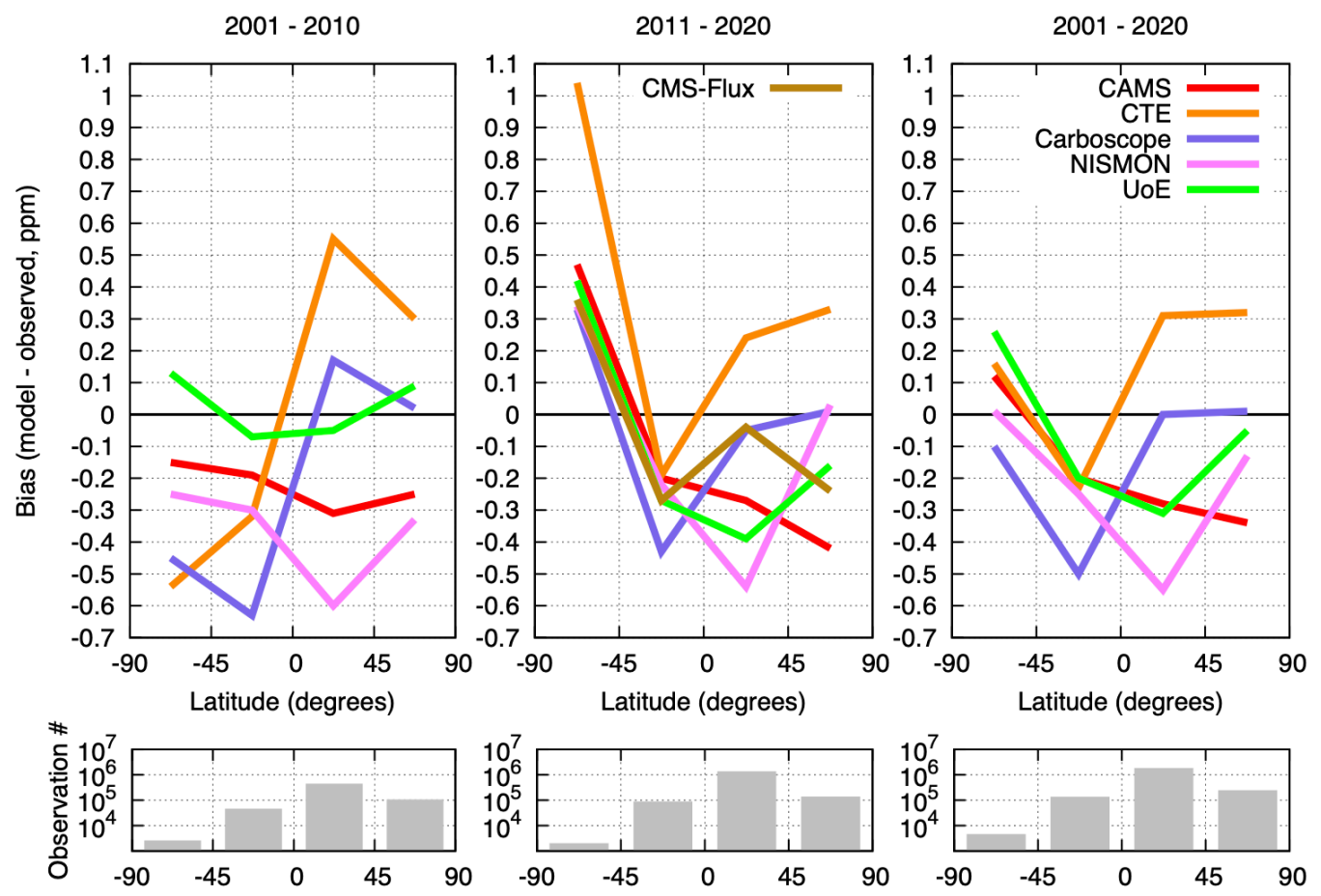

Figure B4. Evaluation of the atmospheric inversion products. The mean of the model minus

3 observations is shown for four latitude bands in three periods: (left) 2001-2010, (centre) 2011-

4 2020, (right) 2001-2020. The six models are compared to independent $\mathrm{CO}_{2}$ measurements made

5 onboard aircraft over many places of the world between 2 and $7 \mathrm{~km}$ above sea level. Aircraft

6 measurements archived in the Cooperative Global Atmospheric Data Integration Project (CGADIP;

7 Cox et al., 2021) from sites, campaigns or programs that cover at least 9 months between 2001

8 and 2020 and that have not been assimilated, have been used to compute the biases of the

9 differences in four $45^{\circ}$ latitude bins. Land and ocean data are used without distinction, and observation density varies strongly with latitude and time as seen on the lower panels. 

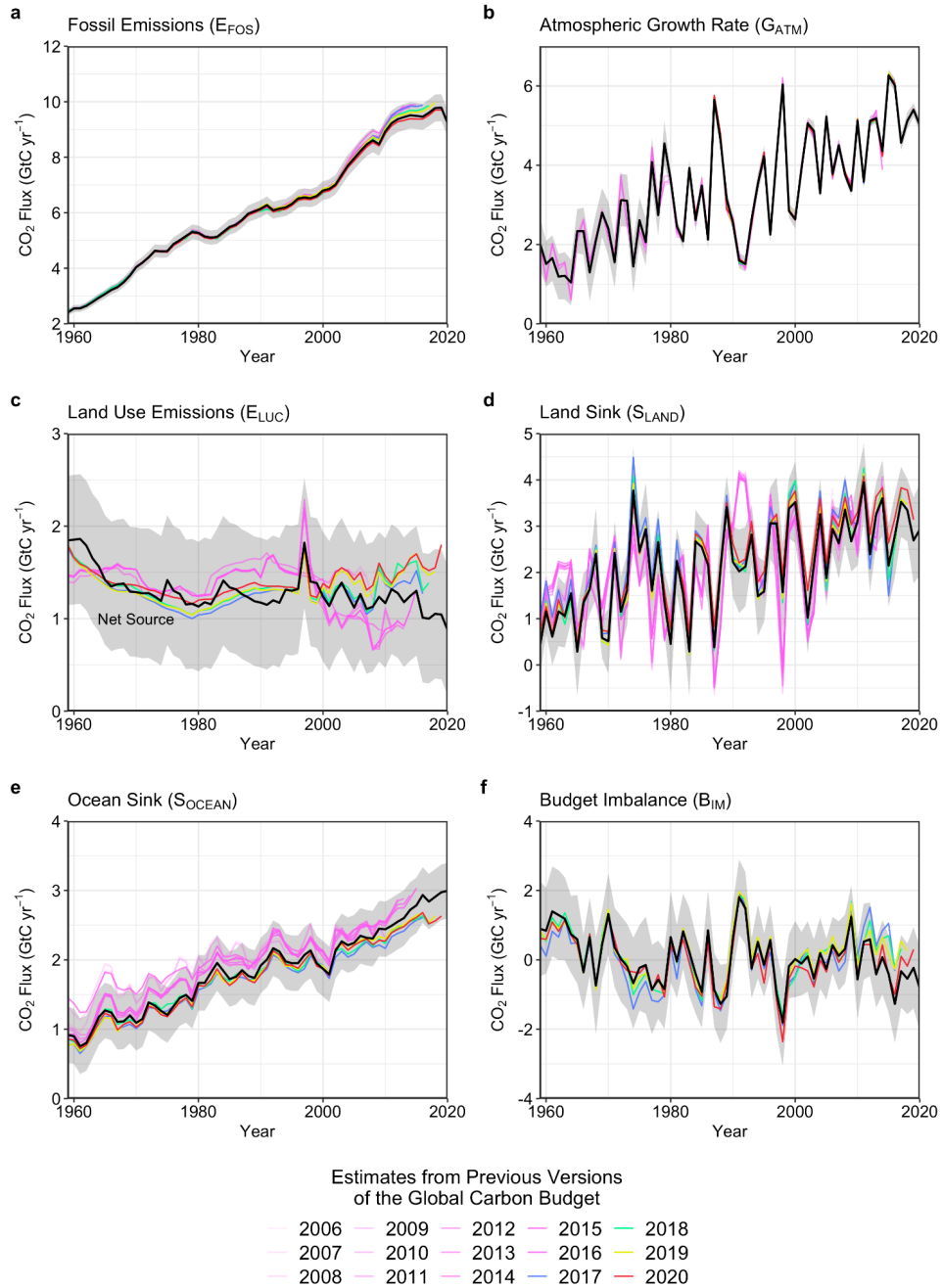

Estimates from Previous Versions

$$
\begin{aligned}
& 2006-2009-2012-2015-2018 \\
& 2007-2010-2013-2016-2019 \\
& 2008-2011-2014-2017-2020
\end{aligned}
$$

2 Figure B5. Comparison of the estimates of each component of the global carbon budget in this

3 study (black line) with the estimates released annually by the GCP since 2006. Grey shading shows

4 the uncertainty bounds representing \pm 1 standard deviation of the current global carbon budget,

5 based on the uncertainty assessments described in Appendix $\mathrm{C}_{\text {. }} \mathrm{CO}_{2}$ emissions from (a) fossil $\mathrm{CO}_{2}$

6 emissions ( $\left.E_{\mathrm{FOS}}\right)$, and (b) land-use change ( $\left.\mathrm{E}_{\mathrm{LUC}}\right)$, as well as their partitioning among (c) the

7 atmosphere $\left(\mathrm{G}_{\mathrm{ATM}}\right)$, $(\mathrm{d})$ the land (S $\left.\mathrm{S}_{\mathrm{LAND}}\right)$, and $(\mathrm{e})$ the ocean (SOCEAN). See legend for the

8 corresponding years, and Tables 3 and A7 for references. The budget year corresponds to the year

9 when the budget was first released. All values are in $\mathrm{GtC} \mathrm{yr}^{-1}$. 
1 Appendix C. Extended Methodology

2 Appendix C.1 Methodology Fossil Fuel $\mathrm{CO}_{2}$ emissions ( $\mathrm{E}_{\mathrm{Fos}}$ )

\section{C.1.1 Cement carbonation}

4 From the moment it is created, cement begins to absorb $\mathrm{CO}_{2}$ from the atmosphere, a process

5 known as 'cement carbonation'. We estimate this $\mathrm{CO}_{2}$ sink, as the average of two studies in the

6 literature (Cao et al., 2020; Guo et al., 2021). Both studies use the same model, developed by Xi et

7 al. (2016), with different parameterisations and input data, with the estimate of Guo and

8 colleagues being a revision of $\mathrm{Xi}$ et al (2016). The trends of the two studies are very similar.

9 Modelling cement carbonation requires estimation of a large number of parameters, including the

10 different types of cement material in different countries, the lifetime of the structures before

11 demolition, of cement waste after demolition, and the volumetric properties of structures, among

12 others (Xi et al., 2016). Lifetime is an important parameter because demolition results in the

13 exposure of new surfaces to the carbonation process. The main reasons for differences between

14 the two studies appear to be the assumed lifetimes of cement structures and the geographic

15 resolution, but the uncertainty bounds of the two studies overlap. In the present budget, we

16 include the cement carbonation carbon sink in the fossil $\mathrm{CO}_{2}$ emission component ( $\mathrm{E}_{\mathrm{FOS}}$ ).

\section{C.1.2 Emissions embodied in goods and services}

18 CDIAC, UNFCCC, and BP national emission statistics 'include greenhouse gas emissions and

19 removals taking place within national territory and offshore areas over which the country has

20 jurisdiction' (Rypdal et al., 2006), and are called territorial emission inventories. Consumption-

21 based emission inventories allocate emissions to products that are consumed within a country,

22 and are conceptually calculated as the territorial emissions minus the 'embodied' territorial

23 emissions to produce exported products plus the emissions in other countries to produce

24 imported products (Consumption $=$ Territorial - Exports + Imports). Consumption-based emission

25 attribution results (e.g. Davis and Caldeira, 2010) provide additional information to territorial-

26 based emissions that can be used to understand emission drivers (Hertwich and Peters, 2009) and

27 quantify emission transfers by the trade of products between countries (Peters et al., 2011b). The

28 consumption-based emissions have the same global total, but reflect the trade-driven movement

29 of emissions across the Earth's surface in response to human activities. We estimate consumption- 
1 based emissions from 1990-2018 by enumerating the global supply chain using a global model of

2 the economic relationships between economic sectors within and between every country (Andrew

3 and Peters, 2013; Peters et al., 2011a). Our analysis is based on the economic and trade data from

4 the Global Trade and Analysis Project (GTAP; Narayanan et al., 2015), and we make detailed

5 estimates for the years 1997 (GTAP version 5), 2001 (GTAP6), and 2004, 2007, and 2011

6 (GTAP9.2), covering 57 sectors and 141 countries and regions. The detailed results are then

7 extended into an annual time series from 1990 to the latest year of the Gross Domestic Product

8 (GDP) data (2018 in this budget), using GDP data by expenditure in current exchange rate of US

9 dollars (USD; from the UN National Accounts main Aggregrates database; UN, 2021) and time

10 series of trade data from GTAP (based on the methodology in Peters et al., 2011a). We estimate

11 the sector-level $\mathrm{CO}_{2}$ emissions using the GTAP data and methodology, include flaring and cement

12 emissions from CDIAC, and then scale the national totals (excluding bunker fuels) to match the

13 emission estimates from the carbon budget. We do not provide a separate uncertainty estimate

14 for the consumption-based emissions, but based on model comparisons and sensitivity analysis,

15 they are unlikely to be significantly different than for the territorial emission estimates (Peters et

16 al., 2012a).

\section{C.1.3 Uncertainty assessment for $\mathrm{E}_{\mathrm{FOS}}$}

18 We estimate the uncertainty of the global fossil $\mathrm{CO} 2$ emissions at $\pm 5 \%$ (scaled down from the published $\pm 10 \%$ at $\pm 2 \sigma$ to the use of $\pm 1 \sigma$ bounds reported here; Andres et al., 2012). This is consistent with a more detailed analysis of uncertainty of $\pm 8.4 \%$ at $\pm 2 \sigma$ (Andres et al., 2014) and at the high-end of the range of \pm 5 - $10 \%$ at $\pm 2 \sigma$ reported by (Ballantyne et al., 2015). This includes an assessment of uncertainties in the amounts of fuel consumed, the carbon and heat contents of fuels, and the combustion efficiency. While we consider a fixed uncertainty of $\pm 5 \%$ for all years, the uncertainty as a percentage of emissions is growing with time because of the larger share of global emissions from emerging economies and developing countries (Marland et al., 2009).

26 Generally, emissions from mature economies with good statistical processes have an uncertainty

27 of only a few per cent (Marland, 2008), while emissions from strongly developing economies such

28 as China have uncertainties of around $\pm 10 \%$ (for $\pm 1 \sigma$; Gregg et al., 2008; Andres et al., 2014).

29 Uncertainties of emissions are likely to be mainly systematic errors related to underlying biases of 30 energy statistics and to the accounting method used by each country. 


\section{$1 \quad$ C.1.4 Growth rate in emissions}

2 We report the annual growth rate in emissions for adjacent years (in percent per year) by

3 calculating the difference between the two years and then normalising to the emissions in the first 4 year: (EFOS(t0+1)-EFOS(t0))/EFOS(t0)×100\%. We apply a leap-year adjustment where relevant to

5 ensure valid interpretations of annual growth rates. This affects the growth rate by about $0.3 \% \mathrm{yr}$ -

$61(1 / 366)$ and causes calculated growth rates to go up approximately $0.3 \%$ if the first year is a leap

7 year and down $0.3 \%$ if the second year is a leap year.

8 The relative growth rate of $E_{F O S}$ over time periods of greater than one year can be rewritten using

9 its logarithm equivalent as follows:

$10 \quad \frac{1}{E_{F O S}} \frac{d E_{F O S}}{d t}=\frac{d\left(\ln E_{F O S}\right)}{d t}$

11 Here we calculate relative growth rates in emissions for multi-year periods (e.g. a decade) by

12 fitting a linear trend to $\ln \left(E_{F O S}\right)$ in Eq. (2), reported in percent per year.

\section{$13 \quad$ C.1.5 Emissions projection for 2021}

14 To gain insight on emission trends for 2021, we provide an assessment of global fossil $\mathrm{CO}_{2}$

15 emissions, $E_{F O S}$, by combining individual assessments of emissions for China, USA, the EU, and India (the four countries/regions with the largest emissions), and the rest of the world. We provide full year estimates for two datasets: IEA (2021b) and our own analysis. This approach differs from last year where we used four independent estimates including our own, because of the unique circumstances related to the COVID-19 pandemic. This year's analysis is more in line with earlier budgets.

21 Previous editions of the Global Carbon Budget (GCB) have estimated YTD emissions, and

22 performed projections, using sub-annual energy consumption data from a variety of sources

23 depending on the country or region. The YTD estimates have then been projected to the full year

24 using specific methods for each country or region. The methods described in detail below.

25 China: The method for the projection uses: (1) the sum of monthly domestic production of raw

26 coal, crude oil, natural gas and cement from the National Bureau of Statistics (NBS, 2021), (2)

27 monthly net imports of coal, coke, crude oil, refined petroleum products and natural gas from the

28 General Administration of Customs of the People's Republic of China (2021); proprietary monthly

29 estimates of sectoral coal consumption by the consultancy SX Coal (2021); and (3) annual energy 
1 consumption data by fuel type and annual production data for cement from the NBS, using data

2 for 2000-2020 (NBS, 2021), with the last year being a preliminary estimate. We estimate the full-

3 year growth rate for 2021 using a Bayesian regression for the ratio between the annual energy

4 consumption data ( 3 above) from 2014 through 2019, and monthly production plus net imports

5 through August of each year ( $1+2$ above) or the corresponding estimate from SX Coal for coal. The

6 uncertainty range uses the standard deviations of the resulting posteriors. Sources of uncertainty

7 and deviations between the monthly and annual growth rates include lack of or incomplete

8 monthly data on stock changes and energy density, variance in the trend during the last three

9 months of the year, and partially unexplained discrepancies between supply-side and

10 consumption data even in the final annual data.

11 Note that in recent years, the absolute value of the annual growth rate for coal energy consumption, and hence total $\mathrm{CO}_{2}$ emissions, has been consistently lower (closer to zero) than the growth or decline suggested by the monthly, tonnage-based production and import data, and this

14 is reflected in the projection. This pattern is only partially explained by stock changes and changes

15 in energy content, and it is therefore not possible to be certain that it will continue in any given

16 year. For 2020 and 2021, COVID-19-related lockdown and reopening in China, similar but delayed

17 restrictions in major export markets, unusual amounts of flooding and extreme weather during

18 the summer months and extraordinarily high local and global prices of many energy products

19 imply that seasonal patterns and correlations between supply, stock changes and consumption

20 may be quite different this year than in the previous years that the regression is based on. Shocks

21 in the housing market and heightened perceptions of political risk among investors may also affect consumption patterns. This adds a major but unquantified amount of uncertainty to the estimate.

USA: We use emissions estimated by the U.S. Energy Information Administration (EIA) in their

24 Short-Term Energy Outlook (STEO) for emissions from fossil fuels to get both YTD and a full year projection (EIA, 2021). The STEO also includes a near-term forecast based on an energy forecasting model which is updated monthly (last update with preliminary data through September 2021), and takes into account expected temperatures, household expenditures by fuel type, energy markets, policies, and other effects. We combine this with our estimate of emissions

29 from cement production using the monthly U.S. cement clinker production data from USGS for

30 January-June 2021, assuming changes in cement production over the first part of the year apply

31 throughout the year. 
1 India: We use monthly emissions estimates for India updated from Andrew (2020b) through

2 August 2021. These estimates are derived from many official monthly energy and other activity

3 data sources to produce direct estimates of national $\mathrm{CO}_{2}$ emissions, without the use of proxies.

4 Emissions from coal are then extended to September using a regression relationship based on

5 power generated from coal, coal dispatches by Coal India Ltd., the composite PMI, time, and days

6 per month. For the last 3-4 months of the year, each series is extrapolated assuming typical

7 trends.

8 EU: We use a refinement to the methods presented by Andrew (2021), deriving emissions from

9 monthly energy data reported by Eurostat. Some data gaps are filled using data from the Joint

10 Organisations Data Initiative (JODI, 2021). Sub-annual cement production data are limited, but

11 data for Germany and Poland, the two largest producers, suggest a small decline. For fossil fuels

12 this provides estimates through July. We extend coal emissions through September using a

13 regression model built from generation of power from hard coal, power from brown coal, total power generation, and the number of working days in Germany and Poland, the two biggest coal consumers in the EU. These are then extended through the end of the year assuming typical trends. We extend oil emissions by building a regression model between our monthly $\mathrm{CO} 2$ estimates and oil consumption reported by the EIA for Europe in its Short-Term Energy Outlook (October edition), and then using this model with EIA's monthly forecasts. For natural gas, the strong seasonal signal allows the use of the bias-adjusted Holt-Winters exponential smoothing method (Chatfield, 1978).

21 Rest of the world: We use the close relationship between the growth in GDP and the growth in emissions (Raupach et al., 2007) to project emissions for the current year. This is based on a

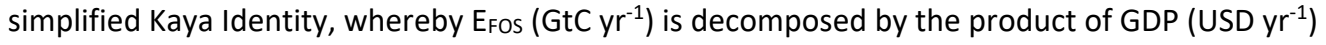
and the fossil fuel carbon intensity of the economy (IFOs; GtC USD ${ }^{-1}$ ) as follows:

Taking a time derivative of Equation (3) and rearranging gives:

$27 \quad \frac{1}{E_{F O S}} \frac{d E_{F O S}}{d t}=\frac{1}{G D P} \frac{d G D P}{d t}+\frac{1}{I_{F O S}} \frac{d I_{F O S}}{d t}$

28 where the left-hand term is the relative growth rate of $\mathrm{E}_{\mathrm{FOS}}$, and the right-hand terms are the relative growth rates of GDP and $I_{F O S}$, respectively, which can simply be added linearly to give the overall growth rate. 
1 The IFOs $_{\text {is }}$ based on GDP in constant PPP (Purchasing Power Parity) from the International Energy

2 Agency (IEA) up to 2017 (IEA/OECD, 2019) and extended using the International Monetary Fund

3 (IMF) growth rates through 2020 (IMF, 2021). Interannual variability in $\mathrm{I}_{\mathrm{FOS}}$ is the largest source of

4 uncertainty in the GDP-based emissions projections. We thus use the standard deviation of the

5 annual $I_{F O S}$ for the period 2009-2019 as a measure of uncertainty, reflecting a $\pm 1 \sigma$ as in the rest of

6 the carbon budget.

7 World: The global total is the sum of each of the countries and regions.

9 Appendix C.2 Methodology $\mathrm{CO}_{2}$ emissions from land-use, land-use change and forestry ( $\left.E_{\mathrm{LuC}}\right)$

10 The net $\mathrm{CO}_{2}$ flux from land-use, land-use change and forestry ( $E_{L U C}$, called land-use change

11 emissions in the rest of the text) includes $\mathrm{CO}_{2}$ fluxes from deforestation, afforestation, logging and

12 forest degradation (including harvest activity), shifting cultivation (cycle of cutting forest for

13 agriculture, then abandoning), and regrowth of forests following wood harvest or abandonment

14 of agriculture. Emissions from peat burning and drainage are added from external datasets (see section C.2.1 below). Only some land-management activities are included in our land-use change emissions estimates (Table A1). Some of these activities lead to emissions of $\mathrm{CO}_{2}$ to the

17 atmosphere, while others lead to $\mathrm{CO}_{2}$ sinks. ELuc is the net sum of emissions and removals due to

18 all anthropogenic activities considered. Our annual estimate for 1960-2020 is provided as the

19 average of results from three bookkeeping approaches (Section C.2.1 below): an estimate using

20 the Bookkeeping of Land Use Emissions model (Hansis et al., 2015; hereafter BLUE) and one using

21 the compact Earth system model OSCAR (Gasser et al., 2020), both BLUE and OSCAR being

22 updated here to new land-use forcing covering the time period until 2020, and an updated version

23 of the estimate published by Houghton and Nassikas (2017) (hereafter updated H\&N2017). All

24 three data sets are then extrapolated to provide a projection for 2021 (Section C.2.5 below). In

25 addition, we use results from Dynamic Global Vegetation Models (DGVMs; see Section 2.5 and

26 Table 4) to help quantify the uncertainty in $E_{\text {LUC }}$ (Section C.2.4), and thus better characterise our

27 understanding. Note that in this budget, we use the scientific $E_{\text {Luc }}$ definition, which counts fluxes

28 due to environmental changes on managed land towards $S_{L A N D}$, as opposed to the national

29 greenhouse gas inventories under the UNFCCC, which include them in $E_{\text {LUC }}$ and thus often report 
1 smaller land-use emissions (Grassi et al., 2018; Petrescu et al., 2020). However, we provide a

2 methodology of mapping of the two approaches to each other further below (Section C.2.3).

\section{$3 \quad$ C.2.1 Bookkeeping models}

4 Land-use change $\mathrm{CO}_{2}$ emissions and uptake fluxes are calculated by three bookkeeping models.

5 These are based on the original bookkeeping approach of Houghton (2003) that keeps track of the

6 carbon stored in vegetation and soils before and after a land-use change (transitions between

7 various natural vegetation types, croplands, and pastures). Literature-based response curves

8 describe decay of vegetation and soil carbon, including transfer to product pools of different

9 lifetimes, as well as carbon uptake due to regrowth. In addition, the bookkeeping models

10 represent long-term degradation of primary forest as lowered standing vegetation and soil carbon

11 stocks in secondary forests, and include forest management practices such as wood harvests.

12 BLUE and the updated H\&N2017 exclude land ecosystems' transient response to changes in

13 climate, atmospheric $\mathrm{CO}_{2}$ and other environmental factors, and base the carbon densities on

14 contemporary data from literature and inventory data. Since carbon densities thus remain fixed

15 over time, the additional sink capacity that ecosystems provide in response to $\mathrm{CO}_{2}$-fertilization

16 and some other environmental changes is not captured by these models (Pongratz et al., 2014).

17 On the contrary, OSCAR includes this transient response, and it follows a theoretical framework

18 (Gasser and Ciais, 2013) that allows separating bookkeeping land-use emissions and the loss of

19 additional sink capacity. Only the former is included here, while the latter is discussed in Appendix

20 D4. The bookkeeping models differ in (1) computational units (spatially explicit treatment of land-

21 use change for BLUE, regional-/ mostly country-level for the updated H\&N2017 and OSCAR), (2)

22 processes represented (see Table A1), and (3) carbon densities assigned to vegetation and soil of

23 each vegetation type (literature-based for the updated H\&N2017 and BLUE, calibrated to DGVMs

24 for OSCAR). A notable difference between models exists with respect to the treatment of shifting

25 cultivation. The update of H\&N2017 changed the approach over the earlier H\&N2017 version:

26 H\&N2017 had assumed the "excess loss" of tropical forests (i.e., when FRA indicated a forest loss

27 larger than the increase in agricultural areas from $\mathrm{FAO}$ ) resulted from converting forests to

28 croplands at the same time older croplands were abandoned. Those abandoned croplands began

29 to recover to forests after 15 years. The updated H\&N2017 now assumes that forest loss in excess

30 of increases in cropland and pastures represented an increase in shifting cultivation. When the

31 excess loss of forests was negative, it was assumed that shifting cultivation was returned to forest. 
1 Historical areas in shifting cultivation were extrapolated taking into account country-based

2 estimates of areas in fallow in 1980 (FAO/UNEP, 1981) and expert opinion (from Heinimann et al.,

3 2017). In contrast, the BLUE and OSCAR models include sub-grid-scale transitions between all

4 vegetation types. Furthermore, the updated H\&N2017 assume conversion of natural grasslands to

5 pasture, while BLUE and OSCAR allocate pasture proportionally on all natural vegetation that

6 exists in a grid-cell. This is one reason for generally higher emissions in BLUE and OSCAR.

7 Bookkeeping models do not directly capture carbon emissions from peat fires, which can create

8 large emissions and interannual variability due to synergies of land-use and climate variability in

9 Southeast Asia, particularly during El-Niño events, nor emissions from the organic layers of

10 drained peat soils. To correct for this, the updated H\&N2017 includes carbon emissions from

11 burning and draining of peatlands in Indonesia, Malaysia, and Papua New Guinea (based on the

12 Global Fire Emission Database (GFED4s; van der Werf et al., 2017) for fire and Hooijer et al. for

13 drainage. Further, estimates of carbon losses from peatlands in extra-tropical regions are added

14 from Qiu et al. (2021). We add GFED4s peat fire emissions to BLUE and OSCAR output as well as

15 the global FAO peat drainage emissions 1990-2018 from croplands and grasslands (Conchedda

16 and Tubiello, 2020), keeping post-2018 emissions constant. We linearly increase tropical drainage

17 emissions from 0 in 1980, consistent with H\&N2017's assumption, and keep emissions from the

18 often old drained areas of the extra-tropics constant pre-1990. This adds $9.0 \mathrm{GtC}$ for FAO

19 compared to $5.6 \mathrm{GtC}$ for Hooijer et al. (2010). Peat fires add another 2.0 GtC over the same

20 period.

21 The three bookkeeping estimates used in this study differ with respect to the land-use change

22 data used to drive the models. The updated H\&N2017 base their estimates directly on the Forest

23 Resource Assessment of the FAO which provides statistics on forest-area change and management

24 at intervals of five years currently updated until 2020 (FAO, 2020). The data is based on country

25 reporting to FAO and may include remote-sensing information in more recent assessments.

26 Changes in land-use other than forests are based on annual, national changes in cropland and

27 pasture areas reported by FAO (FAOSTAT, 2021). On the other hand, BLUE uses the harmonised

28 land-use change data LUH2-GCB2021 covering the entire 850-2020 period (an update to the

29 previously released LUH2 v2h dataset; Hurtt et al., 2017; Hurtt et al., 2020), which was also used

30 as input to the DGVMs (Sec. 2.2.2). It describes land-use change, also based on the FAO data as

31 well as the HYDE3.3 dataset (Goldewijk et al., 2017a, 2017b), but provided at a quarter-degree 
spatial resolution, considering sub-grid-scale transitions between primary forest, secondary forest,

2 primary non-forest, secondary non-forest, cropland, pasture, rangeland, and urban land (Hurtt et

3 al., 2020; Chini et al., 2021). LUH2-GCB2021 provides a distinction between rangelands and

4 pasture, based on inputs from HYDE. To constrain the models' interpretation on whether

5 rangeland implies the original natural vegetation to be transformed to grassland or not (e.g.,

6 browsing on shrubland), a forest mask was provided with LUH2-GCB2021; forest is assumed to be

7 transformed to grasslands, while other natural vegetation remains (in case of secondary

8 vegetation) or is degraded from primary to secondary vegetation (Ma et al., 2020). This is

9 implemented in BLUE. OSCAR was run with both LUH2-GCB2021 and FAO/FRA (as used by

10 Houghton and Nassikas, 2017), where emissions from the latter were extended beyond 2015 with

11 constant 2011-2015 average values. The best-guess OSCAR estimate used in our study is a

12 combination of results for LUH2-GCB2021 and FAO/FRA land-use data and a large number of

13 perturbed parameter simulations weighted against an observational constraint. All three

14 bookkeeping estimates were extended from 2020 to provide a projection for 2021 by adding the

15 annual change in emissions from tropical deforestation and degradation and peat burning and

16 drainage to the respective model's estimate for 2020 (van der Werf et al., 2017, Conchedda \&

17 Tubiello, 2020).

18 For ELUC from 1850 onwards we average the estimates from BLUE, the updated H\&N2017 and

19 OSCAR. For the cumulative numbers starting 1750 an average of four earlier publications is added

20 (30 \pm 20 PgC 1750-1850, rounded to nearest 5; Le Quéré et al., 2016).

21 We provide estimates of the gross land use change fluxes from which the reported net land-use change flux, $E_{L U C}$, is derived as a sum. Gross fluxes are derived internally by the three bookkeeping models: Gross emissions stem from decaying material left dead on site and from products after clearing of natural vegetation for agricultural purposes, wood harvesting, emissions from peat drainage and peat burning, and, for BLUE, additionally from degradation from primary to secondary land through usage of natural vegetation as rangeland. Gross removals stem from regrowth after agricultural abandonment and wood harvesting. Gross fluxes for the updated H\&N2017 2016-2020 and for the 2021 projection of all three models were based on a regression of gross sources (including peat emissions) to net emissions for recent years. 

with longer timescales, such as slow legacy emissions and regrowth, are inseparable from the

4 carbon dynamics due to subsequent land-use change events. We therefore do not adjust gross

5 removals, but only gross emissions to match the corrected net flux. Since DGVMs estimates are

6 only used for an uncertainty range of $E_{L U C}$, which is independent of land-use changes, no correction is applied to the DGVMs data.

\section{C.2.2 Dynamic Global Vegetation Models (DGVMs)}

9 Land-use change $\mathrm{CO}_{2}$ emissions have also been estimated using an ensemble of 17 DGVMs

10 simulations. The DGVMs account for deforestation and regrowth, the most important components

11 of $E_{L U C}$, but they do not represent all processes resulting directly from human activities on land

12 (Table A1). All DGVMs represent processes of vegetation growth and mortality, as well as

13 decomposition of dead organic matter associated with natural cycles, and include the vegetation

14 and soil carbon response to increasing atmospheric $\mathrm{CO}_{2}$ concentration and to climate variability

15 and change. Most models explicitly simulate the coupling of carbon and nitrogen cycles and account for atmospheric $\mathrm{N}$ deposition and $\mathrm{N}$ fertilisers (Table $\mathrm{A} 1$ ). The DGVMs are independent from the other budget terms except for their use of atmospheric $\mathrm{CO}_{2}$ concentration to calculate the fertilization effect of $\mathrm{CO}_{2}$ on plant photosynthesis. DGVMs that do not simulate subgrid scale transitions (i.e., net land-use emissions; see Table A1) used the HYDE land-use change data set (Goldewijk et al., 2017a, 2017b), which provides annual (1700-2019), half-degree, fractional data on cropland and pasture. The data are based on the available annual FAO statistics of change in agricultural land area available until 2015. The new HYDE3.3 cropland/grazing land dataset which now in addition to FAO country-level statistics is constrained spatially based on multi-year satellite land cover maps from ESA CCI LC. Data from HYDE3.3 is based on a FAO which includes yearly data from 1961 up to and including the year 2017. After the year 2017 HYDE extrapolates the cropland, pasture, and urban data, based on the trend over the previous 5 years, to generate data until the year 2020. HYDE also uses satellite imagery from ESA-CCI from 1992 - 2018 for more detailed yearly allocation of cropland and grazing land. The 2018 map is also used for the 2019-2020 period. The original 300 meter resolution data from ESA was aggregated to a 5 arc minute resolution according to the 
1 scale transitions (i.e., gross land-use emissions; see Table A1) also use the LUH2-GCB2021 data set,

2 an update of the more comprehensive harmonised land-use data set (Hurtt et al., 2020), that

3 further includes fractional data on primary and secondary forest vegetation, as well as all

4 underlying transitions between land-use states (850-2020; Hurtt et al., 2011, 2017, 2020; Chini et

5 al., 2021; Table A1). This new data set is of quarter degree fractional areas of land-use states and

6 all transitions between those states, including a new wood harvest reconstruction, new

7 representation of shifting cultivation, crop rotations, management information including irrigation

8 and fertilizer application. The land-use states include five different crop types in addition to the

9 pasture-rangeland split discussed before. Wood harvest patterns are constrained with Landsat-

10 based tree cover loss data (Hansen et al. 2013). Updates of LUH2-GCB2021 over last year's version

11 (LUH2-GCB2020) are using the most recent HYDE/FAO release (covering the time period up to

122021 included). We also use the most recent FAO wood harvest data for all years from 1961 to

13 2019. After the year 2019 we extrapolated the wood harvest data until the year 2020. The

14 HYDE3.3 population data is also used to extend the wood harvest time series back in time. Other

15 wood harvest inputs (for years prior to 1961) remain the same in LUH2.

16 DGVMs implement land-use change differently (e.g., an increased cropland fraction in a grid cell

17 can either be at the expense of grassland or shrubs, or forest, the latter resulting in deforestation;

18 land cover fractions of the non-agricultural land differ between models). Similarly, model-specific

19 assumptions are applied to convert deforested biomass or deforested area, and other forest

20 product pools into carbon, and different choices are made regarding the allocation of rangelands

21 as natural vegetation or pastures.

22 The difference between two DGVMs simulations (See Section C4.1 below), one forced with

23 historical changes in land-use and a second with time-invariant pre-industrial land cover and pre-

24 industrial wood harvest rates, allows quantification of the dynamic evolution of vegetation

25 biomass and soil carbon pools in response to land-use change in each model (ELUc). Using the

26 difference between these two DGVMs simulations to diagnose ELuc means the DGVMs account for

27 the loss of additional sink capacity (around 0.4 $\pm 0.3 \mathrm{GtC}$ yr-1; see Section 2.7.4, Appendix D4),

28 while the bookkeeping models do not.

29 As a criterion for inclusion in this carbon budget, we only retain models that simulate a positive

30 ELUC during the 1990s, as assessed in the IPCC AR4 (Denman et al., 2007) and AR5 (Ciais et al.,

31 2013). All DGVMs met this criterion, although one model was not included in the $E_{\text {Luc }}$ estimate 
1 from DGVMs as it exhibited a spurious response to the transient land cover change forcing after

2 its initial spin-up.

\section{C.2.3 Mapping of national GHG inventory data to ELUC}

4 For the first time, an approach is implemented to reconcile the large gap between ELUC from

5 bookkeeping models and land use, land-use change and forestry (LULUCF) from national GHG

6 Inventories (NGHGI) (see Tab. A8). This gap is due to different approaches to calculating

7 "anthropogenic" $\mathrm{CO}_{2}$ fluxes related to land-use change and land management (Grassi et al. 2018).

8 In particular, the land sinks due to environmental change on managed lands are treated as non-

9 anthropogenic in the global carbon budget, while they are generally considered as anthropogenic

10 in NGHGIs ("indirect anthropogenic fluxes"; Eggleston et al., 2006). Building on previous studies

11 (Grassi et al. 2021), the approach implemented here adds the DGVMs estimates of $\mathrm{CO}_{2}$ fluxes due

12 to environmental change from countries' managed forest area (part of the $S_{\text {LAND }}$ ) to the original

13 ELUC flux. This sum is expected to be conceptually more comparable to LULUCF than simply ELUC.

14 ELUC data are taken from bookkeeping models, in line with the global carbon budget approach. To

15 determine S LAND on managed forest, the following steps were taken: Spatially gridded data of

16 "natural" forest NBP (S S LAND i.e., due to environmental change and excluding land use change

17 fluxes) were obtained with S2 runs from DGVMs up to 2019 from the TRENDY v9 dataset. Results

18 were first masked with the Hansen forest map (Hansen et al. 2013), with a $20 \%$ tree cover and

19 following the FAO definition of forest (isolated pixels with maximum connectivity less than 0.5 ha

20 are excluded), and then further masked with the "intact" forest map for the year 2013, i.e. forest

21 areas characterized by no remotely detected signs of human activity (Potapov et al. 2017). This

22 way, we obtained the SLAND in "intact" and "non-intact" forest area, which previous studies (Grassi

23 et al. 2021) indicated to be a good proxy, respectively, for "unmanaged" and "managed" forest

24 area in the NGHGI. Note that only 4 models (CABLE-POP, CLASSIC, YIBs and ORCHIDEE-CNP) had

25 forest NBP at grid cell level. Two models (OCN and ISBA-CTRIP) provided forest NEP and simulated

26 disturbances at pixel level that were used as basis, in addition to forest cover fraction, to estimate

27 forest NBP. For the other DGVMs, when a grid cell had forest, all the NBP was allocated to forest.

28 LULUCF data from NGHGIs are from Grassi et al. (2021) until 2017, updated until 2019 for Annex I

29 countries. For non-Annex I countries, the years 2018 and 2019 were assumed equal to the average

30 2013-2017. This data includes all $\mathrm{CO} 2$ fluxes from land considered managed, which in principle 
encompasses all land uses (forest land, cropland, grassland, wetlands, settlements, and other

land), changes among them, emissions from organic soils and from fires. In practice, although almost all Annex I countries report all land uses, many non-Annex I countries report only on deforestation and forest land, and only few countries report on other land uses. In most cases,

$5 \mathrm{NGHGI}$ include most of the natural response to recent environmental change, because they use

6 direct observations (e.g., national forest inventories) that do not allow separating direct and

7 indirect anthropogenic effects (Eggleston et al., 2006).

8 To provide additional, largely independent assessments of fluxes on unmanaged vs managed

9 lands, we include a DGVM that allows diagnosing fluxes from unmanaged vs managed lands by

10 tracking vegetation cohorts of different ages separately. This model, ORCHIDEE-MICT (Yue et al.,

11 2018), was run using the same LUH2 forcing as the DGVMs used in this budget (Section 2.5) and

12 the bookkeeping models BLUE and OSCAR (Section 2.2). Old-aged forest was classified as primary

13 forest after a certain threshold of carbon density was reached again, and the model-internal

14 distinction between primary and secondary forest used as proxies for unmanaged vs managed

15 forests; agricultural lands are added to the latter to arrive at total managed land.

16 Tab. A8 shows the resulting mapping of global carbon cycle models' land flux definitions to that of

17 the NGHGI (discussed in Sec. 3.2.2). Note that estimates in this table are based on the global

18 carbon budget estimates from Friedlingstein et al. (2020), which estimated higher emissions from

19 the net land-use change flux ( $\left.E_{L U C}\right)$ and a larger natural terrestrial sink. ORCHIDEE-MICT estimates

20 for SLAND on intact forests are expected to be higher than based on DGVMs in combination with

21 the NGHGI managed/unmanaged forest data because the unmanaged forest area, with about 27

22 mio km2, is estimated to be substantially larger by ORCHIDEE-MICT than, with less than 10 mio

$23 \mathrm{~km} 2$, by the NGHGI, while managed forest area is estimated to be smaller (22 compared to 32 mio

$24 \mathrm{~km} 2$ ). Related to this, SLAND on non-intact lands plus ELUC is a larger source estimated by ORCHIDEE-

25 MICT compared to NGHGI. We also show as comparison FAOSTAT emissions totals (FAO, 2021),

26 which include emissions from net forest conversion and fluxes on forest land (Tubiello et al., 2021)

27 as well as $\mathrm{CO}_{2}$ emissions from peat drainage and peat fires.

\section{C.2.4 Uncertainty assessment for ELUC}

29 Differences between the bookkeeping models and DGVMs models originate from three main

30 sources: the different methodologies, which among others lead to inclusion of the loss of 
1 additional sink capacity in DGVMs (see Appendix D1.4), the underlying land-use/land cover data

2 set, and the different processes represented (Table A1). We examine the results from the DGVMs

3 models and of the bookkeeping method and use the resulting variations as a way to characterise

4 the uncertainty in Eluc.

5 Despite these differences, the $E_{L U C}$ estimate from the DGVMs multi-model mean is consistent with

6 the average of the emissions from the bookkeeping models (Table 5). However there are large

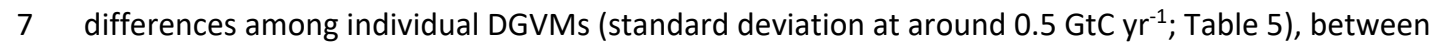

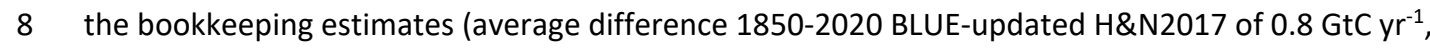

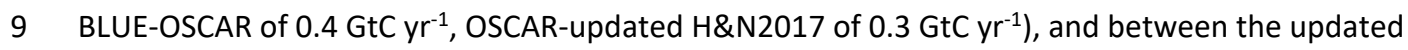

10 estimate of H\&N2017 and its previous model version (Houghton et al., 2012). A factorial analysis

11 of differences between BLUE and H\&N2017 attributed them particularly to differences in carbon

12 densities between natural and managed vegetation or primary and secondary vegetation (Bastos

13 et al., 2021). Earlier studies additionally showed the relevance of the different land-use forcing as

14 applied (in updated versions) also in the current study (Gasser et al., 2020).

15 The uncertainty in Eluc of $\pm 0.7 \mathrm{GtC}_{\mathrm{yr}}{ }^{-1}$ reflects our best value judgment that there is at least $68 \%$

16 chance $( \pm 1 \sigma)$ that the true land-use change emission lies within the given range, for the range of

17 processes considered here. Prior to the year 1959, the uncertainty in $E_{\text {Luc }}$ was taken from the

18 standard deviation of the DGVMs. We assign low confidence to the annual estimates of ELUC

19 because of the inconsistencies among estimates and of the difficulties to quantify some of the

20 processes in DGVMs.

\section{C.2.5 Emissions projections for $E_{L U C}$}

22 We project the 2021 land-use emissions for BLUE, the updated H\&N2017 and OSCAR, starting

23 from their estimates for 2020 assuming unaltered peat drainage, which has low interannual

24 variability, and the highly variable emissions from peat fires, tropical deforestation and

25 degradation as estimated using active fire data (MCD14ML; Giglio et al., 2016). Those latter scale

26 almost linearly with GFED over large areas (van der Werf et al., 2017), and thus allows for tracking

27 fire emissions in deforestation and tropical peat zones in near-real time. During most years,

28 emissions during January-September cover most of the fire season in the Amazon and Southeast

29 Asia, where a large part of the global deforestation takes place, and our estimates capture

30 emissions until the end of September. 
2 Appendix C.3 Methodology Ocean $\mathrm{CO}_{2}$ sink

\section{$3 \quad$ C.3.1 Observation-based estimates}

4 We primarily use the observational constraints assessed by IPCC of a mean ocean $\mathrm{CO}_{2}$ sink of $2.2 \pm$

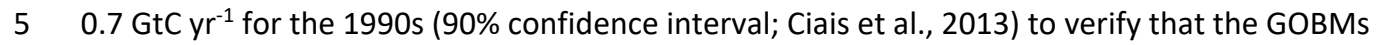

6 provide a realistic assessment of SOCEAN. This is based on indirect observations with seven

7 different methodologies and their uncertainties, using the methods that are deemed most reliable

8 for the assessment of this quantity (Denman et al., 2007; Ciais et al., 2013). The observation-based

9 estimates use the ocean/land $\mathrm{CO}_{2}$ sink partitioning from observed atmospheric $\mathrm{CO}_{2}$ and $\mathrm{O}_{2} / \mathrm{N}_{2}$

10 concentration trends (Manning and Keeling, 2006; Keeling and Manning, 2014), an oceanic

11 inversion method constrained by ocean biogeochemistry data (Mikaloff Fletcher et al., 2006), and

12 a method based on penetration time scale for chlorofluorocarbons (McNeil et al., 2003). The IPCC

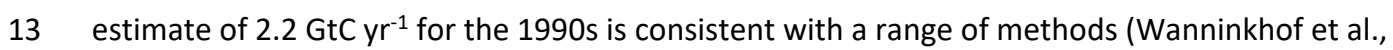

14 2013). We refrain from using the IPCC estimates for the 2000s $\left(2.3 \pm 0.7 \mathrm{GtC}^{-1}\right)$, and the period

15 2002-2011 (2.4 $\pm 0.7 \mathrm{GtC} \mathrm{yr}^{-1}$, Ciais et al., 2013) as these are based on trends derived mainly from

16 models and one data-product (Ciais et al., 2013). Additional constraints summarized in AR6

17 (Canadell et al., 2021) are the interior ocean anthropogenic carbon change (Gruber et al., 2019)

18 and ocean sink estimate from atmospheric $\mathrm{CO}_{2}$ and $\mathrm{O}_{2} / \mathrm{N}_{2}$ (Tohjima et al., 2019) which are used

19 for model evaluation and discussion, respectively.

20 We also use eight estimates of the ocean $\mathrm{CO}_{2}$ sink and its variability based on surface ocean $\mathrm{fCO}_{2}$

21 maps obtained by the interpolation of surface ocean $\mathrm{fCO}_{2}$ measurements from 1990 onwards due

22 to severe restriction in data availability prior to 1990 (Figure 9). These estimates differ in many

23 respects: they use different maps of surface $\mathrm{fCO}_{2}$, different atmospheric $\mathrm{CO}_{2}$ concentrations, wind

24 products and different gas-exchange formulations as specified in Table A3. We refer to them as

$25 \mathrm{fCO}_{2}$-based flux estimates. The measurements underlying the surface $\mathrm{fCO}_{2}$ maps are from the

26 Surface Ocean $\mathrm{CO}_{2}$ Atlas version 2021 (SOCATv2021; Bakker et al., 2021), which is an update of

27 version 3 (Bakker et al., 2016) and contains quality-controlled data through 2020 (see data

28 attribution Table A5). Each of the estimates uses a different method to then map the SOCAT

29 V2021 data to the global ocean. The methods include a data-driven diagnostic method (Rödenbeck

30 et al., 2013; referred to here as Jena-MLS), three neural network models (Landschützer et al., 
1 2014; referred to as MPI-SOMFFN; Chau et al., 2021; Copernicus Marine Environment Monitoring

2 Service, referred to here as CMEMS-LSCE-FFNN; and Zeng et al., 2014; referred to as NIES-FNN),

3 two cluster regression approaches (Gregor et al., 2019; referred to here as CSIR-ML6; and Gregor

4 and Gruber, 2021, referred to as OS-ETHZ-GRaCER), and a multi-linear regression method (lida et

5 al., 2021; referred to as JMA-MLR). The ensemble mean of the $\mathrm{fCO}_{2}$-based flux estimates is

6 calculated from these seven mapping methods. Further, we show the flux estimate of Watson et

7 al. (2020) who also use the MPI-SOMFFN method to map the adjusted $\mathrm{fCO}_{2}$ data to the globe, but

8 resulting in a substantially larger ocean sink estimate, owing to a number of adjustments they

9 applied to the surface ocean $\mathrm{fCO}_{2}$ data and the gas-exchange parameterization. Concretely, these

10 authors adjusted the SOCAT $\mathrm{fCO}_{2}$ downward to account for differences in temperature between

11 the depth of the ship intake and the relevant depth right near the surface, and included a further

12 adjustment to account for the cool surface skin temperature effect. The Watson et al. flux

13 estimate hence differs from the others by their choice of adjusting the flux to a cool, salty ocean

14 surface skin. Watson et al. (2020) showed that this temperature adjustment leads to an upward

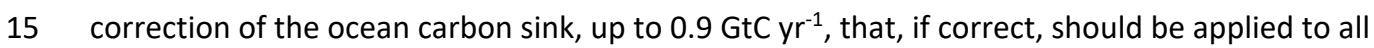

$16 \mathrm{fCO}_{2}$-based flux estimates. So far, this adjustment is based on a single line of evidence and hence

17 associated with low confidence until further evidence is available. The Watson et al flux estimate

18 presented here is therefore not included in the ensemble mean of the $\mathrm{fCO}_{2}$-based flux estimates.

19 This choice will be re-evaluated in upcoming budgets based on further lines of evidence.

20 The $\mathrm{CO}_{2}$ flux from each $\mathrm{fCO}_{2}$-based product is either already at or above $98 \%$ areal coverage (Jena-

21 MLS, OS-ETHZ-GRaCER), filled by the data-provider (using Fay et al., 2021a, method for JMA-MLR;

22 and Landschützer et al., 2020, methodology for MPI-SOMFFN) or scaled for the remaining

23 products by the ratio of the total ocean area covered by the respective product to the total ocean

24 area (361.9e6 km²) from ETOPO1 (Amante and Eakins, 2009; Eakins and Sharman, 2010). In

25 products where the covered area varies with time (e.g., CMEMS-LSCE-FFNN) we use the maximum

26 area coverage. The lowest coverage is $93 \%$ (NIES-NN), resulting in a maximum adjustment factor

27 of 1.08 (Table A3, Hauck et al., 2020).

28 We further use results from two diagnostic ocean models, Khatiwala et al. (2013) and DeVries

29 (2014), to estimate the anthropogenic carbon accumulated in the ocean prior to 1959. The two

30 approaches assume constant ocean circulation and biological fluxes, with SOCEAN estimated as a

31 response in the change in atmospheric $\mathrm{CO}_{2}$ concentration calibrated to observations. The 
1 uncertainty in cumulative uptake of $\pm 20 \mathrm{GtC}$ (converted to $\pm 1 \sigma$ ) is taken directly from the IPCC's

2 review of the literature (Rhein et al., 2013), or about $\pm 30 \%$ for the annual values (Khatiwala et al.,

3 2009).

\section{$4 \quad$ C.3.2 Global Ocean Biogeochemistry Models (GOBMs)}

5 The ocean $\mathrm{CO}_{2}$ sink for 1959-2019 is estimated using eight GOBMs (Table A2). The GOBMs

6 represent the physical, chemical, and biological processes that influence the surface ocean

7 concentration of $\mathrm{CO}_{2}$ and thus the air-sea $\mathrm{CO}_{2}$ flux. The GOBMs are forced by meteorological

8 reanalysis and atmospheric $\mathrm{CO}_{2}$ concentration data available for the entire time period. They

9 mostly differ in the source of the atmospheric forcing data (meteorological reanalysis), spin up

10 strategies, and in their horizontal and vertical resolutions (Table A2). All GOBMs except one

11 (CESM-ETHZ) do not include the effects of anthropogenic changes in nutrient supply (Duce et al.,

12 2008). They also do not include the perturbation associated with changes in riverine organic

13 carbon (see Section 2.7.3).

14 Three sets of simulations were performed with each of the GOBMs. Simulation A applied historical

15 changes in climate and atmospheric $\mathrm{CO}_{2}$ concentration. Simulation $\mathrm{B}$ is a control simulation with

16 constant atmospheric forcing (normal year or repeated year forcing) and constant pre-industrial

17 atmospheric $\mathrm{CO}_{2}$ concentration. Simulation $\mathrm{C}$ is forced with historical changes in atmospheric $\mathrm{CO}_{2}$

18 concentration, but repeated year or normal year atmospheric climate forcing. To derive SOCEAN

19 from the model simulations, we subtracted the annual time series of the control simulation B from

20 the annual time series of simulation A. Assuming that drift and bias are the same in simulations A

21 and B, we thereby correct for any model drift. Further, this difference also removes the natural

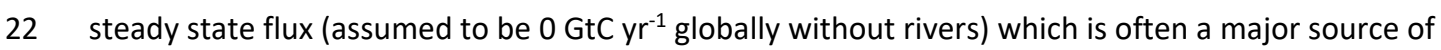

23 biases. Simulation B of IPSL had to be treated differently as it was forced with constant

24 atmospheric $\mathrm{CO}_{2}$ but observed historical changes in climate. For IPSL, we fitted a linear trend to

25 the simulation $B$ and subtracted this linear trend from simulation $A$. This approach assures that

26 the interannual variability is not removed from IPSL simulation A.

27 The absolute correction for bias and drift per model in the 1990s varied between $<0.01 \mathrm{GtC} \mathrm{yr}^{-1}$

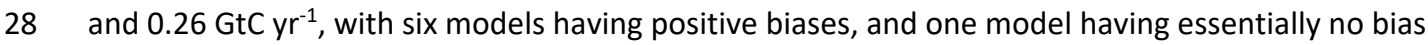

29 (NorESM). The remaining model (MPI) uses riverine input and therefore simulates outgassing in

30 simulation B, i.e., a seemingly negative bias. By subtracting simulation $B$, also the ocean carbon 
1 sink of the MPI model follows the definition of SOCEAN. This correction reduces the model mean

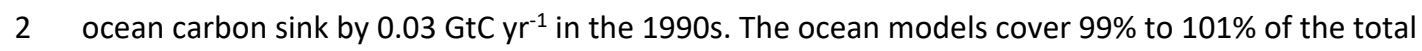

3 ocean area, so that area-scaling is not necessary.

\section{C.3.3 GOBM evaluation and uncertainty assessment for SOCEAN}

5 The ocean $\mathrm{CO}_{2}$ sink for all GOBMs and the ensemble mean falls within $90 \%$ confidence of the

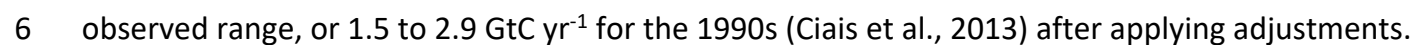

7 An exception is the MPI model, which simulates a low ocean carbon sink of $1.38 \mathrm{GtC}_{\mathrm{yr}}^{-1}$ for the

8 1990s in simulation A owing to the inclusion of riverine carbon flux. After adjusting to the GCB's

9 definition of SOCEAN by subtracting simulation B, the MPI model falls into the observed range with

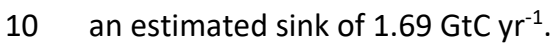

11 The GOBMs and data products have been further evaluated using the fugacity of sea surface $\mathrm{CO}_{2}$

$12\left(\mathrm{fCO}_{2}\right)$ from the SOCAT v2021 database (Bakker et al., 2016, 2021). We focused this evaluation on

13 the root mean squared error (RMSE) between observed and modelled $\mathrm{fCO}_{2}$ and on a measure of

14 the amplitude of the interannual variability of the flux (modified after Rödenbeck et al., 2015).

15 The RMSE is calculated from detrended, annually and regionally averaged time series calculated

16 from GOBMs and data-product $\mathrm{fCO}_{2}$ subsampled to open ocean (water depth $>400$ m) SOCAT

17 sampling points to measure the misfit between large-scale signals (Hauck et al., 2020) The

18 amplitude of the SOCEAN interannual variability (A-IAV) is calculated as the temporal standard

19 deviation of the detrended $\mathrm{CO}_{2}$ flux time series (Rödenbeck et al., 2015, Hauck et al., 2020). These

20 metrics are chosen because RMSE is the most direct measure of data-model mismatch and the A-

21 IAV is a direct measure of the variability of SOCEAN on interannual timescales. We apply these

22 metrics globally and by latitude bands. Results are shown in Fig. B2 and discussed in Section 3.5.5.

23 We quantify the 1- $\sigma$ uncertainty around the mean ocean sink of anthropogenic $\mathrm{CO}_{2}$ by assessing

24 random and systematic uncertainties for the GOBMs and data-products. The random

25 uncertainties are taken from the ensemble standard deviation (0.3 GtC $\mathrm{yr}^{-1}$ for GOBMs, $0.3 \mathrm{GtC} \mathrm{yr}^{-}$

$26{ }^{1}$ for data-products). We derive the GOBMs systematic uncertainty by the deviation of the DIC

27 inventory change 1994-2007 from the Gruber et al (2019) estimate (0.5 GtC $\mathrm{yr}^{-1}$ ) and suggest

28 these are related to physical transport (mixing, advection) into the ocean interior. For the data-

29 products, we consider systematic uncertainties stemming from uncertainty in $\mathrm{fCO}_{2}$ observations

30 (0.2 GtC yr $^{-1}$, Takahashi et al., 2009; Wanninkhof et al., 2013), gas-transfer velocity (0.2 GtC $\mathrm{yr}^{-1}$, 
Ho et al., 2011; Wanninkhof et al., 2013; Roobaert et al., 2018), wind product (0.1 GtC $\mathrm{yr}^{-1}$, Fay et

2 al., 2021a), river flux adjustment (0.2 GtC yr ${ }^{-1}$, Jacobson et al., 2007; Resplandy et al., 2018), and

$3 \mathrm{fCO}_{2}$ mapping (0.2 GtC yr${ }^{-1}$, Landschützer et al., 2014). Combining these uncertainties as their

4 squared sums, we assign an uncertainty of $\pm 0.6 \mathrm{GtC}_{\mathrm{yr}}^{-1}$ to the GOBMs ensemble mean and an

5 uncertainty of $\pm 0.5 \mathrm{GtC}^{-1}$ to the data-product ensemble mean. These uncertainties are

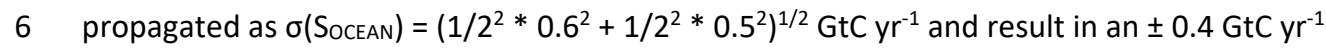

7 uncertainty around the best estimate of SOCEAN.

8 We examine the consistency between the variability of the model-based and the $\mathrm{fCO}_{2}$-based data

9 products to assess confidence in Socean. The interannual variability of the ocean fluxes (quantified

10 as A-IAV, the standard deviation after detrending, Figure $\mathrm{B} 2$ ) of the seven $\mathrm{fCO}_{2}$-based data

11 products plus the Watson et al. (2020) product for $1990-2020$, ranges from 0.16 to $0.26{\mathrm{GtC} \mathrm{yr}^{-1}}^{-1}$

12 with the lower estimates by the three ensemble methods (CSIR-ML6, CMEMS-LSCE-FFNN, OS-

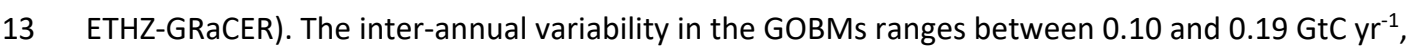

14 hence there is overlap with the lower A-IAV estimates of three data-products.

15 Individual estimates (both GOBMs and data products) generally produce a higher ocean $\mathrm{CO}_{2}$ sink during strong El Niño events. There is emerging agreement between GOBMs and data-products on the patterns of decadal variability of SocEAN with a global stagnation in the 1990s and an extratropical strengthening in the 2000s (McKinley et al., 2020, Hauck et al., 2020). The central estimates of the annual flux from the $\mathrm{GOBMs}$ and the $\mathrm{fCO}_{2}$-based data products have a correlation $r$ of 0.94 (1990-2020). The agreement between the models and the data products reflects some consistency in their representation of underlying variability since there is little overlap in their methodology or use of observations.

\section{Appendix C.4 Methodology Land $\mathrm{CO}_{2}$ sink}

\section{C.4.1 DGVM simulations}

26 The DGVMs model runs were forced by either the merged monthly Climate Research Unit (CRU)

27 and 6 hourly Japanese 55-year Reanalysis (JRA-55) data set or by the monthly CRU data set, both

28 providing observation-based temperature, precipitation, and incoming surface radiation on a

$290.5^{\circ} \times 0.5^{\circ}$ grid and updated to 2020 (Harris et al., 2014, 2020). The combination of CRU monthly

30 data with 6 hourly forcing from JRA-55 (Kobayashi et al., 2015) is performed with methodology

31 used in previous years (Viovy, 2016) adapted to the specifics of the JRA-55 data. 
1 New to this budget is the revision of incoming short-wave radiation fields to take into account

2 aerosol impacts and the division of total radiation into direct and diffuse components as

3 summarised below.

4 The diffuse fraction dataset offers 6-hourly distributions of the diffuse fraction of surface

5 shortwave fluxes over the period 1901-2020. Radiative transfer calculations are based on

6 monthly-averaged distributions of tropospheric and stratospheric aerosol optical depth, and 6-

7 hourly distributions of cloud fraction. Methods follow those described in the Methods section of

8 Mercado et al. (2009), but with updated input datasets.

9 The time series of speciated tropospheric aerosol optical depth is taken from the historical and

10 RCP8.5 simulations by the HadGEM2-ES climate model (Bellouin et al., 2011). To correct for biases

11 in HadGEM2-ES, tropospheric aerosol optical depths are scaled over the whole period to match

12 the global and monthly averages obtained over the period 2003-2020 by the CAMS Reanalysis of

13 atmospheric composition (Inness et al., 2019), which assimilates satellite retrievals of aerosol

14 optical depth.

15 The time series of stratospheric aerosol optical depth is taken from the climatology by Sato et al.

16 (1993), which has been updated to 2012. Years 2013-2020 are assumed to be background years so

17 replicate the background year 2010. That assumption is supported by the Global Space-based

18 Stratospheric Aerosol Climatology time series (1979-2016; Thomason et al., 2018). The time series

19 of cloud fraction is obtained by scaling the 6-hourly distributions simulated in the Japanese

20 Reanalysis (Kobayashi et al., 2015) to match the monthly-averaged cloud cover in the CRU TS

21 v4.03 dataset (Harris et al., 2021). Surface radiative fluxes account for aerosol-radiation

22 interactions from both tropospheric and stratospheric aerosols, and for aerosol-cloud interactions

23 from tropospheric aerosols, except mineral dust. Tropospheric aerosols are also assumed to exert

24 interactions with clouds.

25 The radiative effects of those aerosol-cloud interactions are assumed to scale with the radiative

26 effects of aerosol-radiation interactions of tropospheric aerosols, using regional scaling factors

27 derived from HadGEM2-ES. Diffuse fraction is assumed to be 1 in cloudy sky. Atmospheric

28 constituents other than aerosols and clouds are set to a constant standard mid-latitude summer

29 atmosphere, but their variations do not affect the diffuse fraction of surface shortwave fluxes. 
1 In summary, the DGVMs forcing data include time dependent gridded climate forcing, global

2 atmospheric $\mathrm{CO}_{2}$ (Dlugokencky and Tans, 2021), gridded land cover changes (see Appendix C.2.2),

3 and gridded nitrogen deposition and fertilisers (see Table A1 for specific models details).

4 Four simulations were performed with each of the DGVMs. Simulation 0 (SO) is a control

5 simulation which uses fixed pre-industrial (year 1700) atmospheric $\mathrm{CO} 2$ concentrations, cycles

6 early 20th century (1901-1920) climate and applies a time-invariant pre-industrial land cover

7 distribution and pre-industrial wood harvest rates. Simulation 1 (S1) differs from S0 by applying

8 historical changes in atmospheric $\mathrm{CO} 2$ concentration and N inputs. Simulation 2 (S2) applies

9 historical changes in atmospheric $\mathrm{CO}_{2}$ concentration, $\mathrm{N}$ inputs, and climate, while applying time-

10 invariant pre-industrial land cover distribution and pre-industrial wood harvest rates. Simulation 3

11 (S3) applies historical changes in atmospheric $\mathrm{CO} 2$ concentration, $\mathrm{N}$ inputs, climate, and land

12 cover distribution and wood harvest rates.

$13 \mathrm{~S} 2$ is used to estimate the land sink component of the global carbon budget (S LAND $_{\text {). }}$ S3 is used to

14 estimate the total land flux but is not used in the global carbon budget. We further separate SLAND

15 into contributions from $\mathrm{CO}_{2}(=\mathrm{S} 1-\mathrm{S} 0)$ and climate (=S2-S1-SO).

\section{C.4.2 DGVM evaluation and uncertainty assessment for SLAND}

17 We apply three criteria for minimum DGVMs realism by including only those DGVMs with (1)

18 steady state after spin up, (2) global net land flux ( S LAND $_{\text {- }} E_{L U C}$ ) that is an atmosphere-to-land

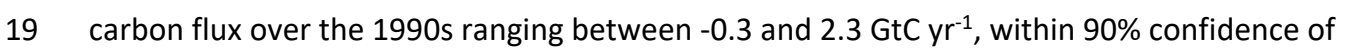

20 constraints by global atmospheric and oceanic observations (Keeling and Manning, 2014;

21 Wanninkhof et al., 2013), and (3) global Eluc that is a carbon source to the atmosphere over the

22 1990s, as already mentioned in section 2.2.2. All 17 DGVMs meet these three criteria.

23 In addition, the DGVMs results are also evaluated using the International Land Model

24 Benchmarking system (ILAMB; Collier et al., 2018). This evaluation is provided here to document,

25 encourage and support model improvements through time. ILAMB variables cover key processes

26 that are relevant for the quantification of SLAND and resulting aggregated outcomes. The selected

27 variables are vegetation biomass, gross primary productivity, leaf area index, net ecosystem

28 exchange, ecosystem respiration, evapotranspiration, soil carbon, and runoff (see Fig. B3 for the

29 results and for the list of observed databases). Results are shown in Fig. B3 and discussed in

30 Section 3.6.5. 
1 For the uncertainty for $S_{L A N D}$, we use the standard deviation of the annual $\mathrm{CO}_{2}$ sink across the

2 DGVMs, averaging to about $\pm 0.6 \mathrm{GtC}^{-1}{ }^{-1}$ for the period 1959 to 2019 . We attach a medium

3 confidence level to the annual land $\mathrm{CO}_{2}$ sink and its uncertainty because the estimates from the

4 residual budget and averaged DGVMs match well within their respective uncertainties (Table 5).

5 Appendix C.5 Methodology Atmospheric Inversions

6 Six atmospheric inversions (details of each in Table A4) were used to infer the spatio-temporal

7 distribution of the $\mathrm{CO}_{2}$ flux exchanged between the atmosphere and the land or oceans. These

8 inversions are based on Bayesian inversion principles with prior information on fluxes and their

9 uncertainties. They use very similar sets of surface measurements of $\mathrm{CO}_{2}$ time series (or subsets

10 thereof) from various flask and in situ networks. One inversion system also used satellite $\mathrm{xCO}_{2}$

11 retrievals from GOSAT and OCO-2.

12 Each inversion system uses different methodologies and input data but is rooted in Bayesian

13 inversion principles. These differences mainly concern the selection of atmospheric $\mathrm{CO}_{2}$ data and

14 prior fluxes, as well as the spatial resolution, assumed correlation structures, and mathematical

15 approach of the models. Each system uses a different transport model, which was demonstrated

16 to be a driving factor behind differences in atmospheric inversion-based flux estimates, and

17 specifically their distribution across latitudinal bands (Gaubert et al., 2019; Schuh et al., 2019).

18 The inversion systems prescribe same global fossil fuel emissions for EFos; specifically, the GCP's

19 Gridded Fossil Emissions Dataset version 2021 (GCP-GridFEDv2021.2; Jones et al., 2021b), which is

20 an update through 2020 of the first version of GCP-GridFED presented by Jones et al. (2021a).

21 GCP-GridFEDv2021.2 scales gridded estimates of $\mathrm{CO}_{2}$ emissions from EDGARv4.3.2 (Janssens-

22 Maenhout et al., 2019) within national territories to match national emissions estimates provided

23 by the GCP for the years 1959-2020, which were compiled following the methodology described in

24 Appendix C.1 based on all information available on 31st July 2021 (R. Andrew, pers. comm.).

25 Typically, the GCP-GridFED adopts the seasonal variation in emissions (the monthly distribution of

26 annual emissions) from EDGAR and applies small corrections based on heating or cooling degree

27 days to account for the effects of inter-annual climate variability on the seasonality emissions

28 (Jones et al., 2021a). However, strategies taken to deal with the COVID-19 pandemic during 2020

29 mean that the seasonality of emissions diverged substantially in 2020 from a typical year. To

30 account for this change, GCP-GridFEDv2021.2 adopts the national seasonality in emissions from

31 Carbon Monitor (Liu et al., 2020a,b) during the years 2019-2020 (Jones et al. 2021b). 
1 The consistent use of GCP-GridFEDv2021.2 for EFos ensures a close alignment with the estimate of

2 EFos used in this budget assessment, enhancing the comparability of the inversion-based estimate

3 with the flux estimates deriving from DGVMs, GOBMs and $\mathrm{fCO}_{2}$-based methods. To account for

4 small differences in regridding, and the use of a slightly earlier file version (GCP-GridFEDv2021.1)

5 for 2000-2018 in CarbonTracker Europe, small fossil fuel corrections were applied to all inverse

6 models to make the estimated uptake of atmospheric $\mathrm{CO} 2$ fully consistent. Finally, we note that

7 GCP-GridFEDv2021.2 includes emissions from cement production, but it does not include the

8 cement carbonation $\mathrm{CO}_{2}$ sink (Xi et al., 2016; Cao et al., 2020; Guo et al. 2021) that is applied to

9 the GCB estimate of EFos in Table 6.

10 The land and ocean $\mathrm{CO}_{2}$ fluxes from atmospheric inversions contain anthropogenic perturbation

11 and natural pre-industrial $\mathrm{CO}_{2}$ fluxes. On annual time scales, natural pre-industrial fluxes are

12 primarily land $\mathrm{CO}_{2}$ sinks and ocean $\mathrm{CO}_{2}$ sources corresponding to carbon taken up on land,

13 transported by rivers from land to ocean, and outgassed by the ocean. These pre-industrial land

$14 \mathrm{CO}_{2}$ sinks are thus compensated over the globe by ocean $\mathrm{CO}_{2}$ sources corresponding to the

15 outgassing of riverine carbon inputs to the ocean, using the exact same numbers and distribution

16 as described for the oceans in Section 2.4. To facilitate the comparison, we adjusted the inverse

17 estimates of the land and ocean fluxes per latitude band with these numbers to produce historical

18 perturbation $\mathrm{CO}_{2}$ fluxes from inversions. Finally, for the presentation of the comparison in Figure

1911 we modified the FF-corrected and riverine-adjusted land sinks from the inversions further, by

20 removing a $0.2 \mathrm{GtCyr}^{-1} \mathrm{CO}_{2}$ sink that is ascribed to cement carbonation in the $\mathrm{GCB}$, rather than to

21 terrestrial ecosystems. The latter is not applied in the inversion products released through GCB or

22 the original data portals of these products.

23 All participating atmospheric inversions are checked for consistency with the annual global growth

24 rate, as both are derived from the global surface network of atmospheric $\mathrm{CO} 2$ observations. In this

25 exercise, we use the conversion factor of $2.086 \mathrm{GtC} / \mathrm{ppm}$ to convert the inverted carbon fluxes to

26 mole fractions, as suggested by Prather (2012). This number is specifically suited for the

27 comparison to surface observations that do not respond uniformly, nor immediately, to each

28 year's summed sources and sinks. This factor is therefore slightly smaller than the GCB conversion

29 factor in Table 1 (2.142 GtC/ppm, Ballantyne et al., 2012). Overall, the inversions agree with the

30 growth rate with biases between 0.03-0.08 ppm (0.06-0.17 GtCyr $\left.{ }^{-1}\right)$ on the decadal average. 
1 The atmospheric inversions are also evaluated using vertical profiles of atmospheric $\mathrm{CO}_{2}$

2 concentrations (Fig. B4). More than 30 aircraft programs over the globe, either regular programs

3 or repeated surveys over at least 9 months, have been used in order to draw a robust picture of

4 the model performance (with space-time data coverage irregular and denser in the $0-45^{\circ} \mathrm{N}$

5 latitude band; Table A6). The six models are compared to the independent aircraft $\mathrm{CO}_{2}$

6 measurements between 2 and $7 \mathrm{~km}$ above sea level between 2001 and 2020. Results are shown in

7 Fig. B4, where the inversions generally match the atmospheric mole fractions to within $0.6 \mathrm{ppm}$ at

8 all latitudes, except for CT Europe in 2010-2020 over the more sparsely sampled southern

9 hemisphere.

\section{Appendix D Processes not included in the global carbon budget}

\section{Appendix D.1 Contribution of anthropogenic $\mathrm{CO}$ and $\mathrm{CH}_{4}$ to the global carbon budget}

12 Equation (1) includes only partly the net input of $\mathrm{CO}_{2}$ to the atmosphere from the chemical

13 oxidation of reactive carbon-containing gases from sources other than the combustion of fossil

14 fuels, such as: (1) cement process emissions, since these do not come from combustion of fossil

15 fuels, (2) the oxidation of fossil fuels, (3) the assumption of immediate oxidation of vented

16 methane in oil production. However, it omits any other anthropogenic carbon-containing gases

17 that are eventually oxidised in the atmosphere, such as anthropogenic emissions of $\mathrm{CO}$ and $\mathrm{CH}_{4}$.

18 An attempt is made in this section to estimate their magnitude and identify the sources of

19 uncertainty. Anthropogenic $\mathrm{CO}$ emissions are from incomplete fossil fuel and biofuel burning and

20 deforestation fires. The main anthropogenic emissions of fossil $\mathrm{CH}_{4}$ that matter for the global

21 (anthropogenic) carbon budget are the fugitive emissions of coal, oil and gas sectors (see below).

22 These emissions of $\mathrm{CO}$ and $\mathrm{CH}_{4}$ contribute a net addition of fossil carbon to the atmosphere.

23 In our estimate of EFos we assumed (Section 2.1.1) that all the fuel burned is emitted as $\mathrm{CO}_{2}$, thus

24 CO anthropogenic emissions associated with incomplete fossil fuel combustion and its

25 atmospheric oxidation into $\mathrm{CO}_{2}$ within a few months are already counted implicitly in EFos and

26 should not be counted twice (same for $\mathrm{E}_{\mathrm{LuC}}$ and anthropogenic $\mathrm{CO}$ emissions by deforestation

27 fires). Anthropogenic emissions of fossil $\mathrm{CH}_{4}$ are however not included in $\mathrm{E}_{\mathrm{Fos}}$, because these

28 fugitive emissions are not included in the fuel inventories. Yet they contribute to the annual $\mathrm{CO}_{2}$

29 growth rate after $\mathrm{CH}_{4}$ gets oxidized into $\mathrm{CO}_{2}$. Emissions of fossil $\mathrm{CH}_{4}$ represent $30 \%$ of total

30 anthropogenic $\mathrm{CH}_{4}$ emissions (Saunois et al. 2020; their top-down estimate is used because it is 
1 consistent with the observed $\mathrm{CH}_{4}$ growth rate), that is $0.083 \mathrm{GtC}^{-1}$ for the decade 2008-2017.

2 Assuming steady state, an amount equal to this fossil $\mathrm{CH}_{4}$ emission is all converted to $\mathrm{CO}_{2}$ by $\mathrm{OH}$

3 oxidation, and thus explain $0.083 \mathrm{GtC} \mathrm{yr}^{-1}$ of the global $\mathrm{CO}_{2}$ growth rate with an uncertainty range

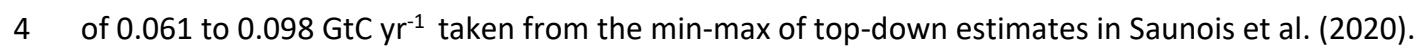

5 If this min-max range is assumed to be $2 \sigma$ because Saunois et al. (2020) did not account for the

6 internal uncertainty of their min and max top-down estimates, it translates into a 1- $\sigma$ uncertainty

7 of $0.019 \mathrm{GtC} \mathrm{yr}^{-1}$.

8 Other anthropogenic changes in the sources of $\mathrm{CO}$ and $\mathrm{CH}_{4}$ from wildfires, vegetation biomass,

9 wetlands, ruminants, or permafrost changes are similarly assumed to have a small effect on the

$10 \mathrm{CO}_{2}$ growth rate. The $\mathrm{CH}_{4}$ and $\mathrm{CO}$ emissions and sinks are published and analysed separately in the

11 Global Methane Budget and Global Carbon Monoxide Budget publications, which follow a similar

12 approach to that presented here (Saunois et al., 2020; Zheng et al., 2019).

13 Appendix D.2 Contribution of other carbonates to $\mathrm{CO}_{2}$ emissions

14 Although we do account for cement carbonation (a carbon sink), the contribution of emissions of 15 fossil carbonates (carbon sources) other than cement production is not systematically included in 16 estimates of $\mathrm{E}_{\mathrm{FOS}}$, except at the national level where they are accounted for in the UNFCCC

17 national inventories. The missing processes include $\mathrm{CO}_{2}$ emissions associated with the calcination 18 of lime and limestone outside cement production. Carbonates are also used in various industries, 19 including in iron and steel manufacture and in agriculture. They are found naturally in some coals. $20 \mathrm{CO}_{2}$ emissions from fossil carbonates other than cement are estimated to amount to about $1 \%$ of

21 EFos (Crippa et al., 2019), though some of these carbonate emissions are included in our estimates 22 (e.g., via UNFCCC inventories).

\section{Appendix D.3 Anthropogenic carbon fluxes in the land-to-ocean aquatic continuum}

24 The approach used to determine the global carbon budget refers to the mean, variations, and 25 trends in the perturbation of $\mathrm{CO}_{2}$ in the atmosphere, referenced to the pre-industrial era. Carbon 26 is continuously displaced from the land to the ocean through the land-ocean aquatic continuum 27 (LOAC) comprising freshwaters, estuaries, and coastal areas (Bauer et al., 2013; Regnier et al., 28 2013). A substantial fraction of this lateral carbon flux is entirely 'natural' and is thus a steady 29 state component of the pre-industrial carbon cycle. We account for this pre-industrial flux where 30 appropriate in our study (see Appendix C.3). However, changes in environmental conditions and 
1 land-use change have caused an increase in the lateral transport of carbon into the LOAC - a

2 perturbation that is relevant for the global carbon budget presented here.

3 The results of the analysis of Regnier et al. (2013) can be summarized in two points of relevance

4 for the anthropogenic $\mathrm{CO}_{2}$ budget. First, the anthropogenic perturbation of the LOAC has

5 increased the organic carbon export from terrestrial ecosystems to the hydrosphere by as much as

$61.0 \pm 0.5 \mathrm{GtC}^{-1} \mathrm{r}^{-1}$ since pre-industrial, mainly owing to enhanced carbon export from soils. Second,

7 this exported anthropogenic carbon is partly respired through the LOAC, partly sequestered in

8 sediments along the LOAC and to a lesser extent, transferred to the open ocean where it may

9 accumulate or be outgassed. The increase in storage of land-derived organic carbon in the LOAC

10 carbon reservoirs (burial) and in the open ocean combined is estimated by Regnier et al. (2013) at

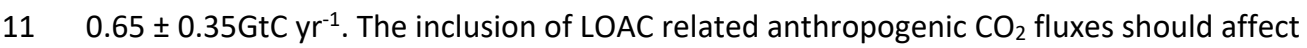

12 estimates of SLAND and SocEAN in Eq. (1) but does not affect the other terms. Representation of the

13 anthropogenic perturbation of $\mathrm{LOAC} \mathrm{CO}_{2}$ fluxes is however not included in the GOBMs and

14 DGVMs used in our global carbon budget analysis presented here.

\section{Appendix D.4 Loss of additional land sink capacity}

Historical land-cover change was dominated by transitions from vegetation types that can provide a large carbon sink per area unit (typically, forests) to others less efficient in removing $\mathrm{CO}_{2}$ from the atmosphere (typically, croplands). The resultant decrease in land sink, called the 'loss of additional sink capacity', can be calculated as the difference between the actual land sink under changing land-cover and the counterfactual land sink under pre-industrial land-cover. This term is not accounted for in our global carbon budget estimate. Here, we provide a quantitative estimate of this term to be used in the discussion. Seven of the DGVMs used in Friedlingstein et al. (2019) performed additional simulations with and without land-use change under cycled pre-industrial environmental conditions. The resulting loss of additional sink capacity amounts to $0.9 \pm 0.3 \mathrm{GtC}$ $\mathrm{yr}^{-1}$ on average over 2009-2018 and $42 \pm 16 \mathrm{GtC}$ accumulated between 1850 and 2018 (Obermeier et al., 2021). OSCAR, emulating the behaviour of 11 DGVMs finds values of the loss of additional

27 sink capacity of $0.7 \pm 0.6 \mathrm{GtC}^{-1}{ }^{-1}$ and $31 \pm 23 \mathrm{GtC}$ for the same time period (Gasser et al., 2020).

28 Since the DGVM-based ELUC estimates are only used to quantify the uncertainty around the

29 bookkeeping models' ELUC we do not add the loss of additional sink capacity to the bookkeeping 30 estimate. 